US Army Corps

of Engineers $S_{\circledast}$

Engineer Research and

Development Center

Ecosystem Management and Restoration Research Program

\title{
A Proposed Ecosystem Services Analysis Framework for the U.S. Army Corps of Engineers
}

Lisa A. Wainger, Anna McMurray, Hannah R. Griscom,

Elizabeth O. Murray, Janet A. Cushing, Charles H. Theiling, and Shawn Komlos

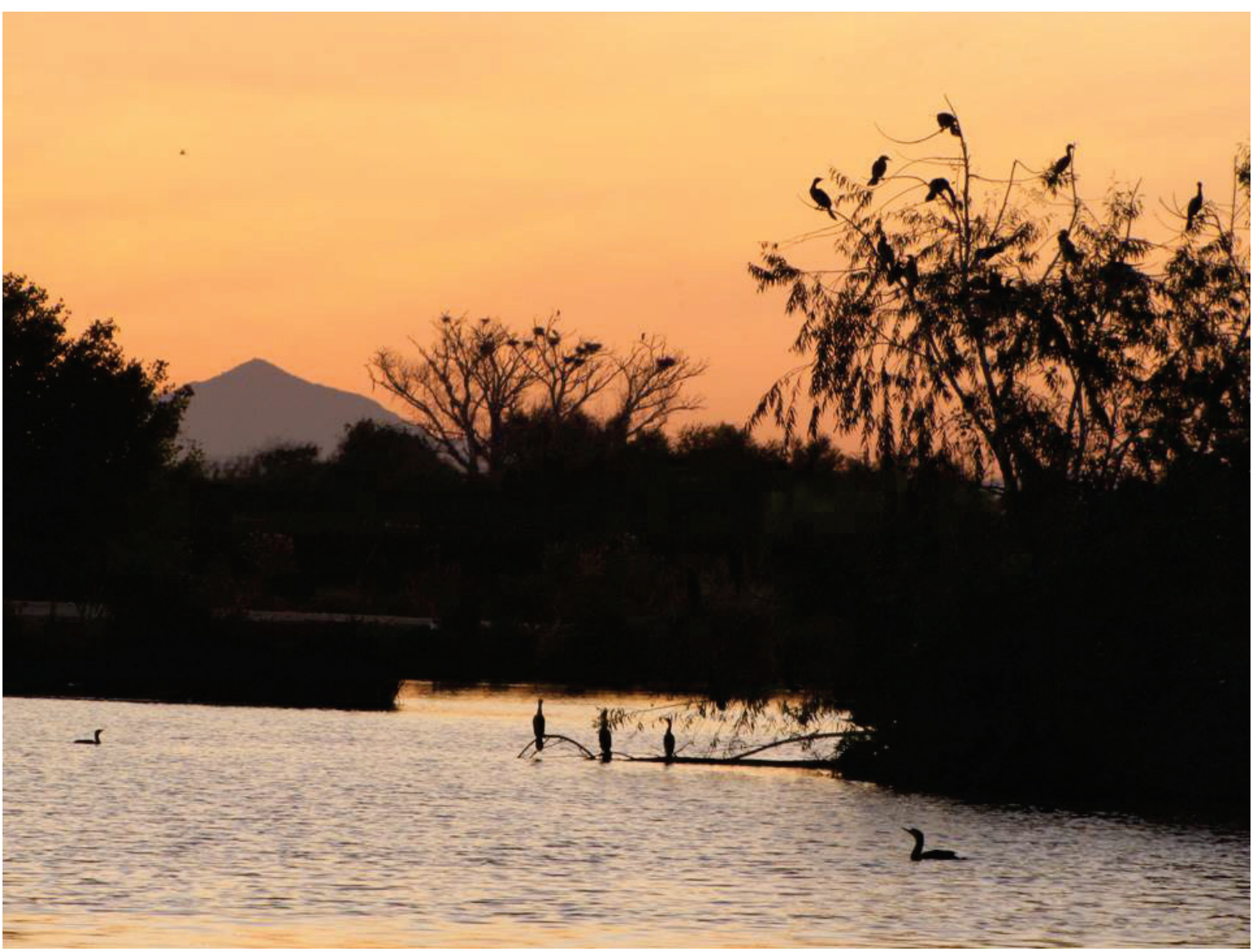


The U.S. Army Engineer Research and Development Center (ERDC) solves the nation's toughest engineering and environmental challenges. ERDC develops innovative solutions in civil and military engineering, geospatial sciences, water resources, and environmental sciences for the Army, the Department of Defense, civilian agencies, and our nation's public good. Find out more at www.erdc.usace.army.mil.

To search for other technical reports published by ERDC, visit the ERDC online library at https://erdclibrary.on.worldcat.org/discovery. 


\section{A Proposed Ecosystem Services Analysis Framework for the U.S. Army Corps of Engineers}

Lisa A. Wainger, Anna McMurray, and Hannah R. Griscom

University of Maryland Center for Environmental Science 146 Williams St

Solomons, MD 20688

Elizabeth O. Murray and Charles H. Theiling

Environmental Laboratory

U.S. Army Engineer Research and Development Center

3909 Halls Ferry Road

Vicksburg, MS 39180-6199

Janet A. Cushing and Shawn B. Komlos

U.S. Army Engineer Institute for Water Resources

7701 Telegraph Road

Alexandria, Virginia 22315

Final report

Approved for public release; distribution is unlimited.

Prepared for Ecosystem Management and Restoration Research Program (EMRRP) and Environmental Laboratory

U.S. Army Engineer Research and Development Center 3909 Halls Ferry Road

Vicksburg, MS 39180-6199

Under Funding Account Code U436285, AMSCO Code 031342 


\section{Abstract}

Ecosystem goods and services (EGS) have been promoted as a way to effectively examine tradeoffs and improve communication of projectrelated environmental outcomes in terms of human well-being. This document proposes a framework to inform the development of any future guidance to U.S. Army Corps of Engineers (USACE) District planners for projecting changes in EGS from proposed civil works activities. The framework offers an analytical and communications approach for incorporating EGS in USACE decision-support processes. The core of the framework is a conceptual model that establishes a series of causal relationships that link management actions to EGS benefits/damages, applying economic concepts in both monetary and non-monetary benefit relevant indicators.

The six-step planning process is used to demonstrate how the EGS framework might be integrated into existing analytic approaches and modified to fit different levels of resource availability and decision contexts. A hypothetical case study is used to demonstrate analytic techniques. The framework is compatible with goals to create a single decision-support document covering National Environmental Policy Act requirements and planning objectives when comparing project alternatives. The example is intended to generally illustrate the use of EGS in any type of program planning or project evaluation.

DISCLAIMER: The contents of this report are not to be used for advertising, publication, or promotional purposes. Citation of trade names does not constitute an official endorsement or approval of the use of such commercial products. All product names and trademarks cited are the property of their respective owners. The findings of this report are not to be construed as an official Department of the Army position unless so designated by other authorized documents. 


\section{Contents}

Abstract....................................................................................................................................... if

Figures and Tables....................................................................................................................................

Preface .............................................................................................................................................. vili

Executive Summary ..........................................................................................................................

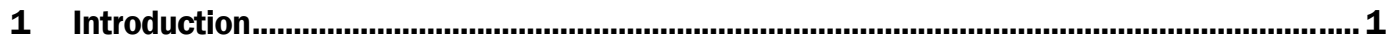

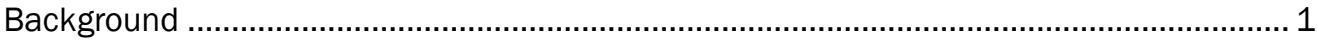

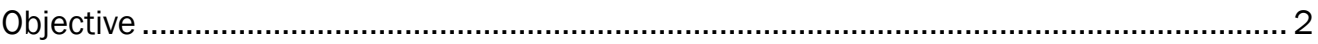

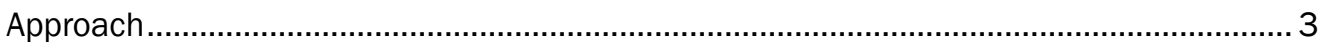

Definition of ecosystem goods and services (EGS) .......................................................... 3

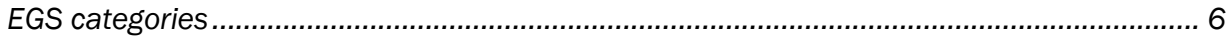

What could an EGS analysis contribute to USACE decision support? ...............................10

How to read this document.......................................................................................... 11

2 Framework Overview.......................................................................................................13

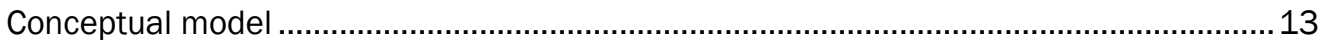

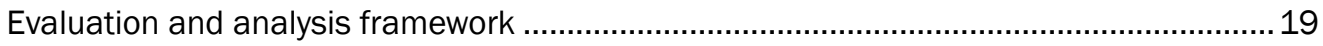

Using products of the EGS conceptual model in decision-making ..................................19

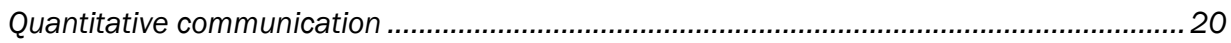

Multi-criteria decision analysis (MCDA) and trade-off analysis ............................................ 21

Benefit aggregation and economic trade-off analysis ....................................................... 22

3 Linking the EGS Analysis to the Six-Step Planning Process ............................................23

Step 1 - Problems and Opportunities............................................................................ 26

Step 1.1 - Identify problems, EGS opportunities, and management measures.................... 30

Step 1.2 - Build EGS conceptual models linking management measures to

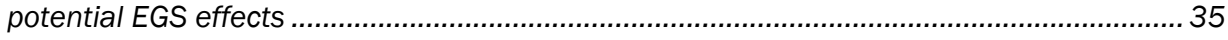

Step 1.3 - Rate EGS impacts and examine EGS planning relevance ................................. 51

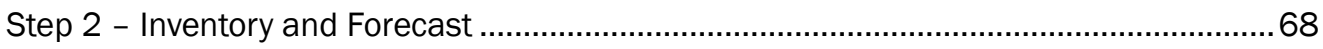

Step 2.1 - Identify available data, analytic approaches, and models...................................68

Step 2.2 - Choose analytic approaches and models .......................................................... 70

Step 2.3 - Characterize existing conditions and forecast future without project

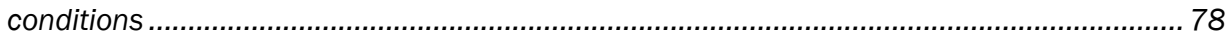

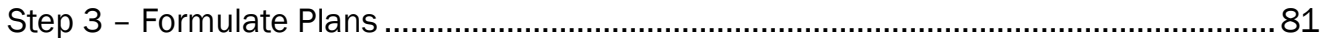

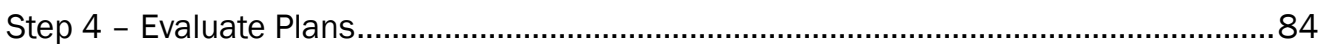

Step 4.1 - Using the impact evaluation and decision criteria tables to evaluate

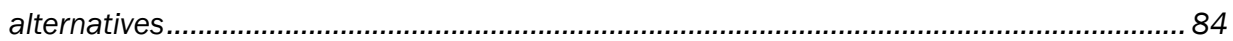

Step 4.2 - Applying models or other analytic tools to measure EGS changes ..................... 86

Step 5 - Compare Plans .......................................................................................... 97

Step 6 - Select Plan and Summarize Target and Incidental EGS Benefits and Harms 
4 Conclusions and Summary of Recommendations for Ecosystem Goods and

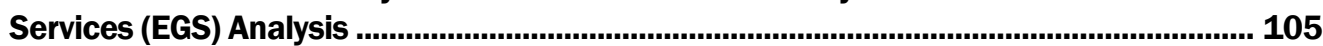

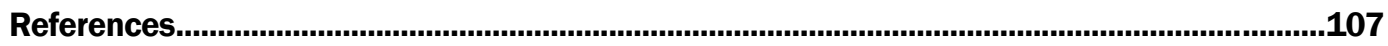

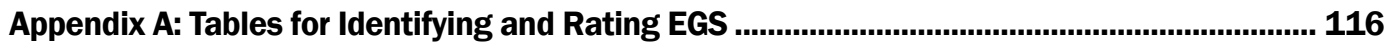

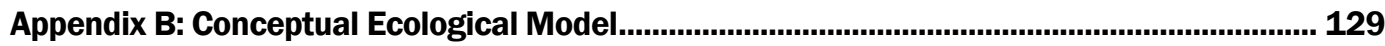

Appendix C: Resources for Evaluating Species or Ecosystem Scarcity and National

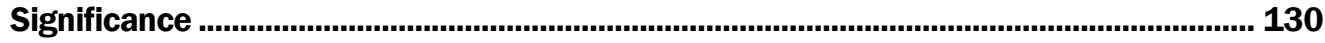

Report Documentation Page 


\section{Figures and Tables}

\section{Figures}

Figure 1. Components of total economic value

Figure 2. The framework EGS conceptual model. The EGS conceptual model consists of cause-and-effect relationships (arrows A-C) and measurable metrics of benefits or harms (boxes 2-4). The arrows represent analyses used to establish that the biophysical changes and socio-economic conditions are sufficient to impart value. Moving from left to right adds progressively more evidence that a management measure will generate a social benefit or harm.

Figure 3. Example EGS conceptual model for a non-use service derived from promoting long-term resilience of a threatened ecosystem.

Figure 4. Example EGS conceptual model for the use service of recreational fishing.

Figure 5. Three approaches for using EGS conceptual model components in decisionmaking

Figure 6. EGS screening during the scoping process.

Figure 7. Problems, opportunities, and potential management measures identified during stakeholder engagement.

Figure 8. Example of column headings for EGS conceptual model. Column headings are derived from the EGS conceptual model, and the green box was added to provide more detailed information for cause-and-effect relationships. Affected ecological processes and structures can be derived from ecological conceptual models specified by current planning procedures.

Figure 9. EGS conceptual model for property flood damage mitigation.

Figure 10. EGS conceptual model for the non-use service of maintaining a threatened native riparian ecosystem.

Figure 11. EGS conceptual model diagram for all EGS used in the Ayola case study...................... 47

Figure 12. EGS valuation methods and expected value metrics... 50

Figure 13. Example response curve for assessing project impact on an ecological outcome given site degradation levels.

Figure 14. A conceptual model of non-use value for Roundtail Chub viability. .58

Figure 15. Decision tree for assigning aggregate impact rating to an EGS change. 60

Figure 16. Timeline of restoration recovery for 50 -year analysis period. 93

Figure B.1. Conceptual ecological model for the case study area. .129

\section{Tables}

Table 1. Key EGS concepts (Murray et al. 2013)........................................................................... 4

Table 2. Definitions and examples of ecosystem goods and services.............................................. 7

Table 3. Overview of the integration of EGS analysis framework and six-step planning process.

Table 4. Alternatives chosen by PDT for Ayola Case Study ............................................................ 27

Table 5. EGS-related products generated at each scoping step.......................................................2 29 
Table 6. Typical ecosystem goods and services by aquatic, coastal, or riparian

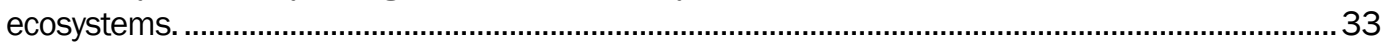

Table 7. Ecosystem goods and services impact evaluation table...................................................52

Table 8. Ecosystem goods and services decision criteria table........................................................52

Table 9. Definitions of duration of project effects.........................................................................5

Table 10. Criteria for determining substantial impact based on magnitude and duration

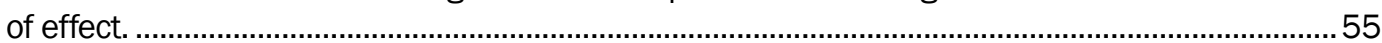

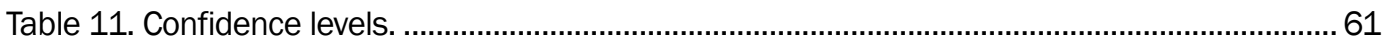

Table 12. Relationship between EGS and USACE mission areas..................................................62

Table 13. Initial criteria for selecting relevant EGS for further analysis. ............................................63

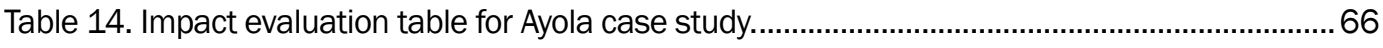

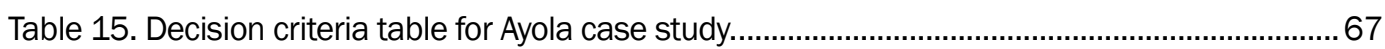

Table 16. EGS to be used in further analysis for Ayola Case Study...............................................67

Table 17. Recommendations for analytic method and model selection............................................70

Table 18. Primary valuation methods applied to EGS, (adapted from Turner et al. [2008],

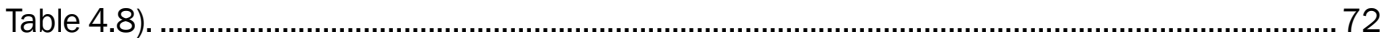

Table 19. Primary economic valuation techniques by EGS..............................................................74

Table 20. Response function models for non-use services in the case study. ................................. 76

Table 21. Baseline conditions and future trends influencing EGS in the FWOP (case

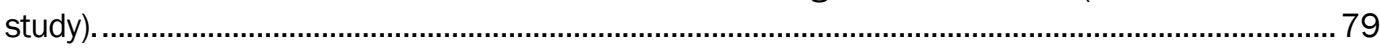

Table 22. Anticipated impacts of management measures on ecological outcomes for the

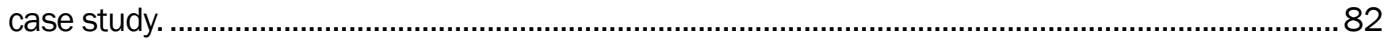

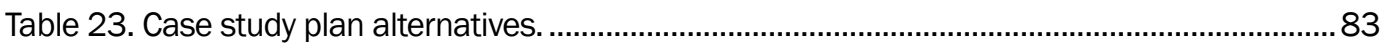

Table 24. Combined impact and decision table for Ayola Alternative B.........................................85

Table 25. Average annual projected reduction in inundated area for FWOP and

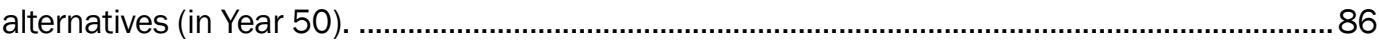

Table 26. Ecological outcome metrics for riparian and aquatic species for FWOP and alternatives (in Year 50)

Table 27. Habitat area conducive to recruitment of foundation tree species for FWOP and alternatives (in Year 50).

Table 28. Plant community composition and diversity functional quality and area for FWOP and alternatives (in Year 50).

Table 29. Native tree cover functional quality and area for FWOP and alternatives (in Year 50).

Table 30. Vegetation density functional quality and area for FWOP and alternatives (in Year 50).

Table 31. Bird diversity functional quality and area for FWOP and alternatives (in Year 50)

Table 32. EGS metrics for riparian non-use services for FWOP and alternatives (end of 50year analysis period).

Table 33. EGS metrics for aquatic non-use services for FWOP and alternatives (end of 50year analysis period).

Table 34. EGS and benefit metrics for property flood risk mitigation (average annual values).

Table 35. Do the plan alternatives meet EGS user preferences? 
Table 36. EGS metrics of general recreation for the FWOP and alternatives (average

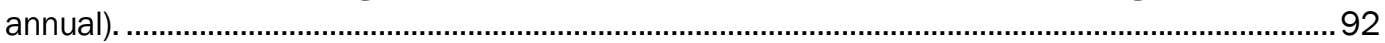

Table 37. Summary of benefits due to project for use services by project alternative......................94

Table 38. Summary of benefits due to project for non-use services (average annual and

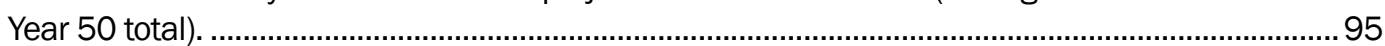

Table 39. Variables and weights used to calculate MCDA aggregate scores....................................99

Table 40. Summary of MCDA results for case study.................................................................100

Table 41. Benefits assessments of the tentatively selected plan (Alternative D). ..........................103

Table A-1. Blank impact evaluation table......................................................................................... 117

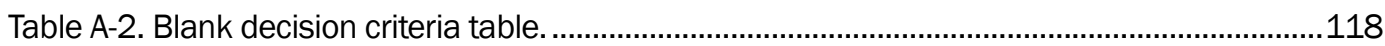

Table A-3. Blank rating documentation table. ..........................................................................119

Table A-4. Rating documentation for case study example Tables 15 and 16.............................119

Table A-5. EGS classification by major categories and sub-categories..........................................128

Table C.1. Resources for evaluating species or ecosystem scarcity and national

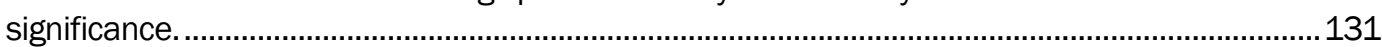




\section{Preface}

This report is part of a series planned by a multi-year Work Unit titled Incorporating Ecosystem Goods and Services in Corps Planning and Environmental Benefits Evaluation. The Work Unit was sponsored by the Ecosystem Management and Restoration Research Program (EMRRP) and jointly managed by the Environmental Laboratory (EL), U.S. Army Engineer Research and Development Center (ERDC), and the U.S. Army Corps of Engineers (USACE), Institute for Water Resources (IWR), under Funding Account Code U436285, AMSCO Code 031342.

People who contributed to this EGS framework report include the following: Dr. Tim Lewis (ERDC EL); Dr. Guillermo Mendoza; Dr. Clyde "Frank" Casey, U.S. Geographical Survey (USGS); and Dr. Tomma Barnes, Wilmington District. Some figures and terms used were inspired by ongoing work of the National Ecosystem Service Partnership, specifically, the joint work of Dr. James Boyd, Dr. Robert Johnston, Dr. Lydia Olander, Dr. Dean Urban, and Dr. Lisa Wainger (National Ecosystem Services Partnership 2014).

This report is published by ERDC under the EMRRP. The USACE proponent for the EMRRP Program is Ms. Mindy Simmons (project initiated under Ms. Rennie Sherman). The Technical Director is Dr. Al Cofrancesco, and the Program Manager is Dr. Trudy Estes (previously Mr. Glenn Rhett) of the ERDC EL. Technical peer review comments were received and incorporated from several people within and outside ERDC: Dr. Richard Cole, Mr. Paul Scodari, Institute for Water Resources; Mr. Brian Harper, Fort Worth District; Dr. Kelly Keefe, Jacksonville District; Dr. Timothy Lewis (ERDC); and Dr. Frank Casey (USGS). Coordination of policy review was conducted by Mr. Bruce Carlson (formerly CECW-P), Dr. Maria Wegner, and Ms. Mindy Simmons (CECWP). The report was also sent to members of the Work Unit Product Delivery Team and Headquarters, USACE, for review. The report was prepared under the general supervision of Ms. Patricia Tolley, Chief, Wetlands and Coastal Ecology Branch; Mr. Mark Farr, Chief, Ecosystem Evaluation and Engineering Division, EL; and Dr. Ilker Adiguzel, Director, EL. Cover photo is from the Tres Rios Restoration Project in California, courtesy of the USACE Los Angeles District Office. 
At the time of publication of this report, Dr. Joe Manous was the Director of IWR.

COL Teresa A. Schlosser was Commander of ERDC, and the Director was Dr. David W. Pittman. 


\section{Executive Summary}

Ecosystem goods and services (EGS) have been promoted as a way to enhance the ability to examine tradeoffs among a multitude of effects and improve communication of environmental outcomes in terms of human well-being. This report proposes an analytic framework to serve as a foundation for the U.S. Army Corps of Engineers ongoing development of effective and consistent social benefit metrics, using monetary or nonmonetary metrics. The intent is to provide policy makers with an opportunity to visualize how development and application of EGS information might look in practice and to reveal the level of effort that might be involved under different applications. It is recognized that this framework is not guidance and will likely be modified as the state of EGS practice evolves and is translated into policy.

EGS are defined here as the socially valued aspects or outputs of ecosystems that depend on self-regulating or managed ecosystem structures and processes. In this definition, EGS are the subset of ecosystem outputs that are recognizable as important to people because they are directly used or appreciated. This definition encompasses the intangible benefits that are derived from preserving and restoring threatened species and ecosystems in addition to the tangible EGS, such as recreation and flood risk mitigation.

\section{What is the framework?}

The framework is an analytical and communications approach for incorporating EGS in USACE decision-support processes. The concepts and basic analytical approaches provided here are potentially applicable to any mission area. To demonstrate potential integration of approaches into decision support, the EGS approaches are aligned with the six-step planning processes because of its widespread use across mission areas.

The core of the framework is the EGS conceptual model that establishes a series of causal relationships that link management actions to EGS benefits/damages. The full framework builds on this conceptual model to develop a suggested set of analytical practices that could be used to assess the magnitude of EGS effects for projects or programs. 


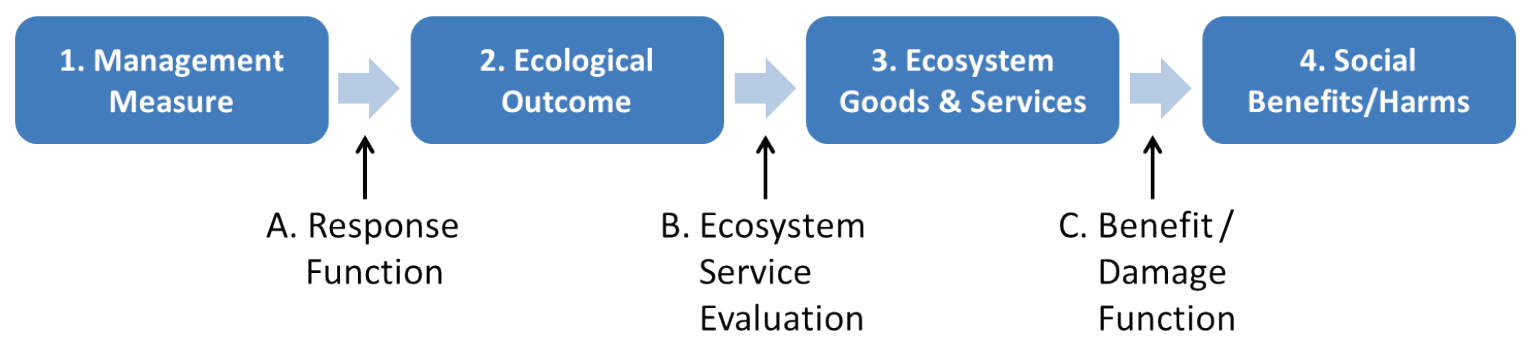

The EGS conceptual model includes three main steps:

A. response function - links management measures (actions) to changes in ecological outcomes that are directly used or appreciated by people

B. ecosystem service evaluation - links ecological outcomes to ecosystem good or service changes by establishing that socio-economic conditions are sufficient to produce benefits or harms (metrics are non-monetary benefit indicators or benefit relevant indicators)

C. benefit/damage function - links ecosystem service changes to measured benefits (usually in monetary units; less often in preference-weighted units derived through structured decision analysis).

The framework includes structured figures and tables as core elements of a consistent system to support a range of decisions-from project scoping to rigorous quantitative comparison of alternatives. Two main tables are suggested to structure the analytic system. The Impact Evaluation Table is used to summarize and communicate magnitude of EGS impacts as part of a screening-level analysis results. This table could serve as the final EGS analysis product for projects with limited resources. The Decision Criteria Table is used to examine the relevance of each affected EGS to planning and to identify a subset of EGS that can be best addressed by a project or program. Other supporting tables, descriptive text, and decision trees provide information for completing the primary tables, options for overcoming data limitations, and considerations for maintaining consistency with USACE guidance.

Through a hypothetical case study, this report demonstrates how the proposed methods may be used to measure EGS benefits with different levels of effort, as appropriate for project needs and data availability. EGS benefits may be assessed through simple metrics (e.g., counts of potentially affected birdwatchers), by transferring empirical results from the published literature (e.g., expected property value enhancements from wetlands), or by applying sophisticated models (e.g., simulations of changes in flood risk to property).

To promote inclusion of a wide range of EGS in decisions, this report introduces a system of non-monetary benefit metrics to capture potential 
benefits/harms when it is not appropriate to monetize EGS impacts. The system of metrics evaluates ecological changes in the context of social, cultural, and economic conditions necessary for ecological changes to affect beneficiaries. Users select only those metrics that are relevant to the specific EGS being considered:

- qualities of ecological outcomes that determine whether use is possible and/or desirable (including quantity, timing, and reliability)

- site access and complementary labor or infrastructure (e.g., boat ramps) necessary to use the service

- potential magnitude of demand based on either demonstrated use or the proximity of people

- scarcity or substitutability of the service.

\section{How could the framework be applied?}

To be useful for decision support, the framework needs to generate measures of the relevant EGS, provide methods for interpreting or aggregating results across a suite of EGS, and avoid adding excessive new analytic requirements. To meet the first need, the EGS framework provides options to limit the EGS that can be evaluated with project resources to those that are within project authorities or are relevant to USACE missions and within the funding capacity of the USACE and its non-federal sponsor. Alternatively, the user is shown an option to analyze all EGS relevant to stakeholders in the event that alternative agreements for funding analyses can be arranged or new guidance is developed.

Further, the framework promotes cost-effective levels of analysis by helping teams to select the level of detail in both analysis and presentation of results that fits the decision context. Three approaches of comparing and/or aggregating EGS metrics are proposed to inform decision-making processes (e.g., to choose a final plan):

- Quantitative metrics are selected to communicate rationale for a project and evaluate cost-effectiveness (social values are implicit).

- A non-monetary index of social value encompassing a comprehensive set of EGS is created by eliciting stakeholder preferences (e.g., via multi-criteria decision analysis).

- A sum of monetized social benefits and/or harms for a subset of EGS is used to justify a project and is compared to costs to demonstrate net social benefits. 


\section{Why this framework?}

The framework introduces many concepts drawn from economics that help to frame project outcomes in terms of social benefits or harms, even when values are not monetized. The overarching goal is to explicitly relate ecological changes to human well-being to improve understanding and communication. To achieve this goal, the framework promotes the development of non-monetary benefit indicators that show, for example, the degree to which a project ameliorates scarcity of a desirable EGS, since this is usually a clear indication of value. Further, the framework promotes measuring project outcomes in terms of specific stakeholder concerns. For example, an ecological change may not generate a benefit if the level of change is insufficient to achieve the minimum quality necessary for an EGS to be practical or safe to use. Therefore, an evaluation of minimum requirements, thresholds, or other non-linearities in the relationship between ecosystem change and beneficiary needs, is promoted as an element of characterizing the benefits produced from a given level of management effort. 


\section{Introduction}

\section{Background}

Ecosystem goods and services (EGS) have been promoted as a way to enhance the ability to examine tradeoffs among a multitude of effects and improve communication of environmental outcomes in terms of human well-being. The U.S. Army Corps of Engineers (USACE) has been exploring the potential of using EGS in decision making, conducting multifaceted research consisting of a systematic review of EGS concepts, policy, tools and potential ways to integrate EGS concepts into USACE decision-making. Several reports and investigations have already been completed, with the results integrated into this Framework.

Chapter Highlights

- $\quad$ EGS are defined as goods and services that are derived from self-regulating or managed ecosystems and that are tangibly used or otherwise appreciated. This definition requires that EGS metrics be framed in terms of improvements in human wellbeing (or welfare).

- Key EGS concepts are introduced to promote consistent EGS measurement; a table of EGS categories (Table 2) is proposed to align EGS definitions with USACE mission areas.

- Principles and Best Practices: A Technical Note (Murray et al. 2013) and longer Technical Report (Tazik et al. 2013) explore the prevalent definitions, classifications, history, and conceptual models relating to ecosystem goods and services, and propose working definitions and conceptual models that are appropriate for USACE use, along with implications for the USACE planning process.

- Policy Review and Analysis: This report (Reed et al. 2013) reviews and analyzes USACE authority, policy, and guidance that either support or impede the integration of information on ecosystem goods and services. The report also reviews other agencies' policies and practices relative to using an ecosystem service-based approach in their programs.

- Review of Data and Analytical Tools: A database catalogs data sources, analytical tools, and models with the potential to support EGS considerations in USACE planning. A synthesis report describes attributes of the tools, discusses strengths and weaknesses, and illustrates how the tools fit in the conceptual model. ${ }^{1}$

${ }^{1}$ Murray, E. O., G. Mendoza, L. Wainger, H. Griscom, and J. Cushing. In preparation. Ecosystem Goods 
- Case Study Retrospective: A technical note describes previous and current USACE efforts to address ecosystem goods and services in the planning process, and summarizes successes and lessons learned, so that such knowledge may be incorporated into the proposed framework. ${ }^{1}$

- Analytical Framework and Practices: Ultimately, the research described above is intended to inform the development of a framework and practices that could be used by USACE Districts to analyze ecosystem goods and services in the planning process (this report).

The research outlined above has resulted in a set of concepts, definitions, and approaches that will be further discussed in the Approach section below.

\section{Objective}

The purpose of this document is to present a framework that can serve as the foundation of any future guidance on measuring changes in EGS from proposed civil works activities. This document is not intended to serve as guidance or instructional material for field practitioners to use during the execution of civil works investigations. Rather, it is intended to deepen understanding of EGS approaches and provide those who might develop policies or guidance with an example of how ecosystem services might apply to each phase of a civil works investigation in support of decisions that might be made about future investments. It is also intended to reveal how and in what contexts ecosystem services information might add value, thereby justifying additional analytic resources.

This framework is further intended to facilitate a USACE response to future requests for information on EGS effects from federal agencies (e.g., OMB et al. 2015). This report demonstrates the integration of the proposed framework within USACE planning; however, concepts and examples may be applicable to other types of decisions or communications. The framework was also designed to support development of a unified decision-support

\footnotetext{
and Services (EGS) Models and Tools: A Synthesis Report of Information in the EGS Models and Tools Catalog. ERDC/EL Technical Report. Vicksburg, MS: US Army Engineer Research and Development Center.

${ }^{1}$ Cushing, J., S Komlos, T. Barnes., C. Theiling, E. O. Murray. In preparation. A Retrospective of Attempts to Incorporate Ecosystem Goods and Services into Corps Planning: Case Studies and Lessons Learned. ERDC/EL Technical Report. Vicksburg, MS: US Army Engineer Research and Development Center.
} 
document that integrates existing planning procedures (USACE 2000, 2013) and National Environmental Policy Act (NEPA), as recommended in recent guidance (White House Council on Environmental Quality 2013).

\section{Approach}

This Framework relies on concepts, definitions, and classifications developed over the course of the work unit, and summarized below.

\section{Definition of ecosystem goods and services (EGS)}

EGS have been defined in multiple ways for different applications. For the purposes of USACE decision support, EGS is defined as follows:

Ecosystem goods and services are socially valued aspects or outputs of ecosystems that depend on self-regulating or managed ecosystem structures and processes. (Murray et al. 2013)

In this definition, EGS are the outputs of ecosystems ${ }^{1}$ that are recognizable as important to people because they are directly used or appreciated. The ecosystems that produce these goods and services may require built structures or a certain amount of management to maintain their services (e.g., a riparian ecosystem that requires irrigation from pumps; a wetland that needs continued invasive species control). However, purely humanengineered infrastructure, such as levees and dikes, are not considered ecosystems in this framework, even if they support minor biological elements (e.g., barnacles). These structures provide important services that may also be EGS, such as flood damage mitigation, but if they do not contain ecosystems, they are likely to be technical substitutes for EGS. ${ }^{2}$

In this framework, EGS are most often defined as final EGS to distinguish them from the so-called intermediate or supporting services (Table 1). Intermediate or supporting services are ecosystem features or processes that are important inputs to EGS but, without further context information, cannot typically be said to produce benefits to people (Boyd and Banzhaf

\footnotetext{
1 Ecosystems are defined in the Principles and Requirements as "dynamic complexes of plant, animal, and microorganism communities and the non-living environment interacting as a system"(White House Council on Environmental Quality 2013).

2 Built infrastructure may contribute to EGS benefits by supporting the establishment or longevity of ecosystems. For example, dikes may enable coastal wetlands to persist and extend the time period of benefits. Wetlands that persist will provide more years of benefits than wetlands that disappear due to erosion, all else equal. The extra years of benefits that are enabled by the dikes will be captured by summing the annual wetland-derived EGS benefits over the planning period.
} 
2007). For example, groundwater recharge is an intermediate EGS, which, in some settings, produces the final EGS of irrigation and drinking water supply and/or recreational fishing opportunities (by assuring stream baseflow needed for fish habitat) ${ }^{1}$. The use of EGS that identify recognizable benefits, or final EGS, promotes communication of benefits and clear evaluation of tradeoffs among different types of beneficial outcomes. The framework does not completely exclude the use of intermediate/supporting services as EGS, which can be useful metrics, as explained later in this section.

Table 1. Key EGS concepts (Murray et al. 2013).

\begin{tabular}{|l|l|}
\hline Concept & Definition \\
\hline Final EGS & $\begin{array}{l}\text { EGS that are directly used or appreciated by people, such as safe drinking water, } \\
\text { recreational fishing opportunities, and the preservation of scarce ecosystems. }\end{array}$ \\
\hline $\begin{array}{l}\text { Intermediate or } \\
\text { supporting EGS }\end{array}$ & $\begin{array}{l}\text { Ecological features or processes, such as water purification and groundwater } \\
\text { recharge, that are important inputs to final EGS but are difficult for people to } \\
\text { directly value or appreciate. }\end{array}$ \\
\hline $\begin{array}{l}\text { Use EGS } \\
\text { (or active-use EGS) }\end{array}$ & $\begin{array}{l}\text { EGS that provide benefits from using or interacting with ecosystems, such as raw } \\
\text { material production, outdoor recreational opportunities, and flood damage } \\
\text { mitigation. }\end{array}$ \\
\hline $\begin{array}{l}\text { Non-use EGS }{ }^{+} \\
\text {(or passive-use EGS) }\end{array}$ & $\begin{array}{l}\text { EGS produced from preserving or restoring a resource without the intent to tangibly } \\
\text { use or enjoy the good or service. This category also includes benefits derived from } \\
\text { knowing a good or service is available to others, now or in the future. Values for } \\
\text { these services are typically captured by the terms existence, altruistic, and bequest } \\
\text { values. }\end{array}$ \\
\hline
\end{tabular}

† Note the use of the term non-use services to distinguish outcomes that have potential value from those that have been demonstrated to have value (i.e., this term is equivalent to a potential non-use value). This language differs from much of the economic literature that uses non-use value to represent aspects of ecosystems that are valued, but not used, and thus are not services in the traditional sense. Non-use services is a useful term here to avoid confusion that might arise from using the term value to refer to something that has not been monetized or otherwise explicitly demonstrated to have value to stakeholders.

The EGS considered in the framework include use and non-use services (definitions in Table 1 and Figure 1). Use services encompass the benefits that people derive from direct on-site use or interaction with ecosystems (e.g., raw material production and outdoor recreation) or from indirect off-site interaction (e.g., flood damage mitigation that occurs from upstream water retention). Non-use services represent the less tangible benefits that people derive from knowing that species or ecosystems exist, that they will be passed along to future generations, or that they are

\footnotetext{
1 Some EGS metrics can represent either intermediate or final EGS, depending on the circumstances. For example, people can directly value improvements in water clarity in a water body (for aesthetic benefits) or might appreciate water clarity indirectly as an input to the final EGS of trout fishing opportunities. For details, see Johnston and Russell (2011).
} 
protected for use by others, or to fulfill stewardship responsibilities (National Research Council [NRC] 1999). For example, recreational fishing is a use service of an ecosystem while the desire to preserve recreational fishing for future generations is a non-use service. Economists have developed three common categories of these non-use services or values: (1) existence; (2) bequest; and (3) altruistic services and economic theory suggest that values of ecosystem changes are incomplete if they do not incorporate these values (Turner et al. 2008). ${ }^{1}$

Figure 1. Components of total economic value.

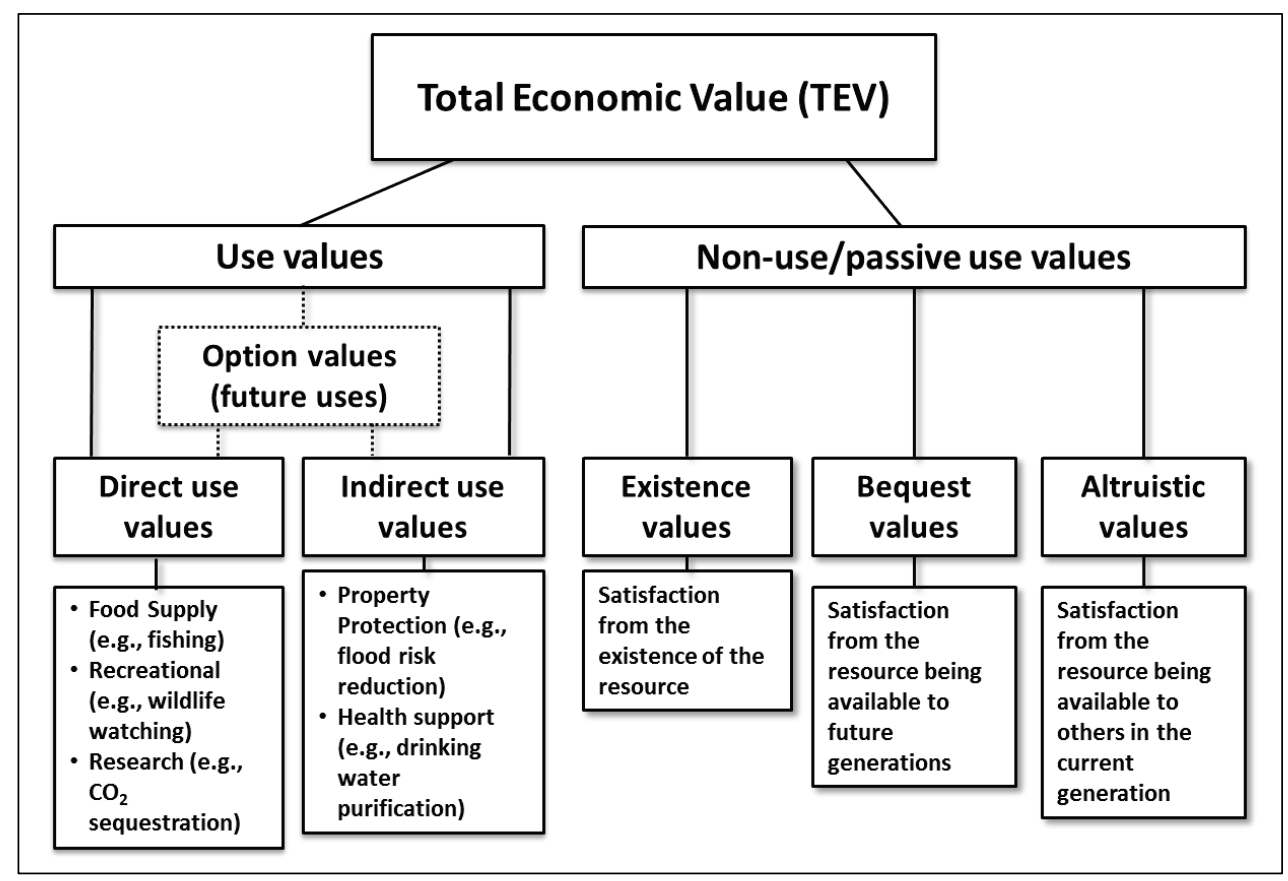

The social benefits/harms derived from changes in ecosystem goods and services are evaluated as effects on people's well-being, including a broad range of outcomes that extend beyond financial gain. Economic methods of determining welfare effects are derived from economic concepts of value that have been developed over centuries by observing human behavior in markets and other situations where people make choices about what to buy, where to invest, or how to spend their free time. Thus, economic values are derived from observed human behavior at particular times and in specific places and are distinct from monetary values that have been developed based solely on ecological qualities or conditions averaged across dissimilar

1 Earlier versions of non-use values frameworks included option value. Theoretical work has revealed that option value is more appropriately classified as a use service (Hanley et al. 2001; Freeman 2003; Turner et al. 2008). 
sites. Applying these economic concepts creates valid measurements of value that are necessary to invest scarce resources where they can create the greatest social good (Champ et al. 2003; Freeman et al. 2014).

Some consider the economic approach of valuing ecosystems based on individual's values to be problematic for failing to recognize the intrinsic value of nature. They argue that ecosystem preservation has an ethical dimension that is not captured by economic values and that intrinsic values are distinct from other values in that they cannot be traded for other goods and services. While it is impossible for an economic framework to include all human concerns, and in particular, it cannot address the question of whether intrinsic value should be traded off for other uses or values, the economic framework applied here incorporates intrinsic values to the extent that it represents human concerns for protecting nature, independent of human use. Since it is impossible to ask nature what it wants, one must ask people to interpret the idea of intrinsic value and here this is accomplished by applying evidence of non-use values.

\section{EGS categories}

The Ecosystem Goods and Services Project Delivery Team has developed a proposed set of general EGS categories that can be related to USACE mission areas (Table 2). This list is similar to some other EGS typologies that have been previously developed (see Murray et al. 2013 for further discussion), but this list emphasizes EGS most likely affected by USACE projects and enables analysts to separate EGS that are outside of USACE primary mission areas, if needed. However, the provided definitions may or may not align with those referenced by current policies. These broad categories of EGS would need to be refined when applied to specific studies. 
Table 2. Definitions and examples of ecosystem goods and services.

\begin{tabular}{|c|c|c|c|}
\hline Category & Definition & Example EGS Indicators ${ }^{1}$ & $\begin{array}{l}\text { Example Practices } \\
\text { That May Influence Service }\end{array}$ \\
\hline $\begin{array}{l}\text { Ecosystem } \\
\text { Sustainability } \\
\text { (Non-use and passive- } \\
\text { use EGS, defined in } \\
\text { Table 1) }\end{array}$ & $\begin{array}{l}\text { The maintenance of } \\
\text { ecosystems' structural and } \\
\text { functional qualities (including } \\
\text { water quality, environmental } \\
\text { flows, vegetation density, etc.) } \\
\text { and resilience to adapt to } \\
\text { change over time. Includes all } \\
\text { non-use or passive-use services } \\
\text { (existence, intergeneration } \\
\text { bequest, or altruistic values) } \\
\text { derived from the diversity or } \\
\text { condition of species, or } \\
\text { ecosystems. }\end{array}$ & $\begin{array}{l}\text { - Native species diversity/other } \\
\text { indices of ecological } \\
\text { community condition and } \\
\text { maintenance of future } \\
\text { viability } \\
\text { - Population viability of a } \\
\text { threatened species } \\
\text { - Frequency of stream base } \\
\text { flow meeting an ecologically } \\
\text { relevant threshold (e.g., } \\
\text { required to maintain a fish } \\
\text { population) }\end{array}$ & $\begin{array}{l}\text { - Ecosystem restoration }{ }^{2} \\
\text { - Habitat improvement }{ }^{2} \\
\text { - Invasive species control2 } \\
\text { - Project impacts to } \\
\text { ecosystems }\end{array}$ \\
\hline $\begin{array}{l}\text { Water Supply and } \\
\text { Regulation }\end{array}$ & $\begin{array}{l}\text { The provision and regulation of } \\
\text { surface and groundwater by } \\
\text { ecosystems which may be used } \\
\text { for domestic, municipal, } \\
\text { industrial, and agricultural } \\
\text { purposes. }\end{array}$ & $\begin{array}{l}\text { Recharge rate of a water } \\
\text { supply aquifer suffering } \\
\text { declining levels } \\
\text { - Number of domestic water } \\
\text { supply wells affected by } \\
\text { seawater intrusion } \\
\text { - Change in hydropower output }\end{array}$ & $\begin{array}{l}\text { - Stream restoration }{ }^{2} \\
\text { - Wetland reforestation }{ }^{2} \\
\text { - Impervious surface } \\
\text { creation } \\
\text { - Floodplain management } \\
\text { - Water management } \\
\text { practices/operations }\end{array}$ \\
\hline $\begin{array}{l}\text { Hazard Mitigation } \\
\text { (Reduced risks to } \\
\text { property and } \\
\text { infrastructure, } \\
\text { human safety) }\end{array}$ & $\begin{array}{l}\text { Ecosystem-induced reduction } \\
\text { of risk of or vulnerability to } \\
\text { natural hazards that threaten } \\
\text { property, infrastructure, human } \\
\text { safety, or natural resources. } \\
\text { Threats include storms, floods, } \\
\text { landslides, fires, and droughts. }\end{array}$ & $\begin{array}{l}\text { - Residential, commercial, and } \\
\text { agricultural area affected by } \\
\text { flooding due to storm surges } \\
\text { - Intensity and frequency of fire } \\
\text { in a populated area } \\
\text { - Bushels of corn protected } \\
\text { from flooding }\end{array}$ & $\begin{array}{l}\text { - Tidal wetland restoration }{ }^{2} \\
\text { - Invasive species } \\
\text { management }{ }^{2} \\
\text { - Alteration of hydrology, } \\
\text { landforms, and plant } \\
\text { communities }\end{array}$ \\
\hline $\begin{array}{l}\text { Navigation } \\
\text { Maintenance }\end{array}$ & $\begin{array}{l}\text { Provision of unobstructed } \\
\text { waterborne transport of goods } \\
\text { and people as supported by } \\
\text { sediment reduction and water } \\
\text { regulation by functioning } \\
\text { ecosystems } 4 \text {. }\end{array}$ & $\begin{array}{l}\text { - Sediment accumulation rate } \\
\text { in navigable channels (e.g., } \\
\text { as a function of land cover) } \\
\text { - Duration of navigable } \\
\text { conditions } \\
\text { - Removal of non-native } \\
\text { aquatic growth }\end{array}$ & $\begin{array}{l}\text { - } \text { Riparian restoration }{ }^{2} \\
\text { - } \text { Erosion control } \\
\text { - } \text { meneficial use of dredged } \\
\end{array}$ \\
\hline Recreation Supply & $\begin{array}{l}\text { Quantity and quality of } \\
\text { recreational opportunities. }\end{array}$ & $\begin{array}{l}\text { - } \\
\text { - } \\
\text { Number and/or diversity of } \\
\text { ecotourism activities } \\
\text { supported }\end{array}$ & $\begin{array}{l}\text { - Wetland, riparian and } \\
\text { stream restoration }{ }^{2} \\
\text { - Habitat restoration }{ }^{2} \\
\text { - } \text { Alteration of water and } \\
\text { land resources (e.g., } \\
\text { impoundments) } \\
\text { - Reservoir management }\end{array}$ \\
\hline
\end{tabular}




\begin{tabular}{|c|c|c|c|}
\hline Category & Definition & Example EGS Indicators ${ }^{1}$ & $\begin{array}{l}\text { Example Practices } \\
\text { That May Influence Service }\end{array}$ \\
\hline $\begin{array}{l}\text { Cultural, Spiritual } \\
\text { and Educational } \\
\text { Support }\end{array}$ & $\begin{array}{l}\text { Maintenance of opportunities } \\
\text { arising from sites and } \\
\text { landscapes that have spiritual } \\
\text { or religious significance, } \\
\text { contribute to a sense of place, } \\
\text { or sustain cultural heritage, } \\
\text { including traditional ways of } \\
\text { life. Also includes opportunities } \\
\text { for scientific discovery and } \\
\text { education. }\end{array}$ & $\begin{array}{l}\text { \% buffering of documented } \\
\text { historic, cultural, or religious } \\
\text { sites with open space or } \\
\text { natural vegetation } \\
\text { - Acreage of relatively } \\
\text { undisturbed ecosystems } \\
\text { accessible for research }\end{array}$ & $\begin{array}{l}\text { - } \text { Habitat restoration }{ }^{2} \\
\text { - } \text { manvive species } \\
\text { management }{ }^{2} \\
\text { - } \text { Land use and land cover } \\
\text { alteration }\end{array}$ \\
\hline Aesthetics & $\begin{array}{l}\text { Aesthetic enjoyment provided } \\
\text { by the condition and relative } \\
\text { placement of landscape and } \\
\text { ecosystem features pleasing to } \\
\text { one or more of the five senses. } \\
\text { Can be an intermediate service } \\
\text { contributing to property value } \\
\text { enhancement, recreation, and } \\
\text { cultural or spiritual values or a } \\
\text { final service outside of any of } \\
\text { these contexts (e.g., loss of } \\
\text { well-being during daily } \\
\text { activities). }\end{array}$ & $\begin{array}{l}\text { - } \% \text { of view from residences or } \\
\text { sensitive commercial } \\
\text { properties that is open water } \\
\text { - Changes in forest canopy } \\
\text { openness } \\
\text { - Frequency of lake turnover } \\
\text { events emitting sulfur smell } \\
\text { - Change in forest harvesting } \\
\text { resulting in forest clearcuts } \\
\text { observed from road while } \\
\text { commuting }\end{array}$ & $\begin{array}{l}\text { - Wetland, riparian and } \\
\text { - } \text { - Habitream restoration restoration }{ }^{2} \\
\text { - } \text { Location, design and } \\
\text { operation of built } \\
\text { structures } \\
\text { - In-stream flow } \\
\text { management }\end{array}$ \\
\hline Food Provisioning & $\begin{array}{l}\text { Provisioning of or contribution } \\
\text { to commercial or subsistence } \\
\text { production of food and the } \\
\text { ecosystem conditions that } \\
\text { support it. }\end{array}$ & $\begin{array}{l}\text { Abundance of a fish species } \\
\text { used for food within tribal } \\
\text { communities } \\
\text { - Population density of edible } \\
\text { fish in streams/lakes used by } \\
\text { subsistence fishers }\end{array}$ & $\begin{array}{l}\text { - } \text { Water management } \\
\text { - } \text { Dabitat restoration }{ }^{2} \\
\text { shellfish beds } \\
\text { - Stream restoration }{ }^{2} \\
\text { - Fish passage on water } \\
\text { control structures }\end{array}$ \\
\hline $\begin{array}{l}\text { Raw Goods and } \\
\text { Materials Provisioning }\end{array}$ & $\begin{array}{l}\text { Provisioning of or contribution } \\
\text { to raw goods and materials. }\end{array}$ & $\begin{array}{l}\text { - Grain size of accessible sand } \\
\text { trees }\end{array}$ & $\begin{array}{l}\text { - In-water structures (e.g., if } \\
\text { they enhance or prevent } \\
\text { access to materials) } \\
\text { - Invasive species control2 } \\
\text { - Wetland or riparian } \\
\text { restoration } 2\end{array}$ \\
\hline $\begin{array}{l}\text { Water Purification and } \\
\text { Waste Treatment to } \\
\text { Protect Human } \\
\text { Health } 3\end{array}$ & $\begin{array}{l}\text { The filtration and removal of } \\
\text { excess nutrients or pollutants } \\
\text { by ecosystems from inland, } \\
\text { coastal, or marine waters. }\end{array}$ & $\begin{array}{l}\text { Pathogen concentration in } \\
\text { water adjacent to public } \\
\text { beaches } \\
\text { - Frequency or extent of } \\
\text { harmful algal blooms in areas } \\
\text { of commercial fishing use or } \\
\text { recreation }\end{array}$ & $\begin{array}{l}\text { - Wetland restoration² } \\
\text { - Water management } \\
\text { - } \quad \text { Riparian restoration } 2 \\
\text { - } \quad \text { Channel configuration }\end{array}$ \\
\hline $\begin{array}{l}\text { Climate Regulation, } \\
\text { Carbon Sequestration }\end{array}$ & $\begin{array}{l}\text { Ecosystem moderation of } \\
\text { adverse climate effects through } \\
\text { sequestration of greenhouse } \\
\text { gases. }\end{array}$ & $\begin{array}{l}\text { - Annual carbon sequestration } \\
\text { rate }\end{array}$ & $\begin{array}{l}\text { - } \text { Reforestation and forest } \\
\text { restoration }{ }^{2} \\
\text { - Wetland restoration }{ }^{2}\end{array}$ \\
\hline
\end{tabular}




\begin{tabular}{|l|l|l|l|}
\hline Category & Definition & Example EGS Indicators ${ }^{1}$ & $\begin{array}{l}\text { Example Practices } \\
\text { That May Influence Service }\end{array}$ \\
\hline $\begin{array}{l}\text { Human Health } \\
\text { Support (other than } \\
\text { water purification) }\end{array}$ & $\begin{array}{l}\text { Ecosystem reduction of the risk } \\
\text { of or vulnerability to health } \\
\text { hazards other than water } \\
\text { quality. Includes changes in air } \\
\text { quality, environmental } \\
\text { stressors, and animal or insect } \\
\text { disease vectors. }\end{array}$ & $\begin{array}{l}\text { Days of unhealthy levels of } \\
\text { particulate matter } \\
\text { Frequency of temperatures } \\
\text { considered dangerous to } \\
\text { health } \\
\text { West Nile disease frequency } \\
\text { reduction }\end{array}$ & $\bullet \begin{array}{l}\text { Wetland and riparian } \\
\text { restoration }\end{array}$ \\
& Habitat restoration ${ }^{2}$ \\
\end{tabular}

1Some example indicators are not features that the USACE may use as a basis to formulate or select plans but are still useful for communicating social benefits of a project.

2Ecosystem restoration and protection, habitat improvement or enhancement, invasive species control, or other stewardship activities could take place under authorities that allow for aquatic ecosystem restoration and protection, mitigation for impacts of USACE projects, management of USACE properties, and delivery of planning and technical services to other agencies/organizations.

3 Water purification for human health is separated from related EGS to provide the ability to distinguish when water quality improvements can be considered to fall within a USACE mission area vs. when they are being tracked to address stakeholder concerns or NEPA requirements. Water quality improvements that benefit species or ecosystems may be captured under Ecosystem Sustainability and Recreation.

${ }^{4}$ Built structures such as levees, dams, and seawalls contribute only indirectly to the ecosystem service of navigation maintenance since they can help to maintain the wetland and forest ecosystems that will prevent sediment from blocking navigation. They directly support navigation, but they are not considered ecosystem services in this framework.

To apply the general EGS list in Table 2, users would need to develop more specific and measurable services to match project efforts to expected outcomes. In addition, teams would need to tailor the indicators to beneficiary concerns. The example indicators in Table 2 are guides to the type of indicators that are needed to communicate welfare effects to stakeholders and policy makers. These indicators sometimes represent ideal metrics that may be too resource-intensive for widespread application. In those cases, they are meant as guides for selecting proxy metrics that represent similar concepts but are feasible to measure with available data, models, and scientific understanding.

The categories in Table 2 are final ecosystem goods and services, except for two cases: (1) climate regulation and carbon sequestration and (2) ecosystem sustainability, which can include both final and intermediate services. Climate regulation and carbon sequestration are used as a distinct category even though the final service might be more clearly defined as some of the other listed EGS including hazard mitigation, property damage mitigation, food provisioning, or human health support. Since carbon sequestration has become widely recognized as a proxy for a range of global benefits that are difficult to quantify, its use is maintained here. 
Ecosystem sustainability is used to encompass all non-use services associated with the restoration or protection of species and ecosystems. The definition of this category follows from work to define ecological conditions that promote biodiversity and associated system integrity and resilience (Noss 1990; NRC 1999). This category includes the existence, bequest, and altruistic values for species and ecosystems of concern, as defined above. It may also encompass broad interests, such as those to preserve genetic and informational resources that might be used by future generations to cure disease, promote crop resilience to pests, or provide cultural resources.

\section{What could an EGS analysis contribute to USACE decision support?}

The primary motivation for developing this framework is to enable EGS to support project-level decision-making and program-level investments. By promoting consistency in how EGS are measured and reported across projects, it could enable decision-makers to aggregate effects of multiple projects and examine many types of tradeoffs. This framework further supports ongoing efforts to clearly express the effects of proposed actions to decision-makers and the public.

This framework is intended to be used to translate changes in ecological conditions into a wide range of socially meaningful outcomes, only some of which will match up to USACE mission areas and specific project authorities. As a result, some EGS may be excluded from parts of the plan formulation, evaluation, and selection (i.e., because they cannot be used to justify a recommended plan). However, encompassing a full range of EGS changes will be useful during disclosure of project-related effects, as required by NEPA, and for developing a plan, with partners, that maximizes benefits for a range of stakeholders and cost-share partners. This framework is not planning guidance, and use of concepts and approaches suggested here will be dependent on the development of USACE policy to incorporate EGS.

To overcome any concerns that the EGS framework would cause the USACE to waste resources measuring outcomes that are beyond its mission areas or not relevant to decision-making, the framework offers options to tailor the analysis. One option is to limit the level of analytical detail used to avoid cost-inefficient approaches, particularly when EGS are outside mission areas. The second option is to consider which EGS should be analyzed at different points during decision support, to develop the best project but also 
limit the scope of the EGS as needed for determining cost-sharing arrangements or other aspects of USACE involvement.

\section{How to read this document}

This document covers general concepts and specific analysis techniques that could be useful for developing policies and guidance for integrating EGS analysis into USACE planning and project analysis, should a supporting policy be developed by the USACE Headquarters. As such, this document is not intended to serve as guidance or instructional material for field practitioners to use during the execution of civil works investigations. Rather, it is intended to deepen understanding of EGS approaches and provide those who might develop policies or guidance with an example of how ecosystem services might apply to each phase of a civil works investigation in support of decisions that might be made about future investments.

The following overview is provided so that readers can choose the sections to read depending on their interests.

- Section 1 (Introduction, this section) presents an overview of the conceptual foundations of the proposed framework and defines key concepts and terms, and overall organization of the document.

- Section 2, Framework Overview, presents a high-level overview of the framework structure.

- Section 3 (Linking the EGS Analysis to the 6-Step Planning Process) includes descriptions of each of the framework's steps and their potential application as part of the 6-Step Planning Process.

- Step 1 provides details regarding the application of the framework and lays out a screening process for evaluating all affected EGS and selecting key EGS for use in plan formulation.

○ The remainder of Section 2 (Steps 2-6) walks readers through the details of potential adaptations of plan formulation and evaluation to include EGS. Where EGS would not require modification of existing Corps planning methods (e.g., use of cost-effective analysis/incremental cost 
analysis [CEA/ICA] to compare alternatives), the document provides limited detail and refers readers to appropriate USACE documentation.

- A hypothetical case study is discussed throughout Section 2 to illustrate how to apply the framework in the 6 steps. The case study discussions are in light blue boxes.

- A progress bar (see below) is provided at the bottom of every page in Section 3 to show which planning step is being discussed. The part of the bar highlighted in red represents the current section.

- Analysis details are provided only where the application of EGS requires methodological changes from current planning. Methods are not intended to be planning guidance. If, at a future date, it is deemed desirable to implement such a framework, specific planning guidance would need to be developed.

- Those interested in analyzing EGS of a selected plan, rather than using EGS in plan formulation, will want to focus on Steps 1, 4, and 6, but will find additional relevant details in Steps 2, 3, and 5 .

- Appendices provide detailed supporting information.

- Example Progress Bar Used in Section 2. 


\section{Framework Overview}

This section describes the basic structure of the conceptual model that forms the backbone of the proposed framework for assessing the EGS effects of a project. More details of how to construct and use the conceptual model-including analytic methods useful for EGS-are described in subsequent sections. These analytic approaches are adaptations of existing methods to the particular challenges of measuring EGS. This section uses simple examples to explain the conceptual model, and Section 2 will more fully illustrate concepts.

\section{Conceptual model}

The EGS conceptual model is series of causal relationships that trace the effects of management measures (actions) through ecological and socio-economic systems to measure the benefits or harms of management measures (Figure 2). The relationships establish that the biophysical changes and socioeconomic conditions are sufficient to impart benefit or loss. By completing each step of the causal chain or web, analysts can ensure that benefit measures are grounded in sound science and necessary assumptions are documented.
Chapter Highlights

- The EGS framework uses a conceptual model to guide the development of effective metrics of social benefits or harms that result from USACE activities. Three main steps are used to create the necessary cause and effect relationships:

- Response function - links management measures to changes in ecological outcomes

- Ecosystem service evaluation - links ecological outcomes to changes in ecosystem goods or services

- Benefit/damage function - links ecosystem service changes to measured benefits.

- This framework proposes specific decision support aids and structured figures and tables for conducting and documenting analysis methods and outcomes. These elements include the following:

- Impact tables and decision trees to select indicators and measure magnitudes of EGS impacts

- Example figures and tables for presenting evidence and assumptions used to measure EGS benefits.

- The EGS framework provides options for tailoring analyses to remain consistent with current USACE guidance such as limiting the EGS that can be used to justify a recommended plan that is fully cost shared.

- The framework promotes cost-effective analysis by providing analysis options that can be tailored to decision context and resource availability. 
Figure 2. The framework EGS conceptual model. The EGS conceptual model consists of cause-and-effect relationships (arrows A-C) and measurable metrics of benefits or harms (boxes 2-4). The arrows represent analyses used to establish that the biophysical changes and socio-economic conditions are sufficient to impart value. Moving from left to right adds progressively more evidence that a management measure will generate a social benefit or harm.

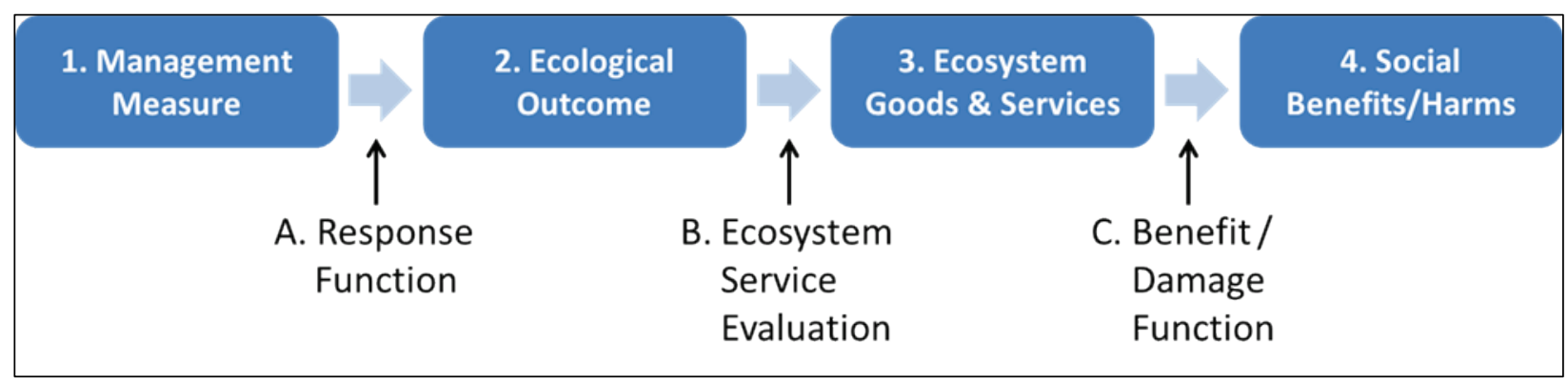

Each type of outcome metric generated by using the EGS conceptual model (Figure 2, Boxes 2-4) reflects potential or measured social welfare benefits. It is not always possible or appropriate (under current USACE guidance) ${ }^{1}$ to develop all of the relationships necessary to monetize an EGS change. However, establishing the earlier relationships in the causal chain produces outcome metrics that communicate project effectiveness (Boxes 2 and 3), when social benefits (Box 4) cannot be directly valued.

Moving from cause to effect in the model (i.e., left to right in Figure 2) requires establishing a chain (or web) of causal relationships (arrows) for one or a bundle of EGS. On-the-ground analysis may require linking up many models and data sets to trace effects through the ecological and social systems. However, three general types of relationships (labeled A, B, and C in Figure 2) are used to represent what is needed, as described below.

\section{A. Response function - linking management measures to ecological outcomes}

The response function measures the effect of implementing one or more actions (Management Measure) on a relevant biophysical change (Ecological Outcome). Not all traditional ecological measures make good ecological outcome metrics. Instead, metrics are selected as outputs of this step because they can be directly linked to an EGS. Ideally, these outcome metrics are the outputs that are directly used or appreciated by people (e.g., game fish abundance) or otherwise require

\footnotetext{
${ }^{1}$ See Text Box 4 for further explanation.
} 
minimal explanation (e.g., annual net rate of carbon sequestration) ${ }^{1}$ to communicate their importance to users or beneficiaries.

The response function often requires establishing multiple causal relationships to produce an ecological outcome that is directly relevant to an EGS. As an example, in Figure 3, the management measure of riparian plantings is first traced through the affected ecological process of native vegetation recruitment, which depends not only on the vegetation planted but the proposed modifications to the hydrologic regime. Plant recruitment is then linked to the ecological outcome of ecosystem resilience, as measured by the metric of expected future native species richness. Although it may never be possible to quantitatively model future native plant species richness (or demonstrate ecosystem resilience with certainty), the conceptual model communicates why the metric of native vegetation recruitment is relevant to the goal of sustaining the riparian ecosystem, based on the best available science.

For initial screening, the analyst does not try to model the relationship between management measure and ecological outcome but instead uses available knowledge to identify a general functional form (e.g., a linear, S-shaped, or exponential response). If the EGS is selected for later in-depth analysis, the analyst would select or develop a model to project feasible outcomes of a specified suite of management measures. A response function model can range from the simple to complex, depending on available resources, but should be based on empirical data whenever possible.

\section{B. Ecosystem service evaluation}

To relate an ecological outcome to the delivery of a final EGS (moving from Box 2 to Box 3 in Figure 2), the analyst uses an ecosystem service evaluation (ESE). To conduct an ESE, the analyst gathers evidence that the ecological change will be used or appreciated to establish that the project site is capable of delivering the service that was only suggested by the ecological outcome metric. For example, as shown in Figure 4, the ecological outcome of an increase in game fish abundance suggests

${ }^{1}$ Carbon sequestration is an ecological outcome and an intermediate EGS metric that, for convenience, is used to represent multiple final EGS affected by climate change (e.g., property flood-damage mitigation, human health). 
that the EGS of recreational fishing will be enhanced, but the ESE step is used to confirm that a fishing benefit is likely. The analyst confirms that the site has public access and gathers evidence of existing or likely recreational use. To determine potential use with the ecological improvement, the analyst could examine local population density, availability of substitute sites, and levels of congestion at existing sites. This step is needed because an ecological change that is not expected to be used or appreciated in some way is not, by the definition used here, an ecosystem service.

The outcome of the ESE is a non-monetary benefit indicator (or indicators) for an EGS. The indicator does not directly measure benefit (or harm) since the analyst has not yet established that people would be willing to trade off other goods and services for that EGS change. Instead, in the case of the recreational fishing ESE, the EGS metric is change in fishing days as an indicator of the magnitude of benefits that might be provided by higher game fish abundance at this site.

ESE techniques differ markedly between use and non-use services. For non-use services, ecological outcomes are appreciated when they address concerns or contribute to values expressed by people, such as fulfilling their desire to sustain specific species or ecosystems.

Establishing the potential for non-use benefits is similar to establishing national significance, as defined by the USACE (USACE 2000), in that it is intended to show that an ecological outcome contributes to a socially important outcome. For example, an analyst might demonstrate that restoring and protecting a declining ecosystem is likely to generate nonuse benefits by documenting that the ecosystems are threatened and are national conservation priorities of multiple stakeholders (Figure 3).

\section{Benefit/Damage function}

The final step of the conceptual model is to explore the use of an economic benefit or damage function to explicitly measure social welfare effects of an EGS change (Box 4). ${ }^{1}$ Economic or social value is quantified in terms of willingness to trade off other goods and services to achieve or avoid the expected changes. When a single EGS is being evaluated, monetary valuation would typically be the preferred method

\footnotetext{
1 Conducting valuation will not be advisable for all services or for all project types and may be counter to USACE guidance, as described in more detail in Section 3.
} 
to measure economic value, although a monetary-equivalent metric (e.g., a barter value) could also be used.

When comparing project alternatives, it is also possible for social value to be captured through preference-weighted non-monetary benefit measures. Such measures are created by eliciting values from stakeholders through a structured process such as multi-criteria decision analysis (MCDA), as described below. However, these preference-weighted measures of value cannot be created for a single EGS in isolation. To generate non-monetary values that are equivalent to monetary values, stakeholders are asked to consider how they would make tradeoffs between all goods and services, in the context of available project alternatives. Therefore, such measures emerge from a decision-support exercise and cannot be generated as an input to decisions, which is the intent of the initial analyses represented in the conceptual model.

For analyzing benefits of a single EGS, the analyst first considers whether the magnitude of benefits or harms derived from changes to EGS (relative to the no-action scenario) can be appropriately valued using an available valuation technique (See Section 3 and planning step 1 for details). Common to all economic valuation approaches is the understanding that local and regional conditions (particularly scarcity) determine the value of an EGS change in a given location and within a specified time period. Therefore, valuation techniques that are sensitive to such site conditions will produce the most accurate values.

In cases where an EGS cannot or should not be monetized, the ecological outcome, EGS metric, or a combination of the two serves as the non-monetary benefit indicator for an individual EGS. Such metrics are not easily summed since they will be in different units. Alternative approaches to evaluate options using multiple metrics are described briefly below.

Two EGS conceptual models will clarify the different methods applied to non-use EGS (Figure 3) and use EGS (Figure 4). Readers will note that the simple conceptual model of Figure 2 is expanded to document intermediate metrics and relationships, as needed. Detailed methods for constructing conceptual models will be presented in Step 1.2. 
Figure 3. Example EGS conceptual model for a non-use service derived from promoting long-term resilience of a threatened ecosystem.

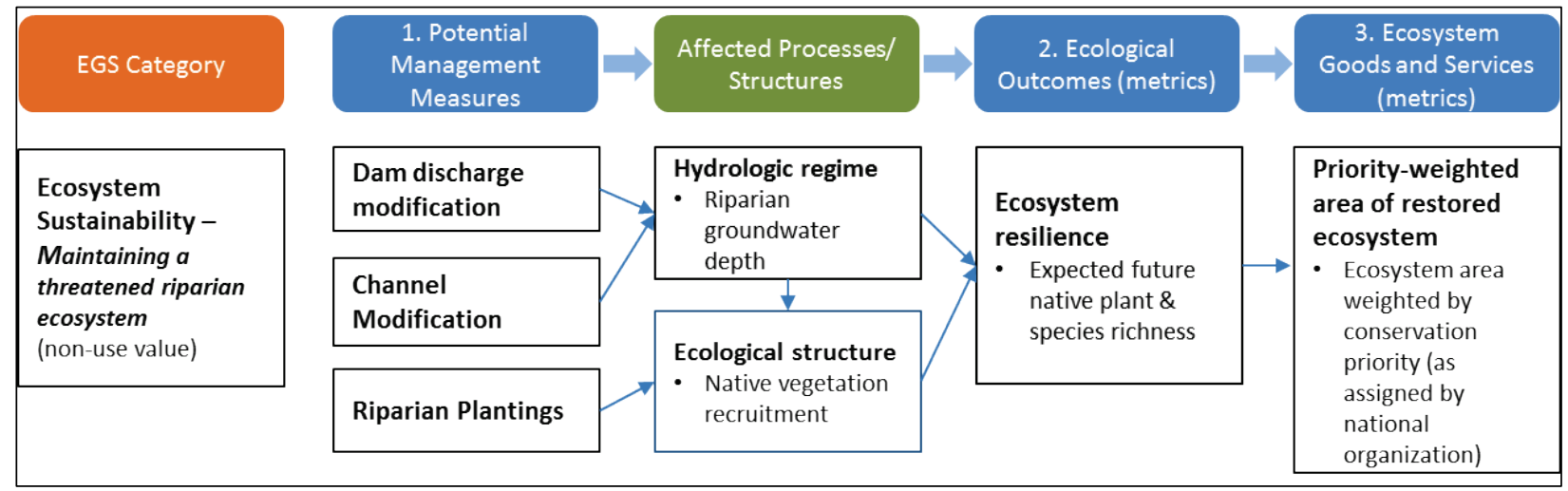

The analysis team builds the non-use conceptual model by first considering which management measures will affect the project's ability to maintain a threatened ecosystem. The team uses available evidence to identify the most relevant ecological processes/structures that are expected to change as a result of the management measures. They then select an ecological outcome metric to reflect the change that will be most important to beneficiaries. In this case, the team identifies that a measure of ecosystem resilience will reflect the stakeholders' concerns about the long-term viability of the ecosystem (as identified in stakeholder meetings). The team then selects an EGS metric to represent the potential value of this change by leveraging ranking criteria that have been created by a non-governmental organization (NGO) to represent national ecosystem conservation priorities. The team identifies a benefit metric for comparing alternatives that is the weighted sum of restored acres in which each acre is weighted by its projected conservation priority rank.

Figure 4. Example EGS conceptual model for the use service of recreational fishing.

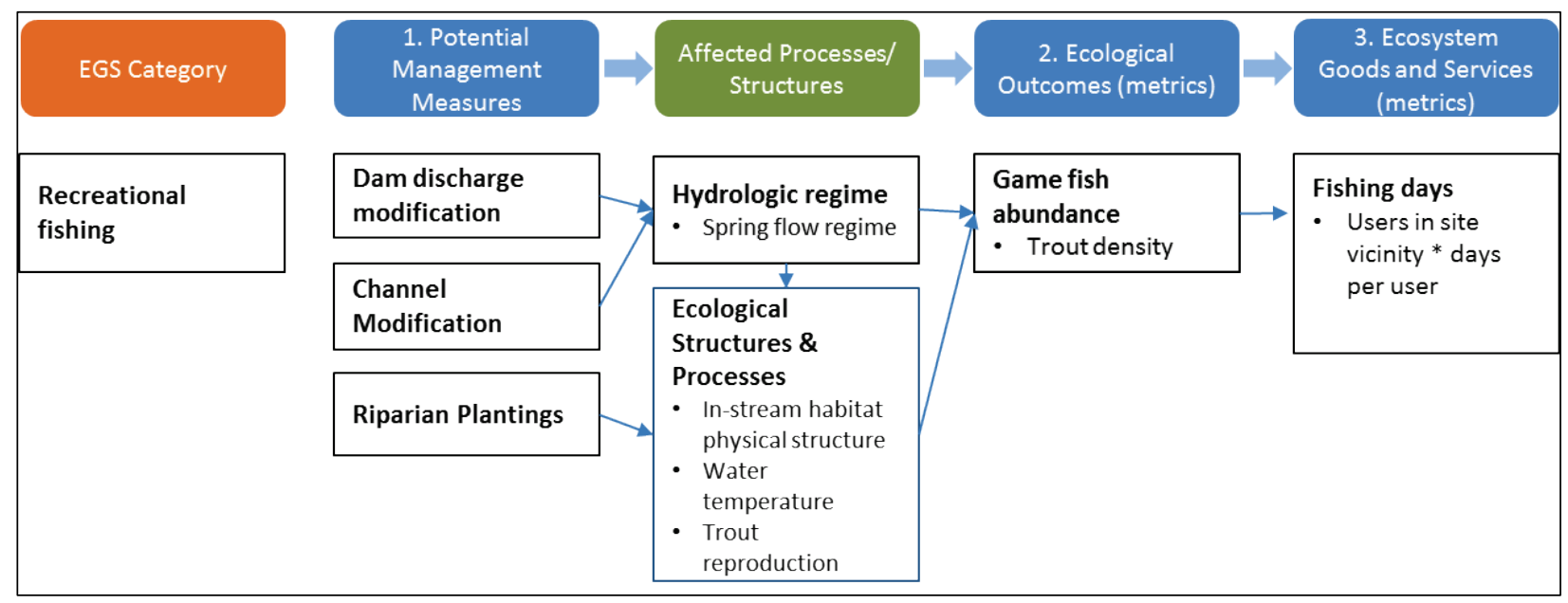


The team builds the use-service conceptual model by first considering which management measures will affect recreational fishing. The team uses available evidence to identify the most relevant ecological processes/ structures that are expected to change as a result of the management measures. They then select an ecological outcome metric to reflect the change that will be most important to users. In this case, the team identifies that changes in the abundance of the dominant game species (measured as trout density) will best represent potential value of site improvements to the user group of recreational anglers. They then select an EGS metric of projected fishing days, which represents the potential number of site users and frequency of use. The fishing days metric is a leading indicator of economic benefits and useful alone. It can also inform an economic benefit transfer that may be conducted later in the process to estimate the monetary value of the change in recreational fishing quality and opportunity using the USACE unit day values or other technique.

\section{Evaluation and analysis framework}

In addition to the EGS conceptual model, the framework consists of tables to guide users through the analysis process and to present results to decision-makers. These tables and supporting material aid teams in determining the social welfare effects of EGS changes, in determining whether an EGS is appropriate to use within a planning analysis based on current USACE guidelines, and in rolling up the outcomes of EGS analysis. The tables that summarize these results could be used to communicate the importance of EGS impacts to society and relevance to the USACE decision-making processes.

\section{Using products of the EGS conceptual model in decision-making}

The EGS framework generates a set of quantitative metrics that must be selected, compared, or aggregated to support decision-making. These measures of changes in one or multiple EGS can potentially serve to inform decision-making processes (e.g., to choose a final plan) in three main ways, as illustrated in Figure 5. The three approaches are (1) Quantitative Communication: quantitative metrics provide rationale for an action (e.g., in CEA); (2) Multi-Criteria Decision Analysis: aggregate scores of multiple types of benefit metrics are used to compare alternatives; or (3) Benefit Aggregation and Tradeoff Analysis: monetized benefits and/or harms may be appropriately aggregated (e.g., to avoid double counting), examined to reveal tradeoffs, and compared to costs. These approaches are 
not mutually exclusive. A combination may be used in selecting a final plan. The choice of approaches will depend on the decision context, such as whether monetary measures are appropriate, interests of project partners, and availability of data, knowledge, and analytical resources.

Figure 5. Three approaches for using EGS conceptual model components in decision-making.

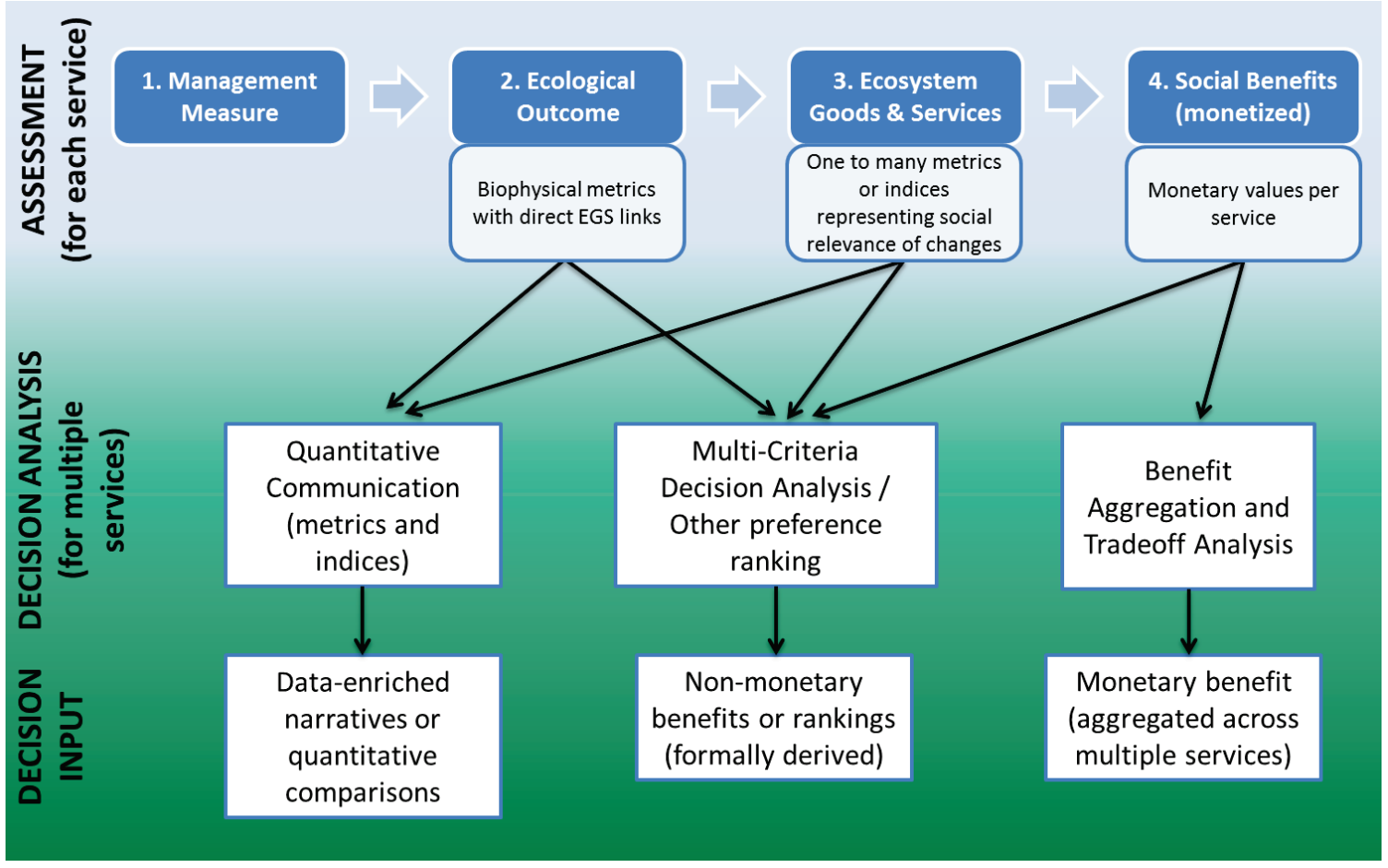

\section{Quantitative communication}

A contribution of the EGS framework is to clearly communicate the potential delivery of wide range of social benefits using diverse indicators. Quantitative communication is the process of taking metrics that may represent ecological or EGS outcomes and applying that information to support comparisons of benefits and tradeoffs using everything from narrative descriptions to quantitative comparisons. These approaches are used in cases when the decision context does not require nor allow for formal cost-benefit analysis. The methods include structured-tounstructured approaches that use available data and knowledge to explain potential benefits or harms. USACE analysts will need to ensure that they are selecting appropriate metrics to use for a given decision process.

A common approach within this category for making comparisons among alternatives is cost-effectiveness analysis and/or incremental cost analysis, which uses one indicator or an aggregate index to compare beneficial 
outcomes per dollar spent across a range of alternatives (USACE 2000, App E). Many other types of less-structured approaches (e.g., graphics, data tables) are used to make quantitative and qualitative comparisons of indicators across alternatives.

Quantitative communication approaches differ from the other two analytical approaches shown in Figure 5-Multi-Criteria Decision Analysis and Benefit Aggregation and Tradeoff Analysis-in two ways. First, indicators produced outside of a framework that explicitly incorporates public preferences (e.g., as measured by surveys or in public forums) are not considered direct measures of social benefits. Second, quantitative communication does not typically involve formal tradeoff analysis among competing goals. Nonetheless, the approach of using indicators to represent beneficial outcomes is widely used by federal agencies and is generally considered reasonable and appropriate when the analysis goal is to judge the ability of alternatives to meet agency missions and not to demonstrate or maximize social benefits.

\section{Multi-criteria decision analysis (MCDA) and trade-off analysis}

The second technique, shown in Figure 5, for quantifying changes in benefits is MCDA or other structured preference elicitation technique. These techniques produce non-monetary benefit measures and/or rank alternatives by acceptability to stakeholders. ${ }^{1} \mathrm{MCDA}$ is an alternative to monetary valuation because, like valuation, it can incorporate public preferences for alternative outcomes and be used to judge the acceptability of tradeoffs among EGS (e.g., Wallenius et al. 2008). In MCDA, ecological outcomes, EGS metrics, and monetary values for individual EGS can be combined into common units to provide an aggregate metric for decision support (see review in Kiker et al. 2005).

Whether or not MCDA represents social values that can be considered equivalent to monetary values depends on whose preferences are elicited. To represent social benefits, MCDA would need to follow approaches comparable to those used in monetary valuation and engage a representative cross section of the public. However, it is much more common for MCDA to be used with a subset of stakeholders (e.g., project

1 MCDA is used here to represent a broad class of related decision support tools, as described in Mendoza and Martins (2006) and Maguire et al. (2014). Other preference elicitation or ranking methods are available (e.g., Goodwin and Wright 2014), although not all are as comprehensive as MCDA. 
development team [PDT] members or selected government and NGO representatives). This common approach is used to rank alternatives by their ability to meet goals of the represented interests (e.g., USACE and NGO cost-share partners). However, the benefit measures developed by such a group are not considered general measures of social welfare (as specified in economic theory) because they do not allow a set of individuals who are representative of all social interests to decide whether or by how much the outcomes improved their welfare. The measures generated are, nonetheless, appropriate for judging how well alternatives address the set of goals that has been defined by those involved.

\section{Benefit aggregation and economic trade-off analysis}

The third analysis technique shown in Figure 5 is the aggregation and further analysis of the monetized benefits and/or damages developed for each EGS. To aggregate benefits and damages estimated for multiple EGS, the PDT must consider whether the beneficiaries and/or types of EGS effects overlap, to choose which values may be appropriately combined (Bromley 1995). The aggregation of benefits and damages across EGS types demonstrates the tradeoffs among different stakeholder groups since EGS will tend to have distinct beneficiary groups that may be helped or harmed by an action. The result of this technique is the total value of benefits (minus damages) produced by the project alternative.

Monetization is often preferred by the Office of Management and Budget (OMB) and policy-makers for demonstrating social benefits since units represent welfare effects can be aggregated across EGS, and are readily compared. However, this technique does not provide an explicit method for including outcomes that are not monetized when comparing projects nor for making tradeoffs between benefits that are monetized and those quantified with other metrics. This limitation is of particular concern when one or more major benefits provided by a project cannot be monetized due to lack of appropriate data or resources. 


\section{Linking the EGS Analysis to the Six-Step Planning Process}

The overarching goal of the planning process is to formulate projects that alleviate problems and maximize public benefits. These public benefits encompass a wide range of economic, environmental and social concerns (USACE 2000). The EGS Framework analysis steps are designed to enhance the ability to meet this goal. Herein is a demonstration of the potential of the framework to integrate with and advance the six-step planning process with attention to the limitations of EGS application for justifying recommended plans (USACE 2000, 2013).

The framework provides an overall structure for integrating EGS into planning; however, some details remain unspecified, either because

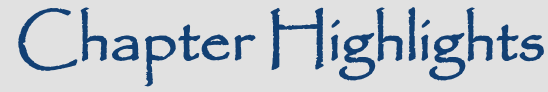

This section demonstrates proposed techniques for adapting the USACE six-step planning process to incorporate EGS. The same principles and techniques could be used to support other USACE decisions processes (e.g., environmental impact analysis) should appropriate guidance be developed.

- The EGS conceptual model, supporting tables, and decision trees are used to evaluate EGS impacts using either scoping-level or detailed analysis.

- Non-monetary EGS benefit metrics are designed to capture aspects of site conditions that impart economic value such as substitutability or scarcity of the EGS.

- Examples are used to demonstrate how EGS benefit metrics may be assessed through simple metrics (e.g., counts of potentially affected users) by transferring results from the published literature (e.g., property value enhancements measured elsewhere) or by applying models (e.g., simulations of flood risk changes to property).

- Concepts are described and then illustrated with a hypothetical case study. they will be project dependent or because further USACE guidance is needed to design EGS application. At present, the USACE has no policy to apply EGS in planning. Therefore, if PDTs believe that consideration of EGS would contribute to their study efforts in a meaningful way, they would need to consult and seek guidance/concurrence from their vertical teams prior to applying EGS.

This section is organized by each of the six planning steps:

1. Problems and Opportunities

2. Inventory and Forecast

3. Formulate Plans

4. Evaluate Plans

5. Compare Plans 


\section{Select Plans.}

For each planning step, an approach is proposed to incorporate EGS and quantify effects. Table 3 provides an overview of how the proposed framework components would fit into current planning. Most technical adaptations to incorporate EGS into the six-step planning process occur in Steps 1 and 2, so later steps include less detail since there is no reiteration of planning details that do not change substantially. ${ }^{1}$ Steps $3-6$ could change as a result of USACE policy changes, but there is no speculation on those changes here.

The following sections describe the EGS analysis for each of the six planning steps and identify existing analytic resources. A hypothetical case study (Text Box 1) is used to demonstrate techniques. 
Table 3. Overview of the integration of EGS analysis framework and six-step planning process.

\begin{tabular}{|c|c|c|c|c|c|c|}
\hline $\begin{array}{l}\text { USACE Six-Step } \\
\text { Planning Process }\end{array}$ & 1. Problems and Opportunities & 2. Inventory and Forecast & 3. Formulate Plans & 4. Evaluate Plans & 5. Compare Plans & 6. Select Plan \\
\hline EGS Analysis & $\begin{array}{l}\text { 1.1 Engage stakeholders and } \\
\text { technical experts to identify } \\
\text { problems, EGS opportunities, and } \\
\text { management measures } \\
\qquad \begin{array}{l}\text { 1.2 Build EGS conceptual models } \\
\text { linking potential management } \\
\text { measures to EGS impacts }\end{array} \\
\text { 1.3 Rate and prioritize some EGS } \\
\text { for further detailed analysis }\end{array}$ & $\begin{array}{l}2.1 \text { Identify available data, } \\
\text { methods and models } \\
\text { 2.2 Choose analytic methods } \\
\text { 2.3. Characterize existing } \\
\text { conditions and forecast } \\
\text { future without-project } \\
\text { conditions }\end{array}$ & $\begin{array}{l}\text { Inform plan } \\
\text { formulation using } \\
\text { EGS conceptual } \\
\text { models and EGS } \\
\text { prioritized by impact } \\
\text { and relevance to } \\
\text { project* }\end{array}$ & $\begin{array}{l}\text { Analyze alternate } \\
\text { plans by } \\
\text { evaluating/ } \\
\text { measuring } \\
\text { changes in EGS* }\end{array}$ & $\begin{array}{l}\text { Summarize } \\
\text { differences } \\
\text { between plans } \\
\text { (describe and } \\
\text { quantify EGS } \\
\text { benefits and/or } \\
\text { harms)* }\end{array}$ & $\begin{array}{l}\text { Provide a } \\
\text { summary of the } \\
\text { EGS benefits and } \\
\text { harms of the } \\
\text { tentatively } \\
\text { selected plan }\end{array}$ \\
\hline $\begin{array}{l}\text { Analysis Tools } \\
\text { Provided by } \\
\text { Framework }\end{array}$ & $\begin{array}{l}\text { - EGS Definitions, Example } \\
\text { Indicators, and Influencing } \\
\text { Actions (Table 2) } \\
\text { - Framework Conceptual Model } \\
\text { (Figure 2) } \\
\text { - Matrix of potentially affected } \\
\text { EGS by ecosystem (Table 6) } \\
\text { - Tables and figures to support the } \\
\text { completion of Impact Evaluation } \\
\text { and Decision Criteria Tables } \\
\text { (Table 7-Table 13) }\end{array}$ & $\begin{array}{l}\text { - EGS Data and Tools } \\
\text { Catalog** } \\
\text { - EGS Conceptual Models } \\
\text { produced in Step } 1.2\end{array}$ & $\begin{array}{l}\text { - EGS Conceptual } \\
\text { Models produced } \\
\text { in Step } 1.2 \\
\text { - EGS prioritized } \\
\text { using Impact } \\
\text { Evaluation and } \\
\text { Decision Criteria } \\
\text { Tables produced } \\
\text { in Step } 1.3\end{array}$ & $\begin{array}{l}\text { - Impact } \\
\text { Evaluation and } \\
\text { Decision } \\
\text { Criteria Tables } \\
\text { produced in } \\
\text { Step } 1.3\end{array}$ & & \\
\hline $\begin{array}{l}\text { Planning Step } \\
\text { Product }\end{array}$ & $\begin{array}{l}\text { - EGS concerns identified by } \\
\text { stakeholders (Figure } 7 \text { ) } \\
\text { - EGS conceptual models } \\
\text { (Figure 5) } \\
\text { - EGS list - prioritized using } \\
\text { Impact Evaluation and Decision } \\
\text { Criteria Tables for plan } \\
\text { formulation (Table } 7 \text { and Table } \\
\text { 8). }\end{array}$ & $\begin{array}{l}\text { Analysis methods and } \\
\text { outputs identified } \\
\text { Narrative of existing and } \\
\text { future without project } \\
\text { (FWOP) conditions with an } \\
\text { emphasis on EGS }\end{array}$ & - Formulated plans & $\begin{array}{l}\text { - Impact } \\
\text { Evaluation and } \\
\text { Decision } \\
\text { Criteria Table } \\
\text { per alternative } \\
\text { OR } \\
\text { - Summary } \\
\text { Tables of EGS } \\
\text { changes }\end{array}$ & $\begin{array}{l}\text { - Summary Table } \\
\text { of (monetized) } \\
\text { benefits and } \\
\text { harms or } \\
\text { benefit/harm } \\
\text { indicators } \\
\text { (uncombined } \\
\text { metrics) }\end{array}$ & $\begin{array}{l}\text { - Summary Table } \\
\text { of all EGS } \\
\text { benefits and } \\
\text { harms of } \\
\text { tentatively } \\
\text { selected plan }\end{array}$ \\
\hline
\end{tabular}

*Include these steps if the EGS framework is being used for plan formulation or selection; not needed if EGS are only being used to characterize the selected plan.

${ }^{* *}$ Accessible through the Army Corps of Engineers Ecosystem Restoration Gateway (http://cw-environment.usace.army.mil/restoration.cfm). 


\section{Step 1 - Problems and Opportunities}

\section{Case Study Description: Hypothetical riparian restoration example ${ }^{1}$}

The hypothetical city of Ayola, AZ (pop. 100,000), and a national NGO partner want to restore 10 miles of a perennial river system and up to 200 acres of riparian forests. Currently, a straightened and incised river channel and a narrow stretch of native vegetation along the river create substandard conditions for aquatic and riparian wildlife and recreational uses. In addition to improved ecological conditions, city residents have expressed a desire for more outdoor recreational opportunities and improved access to the riparian area for walking, birding, and other activities. The city also anticipates aesthetic benefits of riparian restoration for nearby residents.

The project's authorized purpose is to restore riparian and aquatic ecosystems of concern and improve habitat for threatened, and endangered native species. Because both intact desert perennial rivers ${ }^{2}$ and the cottonwood-willow riparian forests ${ }^{3}$ are increasingly rare in the state, several national NGOs have identified restoration of these ecological communities as a high priority. The Roundtail Chub (Gila robusta) and the federally listed endangered Southwestern Willow Flycatcher (Empidonax traillii extimus) are anticipated to benefit from the project.

The USACE is a critical partner in this project because it operates a dam upstream of Ayola for agricultural flood control. To restore the river, several alternatives have been formulated and screened by the PDT. The alternatives are combinations of various management measures, including modifying dam operations to restore environmental flows; planting native vegetation; reconnecting a portion of the channel to a portion of its historic floodplain through the construction of meanders and associated channel blocks; constructing irrigation channels to bring more surface and groundwater to the riparian area; and adding instream log structures for fish habitat. The invasive shrub species tamarisk (Tamarix ramosissima) is not currently in the proposed project area. The closest invasion site is 20 miles away, so monitoring and early treatment are expected to be necessary to prevent invasion over the long-term.

Meanwhile, the city proposes to purchase the necessary easements and build a recreational path, with city resources, to provide public access for trail-based recreation within city limits. The NGO partner has commitments from land owners to sell easements on the agricultural lands within the impacted portion of the floodplain, to mitigate any increases in flood damages to property and to accommodate the construction of stream meanders. The NGO will manage the portion outside the city as a wildlife sanctuary and limit public access.

Table 4 describes the final array of formulated alternatives chosen by the PDT.

1 The sole purpose of this hypothetical study is to provide an example of how the EGS could be used in USACE project planning. The details of the case (e.g., the models used to quantify metrics, the management opportunities chosen) are for illustrative purposes only.

2 These rivers represent a group of aquatic ecosystems that are considered collectively as a conservation priority.

3 Defined as the Cottonwood-Willow series within the Sonoran Riparian and Oasis Forests biome in Brown et al. (1979) classification hierarchy of North America's biotic communities. The dominant species are the Fremont cottonwood (Populus fremontii) and Goodding's willow (Salix gooddingii). 


\section{Case Study Description: Hypothetical riparian restoration example (cont.)}

Table 4. Alternatives chosen by PDT for Ayola Case Study.

\begin{tabular}{|c|c|c|c|c|c|c|}
\hline $\begin{array}{l}\text { Management } \\
\text { Measures }\end{array}$ & $\begin{array}{l}\text { Future Without } \\
\text { Project }\end{array}$ & A & B & C & D & $E$ \\
\hline $\begin{array}{l}\text { Modification } \\
\text { of dam } \\
\text { operations }\end{array}$ & $\begin{array}{l}\text { Continued } \\
\text { operations per } \\
\text { the current } \\
\text { schedule }\end{array}$ & $\begin{array}{l}\text { Continued } \\
\text { operations per } \\
\text { the current } \\
\text { schedule }\end{array}$ & $\begin{array}{l}\text { Incorporate } \\
\text { environmental } \\
\text { flows }\end{array}$ & $\begin{array}{l}\text { Incorporate } \\
\text { environmental } \\
\text { flows }\end{array}$ & $\begin{array}{l}\text { Incorporate } \\
\text { environmental } \\
\text { flows }\end{array}$ & $\begin{array}{l}\text { Incorporate } \\
\text { environmental } \\
\text { flows }\end{array}$ \\
\hline $\begin{array}{l}\text { Construct } \\
\text { irrigation } \\
\text { channels }\end{array}$ & None & None & None & $\begin{array}{l}\text { Construct two } \\
\text { channels }\end{array}$ & $\begin{array}{l}\text { Construct two } \\
\text { channels }\end{array}$ & $\begin{array}{l}\text { Construct two } \\
\text { channels }\end{array}$ \\
\hline $\begin{array}{l}\text { Plant native } \\
\text { vegetation in } \\
\text { riparian area }\end{array}$ & None & None & None & $\begin{array}{l}\text { Plant } 200 \\
\text { acres of } \\
\text { riparian } \\
\text { vegetation }\end{array}$ & $\begin{array}{l}\text { Plant } 200 \\
\text { acres of } \\
\text { riparian } \\
\text { vegetation }\end{array}$ & $\begin{array}{l}\text { Plant } 200 \\
\text { acres of } \\
\text { riparian } \\
\text { vegetation }\end{array}$ \\
\hline $\begin{array}{l}\text { Construct } \\
\text { meanders } \\
\text { and channel } \\
\text { blocks }\end{array}$ & None & None & None & None & $\begin{array}{l}\text { Over } 10 \text {-mile } \\
\text { section }\end{array}$ & $\begin{array}{l}\text { Over 10-mile } \\
\text { section }\end{array}$ \\
\hline $\begin{array}{l}\text { Add log } \\
\text { structures in } \\
\text { river }\end{array}$ & None & $\begin{array}{l}\text { Over } 10-\text { mile } \\
\text { section }\end{array}$ & None & None & None & $\begin{array}{l}\text { Over 10-mile } \\
\text { section }\end{array}$ \\
\hline $\begin{array}{l}\text { Construct } \\
\text { trails }\end{array}$ & None & $\begin{array}{l}\text { Over 5-mile } \\
\text { section }\end{array}$ & $\begin{array}{l}\text { Over 5-mile } \\
\text { section }\end{array}$ & $\begin{array}{l}\text { Over 5-mile } \\
\text { section }\end{array}$ & $\begin{array}{l}\text { Over 5-mile } \\
\text { section }\end{array}$ & $\begin{array}{l}\text { Over 5-mile } \\
\text { section }\end{array}$ \\
\hline
\end{tabular}


The goal of Step 1 of the planning process is to identify problems and opportunities and define planning objectives that address them. Through the scoping process, the PDT creates and documents information from stakeholders and develops initial project alternatives. This process also includes evaluating sources of uncertainty and risk in project performance due to site constraints and other factors.

To adapt this step to EGS analysis, the framework includes methods to assess which of the EGS identified by stakeholders would be most likely affected by management measures. Scoping is adapted to screen all potential EGS issues and use that process to identify a target set of EGS based on the level of biophysical changes and the relative importance of those changes to stakeholders (Figure 6).

Incorporating EGS in this step can be relatively seamless, particularly if the PDT initiates NEPA scoping activities in this step, as suggested in planning guidelines (USACE 2000) and SMART (Specific, Measurable, Attainable, Risk Informed, Timely) planning approaches (USACE 2013). The stakeholder input processes of NEPA can serve the goal of this step to identify all potentially affected stakeholders and EGS, regardless of whether effects are positive or negative.

The differences in EGS scoping, relative to current USACE scoping, lie in the types of products generated and, in some cases, the breadth of issues and stakeholders involved. However, not every project requires or has the resources for a comprehensive assessment. In such cases, the EGS analysis 
can be narrowed to key issues but should always be informed by stakeholder engagement.

The EGS scoping process includes three sub-steps, that will be described in detail below: (1) identify potential EGS effects and desired outcomes by engaging stakeholders; (2) build conceptual cause-and-effect models that include EGS; and (3) apply simple analyses and best professional judgment to estimate impacts of potential management measures.

The outcomes of the EGS scoping process are a set of tables and conceptual models that will guide further planning or EGS analysis in other decision contexts (Table 5). This section describes the creation of these products that build on existing elements of scoping to add breadth and depth for evaluating social concerns.

Table 5. EGS-related products generated at each scoping step.

\begin{tabular}{|l|l|}
\hline Scoping Step & EGS-Related Product \\
\hline $\begin{array}{l}\text { 1.1. Identify problems, EGS opportunities, and } \\
\text { management measures }\end{array}$ & $\begin{array}{l}\text { Flow chart depicting potential management actions to } \\
\text { address EGS opportunities }\end{array}$ \\
\hline $\begin{array}{l}\text { 1.2. Build EGS conceptual (cause-and-effect) } \\
\text { models linking proposed management }\end{array}$ & $\begin{array}{l}\text { Flow chart representing EGS Conceptual Model (or models) } \\
\text { Shows connections between intermediate ecological } \\
\text { changes and EGS outcomes that have been specified in } \\
\text { terms of as biophysical indicators, socio-economic } \\
\text { indicators, or monetary values }\end{array}$ \\
\hline $\begin{array}{l}\text { 1.1. Rate EGS impacts and select a relevant } \\
\text { subset to carry forward }\end{array}$ & $\begin{array}{l}\text { Impact Evaluation Table and Decision Criteria Table } \\
\text { Document expected magnitude of EGS benefits or harms, } \\
\text { prioritize EGS to use as planning objectives, and choose } \\
\text { EGS for in-depth analysis }\end{array}$ \\
\hline
\end{tabular}

Figure 6. EGS screening during the scoping process.

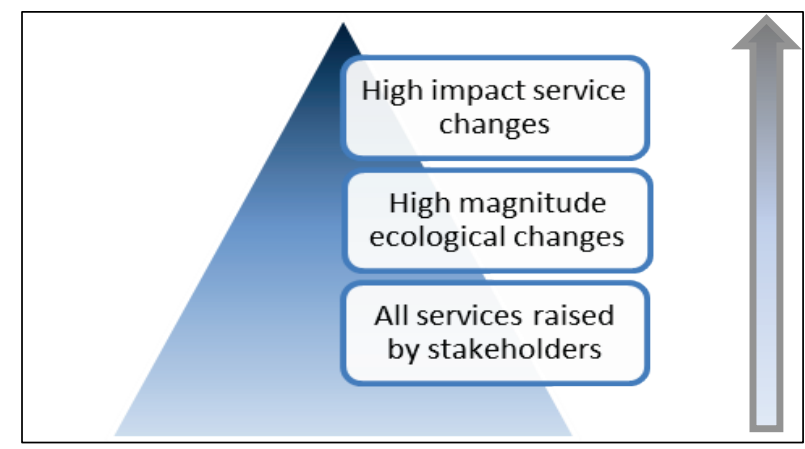

The scoping process provides information that can be used to find the subset of EGS that can be most effectively addressed at a site based on the anticipated changes in ecological and EGS outcomes and potential benefits 
and harms. For some projects, PDTs may want to plan for and conduct detailed analyses on all EGS. In other cases, they may need to target scarce project resources.

\section{Step 1.1 - Identify problems, EGS opportunities, and management measures}

The purpose of this sub-step of scoping is to engage stakeholders to assess a broad suite of desired project outcomes and their relative importance. The team uses these community priorities and values to develop an initial thorough list of problems and opportunities, framed in terms of EGS, and links them to potential management measures and project constraints. Through this process, the USACE meshes the community's concerns with project authorities.

A key question that emerges in this process is "What is the best method for identifying stakeholders relevant to an EGS analysis?” The term stakeholder is defined differently across USACE. The USACE Conflict Resolution and Public Participation Center of Expertise defines stakeholders as those that will potentially be affected or perceive themselves to be affected and may include area residents, businesses, government, and NGOs. ${ }^{1}$

The existing approaches used within NEPA or USACE planning processes to identify and engage stakeholders (USACE 2000) should be largely sufficient to identify most problems or opportunities relevant to EGS. The difference for an EGS analysis may be that the PDT may need to give greater attention to confirming that all potentially interested stakeholders have been included.

During the participatory phase of the scoping process (i.e., charrettes, public meetings, and focus groups), stakeholders do not necessarily need to be asked directly about the EGS defined here since they should be unconstrained when describing their concerns or preferences. Instead, beneficiaries may be asked about the benefits that they currently receive from specific ecosystems or how proposed project alternatives could impact these benefits or produce new effects.

\footnotetext{
${ }^{1}$ A description of methods for engaging stakeholders is beyond the scope of this document, but guidance can be found in Reed (2008).
} 
The PDT, composed of economists, other social scientists, and environmental and engineering technical experts, will ensure that all concerns and opportunities that are affected by ecosystem changes are matched to EGS in this scoping phase. Stakeholders may express concerns about the security of tourism-dependent jobs, for example. It will be up to the PDT to determine whether the project has the potential to affect the local tourism industry, for example, by changing outdoor recreation EGS. It may also be necessary for the PDT to envision future EGS users that may not be current stakeholders, for instance, if a site will create new recreation opportunities.

\section{Tools to identify EGS}

Provided here are several tables to help groups develop the list of affected EGS (Table 2, Table 6, and Table A.5). Table 2 defined general categories, and Table 6 suggests the EGS categories most likely to apply to the ecosystems where the USACE routinely works. In addition, Appendix A provides some suggestions for specific services that are appropriate for analysis (see Table A.5). A PDT can use these categories or develop their own to generate the comprehensive list of affected EGS.

To remain consistent with the definition of EGS as outputs of selfregulating or managed ecosystems (Murray et al. 2013), management actions that are not directly restoring, enhancing, or protecting ecosystems will only have neutral or negative effects on EGS. For example, a seawall that does not contribute to an ecosystem's function or longevity does not provide ecosystem services (even indirectly), although it may provide valued services and/or harm or preclude some EGS.

Identifying non-use services

Analysts are often tempted to insert their specific concerns about the ecosystem when identifying non-use services. However, to make a strong case that EGS changes represent social benefits or harms, EGS used in project justification should be demonstrated to be a concern of the public or institutions acting in the public interest (e.g., interest groups). For example, avoiding extinction of species, loss of viable ecosystems, loss of unique genetic or ecological information, or loss of processes that sustain ecosystems have been demonstrated to have social value (Walsh et al. 1984; NSRE 2000; Loomis and Richardson 2000; Loomis 2005; Richardson and Loomis 2009; Barrio and Loureiro 2010). 
Public opinion surveys and economic literature ${ }^{1}$ are considered to provide the strongest and most economically robust evidence that a non-use service has social value. Studies that elicit individual preferences among a representative set of individuals provide direct evidence of social value and are consistent with economic theory that individuals are best able to judge what influences their welfare (Freeman 2003). Therefore, teams provide evidence of value when they can demonstrate public interest. Alternatively, since many ecological elements have not been valued, many people accept that conservation priorities developed by NGOs and government agencies can reflect the public interest (Peters 2011). Consensus on values is not required for an EGS change to have social value.

1 The purpose of reviewing the economic literature on non-use ecosystem services is not meant to suggest that monetization is required but rather to document which ecosystem characteristics have been shown to have value to people. 
Table 6. Typical ecosystem goods and services by aquatic, coastal, or riparian ecosystems.

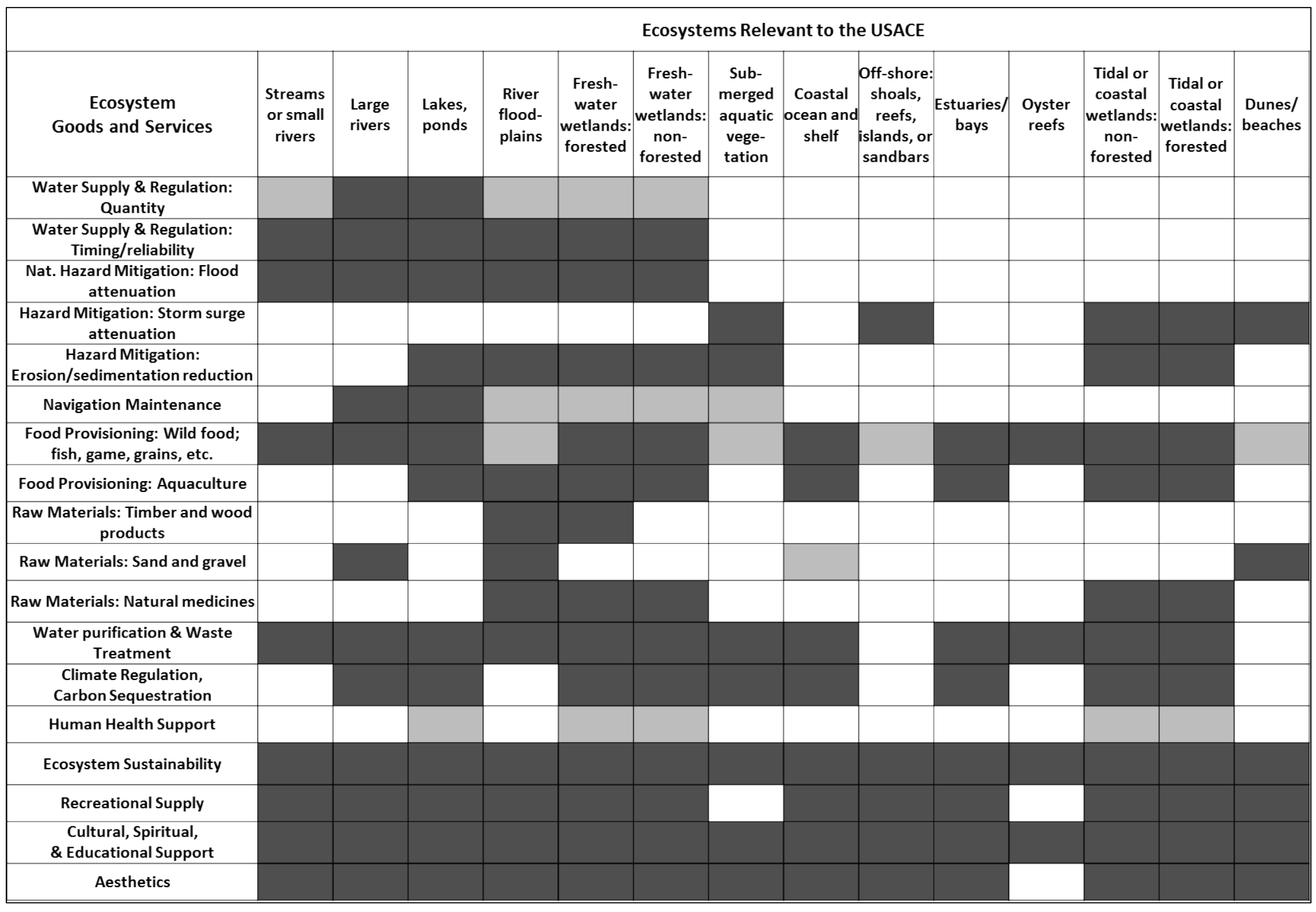




\section{Case Study Example Box. Step 1.1 - Identify problems and EGS opportunities}

In the case study, the PDT develops a public involvement strategy that includes recruiting and meeting with local residents, local and national environmental organizations, natural resource agencies, and local government. The PDT uses the comments collected from public and informal meetings to identify the current problems in the area that may be addressed through the project. Further, stakeholders contribute to identifying opportunities and management measures that may be used to resolve the problems.

To incorporate EGS into the USACE planning process, the PDT phrases the problems raised by stakeholders in terms of current deficits in EGS and identifies specific opportunities for the project to alleviate these deficits and generates a figure to document these results (Figure 7).

Figure 7. Problems, opportunities, and potential management measures identified during stakeholder engagement.

\begin{tabular}{|c|c|}
\hline Problems/EGS Deficits & EGS Opportunities \\
\hline $\begin{array}{l}\text { Loss of native riparian tree } \& \\
\text { shrub community (ecosystem } \\
\text { sustainability) }\end{array}$ & $\begin{array}{l}\text { Support non-use services by } \\
\text { restoring relatively undisturbed } \\
\text { portions of the cottonwood- }\end{array}$ \\
\hline Regional scarcity of breeding & perennial rivers \\
\hline $\begin{array}{l}\text { habitat for the endangered } \\
\text { Southwestern Willow } \\
\text { Flycatcher (ecosystem } \\
\text { sustainability) }\end{array}$ & Support non-use services by \\
\hline $\begin{array}{l}\text { Rangewide declines in } \\
\text { Roundtail Chub habitat } \\
\text { (ecosystem sustainability) }\end{array}$ & $\begin{array}{l}\text { Roundtail Chub and the } \\
\text { Southwestern Willow Flycatcher }\end{array}$ \\
\hline $\begin{array}{l}\text { Flooding in downstream urban } \\
\text { areas (hazard mitigation) }\end{array}$ & Protect property from flooding \\
\hline $\begin{array}{l}\text { Lack of species diversity for } \\
\text { birdwatching (recreation } \\
\text { supply) }\end{array}$ & Provide recreational \\
\hline $\begin{array}{l}\text { No trails along the river } \\
\text { (recreation supply) }\end{array}$ & $\begin{array}{l}\text { walking, running, etc., in the } \\
\text { riparian area }\end{array}$ \\
\hline $\begin{array}{l}\text { Loss of native riparian trees } \\
\text { and shrubs and lower stream } \\
\text { water levels reduce quality of } \\
\text { views from nearby residences } \\
\text { (aesthetics) }\end{array}$ & $\begin{array}{l}\text { Maintain and enhance aesthetic } \\
\text { contributions to adjacent } \\
\text { residences }\end{array}$ \\
\hline
\end{tabular}

Potential Management Measures
Modify dam operations to restore environmental flows

Remove dam to restore environmental flows

Reconnect a portion of the channel to a portion of its historic floodplain through the construction of meanders and associated channel blocks

Construct irrigation channels to bring more surface and groundwater to the riparian area

Plant native riparian vegetation

Transport sediment from above the dam and deposit on river banks to encourage the establishment of native plant species

Construct trails

Add log structures in river

The PDT interprets stakeholder comments to generate a thorough suite of potential management options to address problems and deficits. Some of the identified problems (in red in Figure 7) might not be authorized purposes of the project, but they are carried forward as incidental interests that might be important to potential project partners and other potential uses. Those other potential uses include (1) other reporting (e.g., NEPA); (2) assessing the locally preferred plan; and (3) communicating effects of the tentatively selected plan. During this step, the PDT identifies two constraints they will face in the project planning process: (1) ensure the authorized level of flood damage mitigation and (2) ensure no harm to water rights of other stakeholders. 


\section{Step 1.2 - Build EGS conceptual models linking management measures to potential EGS effects}

The goal of this step is for the PDT or other analysts to identify the most relevant metrics for suggesting and measuring the EGS benefits or harms that were identified in problem scoping (Step 1.1). The EGS conceptual model is the suggested method for conducting this step and organizing available knowledge on EGS benefits/harms of management actions. Within Planning Step 1, the EGS conceptual models could help to guide the PDT in framing problems and opportunities. Further, they could assist with the overarching project formulation to identify EGS that can be enhanced and determine whether those enhancements are consistent with the provided authorities. They also lay the groundwork for identifying model and analysis techniques that will be needed to quantify benefits or harms.

Conceptual models are a set of relationships that may be based on general scientific principles, specific models, or field evidence. An example of these models that the USACE currently uses is the Conceptual Ecological Models (CEM). ${ }^{1}$ In a similar fashion, the EGS conceptual models document the evidence and assumptions necessary to link-through cause-and-effect relationships-the beneficial and detrimental outcomes of potential management measures.

\section{Developing the EGS conceptual model}

The EGS conceptual model is a flow chart that connects management measures through ecological outcomes to EGS benefits. Model development occurs in seven steps. Examples of these steps are shown in the case study that follows.

1. Create five columns (Figure 8) to elaborate the general conceptual model previously discussed (Figure 2).

a. Column 1. EGS(s) being considered. Identifying the EGS at the start to narrow the ecological effects needed to document relevant effects.

b. Column 2. Management measures.

\footnotetext{
${ }^{1}$ CEMs serve as general planning guides for the USACE by connecting broad-scale environmental drivers and stressors to their specific ecological effects in a given system, based on current scientific understanding (Ogden et al. 2005).
} 
c. Column 3. Affected processes/structures.

This column has been added to the base conceptual model to

document intermediate ecological changes needed to build the cause

and effect relationships between management measures and ecological outcomes.

d. Column 4. Ecological Outcomes.

e. Column 5. EGS metrics.

Figure 8. Example of column headings for EGS conceptual model. Column headings are derived from the EGS conceptual model, and the green box was added to provide more detailed information for cause-and-effect relationships. Affected ecological processes and structures can be derived from ecological conceptual models specified by current planning procedures.

\begin{tabular}{|c|c|c|c|c|}
\hline Column 1 & Column 2 & Column 3 & Column 4 & Column 5 \\
\hline EGS Categories & $\begin{array}{c}\text { Potential } \\
\text { Management } \\
\text { Measures }\end{array}$ & $\begin{array}{l}\text { Affected Processes/ } \\
\text { Structures }\end{array}$ & $\begin{array}{l}\text { Ecological } \\
\text { Outcomes (metrics) }\end{array}$ & $\begin{array}{l}\text { Ecosystem Goods } \\
\text { and Services } \\
\text { (metrics) }\end{array}$ \\
\hline
\end{tabular}

Populate column 1-EGS Categories (Figure 8) with the EGS opportunities identified in Step 1.1 (Figure 7). (Refer to Table 2, EGS categories, as needed)

2. Populate column 2-Management measures with those identified in Step 1.1 (Figure 7). Draw arrows showing which EGS are affected by a given management measure or measures.

3. In column 3, identify the subset of ecological structures and processes that are (a) affected by a management measure and (b) will serve as intermediate inputs into the EGS (e.g., fish habitat structure). Include effects needed to understand the mechanisms and potential magnitude of changes in the ecological outcomes. The effects may be extracted from the $\mathrm{CEM}$, if one has been created. Otherwise, the team will need to engage appropriate subject area experts and/or evaluate available evidence to identify ecological changes likely to occur. Draw arrows between management measures and relevant ecological structures and processes.

4. In column 4, identify the ecological outcome (biophysical) metric(s) directly relevant to EGS benefits. As described in the framework overview and below, these metrics should be outcomes directly used (e.g., game fish) or appreciated (e.g., enhanced viability of an endangered species) by people. The metric list is not meant to be exhaustive; rather, it should represent the key ecosystem inputs needed to produce the EGS in Column 1. Draw arrows to represent connections between ecological structures and processes and ecological outcome metrics. 
5. In column 5, identify the EGS metrics that can be used to measure potential EGS benefits by considering quality, use, reliability, and substitutability or scarcity (further elaborated in text below). Draw arrows to represent connections between ecological structures and processes and ecological outcome metrics.

6. Social benefit metrics (e.g., monetizable benefits) may be added as a sixth column. In the case study example that follows, the benefit/damage functions and social benefit metrics are presented in a separate flow chart to simplify models.

In practice, creating conceptual models and the indicators used to represent relevant outcomes is a multi-step and iterative process. The subset of ecological information that is relevant may not be obvious until the EGS benefit metric has been created. Further, new information generated at later stages in the model can alter initial conceptual models.

The intent is for the PDT to use a moderate level of detail when creating EGS conceptual models, as appropriate to a screening analysis. The PDT can reduce the effort involved in this step by leveraging data and information developed as part of a NEPA assessment. However, the EGS analysis could add more social and economic context to the NEPA results by directly summarizing the magnitude of risks or improvements to specific beneficiaries based on their needs and preferences. The EGS that the PDT judges are likely to be unimpacted, or impacted a negligible amount, should be retained throughout the scoping process to show that the EGS were not omitted.

Developing ecological outcome metrics for use and non-use EGS

It is helpful to include potential metrics in the conceptual diagram to guide subsequent steps. Of the metrics created, the ecological outcome metrics may be most important because they enable effective communication and analysis of potential benefits. These metrics are the subset of ecological changes that are of direct relevance to people. Therefore, even though they are biophysical metrics, they should be developed with the EGS user or beneficiary in mind.

Ecological outcome metrics reflect ecosystem qualities that attract users or alter the level of benefits. For example, sediment grain size distribution is not an ecological outcome with direct relevance to people. However, brook trout recruitment is a meaningful outcome to those concerned about this 
species, and it can be projected from ecological qualities including grain size distribution. In sum, the ecological outcome metric reflects the biophysical conditions that are required to deliver an EGS and ideally can be understood by non-ecologists with little to no explanation.

The ecological quality that is embedded in the ecological outcome metric determines whether an ecological change leads to a potential EGS benefit. Ecological quality is judged in terms of what the user needs to safely and reliably benefit from the ecosystem. For example, "Will the change in water quality allow fishing where it wasn't safe before?” The implied metric might be "days that pathogen levels are below safety threshold." Quality may need to reflect spatial and temporal characteristics of the service. For example, the metric may address the question "Will stream baseflow be sufficient during dry months to support fish in the areas where people fish?”

It should be clear how these ecological outcome metrics differ from traditional ecological metrics. They require that the ecological change be assessed in terms of human benefits and risks. Instead of measuring a pathogen level (e.g., Vibrio concentration), the metric of "days that pathogen levels are below safety threshold" involves comparing the pathogen levels to water quality safety standards and considering the frequency of safety violations.

For non-use services, the EGS metrics do not reflect human risks directly but should still reflect what people care about. For example, people may be concerned about the long-term survival and well-being of a species or ecosystem of concern (NSRE 2000). Therefore, the best metrics will not only rank habitat quality but assess the adequacy of the habitat for promoting resilience of the species or ecosystem at risk, for example, by projecting likely reproductive success.

\section{Developing EGS metrics for use services}

Once the ecological metrics have been developed, the EGS metrics are added to reflect the intensity of concern that people have for that biophysical change (i.e., the so what question). Not all biophysical changes will generate benefits or harms. Therefore, the level of concern for the change must be captured either through valuation that captures willingness to give up goods and services to get more of an EGS (or avoid loss of an EGS) or by applying economic concepts that suggest benefits or harms are likely (Wainger and Boyd 2009). 
The purpose of EGS metrics is to provide non-monetary benefit indicators based on characteristics that suggest value as an alternative to conducting economic valuation or as an interim step in valuation. The overarching economic concept that is applied when developing EGS metrics is that value (intensity of concern) is reflected by scarcity. In economic parlance, scarcity is demand in excess of supply. Thus, anything that affects demand for or supply of a service will influence scarcity. In addition, scarcity encompasses substitutability, or the availability of inexpensive and comparable substitutes to a given group of beneficiaries.

Practically speaking, the effect of scarcity translates into the unwritten rule "where a particular ecosystem service is abundant, people are unlikely to value adding more of that service." If there is a landscape full of undisturbed wetlands, one probably would not have much willingness to pay for more wetland-derived EGS. However, this rule is not without exceptions since benefits can accrue non-linearly with the area of an ecosystem.

The conditions that tend to impart value of an EGS change can be broken out into four categories for further consideration at the site and regional scale. ${ }^{1}$ These characteristics are further explained below and in Wainger (2014):

- complements are available (capital and labor needed to use the ecological outputs)

- demand - number and avidity of users or beneficiaries

- reliability of the future stream of services

- scarcity and substitutability.

It may not be necessary to create metrics for each EGS category. Instead, the team can pick the critical condition that will determine likely use or appreciation. Alternatively, the team may need to consider ways to combine indicators in multiple categories, as will be discussed later.

- Availability of capital and labor complements

\footnotetext{
${ }^{1}$ A note to economists: A primary economic valuation study of a specific site would not need to explicitly separate these related effects since people's revealed or stated values would encompass these site characteristics. However, these indicators will provide useful concepts for transferring values across sites when these characteristics vary by location. They also provide a means to compare potential value of sites when valuation is not being conducted.
} 
- Capital and human labor are necessary complements to the biophysical conditions-when they are required to deliver a good or service. The absence of required complements means that an ecological change at a site will not affect users. Consider that a water quality change cannot improve recreational fishing benefits if boat ramps or fishing piers are needed to access the water but have not been constructed.

- Demand - number and avidity of users

- More site use suggests greater benefits or harms from ecological changes because, all else equal, the more ecosystem service users (and the greater their enthusiasm), the more valuable the aggregate benefits will be. The economic value of an ecological change depends on both the change in the number of people who use the service and the change in the value per user. Thus, when evaluating the effects of a biophysical change on users, it is necessary to consider how the change might increase or reduce total use of the site. If users do not have access to a site, then EGS that rely on site access, such as fishing, do not create benefits or harms.

- Scarcity and substitutability

- The availability of substitutes can reduce the harms resulting from an ecosystem service loss or limit benefits due to an increase. Substitutability is a key component of assessing scarcity and documents the availability of alternatives to users, if a service were lost or reduced in quality or quantity. Substitutability represents the observed phenomenon that people do not value an increase in a good or service as highly if they have multiple substitutes available (Bockstael et al. 2000). Because of this behavior, it is rarely accurate to assume that replacement or restoration cost of an ecosystem is a measure of the willingness to pay for the benefits produced by that ecosystem.

- Reliability of the future stream of services

- People derive greater benefits from a good or service that is expected to produce a long stream of future benefits with consistent quality (i.e., a reliable EGS). The evidence that people care about 
reliability comes from markets. One can readily confirm that a car manufactured by a company with a reputation for reliability is worth more on the used car market than a manufacturer with more uncertain performance, all else equal. Similarly, in carbon markets, some types of offset buyers were willing to pay almost $\$ 9 /$ tons carbon dioxide equivalent ( $\left.\mathrm{tCO}_{2} \mathrm{e}\right)$ more when the contract specified a guaranteed delivery compared to no guarantee (PetersStanley et al. 2013).

Text Box 1. What does a benefit indicator need to measure to suggest that a biophysical change equals a benefit?

Biophysical change

For the EGS of birdwatching, the ecological outcome of charismatic bird abundance is sufficient to attract users.

Biophysical change is valued when the following are present:

1. Complements - Capital and labor available to create EGS

- e.g., Boardwalks in marsh provide birding access

2. Demand - Users or beneficiaries present/possible

- e.g., Site is open to public and within driving distance of populated areas

3. Scarcity and substitutability

- e.g., Few alternative birding sites are available or other sites are congested

4. Reliability of the future stream of services

- e.g., Surrounding landscape is protected from development

\section{Developing EGS metrics for non-use services}

EGS metrics for non-use services (intangible values) should represent the intensity of people's concern for the non-use service, as was the case for use services. However, because people do not visit the site to benefit from the service, these services do not rely on having complementary inputs or demand, as for use services. What they do include are documented evidence of concern by individuals or organizations, ideally including the priority of a given site, species, or ecosystem, relative to other conservation goals. Such evidence can come from stakeholder input, public surveys, and targeted analyses produced by academic researchers, governments, or NGOs, which may be produced as maps, ranking criteria, or lists of priority ecosystems and species. 
The acceptability of using any given set of conservation priorities to represent the degree of public concern (or non-use benefit) will vary by the decision context. PDTs may find that local priorities do not align perfectly with authorized project purposes or USACE missions since they may not reflect a national interest. Locally preferred priorities can be considered in formulation but cannot be used to justify a recommended plan, and any costs associated with their inclusion in the final project would be funded by the non-federal cost-share sponsor alone. However, to build the EGS conceptual model, the PDT can use evidence from stakeholder engagement and published sources for initially scoping the level of concern for species or ecosystems.

- Incorporating cultural and spiritual services

- Cultural and spiritual services (as defined in Table 2) ${ }^{1}$ may require special handling in the EGS conceptual model because it may not be appropriate to monetize such services or even to consider characteristics that would quantify value. Such approaches can offend some stakeholders (particularly indigenous peoples) since they conflict with their cultural norms and beliefs. However, if acceptable to stakeholders, qualitative and quantitative methods may be used to describe or measure the intensity of feeling about increase or loss in cultural or spiritual services (e.g., HernándezMorcillo et al. 2013), although the use of quantitative measures is relatively uncommon (Chan et al. 2012).

- For the USACE, the potential for any loss in tribal cultural or spiritual services can effectively constrain the scope of a project. Laws such as those established pursuant to the American Indian Religious Freedom Act, Native American Graves Protection and Repatriation Act, National Historic Preservation Act, among others, and Executive Order 13175 on "Consultation and Coordination with Indian Tribal Governments" require consultation with tribes and consideration of tribal values during planning of activities that might affect cultural practices and resources. In cases where no loss in services is tolerable, it would not be necessary to quantify EGS changes since the project would be required to avoid any damage.

1 Note that the definition being used here is narrower than that used in the commonly cited Millenium Ecosystem Assessment (2005) and captures non-material values such as cultural heritage, sacred areas, and taboos of traditional societies. It excludes cultural use values such as aesthetics and recreation. 


\section{In cases where cultural or spiritual services are unavoidably disrupted, negotiations for mitigation and compensation can reveal intensity of concern.}

\section{Text Box 2. Relationship of EGS metrics for non-use services to USACE significance}

The EGS metrics for non-use services are built upon principles similar to the USACE concept of significance. Significance includes the three categories of institutional, public, and technical significance. These categories identify whether species or ecosystems have legal protection, self-identified beneficiaries (e.g., watershed groups), or potential benefits based on the judgment of technical experts (USACE 2000).

Technical significance is aligned with the idea (presented above) of using government and NGO missions and actions to suggest benefits of preserving species and ecosystems. Further, technical significance incorporates concepts that are typically part of determining conservation priorities such as sites with high ecological quality (i.e., are undisturbed), high habitat connectivity, high species endemism, and scarcity or declining trends.

However, significance criteria (or conservation priorities) do not necessarily represent social benefits or welfare. A government policy that allocates public resources may seek to achieve a goal other than creating net social benefits. Thus, institutional significance can diverge from social benefits that are defined, in mainstream economic welfare theory, as aggregations of individual preferences.

In sum, while significance is used to make internally consistent decisions, it may not strictly represent social benefits. This distinction may or may not be important for final decisionmaking but to promote communication outside the USACE, the EGS framework aims to represent benefits in ways that are consistent with economic welfare theory. Therefore, analysts may need to clarify whether the evidence for non-use benefits has been demonstrated to represent public values or requires making assumptions about public values or best interest. 


\section{Case Study Example Box. Step 1.2 - Developing conceptual models}

To develop the EGS conceptual model for the Ayola, AZ, case study, the PDT creates flow diagrams and supporting tables to visualize and document important links between management measures and outcomes. Following the steps outlined above, the PDT first uses results from the stakeholder elicitation and PDT brainstorming (Figure 7 from Step 1.1) to create the list of EGS to be addressed by the project and to list the potential management measures that may affect those EGS. Next, they begin developing conceptual models for individual EGS.

\section{EGS conceptual model development for a use service}

The team first develops an EGS for a familiar use service: flood damage mitigation to property using the following steps.

1. Identify management measures expected to impact the EGS.

The team selects from the major physical (e.g., dam modification) and biological (e.g., planting) actions of the project (Figure 7) and lists them in Column 2 (Figure 9). All of the management measures from

Figure 7 are needed to assess flood risk to property (as shown in Figure 9).

2. Identify affected ecosystem structures and processes likely to impact the EGS.

The team uses a previously developed CEM (Appendix B) to select the subset of biophysical changes that will be created by the management measures and would tend to influence flood risk to property, as shown in Figure 9, column 2.

Figure 9. EGS conceptual model for property flood damage mitigation.

\begin{tabular}{|c|c|c|c|c|}
\hline EGS Categories & $\begin{array}{c}\text { Potential } \\
\text { Management } \\
\text { Measures }\end{array}$ & $\begin{array}{l}\text { Affected Processes/ } \\
\text { Structures }\end{array}$ & $\begin{array}{c}\text { Ecological } \\
\text { Outcomes (metrics) }\end{array}$ & $\begin{array}{l}\text { Ecosystem Goods } \\
\text { and Services } \\
\text { (metrics) }\end{array}$ \\
\hline \multirow[t]{4}{*}{$\begin{array}{l}\text { Natural Hazard } \\
\text { Flood damage } \\
\text { mitigation }\end{array}$} & $\begin{array}{l}\begin{array}{l}\text { Modify dam } \\
\text { operations }\end{array} \\
\text { Remove dam }\end{array}$ & $\begin{array}{l}\text { Hydrologic Regime } \\
\text { - Flow magnitude, } \\
\text { duration, and } \\
\text { timing } \\
\end{array}$ & $\begin{array}{l}\text { Downstream } \\
\text { flooding intensity \& } \\
\text { frequency }\end{array}$ & $\begin{array}{l}\text { Number of } \\
\text { residences and } \\
\text { businesses at risk } \\
\text { from flooding }\end{array}$ \\
\hline & $\begin{array}{l}\text { Construct meanders } \\
\& \text { associated channel } \\
\text { blocks }\end{array}$ & \multirow{3}{*}{$\begin{array}{l}\text { Ecological Structure } \\
\text { and Processes } \\
\text { - Water } \\
\text { interception, } \\
\text { infiltration, and } \\
\text { uptake, as } \\
\text { modified by } \\
\text { vegetation } \\
\text { Depression } \\
\text { storage }\end{array}$} & & \multirow[t]{3}{*}{ Lost cropland area } \\
\hline & $\begin{array}{l}\begin{array}{l}\text { Construct irrigation } \\
\text { channels }\end{array} \\
\begin{array}{l}\text { Plant native riparian } \\
\text { vegetation }\end{array} \\
\end{array}$ & & & \\
\hline & $\begin{array}{l}\text { Transport sediment } \\
\text { from above the dam } \\
\text { and deposit on } \\
\text { banks }\end{array}$ & & & \\
\hline
\end{tabular}

3. Develop ecological outcome metrics explicitly linked to the EGS being analyzed.

The PDT first chooses flooding intensity and frequency in the immediate vicinity of the project to reflect flood risk to property since this is easiest to project (Figure 9, Column 3). However, looking at this issue in more depth, the PDT discovers that the potential impacts in the project vicinity are minor; a few farms may experience increased flooding over small portions of crop fields. The PDT then broadens the potentially affected area to the enclosing watershed and finds that the town of Springfield (10 miles downstream) currently has properties in the 10-year flood plain that experience intermittent flooding. The technical experts on the PDT expect those property owners to receive some level of flood mitigation benefits from the restored upstream floodplain. 


\section{Case Study Example Box. Step 1.2 - Developing conceptual models (cont.)}

The PDT recognizes that flooding intensity cannot be accurately projected until the mix of measures being implemented is specified in Step 3 (plans formulation) and until models are prepared and run. At this conceptual stage, the team explores likely effects using preferred metrics (regardless of technical feasibility) to elicit best professional judgment of the PDT. In subsequent analysis, the PDT may substitute another metric for the preferred metric to reflect available data or model outputs. The reason for choosing a preferred (or ideal) metric during conceptual modeling is to clarify the human impact being modeled and to close the communication gap that can be created when the team later chooses an analysis metric that reflects an intermediate, but more feasible outcome, such as wetland water holding capacity.

4. Develop EGS metrics that reflect beneficiary needs and preferences.

The PDT next considers the social and economic conditions that affect how much people care about the flood damage mitigation service. The PDT counts the residences and businesses within the part of the floodplain that are likely to experience lower frequency of floods from the project (Figure 9, Column 5).

The land near the project that will be flooded as a result of the dam flow modifications is owned by the non-federal sponsor (NFS) and leased to local farmers. Therefore, losses will be measured as the value of lost rental payments to the NFS and will be considered uncompensated National Economic Development (NED) losses and added to "other direct costs." In addition to EGS metrics, the team would account for the loss of active cropland and recognize this as an effect of the project.

\section{EGS conceptual model development for a non-use service}

The team next analyzes a non-use service, restoring and maintaining the native riparian ecosystem, which includes maintaining species diversity and long-term persistence of the native vegetation.

1. Identify management measures expected to impact the EGS.

As with the flood risk service, all the potential management measures being considered could affect the riparian stream ecosystem and they are listed in column 2 of Figure 10.

Figure 10. EGS conceptual model for the non-use service of maintaining a threatened native riparian ecosystem.

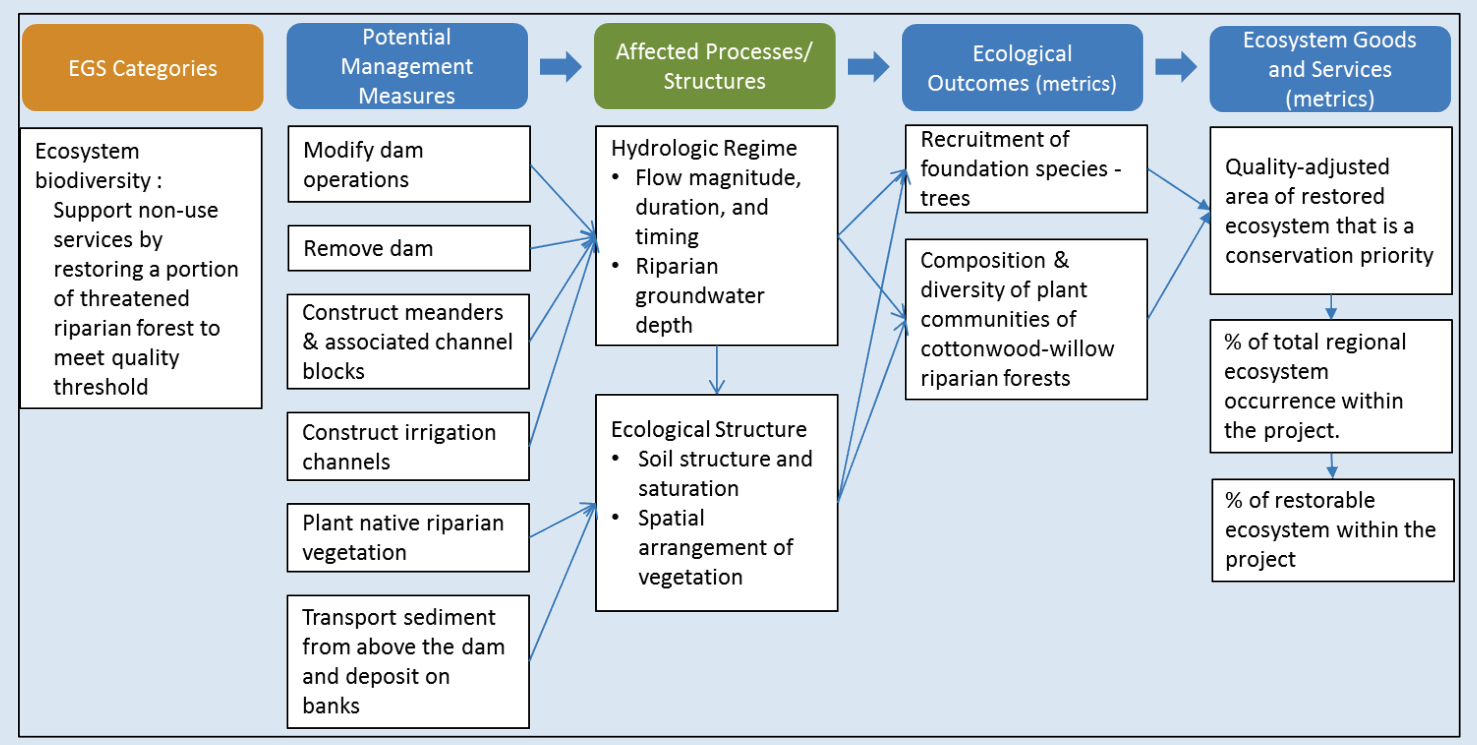

2. Identify affected ecosystem structures and processes likely to impact the EGS.

The list of ecosystem structures and processes are identified for the non-use service by consulting the CEM (Appendix B) and considering which structures and processes will affect the ability of the existing and newly planted riparian vegetation to be maintained at its characteristic diversity (Figure 10, column 3). 


\section{Case Study Example Box. Step 1.2 - Developing conceptual models (cont.)}

3. Develop ecological outcome metrics explicitly linked to the EGS being analyzed.

The PDT identifies two ecological metrics that will be (a) affected by the management measures and (b) will reflect the stakeholders' desires to maintain the system over the long term: recruitment of foundation tree species and composition and diversity of plant communities. The first metric captures the need to keep the dominant and foundational plant species regenerating, to maintain the ecosystem into the future and thereby produce bequest values. The second metric reflects stakeholders' concern that the system retain its characteristic plant composition and diversity to allow the system to be resilient to disturbance and to continue to support the historic mix of animal species that depend on the plant community.

The metrics are intended to reflect the specific conditions that contribute to the stakeholder values and thus must maintain fidelity to expressed preferences. If stakeholders had said that they primarily valued the site's ability to support songbirds, then different restoration goals and metrics would have been picked (e.g., abundance or density of the plant species that bear edible fruit and seeds). However, activities undertaken to promote this service might not be eligible for federal cost-sharing if the species were common and the populations secure.

4. Develop EGS metrics that reflect beneficiary needs and preferences.

The stakeholder-identified value of maintaining characteristic species diversity and long-term persistence of the intact native riparian and aquatic ecosystems overlaps with USACE authorities to the extent that the ecosystems and habitat on the site are recognized as nationally significant. Thus, benefit metrics that will be used in comparing alternatives should reflect this overlap, where it exists.

The PDT creates several EGS metrics to quantify the contribution of this restoration to a national benefit. The first metric, Quality-adjusted area of restored ecosystem that is a conservation priority, (Figure 10, column 5) establishes the portion of the project that is a national conservation priority and quantifies the project's contribution to the conservation goal. The PDT documents that the cottonwoodwillow riparian forest has been identified as one of the most threatened forest types and important to protect in the scientific literature (Stromberg 1993) and by national environmental nonprofits such as the National Wildlife Federation (National Wildlife Federation 2018), the Nature Conservancy (The Nature Conservancy 2018), and by the consortium Partners in Flight (Latta et al. 1999).

To further quantify the project's contribution to non-use services, the PDT creates the metric percentage of the total regional area of the ecosystem that is represented by the project. Although these percentages are likely to be quite small, they can be used for consistently comparing projects with restoration goals. This metric captures the overall scarcity of the ecosystem and suggests how much this project changes the probability of future persistence.

To address the question of whether the EGS in this location is substitutable, the PDT develops a metric of the percentage of total restorable ecosystem that occurs within the project area. The PDT defines restorable sites as those with perennial water supply and low or no invasion by tamarisk; maps of ecosystem extent and condition can be used to assess this metric. This metric is not a direct measure of substitutability of the EGS. However, the availability of alternative restoration sites is an indicator of the scarcity of options to meet this conservation goal. A high percentage indicates that few similar sites are available to be restored, and therefore, the social value of restoring it likely to be higher than an ecosystem that has many substitute restoration sites. (This metric might eventually be quantified as the difference in cost of achieving the restoration goal using one or more alternative sites.)

\section{Completing the EGS conceptual model}

The PDT continues to develop conceptual models for individual services and eventually connects them all within a single figure to show interconnections among EGS (Figure 11). 


\section{Case Study Example Box. Step 1.2 - Developing conceptual models (cont.)}

Figure 11. EGS conceptual model diagram for all EGS used in the Ayola case study.

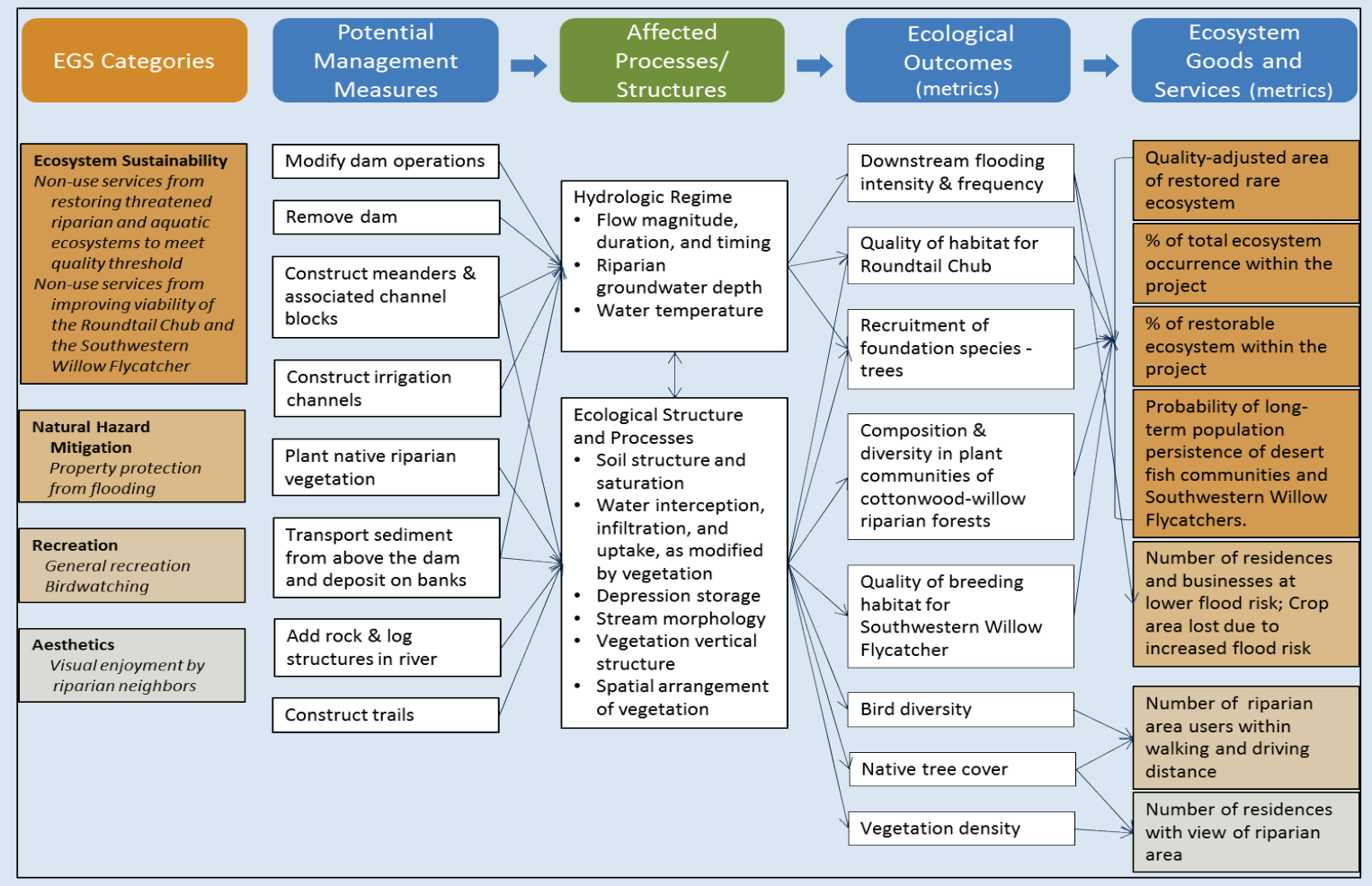

As with the two prior examples, the ecological outcomes are selected to represent the subset of ecological changes that best represent the biophysical changes that are relevant to the EGS. For the non-use services related to species, quality of habitat for Roundtail Chub is chosen because it reflects stakeholders' concerns about the species loss due to ongoing habitat loss. Similarly, quality of breeding habitat for the Southwestern Willow Flycatcher is chosen because it reflects the site's contribution to maintaining viable populations of a federally listed endangered species. Habitat quality for Roundtail Chub does double-duty in the diagram because it is also considered an indicator of the overall health of the desert perennial river system, another stakeholder concern.

Additional use services are represented by bird diversity (EGS - birdwatching), native tree cover (EGS general recreation) and vegetation density (EGS - aesthetics for riparian neighbors). For general recreation, which includes many types of trail users (e.g., runners, walkers, hikers, picnickers), native tree cover was identified to be important for providing shade, with a characteristic amount of canopy openness (as opposed to an uncharacteristically dense shade, which is avoided by users).

The EGS metrics reflect direct measures of the potential users and their satisfaction. For the non-use service of maintaining rare or declining species, the two metrics of probability of long-term population persistence of desert fish communities and Southwestern Willow Flycatchers represent how much people are likely to care about this particular restoration as a function of its ability to deliver a bequest value.

For the remaining use services, two metrics are identified: Number of riparian area users within walking and driving distance, Number of residences with view of riparian area to represent number of recreators and those experiencing aesthetic benefits, respectively. These measures of the potential magnitude of use suggest the potential (relative) magnitude of benefits of a change in these conditions.

A completed EGS conceptual model shows the interconnections between management measures, ecological changes, and potential socio-economic benefits and harms. The boxes beneath the rightmost column represent potential non-monetary benefit metrics for the EGS in the first column with corresponding shading. Boxes and arrows show the connections and dependencies between the primary metrics identified by the PDT.

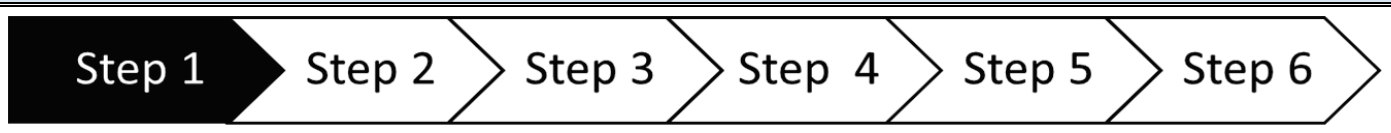




\section{Valuing changes in EGS}

The EGS conceptual model just presented stopped at the step of identifying non-monetary benefit indicators. The next step for some types of projects will be to determine whether a benefit/damage function would be applied to value a given EGS. The EGS indicators represent potential benefits, but valuation explicitly demonstrates social impacts.

If valuation is desired or required, the PDT would identify which services were appropriate to monetize and identify possible robust valuation methods, taking into account current USACE policies (see Text Box 4) and available data and resources. Alternatively, the PDT could decide to forgo monetization and pursue a method of preference-weighting beneficial outcomes as an alternative, such as MCDA (further discussed in Text Box 1). MCDA or other decision tools would be used after all relevant EGS had been assessed with non-monetary benefit indicators or valued in monetary units.

The PDT has two options for monetizing benefits/harms: (1) conduct primary valuation studies or (2) conduct benefit transfer studies. Primary valuation studies are original research to collect and analyze data for a particular site. Services differ in their ability to be monetized by a given primary valuation technique, and thus input from an economist will be essential in choosing appropriate methods (see also Step 2.2). Benefit transfer is an empirical approach in which values measured elsewhere are adjusted and applied to the project site. Benefit transfer is by far the most common technique used by federal agencies to assess benefits relative to project costs but may not be possible if existing primary valuation studies are lacking.

A reason to identify whether services will be monetized early in conceptual model development is that it allows the PDT to (1) identify EGS metrics that may be required inputs to benefit transfer or (2) avoid measuring EGS metrics that will be captured more rigorously as part of a valuation approach. For example, estimating the number of future recreational users (as an EGS indicator) might be used directly in a benefit transfer and thus would complement the monetization process. However, if a primary valuation study were being conducted, the number of recreational users could be estimated more rigorously (e.g., by using a recreation demand model). 


\section{Text Box 3. To monetize or not to monetize}

Economic valuation of EGS can be the clearest way to demonstrate that ecosystems provide benefits to people (Loomis 2005) and is necessary for conducting cost-benefit analysis. Yet, before conducting monetary valuation of EGS, the PDT should consider how well monetization will serve the decision process, whether MCDA is an appropriate alternative and where in the process monetization may best be applied (e.g., during plan development or after plan selection).

A difficulty of relying on monetary valuation is that many types of EGS, particularly non-use services, cannot be readily monetized. As a result, the use benefits that can be monetized may not exceed costs for worthwhile projects. This well-known limitation of cost-benefit analysis is one of the reasons that the Endangered Species Act precludes its use (Brown and Shogren 1998).

An impediment to monetizing all types of EGS is that current USACE policy discourages the use of contingent valuation (CV), a stated preference (SP) technique, for monetizing non-use services (USACE 2000). However, USACE guidance is not explicit on whether all SP techniques, such as contingent choice modeling/experiments, are prohibited. (SP techniques are described in Step 2.2). Without using some type of SP technique, non-use services cannot be monetized, since by definition, SP is the only primary valuation technique available. SP techniques, which rely on people stating how much they value something, are considered less reliable than values revealed through actions (Stevens 2005; Hausman 2012; Desvousges et al. 2012). Biases and inconsistencies in early CV studies generated initial skepticism of SP techniques. However, practitioners have improved upon older techniques and are actively working to overcome challenges (Carson 2012; Desvousges et al. 2012).

Non-monetary approaches to establishing values, such as MCDA, may be needed to represent a full range of concerns. When target EGS are not monetized, MCDA or similar approaches can be used to incorporate the strength of stakeholder preferences to compare and aggregate benefits that are measured in different units. Non-monetary benefit metrics may also be needed to address social equity concerns. For example, if monetary value of property damage avoided is the metric being used to compare projects, 10 expensive homes will appear more important than 10 inexpensive homes, even if the same number of people are protected by the project.

When EGS monetization is desirable, the analyst will want to consider if it can be used in planning or whether it is best applied for quantifying benefits of the selected plan. When monetizable benefits do not align with authorities and associated project goals, they are considered co-benefits and typically cannot be used as justification for a recommended action but may still be useful for communicating anticipated effects of a project and/or disclosing trade-offs, such as those associated with a locally preferred plan. Techniques to monetize the value of ecosystem services are currently prohibited from use as justification for National Ecosystem Restoration (ER) projects that are justified with non-monetized benefits in the Environmental Quality (EQ) account (USACE 2000; Scodari 2009). Therefore, any monetized EGS would need to be reported or counted under a non-EQ account: Other Social Effects, or if appropriate either NED or Regional Economic Development. Thus, monetization of ecosystem restoration projects could have the perverse result of reducing the measurable ER benefits within the current decision-making framework. Valuation of the selected plan can be important for stakeholder communication because of the ease with which results can be understood. However, the challenges of valuing benefits using monetization or MCDA should not be underestimated. Both techniques can be resourceintensive and can be limited by available data and information.

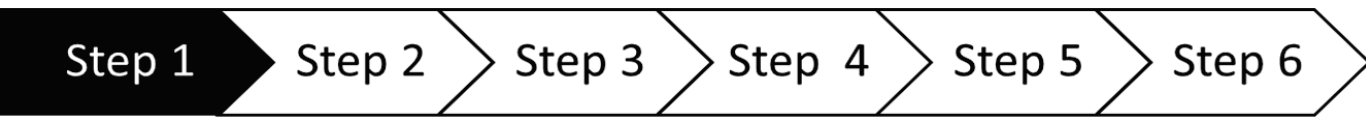




\section{Case Study Example Box. Step 1.2 - Developing conceptual models (cont.) \\ Identifying benefit/damage functions and values}

After having considered the limitations associated with monetization, the PDT identifies all the EGS changes that could feasibly be monetized for use in communicating benefits to a variety of stakeholders. Thus, they include a wide variety of services including those EGS that may not be appropriate for use in plan formulation. The PDT's economist selects a possible valuation method for each service and a likely benefit metric that would be associated with that method (Figure 12). For this moderate-sized case study, the PDT does not expect to have the resources to conduct primary valuation studies for the majority of the EGS. As a result, most services will be evaluated with benefit transfer.

Figure 12. EGS valuation methods and expected value metrics.

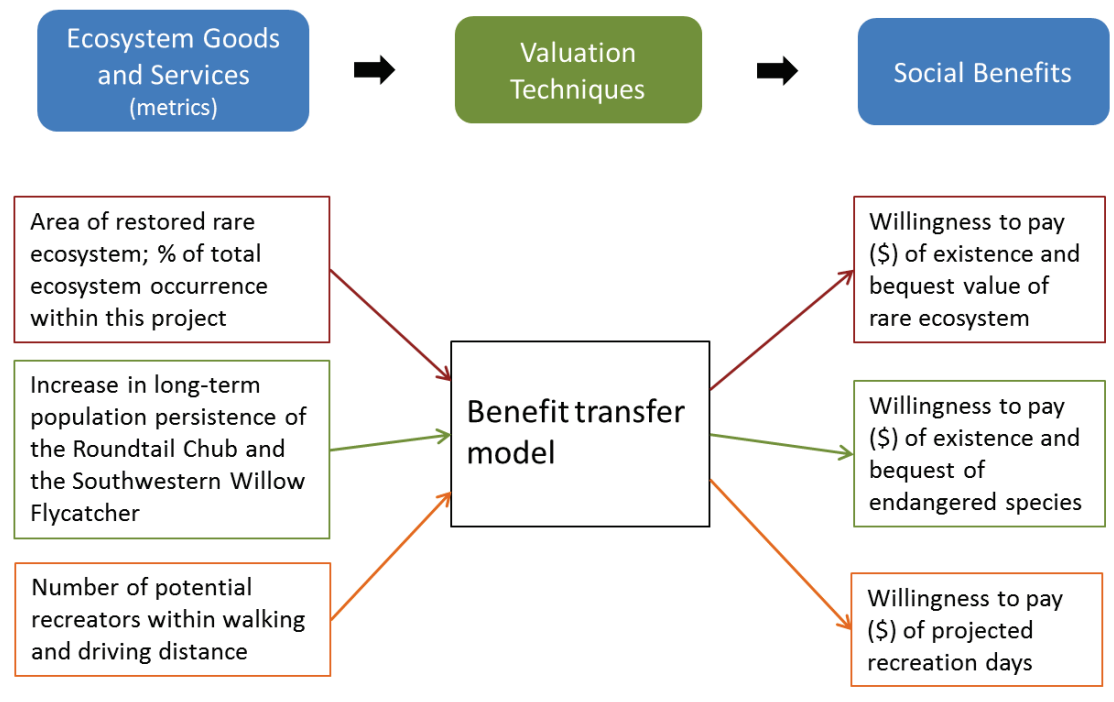

\begin{tabular}{|c|c|c|c|}
\hline $\begin{array}{l}\text { Natural Hazard } \\
\text { Mitigation }\end{array}$ & $\begin{array}{l}\text { Number of properties } \\
\text { (businesses and } \\
\text { residences) protected } \\
\text { from flooding }\end{array}$ & $\begin{array}{l}\text { Damage costs } \\
\text { avoided model }\end{array}$ & $\begin{array}{l}\text { Expected value of } \\
\text { property damages } \\
\text { avoided }\end{array}$ \\
\hline Aesthetics & $\begin{array}{l}\text { Number of residences } \\
\text { with view of riparian area }\end{array}$ & $\begin{array}{l}\text { Hedonic } \\
\text { property value } \\
\text { model }\end{array}$ & $\begin{array}{l}\text { Added value of } \\
\text { property due to } \\
\text { enhanced } \\
\text { aesthetics of } \\
\text { riparian area }\end{array}$ \\
\hline
\end{tabular}

Metrics to quantify economic benefits or value are identified, as appropriate, to complete the EGS conceptual model. Social benefits for some services are measured with consumer surplus, which is a common welfare metric that is defined as the difference between what an individual (or group of individuals) would be willing to pay for a good or service and what is actually paid, summed over all units of the good or service that are used. A parallel measure for producers is producer surplus, which is conceptually similar to economic profit (Holland et al. 2010).

\section{Monetary valuation of non-use services}

The economist identifies benefit transfer using SP valuation studies of the same or similar EGS, if available, as a potential approach to monetize the non-use services. Benefit transfer of SP values would typically be conducted using the metric of willingness to pay for a change in a species population (e.g., Richardson and Loomis 2009). However, since any benefit transfer would need to use contingent valuation studies (a subset of all SP studies) and such use is not supported by current guidance, the economist does not, in the end, propose a valuation of non-use services. 


\section{Case Study Example Box. Step 1.2 - Developing conceptual models (cont.)}

\section{Monetary valuation of use services}

The economist proposes a benefit transfer study to monetize recreational benefits at the site, with the methods to be identified in Step 2, using a willingness-to-pay metric. The proposed approach would be subject to USACE approval and is similar to the unit day value, which is the recommended approach for conducting benefit transfer under NED benefit evaluation procedures (USACE 2000, App. E, Section VII).

The economist also proposes two primary valuation studies that might be conducted using USACE-approved techniques. To measure the flood risk mitigation EGS, the PDT will evaluate the potential property damage costs avoided due to the project (Scodari 2009). In addition, the economist proposes that the PDT considers conducting a hedonic analysis to value changes to property value due to improvements in environmental amenities (Palmquist 2005). The PDT understands that they may need to find a partner (academic or consultant) to fund and carry out this modeling rather than devoting USACE resources to measuring a value that is external to the project authorities.

\section{Step 1.3 - Rate EGS impacts and examine EGS planning relevance}

The goal of this step is to apply the EGS conceptual models to a screeninglevel analysis and create products that perform the following:

- identify the EGS that are most likely to be affected by the project

- summarize the potential magnitude of EGS effects due to the restoration project

- select a subset of EGS for further analysis (if appropriate) that reflect authorized purposes or that will be included in plan formulation for other reasons such as legal compliance or stakeholder concerns.

The products of this step are intended to be used to support further analysis but can also serve as a final product to frame information that is (1) disclosed/considered during NEPA analyses and reporting or (2) to communicate expected changes in EGS of a tentatively selected plan to the public, for projects with limited analysis resources. The following tables are suggested approaches for reporting the results of a screening analysis:

- Table 7. The Impact Evaluation Table is used to summarize information about magnitude and duration of EGS effects on the ecosystem and beneficiary groups and assign an aggregate impact rating.

- Table 8. The Decision Criteria Table is used to identify EGS that will be used as planning objectives and evaluated in-depth. The Table is also used to identify concerns to be managed, address the uncertainty of impacts, and assess whether EGS represent project authorities.

- Table A.3. The Rating Documentation Table (Appendix A) is used to document assumptions used in filling out Table 7 and Table 8. 
Table 7. Ecosystem goods and services impact evaluation table.

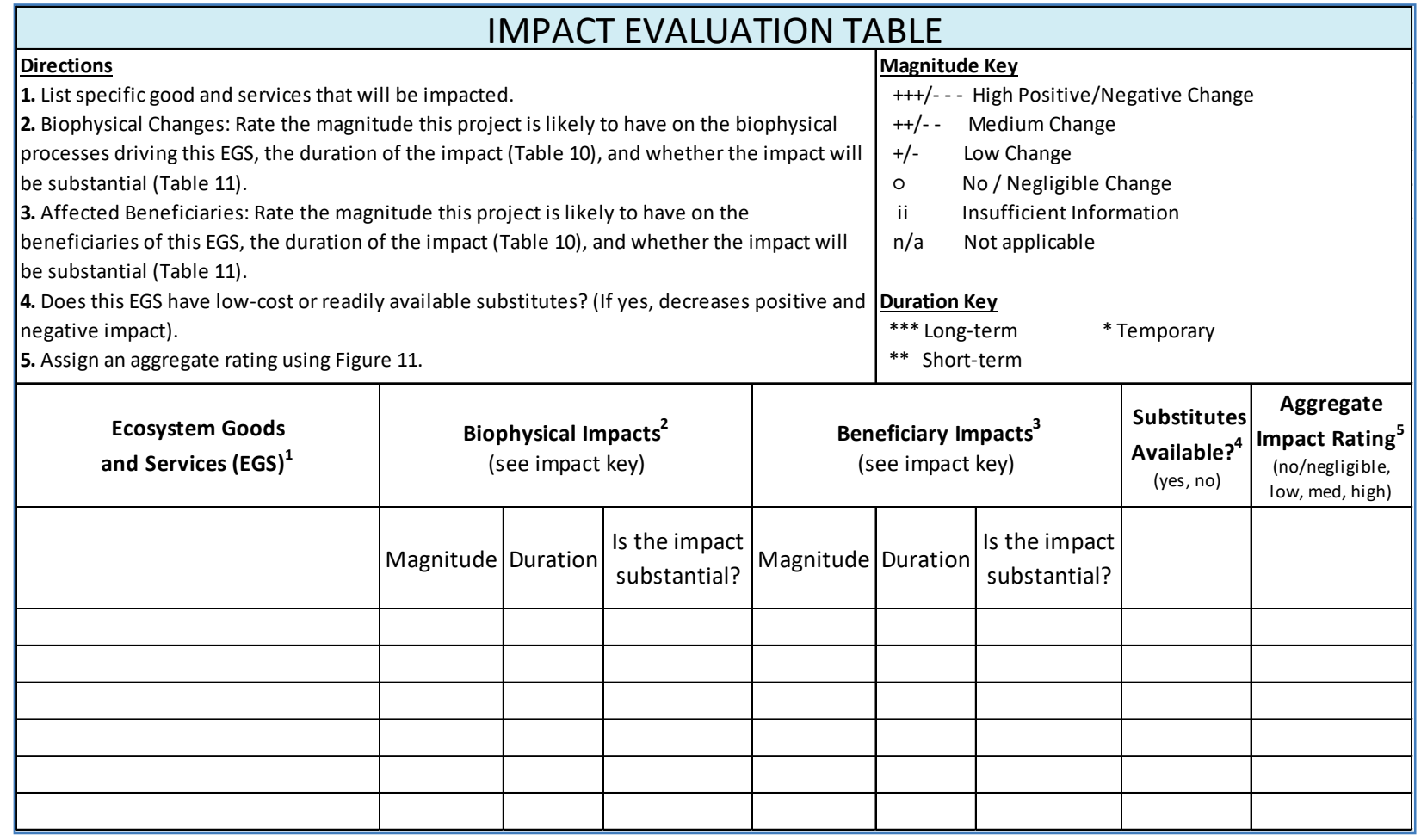

Table 8. Ecosystem goods and services decision criteria table.

\begin{tabular}{|c|c|c|c|c|c|}
\hline \multicolumn{6}{|c|}{ DECISION CRITERIA TABLE } \\
\hline \multicolumn{6}{|c|}{$\begin{array}{l}\text { Directions } \\
\text { 1. Transfer EGS and associated aggregate impact rating from the Impact Evaluation Table. } \\
\text { 2. Rate your overall confidence of the aggregate impact rating (Table 12). } \\
\text { 3. Is this EGS within project authorities? } \\
\text { 4. Are there other important considerations regarding this EGS? (e.g., is it within a Corps mission area (Table 13), is it a NEPA concern, etc.)? } \\
\text { 5. Combine aggregate impact rating with confidence rating (Table 14) and filter EGS by project authorities and other considerations, as } \\
\text { appropriate, to select EGS for further analysis. }\end{array}$} \\
\hline $\begin{array}{l}\text { Ecosystem Goods } \\
\text { and Services (EGS) }\end{array}$ & $\begin{array}{c}\text { Aggregate Impact } \\
\text { Rating }^{1} \\
\text { (no/negligible, low, } \\
\text { med, high) }\end{array}$ & $\begin{array}{l}\text { Confidence } \\
\text { Rating }^{2} \\
\text { (low, med, high) }\end{array}$ & $\begin{array}{l}\text { Within the } \\
\text { project } \\
\text { authorities? } \\
\text { (yes, no) }\end{array}$ & \begin{tabular}{|c|} 
Other \\
considerations? \\
(E.g., Within a \\
mission area? \\
NEPA concern?) \\
(yes, no)
\end{tabular} & $\begin{array}{l}\text { Include in } \\
\text { further } \\
\text { analysis? } \\
\text { (yes, no) }\end{array}$ \\
\hline & & & & & \\
\hline & & & & & \\
\hline & & & & & \\
\hline & & & & & \\
\hline & & & & & \\
\hline & & & & & \\
\hline
\end{tabular}


The following sections discuss methods for completing these tables. Examples of completed tables, using information from the case study, are shown at the end of this section in Table 14 and Table 15.

\section{Evaluating biophysical and beneficiary impacts}

The team assesses the level of projected project impact to each EGS in Table 7 by evaluating the overall magnitude and duration of changes, using available evidence and best professional judgment (rather than complex models) as appropriate to a screening process. The team considers three categories: (1) biophysical impacts; (2) beneficiary impacts; and (3) availability of substitutes. The suite of information developed for Table 7 is used to generate an aggregate impact rating (details below) to suggest the maximum possible EGS benefits or harms of project activities. ${ }^{1}$ To begin to fill in Table 7 , a team populates the first column of EGS using the conceptual models (Figure 11, column 1).

- Evaluating biophysical impacts

○ Magnitude of impacts

The first set of impact columns in Table 7 is used to record the magnitude and duration of biophysical impacts and assess whether the impact is substantial. The team reviews available evidence and assigns a magnitude of negligible, low, medium or high to each EGS to represent the extent of biophysical change and indicate whether EGS impacts are positive or negative (see Table 7, Impact Key).

To characterize the degree of impact, the analyst evaluates the magnitude of biophysical changes within the context of user concerns. A meaningful biophysical affect is one that is noticeable to beneficiaries, such as a change that moves an ecosystem across a quality threshold to produce (or eliminate) a new EGS. For example, a biophysical change could move a stream into a state that supported trout reproduction, thereby generating a new non-use EGS associated with enhanced trout population viability. While it can be challenging to identify ecological thresholds in a given system, a growing number of analytical techniques and ecological datasets are available to help model these thresholds (Andersen et

1 Since the details of project alternative will not yet be established, the analyst will need to evaluate the maximum possible effect of management measures on each EGS. 


\section{al. 2009). When specific thresholds cannot be identified, teams might estimate a range of system change that is likely to be ecologically significant, given the current level of system degradation (see case study example for further information).}

\section{Case Study Example Box. Step 1.3 - Conceptual response function}

The PDT wants to evaluate the effect of restoring riparian groundwater levels (to their historic levels) on foundation tree recruitment (a proxy for long-term ecosystem viability). To guide their thinking, the PDT creates a conceptual model that uses an S-shaped curve to represent the expected response of the ecological outcome metric (foundation tree recruitment) to different levels of hydrologic regime restoration (Figure 13). The curve is non-linear, to represent available evidence that tree recruitment improves rapidly when groundwater levels reach the zone that intersects with tree root zones. This potential for rapid response is represented by the steep part of curve in Figure 13.

However, if the change in hydrology due to the project is insufficient to achieve a target level of hydrologic modification, then the associated ecological outcome, foundation tree recruitment, will not change substantially (represented by the flat parts of the curve in Figure 13). Thus, the PDT can use the conceptual response function to identify any thresholds or nonlinearities in system response. This function can be applied to evaluate the potential magnitude of effect and to design management measures that will be effective at producing an EGS response, as distinct from an incremental ecological change that may not, by itself, overcome current stresses to effect an EGS change.

Figure 13. Example response curve for assessing project impact on an ecological outcome given site degradation levels.

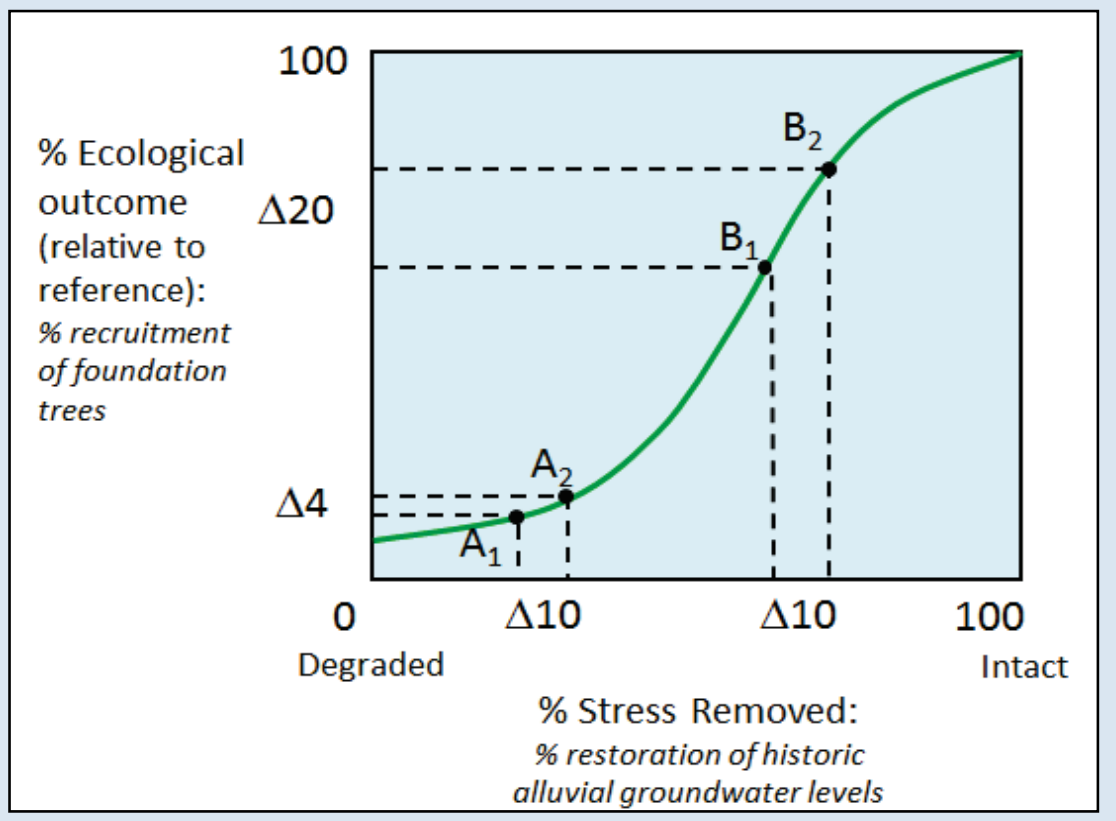

The same degree of restoration or stress removal in a system generates different magnitudes of response in the ecological outcome variable, depending on the overall level of stress in the system and the presence of non-linearities or thresholds in system response. The difference in magnitude of response to management measures at different levels of alteration is illustrated by the small change in ecological outcome when moving from $A_{1}$ to $A_{2}$ (highly altered site), compared to the large change in ecological outcome when moving from $B_{1}$ to $B_{2}$ (moderately altered site). The example metrics (in italics in axis titles) are for the case study, but similar curves could be created for any type of stress and ecological response. Figure adapted from Wainger and Mazzotta (2011). 
○ Duration of impact

To complete the second biophysical impact column in Table 7, the analyst assesses the expected duration of the impact (Table 9).

Temporary and short-term impacts are generally considered less significant than long-term impacts, but effects can vary by project. Duration is coded into the table using the symbols in the Duration Key (top of Table 7).

Table 9. Definitions of duration of project effects.

\begin{tabular}{|l|l|}
\hline Effect Duration & Definition \\
\hline Temporary & $\begin{array}{l}\text { Effects are of short duration and do not have enduring consequences } \\
\text { (days to weeks). }\end{array}$ \\
\hline Short-term & $\begin{array}{l}\text { Effects are likely to last for a limited time, for example, only during the } \\
\text { lifespan of the active construction of the project and do not have } \\
\text { enduring consequences (months to years). }\end{array}$ \\
\hline Long-term & $\begin{array}{l}\text { Effects are expected to continue over an extended period or are of } \\
\text { short duration and/or recurring and have enduring consequences } \\
\text { (multiple years or more). }\end{array}$ \\
\hline
\end{tabular}

- Are the impacts substantial?

Substantial impacts are defined as those that will generate changes in EGS that are likely to be important to users or beneficiaries and have non-trivial values. Once the analyst has identified the magnitudes and durations of the impacts, they judge whether or not each of these impacts will be substantial (positive or negative) by combining the two ratings, as shown in Table 10. (A "maybe" in Table 10 means that the analyst must use case-specific knowledge (or that of other experts) to evaluate the severity of the impact.) The analyst would record the determinations in the third columns of the biophysical and beneficiary sections of Table 7 and document assumptions in Table A.3.

Table 10. Criteria for determining substantial impact based on magnitude and duration of effect.

\begin{tabular}{|l|l|l|l|l|}
\hline \multicolumn{2}{|c|}{} & \multicolumn{3}{|c|}{ Duration of Effect } \\
\cline { 3 - 5 } \multicolumn{2}{c|}{} & Temporary & \multicolumn{1}{|c|}{ Short-term } & \multicolumn{1}{c|}{ Long-term } \\
\hline \multirow{3}{*}{$\begin{array}{l}\text { Ratings for } \\
\text { biophysical or } \\
\text { beneficiary impacts }\end{array}$} & Negligible & NO & NO & NO \\
\cline { 2 - 5 } & Small magnitude & NO & NO & MAYBE* \\
\cline { 2 - 5 } & Medium magnitude & NO & MAYBE* & YES \\
\cline { 2 - 5 } & Large magnitude & MAYBE* & YES & YES \\
\hline
\end{tabular}

*Determinations should be made on a case-by-case basis. 
- Evaluating beneficiary impacts in Table 7

The second set of columns in Table 7 is used to record the magnitude and duration of beneficiary impacts and assess whether the impact is substantial. Assessing the magnitude of beneficiary impacts for use and non-use services requires distinct approaches, as discussed below. To evaluate the duration and whether the impact will be substantial, the analyst applies the same definitions of duration and impact as those used for the biophysical impacts (Table 9 and Table 10).

- Magnitude of beneficiary impacts for use services

To complete the first column of beneficiary impacts in Table 7 , the analyst considers available evidence to assign an impact magnitude of negligible, low, medium, or high and indicates whether effects are positive or negative. The magnitude reflects the number of affected users or beneficiaries and their expected sensitivity to the expected change. User or beneficiary sensitivity reflects how much users would care about a change in the service if they did not make any substitutions across sites or EGS (because availability of substitutes is considered separately).

To estimate the number of users, the analyst will usually need to identify what types of people benefit and the scale over which the service is provided or the service area. The service area will vary by EGS since some EGS will require site access (e.g., recreation) or proximity (e.g., property flood damage mitigation), but other services will not (e.g., climate regulation and ecosystem sustainability). For example, to suggest how much agricultural land is at risk of flooding, analysts can use a geographic information system (GIS) to overlay land cover data with Federal Emergency Management Administration flood zone maps (or topography) to estimate acreage potentially affected by a change in a flood risk. If the service area cannot be empirically determined, the analyst should use best professional judgment for the screening. A practical and common approach is to use county, watershed, or state boundaries to identify the pool of potential beneficiaries when a more specific service area cannot be identified.

Similar to assessing service area, the number of potential users or beneficiaries can often be estimated with relative ease by using 
readily available survey data and GIS data of population distribution and characteristics. Whether people are potential users or beneficiaries of a service is often assessed by matching sociodemographic characteristics of known users (identified with survey data) to characteristics of the group with access or proximity to a site (e.g., households within the geographic service area) (Boyd and Wainger 2002; Troy and Wilson 2006; Wainger et al. 2010; Bateman et al. 2011; Mazzotta et al. 2015).

After assessing total potential demand, it is often useful to assess the sensitivity of users to a change in an EGS by analyzing the dependency and vulnerability of affected people. For example, instead of considering all potential households in the affected flood zone, it can be useful to assess the number of households in poverty within this zone since preventing harm to groups with less capacity to recover may be a priority. The specific variables assessed will vary by EGS but may require, for example, establishing the presence and estimating the size of vulnerable populations (e.g., subsistence fishers, households in poverty); considering economic dependency (e.g., number and size of local businesses that depend on the EGS); or establishing cultural conditions (e.g., views considered valuable by local residents).

Given the potential complexities of each case study, absolute rules for determining degree of impact are not possible. The analyst may seek advice from a broad range of experts to identify magnitude of impact and use the public meetings and focus groups of the scoping stage as evidence of individual and community priorities and values.

Magnitude of beneficiary impacts for non-use services

Assessing the magnitude of beneficiary impacts for non-use services (existence, bequest, and altruistic) calls for a different method than estimating the number of people that use the site, since by definition, people do not use the site. Instead, it requires considering the social importance of the EGS and the relative priority of protecting and enhancing a given EGS at a particular site. A variety of approaches might be brought to bear on evaluating social importance of protecting ecosystems and their elements, but here scarcity is described as a key characteristic that contributes to importance of protecting species and ecosystems, as a way to guide thinking. 


\section{Case Study Example Box. Step 1.3 - Conceptual response function \\ Conceptual benefit function for non-use services}

Through stakeholder interactions, the PDT determines that non-use values for the Roundtail Chub depend largely on how much the project improves the probability of their persistence into the future (i.e., bequest value). As a result, the change in likelihood of persistence can serve as a proxy for the non-use values generated by a project. The team forms a committee of ecologists to generate a theoretical curve (based on limited empirical evidence) to reflect probability of persistence as a function of total habitat area (Figure 14).

The ecologists use theory and data to draw a curve to represent how probability of persistence (and value) changes as a function of regional habitat extent. In Figure 14, the curve is steep over the range of $15 \%-35 \%$ of historic extent to roughly reflect ecological thinking that this range is consistent with the minimum amount of habitat needed to ensure long-term persistence of species (Tear et al. 2005) and ecosystems (Nicholson et al. 2009; Rodríguez et al. 2011). The flat part of the curve in the $0 \%-15 \%$ range of historic habitat reflects the idea that if the extent falls below $15 \%$ of historic range, long-term viability will be quite low.

The steep part of the curve is labeled the "maximum marginal benefits zone" to reflect that a change in this region generates the largest change in benefits and is likely to be associated with the most cost-effective actions to ensure long-term viability of the species. In most cases, data will not be available to draw benefit curves precisely or even to quantitatively assess remaining habitat or ecosystem extent. ${ }^{1}$ However, this example illustrates the type of evidence that analysts could seek to apply, even if they have to make assumptions and use sensitivity analyses to bound potential ranges of effects.

Figure 14. A conceptual model of non-use value for Roundtail Chub viability.

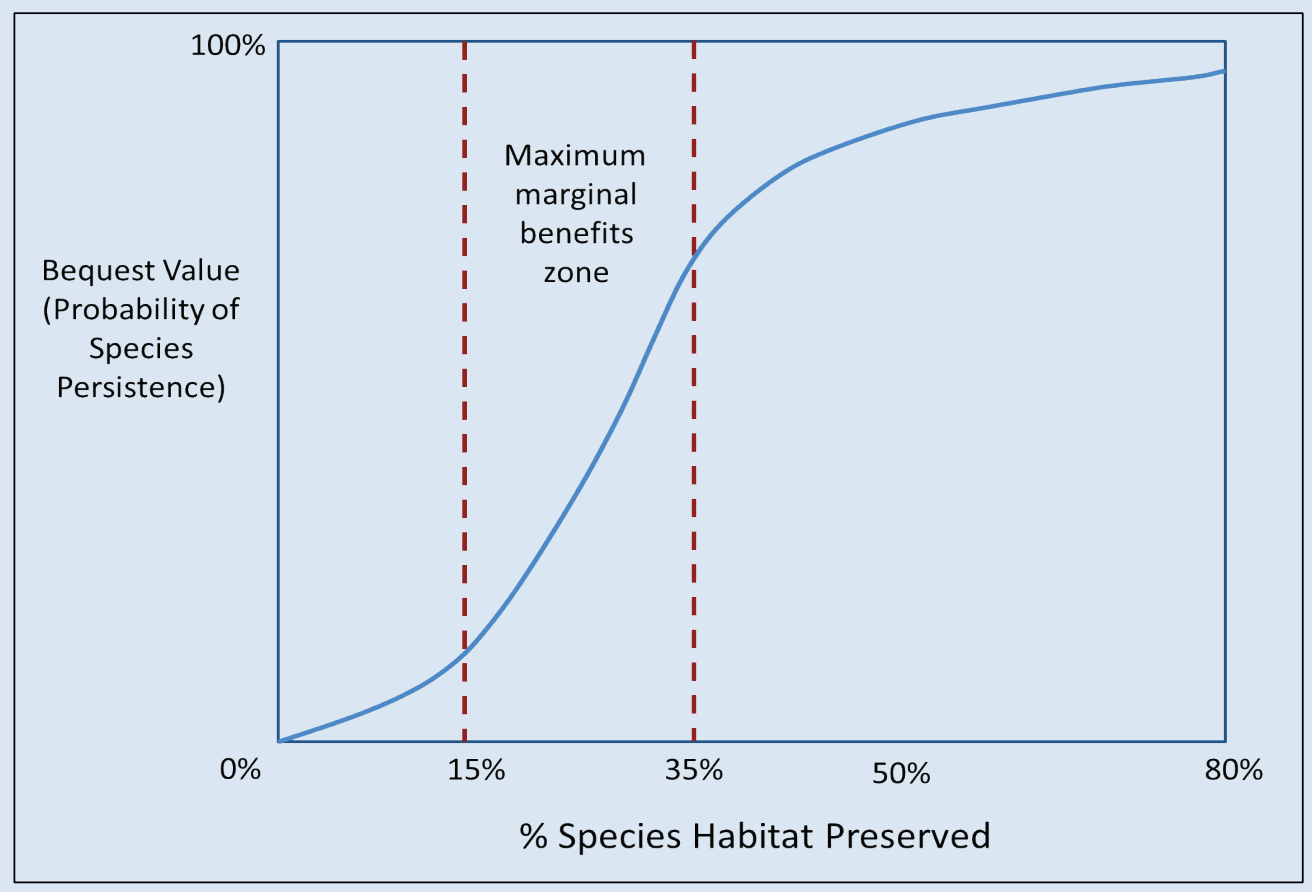

This curve is an example of a model that might be created through a consensus process among stakeholders and does not reflect current USACE guidelines. Empirical evidence for the general shape of the curve comes from studies of minimum viable population size (the size needed to avoid extinction) (Traill et al. 2007, 2010) and some recent work with vertebrates (Banks-Leite et al. 2014). The PDT uses this curve as a proxy for social value but acknowledges that it has not been empirically demonstrated to represent value.

${ }^{1}$ Tools for evaluating species or ecosystem scarcity are provided in Appendix C, Table C.1 and are discussed in Step 2 and Step 4. Population viability models are also widely available. See Brook et al. (2000) for a test of common software packages. 
- Assessing the availability of substitutes in impact evaluation table To complete the column on availability of substitutes in Table 7 , the analyst assesses whether users or beneficiaries have comparable goods and services available to them. All else equal, few substitutes suggest higher value of a change in EGS. With fewer substitutes, users have less ability to adapt to a loss in the service and more to gain from added services.

The analyst would use the service area developed for the impact analysis and evaluate the number and quality of substitutes within the service area. Substitutes may be technical substitutes or alternative locations with similar characteristics. Technical substitutes, such as dams and levees that reduce flooding risk to property, may already exist on site, potentially lowering or eliminating the value of the change in an EGS.

Alternative locations are substitutes when they can provide the EGS to the same user or beneficiary population. Both the abundance and congestion of alternative sites (e.g., for recreation) can be used to suggest availability of substitutes. Low abundance and high congestion imply that adding more supply of an EGS will be valued. Other site qualities may affect the acceptability of substitutes. The analyst should generally answer "yes" for substitutes when there is a reasonable expectation that people would be able to find the service in a nearby location.

For non-use services, the availability of alternative restoration locations (or lack thereof) can be used to measure availability of substitutes. GIS analyses may be able to suggest if other sites exist that have similar attributes (e.g., connectivity, level of buffering from development) (See Appendix C, Table C.1). Planners may also supplement their own resources by consulting local and regional conservation organizations to assess alternative opportunities for restoring the same ecosystem or species habitat (e.g., TNC Conservation Portfolio 2011). More generally, stakeholders can be consulted to confirm whether substitutes (technical or ecosystem) are acceptable.

Risk or threat assessments may identify how scarcity will change over time. For example, a recent study mapped the areas of the contiguous United States that were at risk of experiencing water shortages based 
on expected supply and demand under changing climate conditions (Roy et al. 2010). This type of information might be applied to suggest that an ecosystem that supplies water in a high-risk area will have lower availability of substitutes because of expectations of future scarcity. Some available databases for such evaluations are provided in Appendix C, Table C.1.

- Aggregate impact rating in impact evaluation table

Once the analysts identify whether the biophysical and beneficiary impacts are substantial and if there are substitutes available, they combine the ratings to generate an aggregate impact rating using the decision tree in Figure 15. EGS that are rated as having high or medium impact at this stage are the most likely candidates for use in plan formulation or in benefit assessment of the tentatively selected plan.

Figure 15. Decision tree for assigning aggregate impact rating to an EGS change.

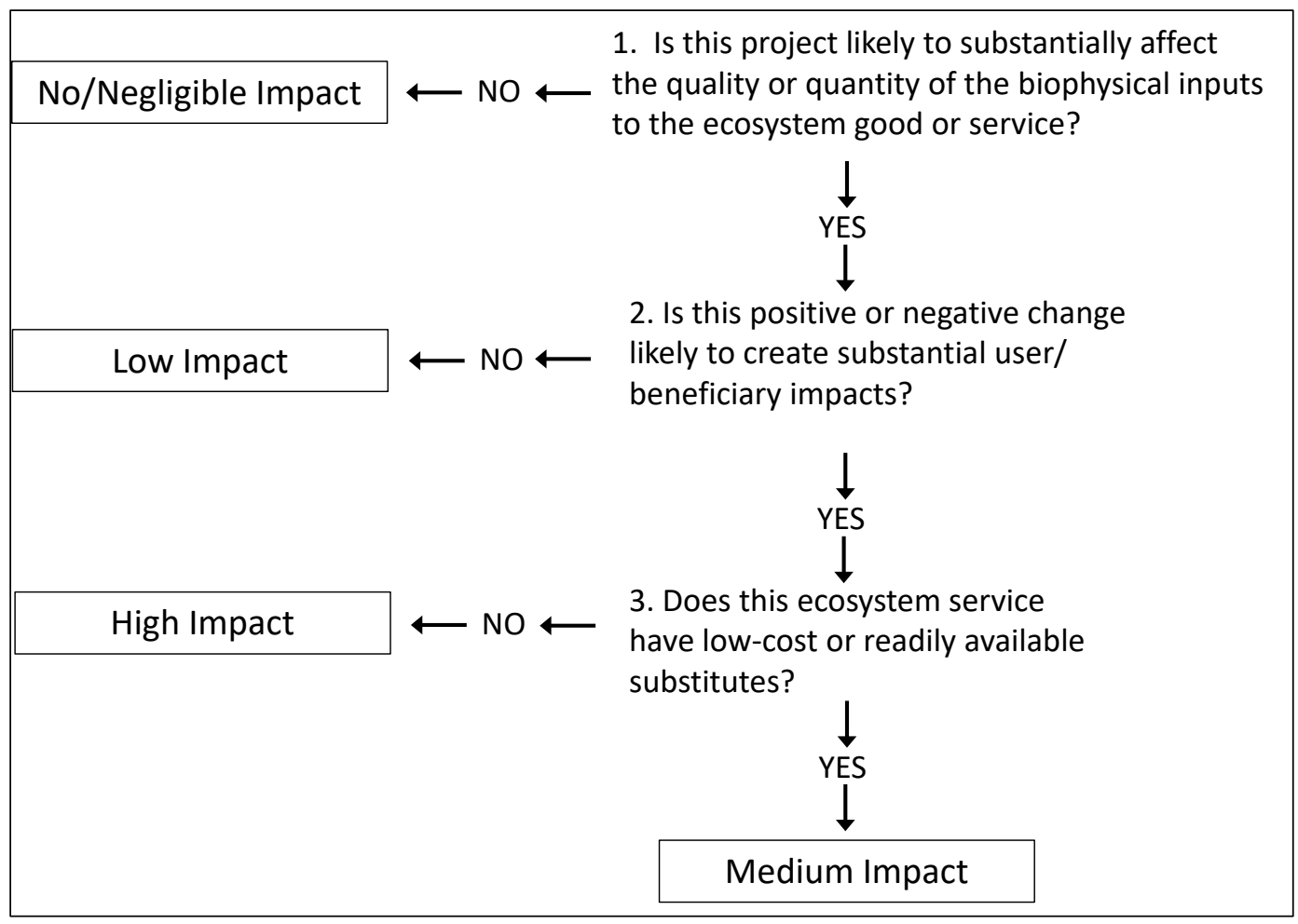

Decision criteria table

Once the EGS impact table is complete, the analyst has an understanding of which EGS will be most affected by the project and are likely to create the highest benefits (or harms). The next step is to complete the Decision Criteria Table to identify the EGS that will be targeted in the development 
of project alternatives and that can be used to justify a recommended plan or determine actions that can be cost shared. The analysis team begins to fill in the Decision Criteria Table (Table 8) by transferring the EGS and aggregate impact ratings. The team then proceeds to fill in the confidence rating, the alignment with project authorities and USACE mission areas, and other considerations that may determine whether the team will include a given EGS for further analysis.

- Confidence rating in decision criteria table

The analyst assesses confidence in the aggregate impact ratings using the categories in Table 11 and available information. If impacts are highly uncertain, it suggests that the analyst needs to conduct further analyses before defining plan alternatives because high uncertainty means that the EGS benefits may not be realized or that harms could be more significant than initially estimated.

Table 11. Confidence levels.

\begin{tabular}{|l|l|}
\hline Confidence Level & Definition \\
\hline Low Confidence & Little to no evidence is available to project the potential effect. \\
\hline Medium Confidence & $\begin{array}{l}\text { Some evidence suggests the effect will occur but mitigating factors } \\
\text { make it difficult to determine the direction or magnitude of effect. }\end{array}$ \\
\hline High Confidence & $\begin{array}{l}\text { The effect is very likely or certain to occur based on available } \\
\text { evidence. }\end{array}$ \\
\hline
\end{tabular}

- Assessing project authorities and mission areas in Decision Criteria Table

For planning purposes, the analyst would need to identify the EGS that fall within and outside of authorized project purposes. Such information is critical because the authorized purpose governs what information can be used to justify an action and how costs are allocated (across purposes for multi-purpose projects) and/or split/apportioned among cost-share partners. Further, knowing which EGS may be generated by a project can help to identify potential project partners to invest in delivery of unsupported EGS, as long as those efforts do not unintentionally detract from the project's authorized purposes. In some cases, EGS that fall outside of project authorities might occur without any extra investment (i.e., incidental benefits). In these cases, outside partners might still be needed (under current guidance) to fund detailed analysis of these EGS (if desired) if analyses are beyond the funding capacity of the USACE and its non-federal sponsor. 
Table 8 includes a column that asks whether services are in the project authorities and/or USACE mission areas. By entering yes or no, the analyst distinguishes which EGS can be used to justify an action and determine how costs for analysis or actions are apportioned among cost-share partners.

The Planning Guidance Notebook (ER 1105-2-100) (USACE 2000) presents the following:

Federal interest in water resources development is established by law. Within the larger Federal interest in water resource development, the Corps of Engineers is authorized to carry out projects in seven mission areas: navigation, flood damage mitigation, ecosystem restoration, hurricane and storm damage reduction, water supply, hydroelectric power generation and recreation.

Table 12 provides a cross-walk between the EGS and associated USACE mission area. An in-depth discussion of mission authorities is provided in Reed et al. (2013).

Table 12. Relationship between EGS and USACE mission areas.

\begin{tabular}{|c|c|}
\hline Ecosystem Good or Service & USACE Mission Areas \\
\hline Ecosystem Sustainability & Ecosystem Restoration (primary) \\
\hline Water Supply and Regulation & Water Supply (secondary) \\
\hline $\begin{array}{c}\text { Natural Hazard Mitigation (Property } \\
\text { damage avoided and human safety) }\end{array}$ & $\begin{array}{c}\text { Flood and Coastal Storm Damage } \\
\text { Mitigation }{ }^{1} \text { (primary) }\end{array}$ \\
\hline Navigation & Navigation (primary) \\
\hline Recreation & Recreation (secondary) \\
\hline Cultural, Spiritual, and Education & Not a mission area \\
\hline Aesthetics & Not a mission area \\
\hline Food Provisioning & Not a mission area \\
\hline Raw Goods and Materials Provisioning & Hydroelectric Power Generation \\
(secondary)
\end{tabular}

1 Flood and Coastal Damage Mitigation encompasses the aspects of flood risk management that can be attributed to ecosystems. 
- Other considerations

A variety of other factors may determine whether an EGS is carried forward as part of planning or other types of in-depth analysis. Primarily, EGS may be carried forward for analysis to comply with federal laws and address stakeholder concerns.

- Select EGS for further analysis

To complete the last column in Table 8 , the analysis team combines the information to select a subset of services for further analysis. Table 13 provides suggested criteria for selecting a subset of relevant EGS based on the aggregate impact rank and the confidence ratings. In general, higher impact and higher uncertainty (lower confidence) suggests the need for further analysis, although uncertainty is more likely to be a factor if impacts are expected to be negative. The other main criterion used to select EGS are high potential benefits (based on aggregate impact rating). To be consistent with NEPA and to ensure full communication, all EGS raised by stakeholders should be evaluated and carried forward into final documentation, even if effects are negligible or non-existent.

Table 13. Initial criteria for selecting relevant EGS for further analysis.

\begin{tabular}{|l|l|c|c|c|}
\hline \multicolumn{2}{|c|}{} & \multicolumn{3}{|c|}{ Confidence in Impact Ratings } \\
\cline { 2 - 5 } \multicolumn{2}{|c|}{} & High & Medium & Low \\
\hline \multirow{3}{*}{$\begin{array}{l}\text { Aggregate } \\
\text { Impact } \\
\text { Rating* }\end{array}$} & Low & NO & $\begin{array}{c}\text { NO (if positive)/ } \\
\text { MAYBE (if } \\
\text { negative) }\end{array}$ & $\begin{array}{c}\text { NO (if positive)/ } \\
\text { MAYBE (if } \\
\text { negative) }\end{array}$ \\
\cline { 2 - 5 } & Medium & $\begin{array}{c}\text { NO (if positive)/ } \\
\text { MAYBE (if } \\
\text { negative) }\end{array}$ & $\begin{array}{c}\text { NO (if positive)/ } \\
\text { YES (if negative) }\end{array}$ & $\begin{array}{c}\text { NO (if positive)/ } \\
\text { YES (if negative) }\end{array}$ \\
\cline { 2 - 5 } & High & YES & YES & YES \\
\hline
\end{tabular}

* The analyst may choose to evaluate low or negligible negative impacts to comply with federal laws and address stakeholder concerns.

Once the affected EGS are identified, USACE guidance currently says that the criteria that are central to the decision to conduct detailed analyses include requirement of law, executive order, or policy governing actions of the USACE; relevance to the authorized purposes; and available resources for the cost-share partner to participate in funding analyses. For those EGS that do not satisfy these criteria, 


\section{analyses may be omitted or conducted using low-cost analytic tools (i.e., qualitative descriptions of effects). Other EGS can be carried forward to represent partner goals or the locally preferred plan, for plans where other partners are sharing analysis costs.}

\section{Case Study Example Box. Step 1.3 - Conceptual response function (cont.)}

\section{Select EGS for further analysis in the case study}

For the Ayola case study, the PDT develops interdisciplinary teams of subject area experts to complete the Impact Evaluation and Decision Criteria Tables. To start, each team is assigned an EGS from the conceptual model and tasked with interpreting existing knowledge and data to complete the Impact Assessment Table. Teams are interdisciplinary to ensure that the biophysical change ratings capture effects that will be important to end users and to ensure that users and beneficiaries are properly identified.

\section{Birdwatching EGS team}

Column 1. The birdwatching EGS team begins by examining the expected biophysical impacts. They evaluate how bird diversity is expected to change as a result of the management measures. Using focus groups, they identify the changes in bird diversity that are important to users and stakeholders. To assess how the planned riparian enhancement might perform in terms of changing native and migrant bird diversity, they consult the scientific literature that was used during the EGS conceptual model development and call local experts. Similar to Figure 13, the team creates a conceptual non-linear response function to document their finding that restoring the characteristic vegetation vertical structure is expected to produce characteristic bird diversity as a function of how well it matches reference conditions for this ecosystem. They consider that, under the best possible outcome, the management measures should move the site close to reference conditions. Accordingly, they assess a biophysical impact rating of a high positive effect (+++) in Table 14.

Column 2. To fill in the duration column, they consider that the project site will be protected in perpetuity and that the city has a plan to manage invasive species over the long term. They consult the Table 9 duration categories and conclude that the duration of the bird diversity change is most likely to be long term (***).

Column 3. Finally, they consult Table 10 to assign a yes to the substantial impact column under the biophysical impacts.

Column 4. The same interdisciplinary team completes the beneficiary impact section by first defining the birdwatching service area and the set of potential beneficiaries. They define the potential beneficiaries as the birdwatchers driving from the surrounding area (as opposed to tourists from distant areas) as a conservative estimate of potential benefits because the town does expect the site to draw tourists. They use GIS data on predicted birding participation by location that is available from the U.S. Environmental Protection Agency (US EPA) EnviroAtlas (methods described in Mazzotta et al. 2015) to estimate the expected number of birders that would use the site. They sum the user days of the pixels that fall within the site polygon and judge the number to be a medium level of use (++).

Column 5. The duration of the change is judged to be long term $(* * *)$ since the area is expected to remain populated, and trends indicate birding participation in the region is growing. To complete the beneficiary section, they consult Table 10 to assign a yes to the substantial impact column under the beneficiary impacts. (In cases where the table provides a maybe, the team must weigh additional project factors, such as level of stakeholder interest, to judge whether the impact should be classified as substantial).

Column 6. Next, they consider the availability of substitute birding sites. The closest site with the bird diversity that is equivalent to expected project outcomes is 25 miles away. Further, opportunities for birdwatching (of any quality) in this ecosystem are only available on private property within the city limits. Thus, the team determines that substitutes are largely unavailable and they enter no in Table 14.

They consult the decision tree in Figure 15 and assign an impact rating of high to this EGS change. They document their assumptions for the biophysical and beneficiary effects in Appendix Table A.4. 


\section{Case Study Example Box. Step 1.3 - Conceptual response function (cont.) Impact table completion}

Other teams conduct similar analyses to complete Table 14 for all EGS raised during scoping. The end result of the team evaluation is that the most substantial changes are expected for the non-use EGS associated with ecosystem sustainability, property flood damage mitigation, and birdwatching. For a detailed explanation of how each EGS was rated, refer to Table A.4.

\section{Decision criteria table}

The EGS team completes the 5 columns in Table 15 through the following steps.

Column 1. They carry over the EGS aggregate impact rating from Table 14. For birdwatching the rating is high, signifying that the EGS will be potentially valuable to stakeholders.

Column 2. They judge their confidence in their assumptions that led to the aggregate rating. In the case of the birdwatching EGS team, the greatest uncertainty is whether the birds that are currently absent will be attracted to the site. The team is familiar with other restoration sites that were able to enhance bird diversity through similar plantings and invasive species control, and thus, they judge the certainty of beneficial outcomes to be high.

Column 3. They assess whether each EGS is an authorized purpose of the project. The answer for birdwatching is no, even though the non-federal sponsor is interested in this EGS.

Column 4. They assess whether the EGS is important to consider in planning because it falls within broader USACE mission areas, is a concern raised during the NEPA analysis, or other factors. The birdwatching team notes that recreation is part of the USACE federal interest, so they enter yes into the Other Considerations column.

Column 5. They assess whether the EGS should be further analyzed because it will be used in plan formulation and evaluation. Because the non-federal partner is highly dependent on USACE funding and no other partners are being engaged, the team only assigns yes to EGS that have a yes in either of the prior two columns (i.e., it is a project authority or other considerations cause it to be a planning concern). The birdwatching determination is yes because it is incidental to the primary purpose but within a mission area supported by USACE (Table 12). The team also notes (in supporting documentation) that the two recreation EGS are secondary goals meaning that enhancements made to them cannot interfere with primary goals, and only $15 \%$ of project costs can be to enhance them.

\section{Final selection}

Using Table 15, the PDT selects the project's planning objectives based on EGS that can be fully cost shared because they are based on project authorities or because they support other mission areas (Table 16). 


\section{Case Study Example Box. Step 1.3 - Conceptual response function (cont.)}

Table 14. Impact evaluation table for Ayola case study.

\begin{tabular}{|c|c|c|c|c|c|c|c|c|}
\hline \multicolumn{9}{|c|}{ IMPACT EVALUATION TABLE } \\
\hline \multicolumn{5}{|c|}{$\begin{array}{l}\text { Directions } \\
\text { 1. List specific good and services that will be impacted. } \\
\text { 2. Biophysical Changes: Rate the magnitude this project is likely to have on the } \\
\text { biophysical processes driving this EGS, the duration of the impact (Table 10), and } \\
\text { whether the impact will be substantial (Table 11). } \\
\text { 3. Affected Beneficiaries: Rate the magnitude this project is likely to have on the } \\
\text { beneficiaries of this EGS, the duration of the impact (Table 10), and whether the } \\
\text { impact will be substantial (Table 11). } \\
\text { 4. Does this EGS have low-cost or readily available substitutes? (If yes, decreases } \\
\text { positive and negative impact). } \\
\text { 5. Assign an aggregate rating using Figure 11. }\end{array}$} & \multicolumn{4}{|c|}{ 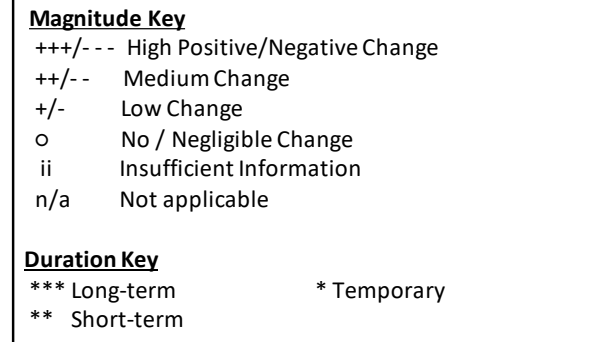 } \\
\hline \multirow[t]{2}{*}{$\begin{array}{l}\text { Ecosystem Goods } \\
\text { and Services (EGS) }\end{array}$} & \multicolumn{3}{|c|}{$\begin{array}{l}\text { Biophysical Impacts }{ }^{2} \\
\text { (see impact key) }\end{array}$} & \multicolumn{3}{|c|}{$\begin{array}{c}\text { Beneficiary Impacts }^{3} \\
\text { (see impact key) }\end{array}$} & $\begin{array}{c}\text { Substitutes } \\
\text { Available? } \\
\text { (yes, no) }\end{array}$ & $\begin{array}{l}\text { Aggregate } \\
\text { Impact Rating } \\
\text { (no/negligible, }\end{array}$ \\
\hline & Magnitude & Duration & $\begin{array}{l}\text { Is the impact } \\
\text { substantial? }\end{array}$ & Magnitude & Duration & \begin{tabular}{|l|} 
Is the impact \\
substantial?
\end{tabular} & & \\
\hline \multicolumn{9}{|l|}{ Ecosystem Sustainability } \\
\hline $\begin{array}{l}\text { Non-use services from restoring } \\
\text { a portion of a threatened } \\
\text { riparian forest to meet quality } \\
\text { threshold }\end{array}$ & +++ & $* * *$ & Yes & + & $* * *$ & Maybe --> Yes & No & High \\
\hline $\begin{array}{l}\text { Non-use services from restoring } \\
\text { a portion of a threatened desert } \\
\text { perennial river ecosystem to } \\
\text { meet quality threshold }\end{array}$ & ++ & $* * *$ & Yes & + & $* * *$ & Maybe --> Yes & No & High \\
\hline $\begin{array}{l}\text { Non-use services from improving } \\
\text { viability of the declining species } \\
\text { Roundtail Chub }\end{array}$ & ++ & $* * *$ & Yes & + & $* * *$ & Maybe --> Yes & No & High \\
\hline $\begin{array}{l}\text { Non-use services from improving } \\
\text { viability of the endangered } \\
\text { Southwestern Willow Flycatcher }\end{array}$ & ++ & $* * *$ & Yes & + & $* * *$ & Maybe --> Yes & No & High \\
\hline \multicolumn{9}{|l|}{$\begin{array}{l}\text { Natural Hazard Mitigation, } \\
\text { Property \& Infrastructure } \\
\text { Protection, Human Safety }\end{array}$} \\
\hline $\begin{array}{l}\text { Property protection from } \\
\text { flooding }\end{array}$ & + & $* * *$ & Maybe --> Yes & ++ & $* * *$ & Yes & No & High \\
\hline \multicolumn{9}{|l|}{ Recreation } \\
\hline General Recreation & ++ & $* * *$ & Yes & ++ & $* * *$ & Yes & Yes & Medium \\
\hline Birdwatching & +++ & $* * *$ & Yes & ++ & $* * *$ & Yes & No & High \\
\hline \multicolumn{9}{|l|}{ Aesthetics } \\
\hline $\begin{array}{l}\text { Visual enjoyment by riparian } \\
\text { neighbors }\end{array}$ & ++ & $* * *$ & Yes & + & $* * *$ & Maybe --> No & No & Low \\
\hline
\end{tabular}




\section{Case Study Example Box. Step 1.3 - Conceptual response function (cont.)}

Table 15. Decision criteria table for Ayola case study.

\begin{tabular}{|c|c|c|c|c|c|}
\hline \multicolumn{6}{|c|}{ DECISION CRITERIA TABLE } \\
\hline \multicolumn{6}{|c|}{$\begin{array}{l}\text { Directions } \\
\text { 1. Transfer EGS and associated aggregate impact rating from the Impact Evaluation Table. } \\
\text { 2. Rate your overall confidence of the aggregate impact rating (Table 12). } \\
\text { 3. Is this EGS within project authorities? } \\
\text { 4. Are there other important considerations regarding this EGS? (e.g., is it within a Corps mission area (Table 13), is it a NEPA concern, etc.)? } \\
\text { 5. Combine aggregate impact rating with confidence rating (Table 14) and filter EGS by project authorities and other considerations, as appropriate, to select EGS } \\
\text { for further analysis. }\end{array}$} \\
\hline $\begin{array}{l}\text { Ecosystem Goods } \\
\text { and Services (EGS) }\end{array}$ & $\begin{array}{c}\text { Aggregate Impact } \\
\text { Rating } \\
\text { (no/negligible, low, med, } \\
\text { high) }\end{array}$ & $\begin{array}{c}\text { Confidence Rating } \\
\text { (low, med, high) }\end{array}$ & $\begin{array}{l}\text { Within the project } \\
\text { authorities? } \\
\text { (yes, no) }\end{array}$ & $\begin{array}{l}\text { Other } \\
\text { considerations } ?^{4} \\
\text { (E.g., Within a mission } \\
\text { area? } \\
\begin{array}{c}\text { NEPA concern?) } \\
\text { (yes, no) }\end{array}\end{array}$ & $\begin{array}{l}\text { Include in further } \\
\text { analysis? }^{5} \\
\text { (yes, no) }\end{array}$ \\
\hline \multicolumn{6}{|l|}{ Ecosystem Sustainability } \\
\hline $\begin{array}{l}\text { Non-use services from restoring a } \\
\text { portion of a threatened riparian } \\
\text { forest to meet quality threshold }\end{array}$ & High & Medium & Yes & - & Yes \\
\hline $\begin{array}{l}\text { Non-use services from restoring a } \\
\text { portion of a threatened desert } \\
\text { perennial river ecosystem to meet } \\
\text { quality threshold }\end{array}$ & High & Medium & Yes & - & Yes \\
\hline $\begin{array}{l}\text { Non-use services from improving } \\
\text { viability of the declining species } \\
\text { Roundtail Chub }\end{array}$ & High & Medium & Yes & - & Yes \\
\hline $\begin{array}{l}\text { Non-use services from improving } \\
\text { viability of the endangered } \\
\text { Southwestern Willow Flycatcher }\end{array}$ & High & Medium & Yes & - & Yes \\
\hline \multicolumn{6}{|l|}{$\begin{array}{l}\text { Natural Hazard Mitigation, Property } \\
\text { \& Infrastructure }\end{array}$} \\
\hline Property protection from flooding & High & Medium & No & Yes & Yes \\
\hline \multicolumn{6}{|l|}{ Recreation } \\
\hline General Recreation & Medium & Medium & No & Yes & Yes \\
\hline Birdwatching & High & High & No & Yes & Yes \\
\hline \multicolumn{6}{|l|}{ Aesthetics } \\
\hline $\begin{array}{l}\text { Visual enjoyment by riparian } \\
\text { neighbors }\end{array}$ & Low & Medium & No & No & No \\
\hline
\end{tabular}

Table 16. EGS to be used in further analysis for Ayola Case Study.

\section{Planning objectives based on project authorities}

1. Support non-use services by restoring a portion of a threatened riparian forest to meet quality threshold.

2. Support non-use services by restoring a portion of a threatened desert perennial river to meet quality threshold.

3. Support non-use services by improving viability of the declining species, Roundtail Chub.

4. Support non-use services by improving viability of endangered Southwestern Willow Flycatcher.

\section{Other considerations within mission areas}

1. Protect property from flooding.

2. Improve general recreational opportunities (hiking, walking, picnicking, etc).

3. Improve birdwatching opportunities. 


\section{Step 2 - Inventory and Forecast}

The primary purpose of Step 2 of the USACE planning process (Inventory and Forecast) is to refine the understanding of opportunities to address problems and to identify any impediments to success (USACE 2000). Teams do this by defining and characterizing existing and FWOP conditions at a site. To incorporate EGS in this step, the PDT evaluates the FWOP conditions for all EGS being used for plan formulation (e.g., results of Decision Table 15 screening) or final benefits assessment (EGS with high or medium aggregate impact ratings that fall outside of planning objectives). ${ }^{1}$ In addition, the PDT identifies and selects resources to
Section Highlights

- This planning step - to assess available analytic tools and create forecasts of future conditions - could be modified to encompass EGS without substantial changes to methods already in use.

- An EGS tools database (created under this work unit) that can inform selection of models to project ecological outcome and EGS metrics is briefly described.

- Economic valuation methods of benefit transfer and primary valuation alternatives and match primary valuation techniques to EGS types are presented.

- It is recommended that economists choose and conduct valuation techniques to ensure best practices are followed. compare the EGS with and without the project to support subsequent planning steps. Thus, while collecting the usual inventory and forecasting data and information, the PDT should also seek to do the following:

- identify available data, analytic approaches, and models for quantifying changes in the EGS

- choose among available data, methods, and models

- define the FWOP baseline with an emphasis on the major forces that would change either the condition or value of the EGS being produced or impacted by the project. The FWOP for EGS analysis should be consistent with other USACE planning processes. The current expectation is that the FWOP builds upon the data and information developed in the Scoping Step.

\section{Step 2.1 - Identify available data, analytic approaches, and models}

To begin the inventory step, the PDT revisits the conceptual models that were developed under Step 1 to understand which metrics would be ideal for analyzing changes in ecological outcomes, EGS, and finally social

1 PDTs may have restrictions on the level of resources that can be devoted to evaluation of incidental benefits and should check with their vertical team to set analysis priorities.

\section{Step 1}


benefits and harms (refer to Figure 11 and Figure 12). From the set of ideal metrics, the PDT evaluates the data and models that are available to costeffectively measure the metrics for the project alternatives.

If the ideal metrics identified in the EGS conceptual models cannot be measured and projected, the PDT would document the rationale for the metric substitution (in A.3 the Rating Documentation Table in Appendix A) to retain the connection between the metric and potential EGS benefits or harms. Using the desired metrics as a guide, the PDT identifies available data to characterize current conditions.

Databases aimed at characterizing the condition and restorability of ecosystem goods and services are under development, such as the US EPA EnviroAtlas map of potentially restorable wetlands by watershed (US EPA 2014). Because data and model availability are changing rapidly, PDTs will find it useful to conduct a search of materials at the time of analysis. In addition, several portals that document data availability and case studies are also being developed, such as the Ecosystem Services Partnership (http://www.fsd.nl/esp/) and the National Ecosystem Services Partnership (nespguidebook.com).

In contrast to biophysical data, PDTs may be less familiar with social or economic data sources that are required to characterize the potential users or beneficiaries of EGS. Basic socio-demographic and economic data are available from federal government websites such as the U.S. Census Bureau and the Bureau of Labor Statistics. State and local government offices provide additional resources such as tax assessment databases of property. In addition, several databases of economic valuation literature are available and may be useful for determining whether a benefit transfer study is feasible (e.g., Environmental Valuation Reference Inventory). Social scientists can help to guide the selection and use of data for analyses.

In addition to current data, the PDT will need to identify available tools and/or models that may be useful for projecting EGS changes due to management measures.

The PDT should consult the technical documentation of any EGS tool being considered. Many EGS-specific models have aspects that may make them unsuitable for use in plan evaluation, such as monetization of nonuse services. PDTs should consult with their planning centers of expertise 
prior to using a model to determine the resources and information needed to have the model reviewed and approved by headquarters for planning.

\section{Step 2.2 - Choose analytic approaches and models}

Once the PDT has evaluated the tools that are currently available, they choose whether to use existing models or to develop their own analytic approaches to demonstrate relationships between management measures and benefits or harms. However, the level of detail should not be greater than that needed to inform the decision-making process efficiently and effectively. Table 17 provides general recommendations for selecting the appropriate analytic approaches and methods. EGS analysis approaches that the PDT might develop can include indicator systems based on conceptual models, statistical models, or complex simulation models.

Table 17. Recommendations for analytic method and model selection.

\begin{tabular}{|l|l|}
\hline Guideline & Approach \\
\hline $\begin{array}{l}\text { Measure potential EGS benefits } \\
\text { from the beneficiary's } \\
\text { perspective }\end{array}$ & $\begin{array}{l}\text { To ensure benefit metrics represent the perspectives of the users or } \\
\text { beneficiaries (and not just the analysts), it is best practice to consult with } \\
\text { social scientists, such as environmental economists and cultural } \\
\text { anthropologists, who can apply appropriate techniques for eliciting and } \\
\text { describing preferences. }\end{array}$ \\
\hline $\begin{array}{l}\text { Choose models that are sensitive } \\
\text { to differences among alternatives }\end{array}$ & $\begin{array}{l}\text { Compare project alternatives with models that have sufficient precision to } \\
\text { ensure that calculated differences are meaningful. }\end{array}$ \\
\hline Right-size the modeling effort & $\begin{array}{l}\text { The time needed to build or apply EGS evaluation models should } \\
\text { represent an appropriate proportion of the PDT's resources. }\end{array}$ \\
\hline $\begin{array}{l}\text { Ensure transparency of methods } \\
\text { and assumptions }\end{array}$ & $\begin{array}{l}\text { PDTs should avoid black-box tools whose methods cannot be clearly } \\
\text { explained. }\end{array}$ \\
\hline Clarify uncertainty & $\begin{array}{l}\text { Results should be reported in ways that reveal the uncertainties of the } \\
\text { analysis and opportunities for adaptive management. }\end{array}$ \\
\hline
\end{tabular}

Models used in plan evaluation will be required to pass rigorous peer review to be certified. Review criteria emphasize the need for model assumptions to be transparent and supported by evidence. Thus, models for plan formulation should follow accepted professional practices and provide clear documentation of and reasoning behind data manipulations and the functional forms used.

For models used outside of plan evaluation, the choice of approaches will depend on whether scientific understanding is sufficient to explicitly link management measures to valued environmental outcomes. Often data are not available to build empirical models, and a variety of approaches may

\section{Step $1>$ Step $2>$ Step $3>$ Step $4>$ Step $5>$ Step 6}


be used to overcome data limitations. Among the options to overcome data limitations is to apply conceptual relationships that have a strong theoretical basis, if not direct empirical evidence (see examples in Wainger and Mazzotta 2011). For example, indicator systems can be developed with GIS analysis, leading to a highly cost-effective tool for demonstrating that benefits or harms are likely to be produced, even when the exact functional form is unknown. However, indicator systems that are based on explicit conceptual models are preferable to a kitchen sink approach that incorporates every metric that might be relevant to promote scientific rigor (Dale and Beyeler 2001).

If an index of metrics is desired, one option is for the analyst to develop methods that explicitly weight indicators in a transparent manner, based on their relative contributions to outcomes. Alternatively, various tools are available, such as MaxEnt (Phillips et al. 2004), to apply statistical methods that will combine metrics in ways that minimize unintentional double-counting of the same properties (Ferraro 2004; Tran et al. 2004).

\section{Choosing to monetize changes in EGS}

The team re-evaluates the initial decisions made during Step 1 of planning regarding whether to monetize EGS to confirm that adequate data and scientific understanding exist to generate valid and useful valuation results. A brief description of issues and considerations to address is provided here. However, there is no substitute for consulting with an economist who understands the strengths and limitations of various approaches to ensure analysis methods are applied appropriately.

A common impediment to robust economic valuation has nothing to do with the challenge of applying economic techniques. Rather, valuation often cannot be conducted because the change in ecological outcomes either cannot be robustly predicted or cannot be related to a change that people use or appreciate-as captured in an EGS. Valuation relies on being able to project a quantitative biophysical response due to a management action (i.e., a response function) and an understanding of how an environmental change influences well-being. If either condition is missing, due to limits in data or understanding, valuation is not possible.

When the ecological change can be projected, the analyst examines whether primary valuation or benefit transfer is feasible and appropriate. Primary studies that use site-specific data are generally considered more accurate 
than benefit transfer studies that depend on data collected at other sites. Primary techniques include (1) market valuation; (2) revealed preference approaches; (3) stated preferences approaches; and (4) defensive and damage costs avoided approaches (Table 18). ${ }^{1}$ To consider the feasibility of conducting primary studies, the PDT evaluates whether resources and data are sufficient (Table 19). Primary valuation techniques vary widely in time requirements and data needs. In particular, methods that include surveys (e.g., stated preference techniques) conducted or paid for by federal agencies require approval by the OMB, which can be a lengthy process. ${ }^{2}$ PDTs should follow USACE guidance for selecting and applying these techniques appropriately (Scodari 2009; Bushnell and Knight 2011). Current guidance prohibits use of contingent valuation approaches for nonuse EGS (as discussed in Text Box 4).

Benefit transfer is widely used by federal agencies because it can be a more cost-efficient tool, relative to primary studies. However, the accuracy and ease of use depends on the availability of appropriate existing primary valuation studies. Benefit transfer must be carefully applied to avoid common pitfalls such as (1) ensuring that a comparable service is being transferred, (2) matching the situational context (e.g., similar scarcity level of the EGS), or (3) controlling for differences among sites (Ready and Navrud 2005; Rosenberger and Stanley 2006; Johnston and Wainger 2015). The improper transfer of EGS values between studies with different contexts can lead to large errors in the resulting value estimate.

Table 18. Primary valuation methods applied to EGS, (adapted from Turner et al. [2008], Table 4.8).

\begin{tabular}{|l|l|l|}
\hline \multirow{3}{*}{$\begin{array}{l}\text { Market } \\
\text { Valuation }\end{array}$} & $\begin{array}{l}\text { Valuation Method } \\
\text { Transactions }\end{array}$ & Description \\
\cline { 2 - 3 } & Production Function & $\begin{array}{l}\text { Derives value from household's or firm's inverse demand } \\
\text { function based on observations of use. }\end{array}$ \\
\hline \multirow{2}{*}{$\begin{array}{l}\text { Revealed } \\
\text { Preferences }\end{array}$} & Hedonic Price Method & $\begin{array}{l}\text { Derives value based on the contribution of an ecosystem } \\
\text { to the production of marketed goods (e.g., pollination } \\
\text { contribution to crop profits). }\end{array}$ \\
\cline { 2 - 3 } & Travel Cost Method & $\begin{array}{l}\text { Derives an implicit value for an EGS from market prices of } \\
\text { goods (e.g., contribution of adjacent wetlands to home } \\
\text { values). }\end{array}$ \\
\hline
\end{tabular}

1 See Freeman et al. (2014), Champ et al. (2003), and US EPA (2009) for in-depth descriptions of valuation techniques.

2 Paperwork Reduction Act of 1980 (44 U.S.C. § 3501-3521) requires OMB review and approval of surveys conducted or funded by federal agencies. 


\begin{tabular}{|c|c|c|}
\hline & Valuation Method & Description \\
\hline \multirow{2}{*}{$\begin{array}{l}\text { Stated } \\
\text { Preference }\end{array}$} & $\begin{array}{l}\text { Contingent Valuation (open- } \\
\text { ended and discrete choice) }\end{array}$ & $\begin{array}{l}\text { Creates a hypothetical market by asking survey } \\
\text { respondents to state their willingness-to-pay or } \\
\text { willingness-to-accept payment for an outcome (open- } \\
\text { ended) or by asking them to choose particular actions or } \\
\text { policies with given outcomes and costs (discrete choice). }\end{array}$ \\
\hline & $\begin{array}{l}\text { Contingent Choice } \\
\text { Modeling/Experiments }\end{array}$ & $\begin{array}{l}\text { Creates a hypothetical market by asking survey } \\
\text { respondents to choose among multi-attribute bundles of } \\
\text { goods/services with associated costs; derives EGS value } \\
\text { using statistical models. }\end{array}$ \\
\hline \multirow{4}{*}{$\begin{array}{l}\text { Defensive and } \\
\text { Damage Costs } \\
\text { Avoided }\end{array}$} & Damage Costs Avoided & $\begin{array}{l}\text { Value is inferred from the direct and indirect expenses } \\
\text { incurred as a result of damage to the built environment or } \\
\text { to people (e.g., costs of rebuilding homes and } \\
\text { infrastructure and lost business revenues, costs of } \\
\text { treating illness). }\end{array}$ \\
\hline & $\begin{array}{l}\text { Averting Behavior/Defensive } \\
\text { Expenditures }\end{array}$ & $\begin{array}{l}\text { Value is inferred from costs and expenditures incurred in } \\
\text { mitigating or avoiding damages (e.g., the cost of an } \\
\text { installed air filtration system suggests a minimum } \\
\text { willingness-to-pay to avoid discomfort or illness from } \\
\text { polluted air). }\end{array}$ \\
\hline & Replacement/Restoration Cost & $\begin{array}{l}\text { Value is inferred from potential expenditures incurred from } \\
\text { replacing or restoring an EGS (e.g., water treatment costs } \\
\text { avoided). }\end{array}$ \\
\hline & Public Pricing & $\begin{array}{l}\text { Public investment serves as a surrogate for market } \\
\text { transactions (e.g., wetland restoration expenditures or } \\
\text { costs to preserve open space). }\end{array}$ \\
\hline
\end{tabular}

\section{Step $1>$ Step $2>$ Step 3 $>$ Step $4>$ Step $5>$ Step 6}


Table 19. Primary economic valuation techniques by EGS.

\begin{tabular}{|c|c|c|}
\hline EGS Category & Specific EGS Example & $\begin{array}{l}\text { Common Primary* Valuation } \\
\text { Techniques }\end{array}$ \\
\hline $\begin{array}{l}\text { Ecosystem Sustainability } \\
\text { (Non-use services) }\end{array}$ & $\begin{array}{l}\text { Preservation of species and } \\
\text { ecosystems }\end{array}$ & $\begin{array}{l}\text { Stated Preference (contingent } \\
\text { valuation, } \dagger \text { contingent choice) }\end{array}$ \\
\hline Water Supply and Regulation & Irrigation water supply & $\begin{array}{l}\text { Market Analysis } \\
\text { Costs Avoided } \neq\end{array}$ \\
\hline $\begin{array}{l}\text { Natural Hazard Mitigation, } \\
\text { Property and Infrastructure } \\
\text { Damage Mitigation, Human } \\
\text { Safety }\end{array}$ & $\begin{array}{l}\text { Mitigation of property damage } \\
\text { from flooding / storm surges }\end{array}$ & Damage Costs Avoided $\ddagger$ \\
\hline Navigation & $\begin{array}{l}\text { Commercial Shipping (supported } \\
\text { by sediment retention of } \\
\text { ecosystem) }\end{array}$ & Dredging Costs Avoided $\ddagger$ \\
\hline Recreation & Fishing & Travel Cost \\
\hline $\begin{array}{l}\text { Cultural, Spiritual and } \\
\text { Educational Support }\end{array}$ & Sacred ecosystem & $\begin{array}{l}\text { Stated Preference } \\
\text { Travel Cost }\end{array}$ \\
\hline Aesthetics & Property value support & Hedonic Price \\
\hline Food Provisioning & Nut production & $\begin{array}{l}\text { Market Valuation } \\
\text { Production Function }\end{array}$ \\
\hline $\begin{array}{l}\text { Raw Goods and Materials } \\
\text { Provisioning }\end{array}$ & Peat supply & $\begin{array}{l}\text { Market Valuation } \\
\text { Production Function }\end{array}$ \\
\hline $\begin{array}{l}\text { Water Purification and Waste } \\
\text { Treatment }\end{array}$ & Drinking water & $\begin{array}{l}\text { Treatment Costs Avoided } \neq \\
\text { Stated Preference }\end{array}$ \\
\hline $\begin{array}{l}\text { Climate Regulation, Carbon } \\
\text { Sequestration }\end{array}$ & Carbon sequestration & Costs Avoided $\ddagger$ \\
\hline Human Health & Illness avoided & $\begin{array}{l}\text { Hedonic Price } \\
\text { Defensive Behavior } ¥ \\
\text { Costs Avoided } \neq \\
\text { Stated Preference }\end{array}$ \\
\hline
\end{tabular}

* Any EGS can be valued using benefit transfer, so only primary valuation techniques are listed.

† Contingent valuation techniques are currently prohibited from use by USACE guidance for non-use services (USACE 2000).

$\ddagger$ Although these techniques have been used in many contexts, including legal proceedings, the use of prices, avoided costs, and replacement costs do not directly measure economic benefits and must be used with caution (National Research Council [NRC] 2005; U.S. Environmental Protection Agency [EPA], Science Advisory Board 2009). However, these metrics can provide information similar to economic benefits and are relatively easy to measure.

Two types of benefit transfer can be developed: value transfer and functional transfer. Functional transfers are considered to have lower error than value transfers because they use empirical models to correct for location differences and known biases among different types of primary valuation approaches. 
In value transfer, analysts derive a single value per beneficiary or per user day, usually by averaging values from similar study sites. The studies used to create the single value needs to be representative of the degree of environmental change and site context of the project. Therefore, to determine if value transfer is feasible, the analyst needs to confirm that available studies are sufficient in number and similarity to the case being valued. The unit day value approach used by the USACE to represent recreational benefits is a type of value transfer approach, and it adjusts values to reflect scarcity.

In a functional transfer, empirical relationships are built from many studies to model how values vary across sites. The models use variables such as population demographics and environmental conditions to evaluate how those variables contribute to or detract from value at a given site. To determine if functional transfer is feasible, the analyst must either find an existing statistical meta-analysis or develop a statistical model using many studies of the same EGS. PDTs can query databases of economic valuation studies to examine the availability of meta-analyses (i.e., transfer functions) and appropriate individual studies for developing a value transfer or functional transfer.

Although benefit transfer is widely used, it has known limitations due to the difficulty of transferring values across dissimilar sites. Practitioners manage error by carefully tailoring the analysis to the project conditions (Rosenberger and Loomis 2001; Wilson and Hoehn 2006; Johnston and Wainger 2015). PDTs will find that multiple simple EGS valuation tools have been developed, many of them GIS based, that apply benefit transfer approaches but use limited site-specific information. A typical approach is to assign an aggregate EGS value to a land cover type (e.g., wetland and forest) and sum those per-acre values over the project area. Such tools are not thought to provide values that can be robustly attributed to a project. Such tools can lack the ability to compare alternatives, lack sensitivity to ecological functional qualities and demand conditions (e.g., size of the beneficiary population), and generally can be expected to have high error compared to a study that was tailored to site conditions. Thus, tools that use generic per-acre values by land cover type do not usually provide defensible economic values for project comparisons. 


\section{Case Study Example Box. Step 2.2 - Choosing analytic methods}

Using the EGS conceptual models (Figure 11), the PDT identifies analytic methods that would be needed to further refine or quantify relationships between management measures and measures of benefits or harms. These relationships can take many forms including enhanced conceptual models, empirical cause-and-effect functions, and simulation models that incorporate multiple changes dynamically to project outcomes.

\section{Ecosystem sustainability - non-use services}

The PDT uses different approaches to model identification for each conceptual model step.

1. Response function - The PDT convenes an expert panel to review and select the most relevant models to quantify how management measures will affect ecological structures and processes (Column 2 in Figure 11) and then generate estimates of changes in the ecological outcome metrics (Column 3 in Figure 11) for the non-use services. Table 20 provides a list of the final models that the panel decides to use along with a short justification for their use. ${ }^{1}$

Table 20. Response function models for non-use services in the case study.

\begin{tabular}{|c|c|c|}
\hline Ecological Outcome Metric & Models & Use and Justification of Models \\
\hline $\begin{array}{l}\text { Habitat quality for } \\
\text { Roundtail Chub }\end{array}$ & $\begin{array}{l}\text { Bonar et al. (2010)/ Hydrologic } \\
\text { Engineering Center Ecosystem } \\
\text { Functions Model (HEC-EFM) }{ }^{2}\end{array}$ & $\begin{array}{l}\text { The PDT uses a subset of variables, } \\
\text { derived from Bonar et al. (2010) to } \\
\text { characterize habitat suitability for the } \\
\text { chub species and to forecast habitat } \\
\text { effects of the alternatives using HEC- } \\
\text { EFM. }\end{array}$ \\
\hline $\begin{array}{l}\text { Recruitment of foundation } \\
\text { species - trees }\end{array}$ & $\begin{array}{l}\text { Hydrologic Engineering Center } \\
\text { River Analysis System (HEC- } \\
\text { RAS)3/HEC-EFM }\end{array}$ & $\begin{array}{l}\text { The PDT uses the HEC-RAS and HEC-EFM } \\
\text { models to dynamically calculate flood } \\
\text { frequency and duration and soil } \\
\text { moisture, under the project alternatives. } \\
\text { Soil moisture determines the expansion } \\
\text { potential for riparian species requiring } \\
\text { saturated soils within } 10 \text { feet of the soil } \\
\text { surface (e.g., cottonwood and willow } \\
\text { species). }\end{array}$ \\
\hline $\begin{array}{l}\text { Composition and diversity } \\
\text { in plant communities of } \\
\text { cottonwood-willow riparian } \\
\text { forests }\end{array}$ & $\begin{array}{l}\text { "Maintain Characteristic Plant } \\
\text { Communities" } \\
\text { Hydrogeomorphic (HGM) } \\
\text { model for Cottonwood-Willow } \\
\text { and Mesquite Communities }{ }^{4}\end{array}$ & $\begin{array}{l}\text { The PDT applies this model to estimate } \\
\text { plant community functional capacity } \\
\text { indices (FCl) for this arid riverine system. }\end{array}$ \\
\hline $\begin{array}{l}\text { Quality of breeding habitat } \\
\text { for the Southwestern } \\
\text { Willow Flycatcher }\end{array}$ & $\begin{array}{l}\text { Modified version of Model } 2 \\
\text { from Hatten et al. (2010) }\end{array}$ & $\begin{array}{l}\text { This model links spatial environmental } \\
\text { variables and flycatcher breeding } \\
\text { habitat. The PDT uses the modified } \\
\text { version of this model, which applies the } \\
\text { most predictive variables for calculating } \\
\text { the change in Southwestern Willow } \\
\text { Flycatcher breeding habitat. }\end{array}$ \\
\hline
\end{tabular}

1 PDTs should ensure that models used in planning are certified or approved by the appropriate Planning Center of Expertise.

2 http://www.hec.usace.army.mil/software/hec-efm/

3 http://www.hec.usace.army.mil/software/hec-ras/

4 This is one of multiple HGM assessment models developed in the 2009 draft report A Planning-based Wetlands Functional Assessment Model for Southern Arizona's Arid Riverine Systems and Their Associated Riparian Habitats by A. C. Webb and K. A. Burks-Copes. Though it is a draft, the model captures the vegetation composition changes the PDT hopes to see on the site, and they work with Eco-PCX to certify it for use on the project.

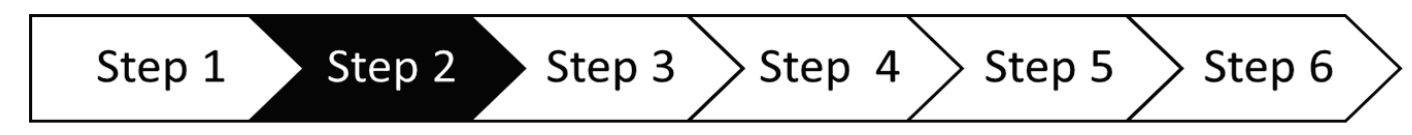




\section{Case Study Example Box. Step 2.2 - Choosing analytic methods (cont.)}

2. ESE -To demonstrate that the project affects an EGS and not just an ecological outcome, the PDT will measure the scarcity of the relevant ecosystems and species (see Step 1, section 1.2). For ecosystemderived EGS, the PDT chooses to use GIS analysis to estimate the increase in total remaining area of the two ecosystems in decline, riparian and desert perennial river, and to evaluate the availability of substitute restoration sites. The post-project site will have to meet a functional quality threshold to be considered part of the restored area of the ecosystem.

For the species-derived EGS, the PDT will assess the project's contribution to the long-term persistence of the Southwestern Willow Flycatcher using the percentage increase in breeding territories, relative to the U.S. Fish and Wildlife Service (USFWS) minimum target of breeding territories (Finch et al. 2002) established to keep the population secure. For Roundtail Chub, they will use the percentage increase in habitat within the Lower Colorado River Basin in relation to its historic habitat range in the river basin.

3. Benefit/damage function -Because the project falls under the EQ business line, the PDT chooses not to monetize the benefits of the plan alternatives and therefore does not spend time identifying data and models at this stage. They decide to use the EGS metrics as proxies for measuring social benefits and plan to revisit the option to monetize these benefits for the tentatively selected plan for communication purposes (See Step 6).

\section{Natural hazard mitigation: Property flood damage mitigation}

1. Response function - Dam engineers, hydrologists, flood modelers, and GIS technicians plan to work together to apply the HEC-RAS model to estimate the changes in flooding intensity and frequency with each alternative. HEC-RAS has the ability to model flood events and produce water surface profiles over the length of the modeled stream. Using the companion GIS utility, HEC-GeoRAS, ${ }^{1}$ those water surface profiles can be converted to flood inundation maps. Once the projected flood plain is mapped in the GIS software (ESRI ArcMap), the change in the area flooded will be estimated.

2. Ecosystem service evaluation - The outputs of the HEC-GeoRAS analysis will be combined with tax assessment data to estimate the total change in number of flooded properties for the 2-, 5-, and 10-year return interval floods. The outputs of the analysis will be an estimate of the total number of residences and businesses affected by these frequent events and the annualized decrease in the number of days that these properties are expected to be flooded.

3. Benefits function - The PDT will estimate the social benefits using the damage costs avoided to property owners and municipalities, following NED guidance (Scodari 2009).

\section{General recreation and birdwatching}

1. Response function - To quantify the ecological outcome metric of bird diversity (natives and migrants), the PDT extracts a variable from the Wildlife Habitat Function HGM model for the Cottonwood-Willow and Mesquite Communities ecosystem ${ }^{2}$. The variable of number of vegetation layers present has been linked to bird niche availability and bird diversity. The PDT uses available evidence to determine that the tree stratum index must be greater than 0.4 (on a scale of 0 to 1 ) to be consistent with the habitat needs of multiple bird species in this habitat.

To address general recreation (e.g., hiking), the PDT modifies the Maintain Characteristic Plant Communities model for Cottonwood-Willow and Mesquite Communities to address those factors most important to visitors. They combine the first term in the model (including species richness variable, wetland indicator score, and invasive species variable) with canopy tree coverage.

2. Ecosystem service evaluation - The number of potential new recreation user days due to the project will be estimated using available data and a GIS analysis (as conducted to fill out the Impact Evaluation Table 14). The GIS analysis will be verified (and refined as needed) using measured visitation data from a similar park in a similar city in Arizona.

1 http://www.hec.usace.army.mil/software/hec-georas/

22009 draft report A Planning-based Wetlands Functional Assessment Model for Southern Arizona's Arid Riverine Systems and Their Associated Riparian Habitats by A. C. Webb and K. A. Burks-Copes.

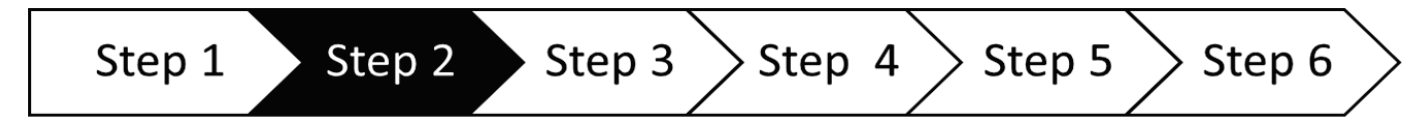




\section{Case Study Example Box. Step 2.2 - Choosing analytic methods (cont.)}

3. Benefit/damage function - The PDT will not monetize the benefits of the alternative plans and therefore will use the user day metrics as proxies for benefits. They will revisit the opportunity to conduct benefit transfer for this EGS for the selected plan.

\section{Aesthetics for riparian homeowners}

1. Response function - Both native tree cover and characteristic vegetation density (i.e., matching reference conditions) have been identified as proxies for people's aesthetic enjoyment of southwestern riparian ecosystems (Weber and Stewart 2009). Therefore, the first step in quantifying the aesthetic benefits of the project is to evaluate how the management measures affect these variables. Since the aesthetic and recreation EGS share the ecological outcome metric, native tree cover, the PDT will employ the same response functions for both EGS. To estimate vegetation density, the PDT will use the second term in the Maintain Characteristic Plant Communities equation for Cottonwood-Willow and Mesquite Communities, which includes tree, shrub, and herbaceous vegetation canopy cover variables, from the HGM model ${ }^{1}$. The model products will be FCls. The PDT judges that each of these metrics must have a minimum $\mathrm{FCl}$ score of 0.5 (on a scale of 0 to 1 ) to provide aesthetic benefits to neighboring residences.

2. Ecosystem service evaluation - The PDT will count the number of residences near the site that will have a full or partial view of the restored riparian area using GIS viewshed analysis. This metric of number of residences is a simple proxy for magnitude of potential benefit since riparian restoration has been shown to increase aesthetic benefits (as capitalized in home values).

3. Benefit/damage function - As with the non-use and recreational services, the PDT chooses to use the non-monetary ESE metrics to suggest benefits of the alternative plans. Once a plan has been selected, the PDT will consider the option to conduct a hedonic analysis to estimate the increase in property values that could result from the riparian area's improved aesthetics.

\section{Step 2.3 - Characterize existing conditions and forecast future without project conditions}

The descriptions of existing conditions and FWOP conditions for EGS analysis should identify major forces impacting either the condition or value of the EGS being produced or impacted by the project. The future flow and value of ecosystem services can be influenced by changes in the quality and quantity of the ecosystem structures and processes and by changes in user preferences and needs. For example, the PDT would need to identify whether future urban growth might put more residences at risk of flooding due to the project. The conceptual models may be used here to identify the relevant risk factors and trends in both ecosystems and human uses of those ecosystems, within the corresponding EGS service areas.

12009 draft report A Planning-based Wetlands Functional Assessment Model for Southern Arizona's Arid Riverine Systems and Their Associated Riparian Habitats by A. C. Webb and K. A. Burks-Copes.

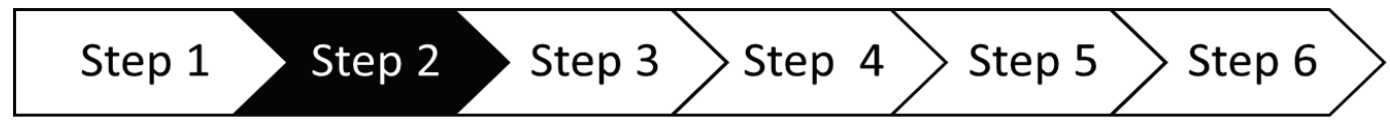




\section{Case Study Example Box. Step 2.3 - Forecasting FWOP}

For the case study area, the PDT considers the baseline conditions of the Response Function or Ecosystem Service Evaluation and forecasts potential changes in the key factors needed to deliver EGS that are beyond the control of the project. These factors may reflect any environmental or human drivers that contribute to degrading, improving, or stabilizing the system. The PDT chooses a period of analysis of 50 years to use when considering which trends are likely to result in substantial changes to any of these qualities. The PDT considers all major factors influencing any EGS (including those outside the project authorities and mission areas) to enable any EGS analysis to use this FWOP. Table 21 lists the biophysical and social baseline conditions and trends that influence the case study project site (column 1) and the expected resulting changes in the EGS for the FWOP (column 2).

Table 21. Baseline conditions and future trends influencing EGS in the FWOP (case study).

Biophysical and Social Baseline Conditions and Forecasted
Trends

Hydrological and floodplain functioning

- Sediment buildup behind the dam has led to slightly increased sediment delivery and more frequent peak flows during the past decade. However, dam water holding capacity will be maintained to ensure originally authorized level of flood risk.

- Regional hydrological modification, including normal operation of other dams, is expected to continue within this watershed and the ecoregion.

- Increased frequency and magnitude of drought conditions are projected for this region as a result of climate change.

- New zoning restrictions in Springfield will restrict further development in the town's floodplain.
Expected Changes in EGS in the FWOP

Property flood damage mitigation

- Flooding in areas within and downstream of the project is expected to occur at the same frequency and magnitude because hydrological modifications (e.g., due to water withdrawals) will not have a significant effect on water volumes during storms.

- Because of the new zoning restrictions in the floodplain of Springfield, the amount of vulnerable property in the floodplain is expected to remain constant.

\section{Non-use services}

- Continued dam operations and expected drought conditions will provide substandard conditions for riparian and aquatic ecosystems and species in the project area. Therefore, there will be a negative impact on the non-use services associated with the ecosystems and species.

- Increased drought conditions and regional hydrological modification are expected to continue to threaten the cottonwood-willow forests, desert perennial rivers, and associated species throughout their range.

\section{Water withdrawals}

- Withdrawals from the river system have increased over the last 50 years due to demand from municipal and agricultural sources. In some areas, primarily outside of the project area, water withdrawals have lowered riparian water levels below the rooting zone of existing riparian vegetation, leading to replacement of riparian woodlands with drought-tolerant species.

- Human population in the area is expected to grow, which will increase domestic water use, but at reduced per capita rates relative to historic rates, due to increased conservation measures. An increased demand for golf courses is projected to increase commercial water use.

- Withdrawals are trending upward in the project area, but water levels are not expected to routinely drop below the current vegetation rooting zone in the next 50 years. The withdrawals, however, are expected to reduce the overall flow of the river at times that are critical for fish survival.

\section{Non-use services}

- Water withdrawals will have minor negative impacts on the riparian ecosystem, the Southwestern Willow Flycatcher, and associated non-use services.

- Reduced river flow during critical low-flow periods will negatively impact the perennial river ecosystem, the Roundtail Chub, and the associated non-use services.

- Regionally, increasing withdrawals will continue to reduce the extent of riparian woodlands and desert perennial river ecosystems.

\section{Step 1




\begin{tabular}{|c|c|}
\hline \multicolumn{2}{|c|}{ Case Study Example Box. Step 2.3 - Forecasting FWOP (cont.) } \\
\hline $\begin{array}{l}\text { Biophysical and Social Baseline Conditions and Forecasted } \\
\text { Trends }\end{array}$ & Expected Changes in EGS in the FWOP \\
\hline $\begin{array}{l}\text { Invasive plants } \\
\text { - The invasive tree species tamarisk (Tamarix } \\
\text { ramosissima) is present within } 20 \text { miles of the } \\
\text { site. Recent biocontrol programs are reducing the } \\
\text { reproductive potential of tamarisk in the region. } \\
\text { As a result, site colonization potential is declining. }\end{array}$ & $\begin{array}{l}\text { Non-use services } \\
\text { - If tamarisk does invade, it will have a negative } \\
\text { impact on the native riparian and aquatic } \\
\text { ecosystems, thereby reducing the non-use } \\
\text { services associated with maintaining native } \\
\text { ecosystems. Since it will have a negative impact } \\
\text { on the desert perennial river ecosystem, it is also } \\
\text { projected to harm the Roundtail Chub (dependent } \\
\text { on the ecosystem) and the non-use services } \\
\text { associated with the species. } \\
\text { - Tamarisk invasion will threaten the existence of } \\
\text { cottonwood-willow riparian forests and perennial } \\
\text { desert river ecosystems over the long term, } \\
\text { throughout the region. } \\
\text { - If tamarisk invades, evidence shows that it will } \\
\text { provide suitable habitat for the Southwestern } \\
\text { Willow Flycatcher (Paxton et al. 2007; Sogge et } \\
\text { al. } 2010 \text { ). Therefore, it would be expected to } \\
\text { have a neutral impact on the non-use services } \\
\text { associated with this species. } \\
\text { Recreation } \\
\text { - If tamarisk invades, it will have a modest } \\
\text { negative impact on trail-based recreation due to } \\
\text { loss of diversity of watchable species. } \\
\text { Aesthetics } \\
\text { - If tamarisk invades, it is predicted to have a } \\
\text { negative impact on the aesthetic value to nearby } \\
\text { residences due to changes in native tree cover } \\
\text { and vegetation density. }\end{array}$ \\
\hline $\begin{array}{l}\text { Local Recreation Trends } \\
\text { - Participation in recreational activities, namely } \\
\text { birding and hiking, in the region has been } \\
\text { increasing in recent years and is expected to } \\
\text { continue increasing. } \\
\text { - No new public access to the riparian area is } \\
\text { anticipated in current city plans. }\end{array}$ & $\begin{array}{l}\text { Recreation } \\
\text { - The growing participation in recreational } \\
\text { activities will lead to significant increases in } \\
\text { demand for existing recreational sites within the } \\
\text { city and in its vicinity. As a result, increased } \\
\text { congestion is expected in the existing sites. }\end{array}$ \\
\hline $\begin{array}{l}\text { Residential development } \\
\text { - There are currently } 25 \text { residences with a clear } \\
\text { view of the river and riparian area (but not in the } \\
\text { floodplain). As the urban population increases, } \\
\text { there is likely to be increased development in } \\
\text { areas zoned for residential use in the areas with } \\
\text { river views. }\end{array}$ & $\begin{array}{l}\text { Aesthetics } \\
\text { - Given the expected development in river view } \\
\text { areas, more residential properties will receive } \\
\text { aesthetic benefits from the view. }\end{array}$ \\
\hline
\end{tabular}

Local Recreation Trends

Participation in recreational activities, namely birding and hiking, in the region has been increasing in recent years and is expected to

No new public access to the riparian area is anticipated in current city plans.

Residential development

There are currently 25 residences with a clear view of the river and riparian area (but not in the areas zoned for residential use in the areas with in EGS in the FWOP

If tamarisk does invade, it will have a negative impact on the native riparian and aquatic ecosystems, thereby reducing the non-use services associated with maintaining native ecosystems. Since it will have a negative impact on the ecosystem) and the non-use services

Tamarisk invasion will threaten the existence of cottonwood-willow riparian forests and perennial desert river ecosystems over the long term,

If tamarisk invades, evidence shows that it will provide suitable habitat for the Southwestern Willow Flycatcher (Paxton et al. 2007; Sogge et se services Recreation

If tamarisk invades, it will have a modest negative impact on trail-based recreation due to Aesthetics residences due to changes in native tree cover and vegetation density.

\section{Recreation}

The growing participation in recreational activities will lead to significant increases in city and in its vicinity. As a result, increased congestion is expected in the existing sites.

\section{Aesthetics} areas, more residential properties will receive aesthetic benefits from the view.

\section{Step $1>$ Step $2>$ Step 3 $>$ Step $4>$ Step $5>$ Step 6}




\section{Step 3 - Formulate Plans}

The goal of Step 3 of planning is to designate alternative plans that can be tested for their ability to maximize goals (USACE 2000). To incorporate EGS into Step 3 of planning, PDTs should follow the usual procedures for plan formulation but add the step of using the EGS conceptual models to identify opportunities to simultaneously enhance (or mitigate harm to) the full bundle of selected services . Further, explicit response functions- including nonlinearities between actions and the level of ecological change necessary to generate benefits-are developed to guide

\section{Section Highlights}

- This section describes how EGS might be used in creating project alternatives to maximize the bundle of EGS produced.

- The team considers whether management measures and levels of intervention are complementary or antagonistic to the production of the targeted bundle of EGS, when implemented simultaneously.

- Products of this step are the following:

1. Table rating the magnitude of expected impact of management measures on measurable ecological outcomes.

2. List of alternative projects to evaluate. the team in designing the appropriate levels of intervention.

For Step 3, the EGS framework includes a table to organize the evidence of management effectiveness in terms of ecological outcomes. The table is used to reveal whether increases in one service come at the expense of other services for a given plan (are antagonistic) or whether they are mutually supportive (are complementary). As analysts complete the table, they use the response function to identify the level of management intervention needed to create meaningful change in the ecological outcome metrics (i.e., incorporate threshold effects).

Here, a table is used to compare management measures to ecological outcomes since the ecological metrics developed in the EGS conceptual models are the foundation of the EGS benefits. However, when management measures interfere with direct use of EGS (e.g., prevent access, reduce aesthetics), the team will also need to build a table documenting effects of management measures on EGS metrics to identify constraints.

The case study example, below, illustrates how the team applies the EGS conceptual models and the response functions to vet assumptions about the ability of management measures to produce benefits. This step potentially advances plan formulation in two ways. First, the ecological outcome metrics are explicitly linked to beneficiary needs and desires through the conceptual models. Second, the response functions provide

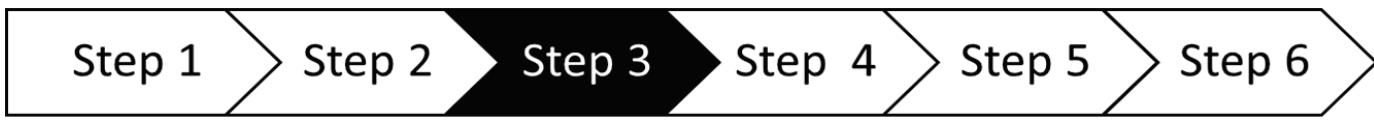


the technical support needed to project likely outcomes based on documented evidence that management measures are likely to be effective at generating EGS for a given site. Thus, referencing these functions can promote success of restoration project design by incorporating the advice that restoration sites and goals be appropriately matched (Palmer et al. 2005, 2011; Feld et al. 2011).

\section{Case Study Example Box. Step 3.1 - Plan formulation}

In the case study, the PDT uses the EGS conceptual model (Figure 11) to formulate sets of management measures that generate bundles of EGS. To characterize the expected effectiveness of potential management measures, the PDT first summarizes the relative contribution of each measure to the ecological outcomes (Table 22). The team considers alternative levels of intervention to find the level that maximizes beneficial outcomes of individual services. Then, the PDT uses the table to evaluate which measures are complementary or antagonistic by examining whether or not a measure is consistently positive across outcomes.

Table 22. Anticipated impacts of management measures on ecological outcomes for the case study.

\begin{tabular}{|c|c|c|c|c|c|c|c|c|c|c|}
\hline \multirow{2}{*}{$\frac{\text { Ecological outcomes }}{\text { Level of intervention }}$} & \multicolumn{2}{|c|}{$\begin{array}{l}\text { Manipulate } \\
\text { Dam } \\
\text { Discharge }\end{array}$} & \multicolumn{2}{|c|}{$\begin{array}{c}\text { Construct } \\
\text { Meanders } \\
\text { and Channel } \\
\text { Blocks }\end{array}$} & \multicolumn{2}{|c|}{$\begin{array}{l}\text { Construct } \\
\text { Irrigation } \\
\text { Channels }\end{array}$} & \multirow[t]{2}{*}{$\begin{array}{l}\text { Plant Native } \\
\text { Riparian } \\
\text { Vegetation }\end{array}$} & \multirow[t]{2}{*}{$\begin{array}{l}\text { Transport } \\
\text { Sediment } \\
\text { and Deposit } \\
\text { on Banks }\end{array}$} & \multirow[t]{2}{*}{$\begin{array}{l}\text { Add } \\
\text { Logs }\end{array}$} & \multirow[t]{2}{*}{$\begin{array}{l}\text { Construct } \\
\text { Trails }\end{array}$} \\
\hline & Low & Med & $5 \mathrm{mi}$ & $10 \mathrm{mi}$ & 2 & 4 & & & & \\
\hline $\begin{array}{l}\text { Flooding intensity } \\
\text { and frequency } \\
\text { (agricultural areas) }\end{array}$ & 0 & - & 0 & 0 & 0 & 0 & 0 & 0 & 0 & 0 \\
\hline $\begin{array}{l}\text { Flooding intensity } \\
\text { and frequency } \\
\text { (downstream urban } \\
\text { areas) }\end{array}$ & 0 & 0 & + & + & + & + & + & + & 0 & 0 \\
\hline $\begin{array}{l}\text { Habitat quality for } \\
\text { Roundtail Chub }\end{array}$ & + & ++ & ++ & ++ & + & + & + & + & + & 0 \\
\hline $\begin{array}{l}\text { Recruitment of } \\
\text { foundation tree } \\
\text { species }\end{array}$ & 0 & ++ & 0 & 0 & ++ & + & +++ & + & 0 & 0 \\
\hline $\begin{array}{l}\text { Composition and } \\
\text { diversity in plant } \\
\text { communities of } \\
\text { cottonwood-willow } \\
\text { forests }\end{array}$ & 0 & ++ & 0 & 0 & ++ & + & +++ & + & 0 & 0 \\
\hline Vegetation density & 0 & ++ & 0 & 0 & ++ & + & ++ & + & 0 & 0 \\
\hline $\begin{array}{l}\text { Quality of breeding } \\
\text { habitat for } \\
\text { Southwestern } \\
\text { Willow Flycatcher }\end{array}$ & 0 & ++ & 0 & 0 & ++ & + & ++ & + & 0 & 0 \\
\hline Bird diversity & 0 & ++ & 0 & 0 & ++ & + & ++ & + & 0 & 0 \\
\hline Native tree cover & 0 & ++ & 0 & 0 & ++ & + & +++ & + & 0 & 0 \\
\hline
\end{tabular}

Key: +++/- - - High Positive/Negative Change; ++/- - Medium Change; +/- Low Change; ○ No / Negligible Change; ii Insufficient Information; n/a Not applicable

Step $1>$ Step $2>$ Step $3>$ Step $4>$ Step $5>$ Step $6>$




\section{Case Study Example Box. Step 3.1 - Plan formulation (cont.)}

From Table 22, the team determines that all but one management measure generates consistently positive or neutral effects across all EGS suggesting measures are largely complementary. The one exception is the risk of increased flooding for adjacent agricultural lands that could result from modifying dam operation to restore environmental flows needed by native fish. This small risk of lost flood damage mitigation was managed by engaging non-federal partners (who own and lease the cropland) to alter leases to avoid private crop damages.

The PDT finds that some levels of intervention are inadequate to generate benefits or generate unacceptable harms. Dam removal was quickly excluded from the final array of plan alternatives because it was shown to produce substantial harm to the surrounding area. Second, evidence was insufficient that sediment transfer would generate the desired ecological outcomes. The team also identifies that low changes to dam discharge will not generate the necessary level of riparian ground water levels to maintain native tree species throughout the restoration site but that moderate amounts of modification will create the desired changes. They further identify that 5 miles of meanders and channel blocks are likely to be sufficient to create desired fish habitat and that 2 miles of irrigation channels are preferable to 4 miles because of harms that could occur to riparian vegetation from a higher degree of intervention.

Using the table, the team devises alternatives that represent different levels of intervention (and spending) so that the cost effectiveness of more and less intensive restoration choices can eventually be compared. Where relationships are uncertain, the PDT may conduct additional investigations to understand limitations and strengths of different restoration approaches and to devise the final list of plan alternatives (Table 23).

Table 23. Case study plan alternatives.

\begin{tabular}{|c|c|}
\hline & $\begin{array}{l}\text { Iternative A } \\
\text { Add log structures over 10-mile section } \\
\text { Construct trails over 5-mile section }\end{array}$ \\
\hline & $\begin{array}{l}\text { Modify dams to incorporate environmental flows } \\
\text { Construct trails over 5-mile section }\end{array}$ \\
\hline & $\begin{array}{l}\text { Modify dams to incorporate environmental flows } \\
\text { Construct two irrigation channels } \\
\text { Plant } 200 \text { acres of native riparian vegetation } \\
\text { Construct trails over 5-mile section }\end{array}$ \\
\hline & $\begin{array}{l}\text { Modify dams to incorporate environmental flows } \\
\text { Construct two irrigation channels } \\
\text { Plant } 200 \text { acres of native riparian vegetation } \\
\text { Construct meanders over 10-mile section } \\
\text { Construct trails over 5-mile section }\end{array}$ \\
\hline & $\begin{array}{l}\text { Modify dams to incorporate environmental flows } \\
\text { Construct two irrigation channels } \\
\text { Plant } 200 \text { acres of native riparian vegetation } \\
\text { Construct meanders over } 10 \text {-mile section } \\
\text { Add log structures over 10-mile section } \\
\text { Construct trails over 5-mile section }\end{array}$ \\
\hline
\end{tabular}

\section{Step $1>$ Step $2>$ Step $3>$ Step $4>$ Step $5>$ Step 6}




\section{Step 4 - Evaluate Plans}

The goal of Step 4 is to evaluate the impacts of alternative plans relative to the FWOP scenario (USACE 2000) using a level of effort appropriate to the project size and scope. Analysts will use the EGS selected in Step 1.3 and the analysis tools selected in Step 2.2 to generate quantitative or qualitative estimates of (1) the ecological outcome metrics, (2) EGS metrics, and (3) monetized benefit or damage metrics for each plan (where possible and desirable). The EGS analysis follows all relevant USACE guidelines for reporting changes relative to the no-action baseline, as represented by the FWOP (USACE 2000).

The next two sections describe (1) applying the tables developed in Step 1.3 to evaluate plans using minimal additional analytic resources and (2) using newly developed models to project

\section{Section Highlights}

- This section demonstrates how EGS might be used in evaluating alternatives using quantitative benefit indicators and monetary values.

- Two analysis options are presented-one that limits the need for new analyses and one that requires more intensive model investment-to demonstrate how analyses may be right-sized to projects.

- The case study illustrates some of the analytical differences in EGS measurement compared to ecological measurements.

- The team set thresholds for some ecological outcome metrics to identify the range of ecosystem conditions that are consistent with user or beneficiary perspectives of benefits.

- The team incorporated beneficiary responses to ecological change when estimating how EGS change through time.

- The products of this step are tables summarizing a wide range of benefit metrics (monetary and non-monetary) for the FWOP and each alternative. changes in EGS benefits. The metrics that are eventually chosen to represent EGS changes of alternatives (ecological outcomes, EGS metrics or values) will depend on model capabilities and data and resource constraints, as illustrated in the case study.

\section{Step 4.1 - Using the impact evaluation and decision criteria tables to evaluate alternatives}

Teams with limited resources can simplify analyses by applying the impact evaluation and decision criteria tables (developed in Step 1.3) to compare alternatives and omit further quantitative analysis. The tradeoff will be that results will be subject to higher uncertainty than more complete analyses. To use this method, PDTs would develop separate impact evaluation and decision tables for each alternative and compare results across alternatives.

Step $1 \sum$ Step $2 \sum$ Step $3>$ Step $4>$ Step $5 \sum$ Step 6




\section{Case Study Example Box. Step 4.1 - Impact evaluation and decision criteria table}

The PDT develops new impact and decision tables for each alternative using the same qualitative assessments and information sources that they used for building tables in Step 1.3. An example result for alternative $B$ is provided in Table 24. In this case, the impact evaluation table was combined with the decision criteria table from Step 1.3.

Table 24. Combined impact and decision table for Ayola Alternative B.

\begin{tabular}{|c|c|c|c|c|c|c|c|c|c|c|}
\hline \multicolumn{11}{|c|}{ IMPACT EVALUATION TABLE - Alternative B } \\
\hline \multicolumn{7}{|c|}{$\begin{array}{l}\text { Impact Table Directions } \\
\text { 1. List specific good and services that will be impacted. } \\
\text { 2. Biophysical Changes: Rate the magnitude this project is likely to have on the biophysical processes driving } \\
\text { this EGS, the duration of the impact (Table 8), and whether the impact will be substantial (Table 9). } \\
\text { 3. Affected Beneficiaries: Rate the magnitude this project is likely to have on the beneficiaries of this EGS, the } \\
\text { duration of the impact (Table } 8 \text { ), and whether the impact will be substantial (Table 9). } \\
\text { 4. Does this EGS have low-cost or readily available substitutes? (If yes, decreases positive and negative impact). } \\
\text { 5. Assign an aggregate rating using Figure } 11 . \\
\text { 6. Rate your overall confidence of the aggregate impact rating (Table 10). } \\
\text { 7. Is this EGS in the Corps Federal interest (Table 11)? Can Corps project funds be used to support it? }\end{array}$} & \multicolumn{4}{|c|}{\begin{tabular}{|ll} 
Impact Key \\
$+++/--$ & High Positive/Negative Change \\
$++/--$ & Medium Change \\
$+/-$ & Low Change \\
0 & No / Negligible Change \\
ii & Insufficient Information \\
n/a & Not applicable \\
Duration Key & \\
$* * *$ & Long-term \\
$* *$ & Short-term
\end{tabular}} \\
\hline \multirow[t]{2}{*}{ EGS Categories $^{1}$} & \multicolumn{3}{|c|}{$\begin{array}{c}\text { Biophysical Impacts }{ }^{2} \\
\text { (see impact key) }\end{array}$} & \multicolumn{3}{|c|}{$\begin{array}{l}\text { Beneficiary Impacts }{ }^{3} \\
\text { (see impact key) }\end{array}$} & $\begin{array}{c}\text { Substitutes } \\
\text { Available? }^{4} \\
\text { (yes, no) }\end{array}$ & \multirow[t]{2}{*}{\begin{tabular}{|c|} 
Aggregate \\
Impact Rating \\
(no/negligible, \\
low, med, high) \\
\end{tabular}} & \multirow[t]{2}{*}{$\begin{array}{l}\text { Confidence } \\
\text { Rating }^{6} \\
\text { (low, med, high) }\end{array}$} & \multirow[t]{2}{*}{$\begin{array}{c}\text { EGS in Corps } \\
\text { Federal Interest? } \\
\quad\left(\text { yes }^{*}, \text { no }\right)\end{array}$} \\
\hline & Magnitude & Duration & $\begin{array}{l}\text { Is the impact } \\
\text { substantial? }\end{array}$ & Magnitude & Duration & $\begin{array}{l}\text { Is the impact } \\
\text { substantial? }\end{array}$ & & & & \\
\hline \multicolumn{11}{|l|}{ Ecosystem Sustainability } \\
\hline $\begin{array}{l}\text { Restoration of a portion of } \\
\text { threatened riparian forest to a } \\
\text { self-sustaining state }\end{array}$ & + & *** & Yes & o & $* * *$ & No & No & Low & Medium & Yes \\
\hline $\begin{array}{l}\text { Restoration of a portion of } \\
\text { threatened desert perennial } \\
\text { river to a self-sustaining state }\end{array}$ & + & $* * *$ & Yes & + & $* * *$ & Yes & No & High & Medium & Yes \\
\hline $\begin{array}{l}\text { Viability enhancement of the } \\
\text { Roundtail Chub }\end{array}$ & + & $* * *$ & Yes & + & $* * *$ & Yes & No & High & Medium & Yes \\
\hline $\begin{array}{l}\text { Viability enhancement of the } \\
\text { endangered Southwestern } \\
\text { Willow Flycatcher }\end{array}$ & + & $* * *$ & Yes & 0 & $* * *$ & No & No & Low & Medium & Yes \\
\hline \multicolumn{11}{|l|}{$\begin{array}{l}\text { Natural Hazard Mitigation, } \\
\text { Property \& Infrastructure } \\
\text { Protection, Human Safety }\end{array}$} \\
\hline $\begin{array}{l}\text { Property protection from } \\
\text { flooding }\end{array}$ & o & $* * *$ & No & 0 & $* * *$ & No & No & No/Negligible & Medium & Yes \\
\hline \multicolumn{11}{|l|}{ Recreation } \\
\hline General recreation & + & $* * *$ & Yes & + & $* * *$ & Yes & Yes & Medium & Medium & Yes \\
\hline Birdwatching & + & $* * *$ & Yes & + & $* * *$ & No & No & Low & High & Yes \\
\hline \multicolumn{11}{|l|}{ Aesthetics } \\
\hline $\begin{array}{l}\text { Visual enjoyment by riparian } \\
\text { neighbors }\end{array}$ & + & $* * *$ & No & + & $* * *$ & No & No & No/Negligible & Medium & No \\
\hline
\end{tabular}

Some of the EGS that were rated as having high impact were omitted from the comparison of alternatives because they fell outside authorized project purposes (Step 1.3). In addition, the PDT was not compelled to analyze any incidental EGS effects to support the NEPA process nor to address stakeholder concerns. Incidental EGS benefits may be included to represent the locally preferred plan or as supplementary information, resources permitting. 


\section{Step 4.2 - Applying models or other analytic tools to measure EGS changes}

To conduct an in-depth analysis of the EGS selected for further analysis with the impact evaluation and decision criteria tables (Table 7 and Table 8), the PDT would apply the analytic methods chosen in Step 2.2. Each EGS requires a distinct analysis to establish the necessary linkages between the management measures and potential benefits or harms. However, some models may be reused for multiple EGS if they rely on the same or similar metrics at some point in the causal chain.

As analysis proceeds, the PDT would identify any EGS that lack sufficient data and understanding for robustly quantifying changes due to the project. To overcome data limitations, the team has a choice of relying on the conceptual models to qualitatively judge likely magnitude of impacts for these EGS or eliminating them entirely from consideration.

\section{Case Study Example Box. Step 4.2 - Plan evaluation by measuring EGS changes}

For the case study, the services that have been carried forward for alternatives analysis (from Step 1.3) are Ecosystem Sustainability, Natural Hazard Damage Reduction/Mitigation, and Recreation. Other EGS models are applied to the tentatively selected plan only (Step 6).

\section{Applying response function models to estimate ecological outcomes}

The PDT uses the models selected in Step 2.2 to generate the empirical response functions for the alternatives, as illustrated in Tables 25-31. Response functions are then used to evaluate the ecological outcome metrics for the set of management measures in the FWOP and each alternative.

For the metric of downstream flooding intensity and frequency, the PDT uses the HEC-RAS and HECGeoRas model outputs to estimate the reduction in flooded area for the town of Springfield (Table 25). Modeling suggests that the primary benefits due to the project would be to reduce the area flooded and depth of flooding during high-frequency storms (2-, 5-, and 10-year return intervals).

Table 25. Average annual projected reduction in inundated area for FWOP and alternatives (in Year 50).

\begin{tabular}{|l|c|c|c|c|c|c|}
\hline Metric & FWOP & A & B & C & D & E \\
\hline $\begin{array}{l}\text { Flooding intensity and } \\
\text { frequency - average annual } \\
\text { change in inundated area }\end{array}$ & $\begin{array}{c}\text { No } \\
\text { change }\end{array}$ & $\begin{array}{c}\text { No } \\
\text { change }\end{array}$ & $\begin{array}{c}\text { No } \\
\text { change }\end{array}$ & 5 acres & 20 acres & 20 acres \\
\hline
\end{tabular}

For the Roundtail Chub and Southwestern Willow Flycatcher EGS, the team measures the quality-adjusted acres of habitat for each species (i.e., acres that meet the quality thresholds established in Step 2.2) that the FWOP and different alternatives will provide based on the outputs of the Bonar et al. (2010) and Hatten et al. (2010) models (Table 26).

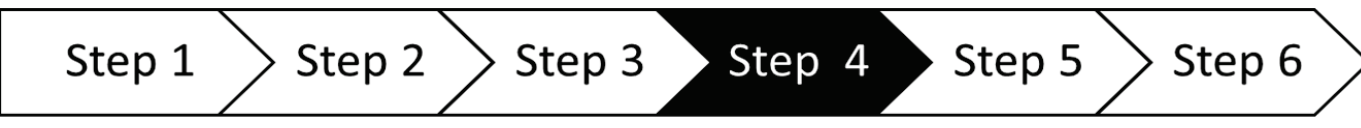




\section{Case Study Example Box. Step 4.2 - Plan evaluation by measuring EGS changes (cont.)}

Table 26. Ecological outcome metrics for riparian and aquatic species for FWOP and alternatives (in Year 50).

\begin{tabular}{|l|c|c|c|c|c|c|}
\hline Metric & FWOP & A & B & C & D & E \\
\hline $\begin{array}{l}\text { Functional habitat for the } \\
\text { Roundtail Chub }\end{array}$ & 5 acres & 5 acres & 20 acres & 20 acres & 40 acres & 40 acres \\
\hline $\begin{array}{l}\text { Functional breeding habitat } \\
\text { for the Southwestern Willow } \\
\text { Flycatcher }\end{array}$ & 14 acres & 14 acres & 14 acres & 108 acres & 131 acres & 131 acres \\
\hline
\end{tabular}

For the metric recruitment of foundation tree species, the PDT uses the HEC-RAS and HEC-EFM models to produce a geospatial map of groundwater levels and uses that map to estimate the area in each project alternative (Table 27 ) that has an annual probability of $80 \%$ or more of meeting the soil moisture criterion necessary for these species to survive.

Table 27. Habitat area conducive to recruitment of foundation tree species for FWOP and alternatives (in Year 50).

\begin{tabular}{|l|c|c|c|c|c|c|}
\hline Metric & FWOP & A & B & C & D & E \\
\hline $\begin{array}{l}\text { Area with sufficient soil } \\
\text { moisture for tree } \\
\text { recruitment }\end{array}$ & 20 acres & 20 acres & 60 acres & 60 acres & 80 acres & 80 acres \\
\hline
\end{tabular}

The rest of the ecological outcome metrics are produced using HGM models from the draft HGM guidebook for Arizona's arid riverine systems and associated riparian habitats. The model results provide the acreage achieving each distinct $\mathrm{FCl}$ within the study area (Tables 28-31). All acreages are included in these tables, even if their corresponding $\mathrm{FCl}$ value is zero, to show how the plan alternatives will affect different parts of the project area. However, when assessing the EGS metrics below, acres that do not meet a quality threshold (determined through expert professional judgment) are not included in the average score for each project.

Table 28. Plant community composition and diversity functional quality and area for FWOP and alternatives (in Year 50).

\begin{tabular}{|c|c|c|c|c|c|c|c|c|c|c|c|c|}
\hline \multicolumn{2}{|c|}{ FWOP } & \multicolumn{2}{c|}{ A } & \multicolumn{2}{c|}{ B } & \multicolumn{2}{c|}{ C } & \multicolumn{2}{c|}{ D } & \multicolumn{2}{c|}{$\mathrm{E}$} \\
\hline FCI & Acres & $F C l$ & Acres & $F C I$ & Acres & $F C l$ & Acres & FCI & Acres & FCI & Acres \\
\hline 0.84 & 20 & 0.84 & 20 & 0.9 & 20 & 0.9 & 20 & 0.9 & 20 & 0.9 & 20 \\
\hline 0 & 180 & 0.3 & 20 & 0.55 & 50 & 0.72 & 180 & 0.82 & 180 & 0.82 & 180 \\
\hline- & - & 0 & 160 & 0 & 130 & - & - & - & - & - & - \\
\hline
\end{tabular}

Table 29. Native tree cover functional quality and area for FWOP and alternatives (in Year 50).

\begin{tabular}{|c|c|c|c|c|c|c|c|c|c|c|c|}
\hline \multicolumn{2}{|c|}{ FWOP } & \multicolumn{2}{|c|}{ A } & \multicolumn{2}{|c|}{ B } & \multicolumn{2}{|c|}{ C } & \multicolumn{2}{|c|}{ D } & \multicolumn{2}{c|}{$\mathrm{E}$} \\
\hline$F C l$ & Acres & $F C l$ & Acres & $F C l$ & Acres & $F C l$ & Acres & $F C l$ & Acres & $F C l$ & Acres \\
\hline 1 & 20 & 1 & 20 & 1 & 20 & 1 & 20 & 1 & 20 & 1 & 20 \\
\hline 0 & 180 & 0 & 180 & 0 & 180 & 0.6 & 180 & 0.93 & 180 & 0.93 & 180 \\
\hline
\end{tabular}




\section{Case Study Example Box. Step 4.2 - Plan evaluation by measuring EGS changes (cont.)}

Table 30. Vegetation density functional quality and area for FWOP and alternatives (in Year 50).

\begin{tabular}{|c|c|c|c|c|c|c|c|c|c|c|c|c|}
\hline \multicolumn{2}{|c|}{ FWOP } & \multicolumn{2}{|c|}{ A } & \multicolumn{2}{c|}{ B } & \multicolumn{2}{c|}{ C } & \multicolumn{2}{c|}{ D } & \multicolumn{2}{c|}{$\mathrm{E}$} \\
\hline FCI & Acres & FCl & Acres & FCl & Acres & FCI & Acres & FCI & Acres & FCI & Acres \\
\hline 1 & 20 & 1 & 20 & 1 & 20 & 1 & 20 & 1 & 20 & 1 & 20 \\
\hline 0 & 180 & 0 & 120 & 0.4 & 100 & 0.75 & 180 & 0.97 & 180 & 0.97 & 180 \\
\hline- & - & - & - & 0 & 80 & - & - & - & - & - & - \\
\hline
\end{tabular}

Table 31. Bird diversity functional quality and area for FWOP and alternatives (in Year 50).

\begin{tabular}{|c|c|c|c|c|c|c|c|c|c|c|c|}
\hline \multicolumn{2}{|c|}{ FWOP } & \multicolumn{2}{c|}{ A } & \multicolumn{2}{c|}{ B } & \multicolumn{2}{c|}{ C } & \multicolumn{2}{c|}{ D } & \multicolumn{2}{c|}{$\mathrm{E}$} \\
\hline$F C l$ & Acres & $F C l$ & Acres & $F C l$ & Acres & $F C l$ & Acres & FCI & Acres & FCI & Acres \\
\hline 1 & 20 & 1 & 20 & 1 & 20 & 1 & 20 & 1 & 200 & 1 & 200 \\
\hline 0 & 180 & 0 & 180 & 0 & 180 & 0.75 & 180 & - & - & - & - \\
\hline
\end{tabular}

\section{Ecosystem service evaluation and benefit functions}

Using the models and techniques from Step 2.2, the team measures benefits using non-monetary benefit indicators for the ecosystem sustainability and recreation EGS and uses both monetary and non-monetary benefit measures for the property flood damage mitigation EGS.

\section{Ecosystem sustainability - Non-use services of riparian and aquatic ecosystems and species}

Using output of the HGM models, the PDT quantifies the EGS metrics identified in Step 1.2 and in Figure 11. These metrics complement the ecological outcome metrics and are used to describe the potential benefits derived from the non-use services of the project.

\section{Riparian ecosystems}

To describe the relative importance of restoring the cottonwood-willow riparian forest, the PDT documents that the ecosystem extent appears close to a (theoretical) threshold that may reduce its chances for persistence Figure $14 .{ }^{1}$ Studies reveal that in the ecoregion only $10 \%$ of the native riparian areas remain (Noss et al. 1995), due to invasion by non-native plants, water withdrawals, and land conversion.

The PDT quantifies the quality-adjusted area of this ecosystem at risk by combining the two ecological outcome metrics for this EGS into an index representing long-term viability for the ecosystem. The PDT uses only the acres that have a score of at least 0.5 for the composition and diversity metric (Table 28) and only counts acres with sufficient soil moisture for tree recruitment (Table 29). The team multiplies the acres meeting both criteria by $\mathrm{FCl}$ scores to generate the total quality-adjusted acres.

To further distinguish the importance of this restoration project, the team measures the proportion of ecosystem cover that will be added and the availability of substitute sites. The proportional change in the ecosystem extent is measured by dividing the area being added by the extent of the current ecosystem, as calculated within a GIS using available land cover data (USGS 2011). ${ }^{2}$ To calculate the availability of substitute restoration sites, the PDT maps condition of the riparian ecosystem and relates condition to areas that might be feasibly restored, using data from the National Gap Analysis Program and a master's thesis from a nearby university.

1 PDTs need to evaluate the appropriateness of using thresholds, given that they may not be meaningful for all ecosystems or species. In particular, if species are able to adapt to altered systems, then the use of thresholds of historic habitat extent may be inappropriate (Hobbs et al. 2009).

2 To estimate total ecosystem acreage remaining, the PDT identified extent of a group of related riparian ecosystems (Warm Desert Riparian Woodland and Shrubland) and then screened for the sub-set of these areas most likely to contain cottonwood-willow cover, based on additional data sources.

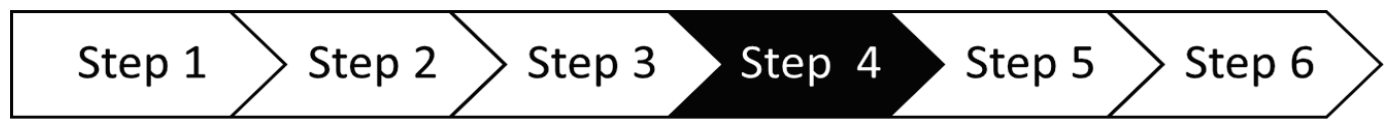




\section{Case Study Example Box. Step 4.2 - Plan evaluation by measuring EGS changes (cont.)}

The PDT determines that approximately $60 \%$ of the ecosystem is difficult to restore because it contains high coverage of tamarisk, is within 1 mile downstream of tamarisk, or is threatened by water withdrawals that will cause the streams to become ephemeral rather than perennial. The PDT also finds that $20 \%$ is relatively undisturbed and needs no restoration. Therefore, the total area of restorable (moderately impacted) cottonwood-willow forest, including the project site, is approximately $20 \%$ of the remaining ecosystem (21,800 acres) Table 32.

\section{Riparian species}

The PDT records that the Southwestern Willow Flycatcher has been federally listed as endangered since 1995 , to demonstrate that it is a conservation priority. To assess the contribution of the project to this species' viability, the PDT evaluates the project's contribution towards a target of a minimum of 1,950 flycatcher territories in the United States. This target was created by the USFWS to fulfill a goal of supporting long-term population viability (Finch et al. 2002). The most recent survey of the birds in 2007 estimated that there were 1,299 territories (Durst et al. 2008). The PDT uses an average territory size of 6.4 acres (2.6 hectares) from Hatten et al. (2010) and the acres of flycatcher habitat projected by the response function model to estimate the territories for the FWOP and alternatives. They also estimate the percentage of the USFWS goal achieved at the end of the analysis period (Table 32).

Table 32. EGS metrics for riparian non-use services for FWOP and alternatives (end of 50-year analysis period).

\begin{tabular}{|l|c|c|c|c|c|c|}
\hline Metric & FWOP & A & B & C & D & E \\
\hline $\begin{array}{l}\text { Quality-screened acres of } \\
\text { cottonwood-willow forest with } \\
\text { adequate soil moisture for } \\
\text { foundation tree recruitment }\end{array}$ & 16.8 & 16.8 & 45.5 & 60 & 60 & 60 \\
\hline $\begin{array}{l}\text { Percentage of the total ecosystem } \\
\text { (109,000 acres) that will occur } \\
\text { within the project area }\end{array}$ & $0.02 \%$ & $0.02 \%$ & $0.04 \%$ & $0.06 \%$ & $0.06 \%$ & $0.06 \%$ \\
\hline $\begin{array}{l}\text { Percentage of total restorable } \\
\text { ecosystem (21,800 acres) that will } \\
\text { occur within the project area }\end{array}$ & $0.08 \%$ & $0.08 \%$ & $0.21 \%$ & $0.28 \%$ & $0.28 \%$ & $0.28 \%$ \\
\hline $\begin{array}{l}\text { Contribution to population viability } \\
\text { of Southwestern Willow Flycatcher } \\
\text { in terms of number of territories }\end{array}$ & 2 & 2 & 2 & 17 & 20 & 20 \\
\hline $\begin{array}{l}\text { Percent of USFWS goal for } \\
\text { Southwestern Willow Flycatcher } \\
\text { territories achieved }\end{array}$ & $0.11 \%$ & $0.11 \%$ & $0.11 \%$ & $0.87 \%$ & $1.05 \%$ & $1.05 \%$ \\
\hline
\end{tabular}

\section{Aquatic ecosystems and species}

As with the riparian ecosystem, the PDT first documents that the aquatic ecosystem and species being used in metrics are conservation priorities. They find that the Desert Fish Habitat Partnership, a national consortium of federal, state, and local stakeholders, has identified both the river ecosystems and the Roundtail Chub as conservation priorities (Desert Fish Habitat Partnership Workgroup 2008). The Roundtail Chub has also been designated as a sensitive species by both the U.S. Forest Service and the Bureau of Land Management (Arizona Game and Fish Department 2006). Furthermore, the Nature Conservancy has recognized the importance of conserving and restoring Arizona's desert rivers (The Nature Conservancy's Center for Science and Public Policy 2018). 


\section{Case Study Example Box. Step 4.2 - Plan evaluation by measuring EGS changes (cont.)}

To assess the quality-adjusted area of the restored aquatic system, the PDT uses the ecological outcome metric, habitat quality for the threatened Roundtail Chub, to identify the percentage of perennial river ecosystems in the state that would fall within the project area (Table 33). The PDT uses the Arizona Statewide Freshwater Assessment (The Nature Conservancy's Center for Science and Public Policy 2010) and a GIS analysis that is similar to that used for terrestrial ecosystems. Of the remaining perennial rivers in the state, the PDT identifies $34 \%$ as restorable; $17 \%$ as not needing restoration; $49 \%$ are deemed unrestorable due to invasive plant introductions, water withdrawals, and channelization.

To estimate the project's contribution to the population viability of the Roundtail Chub, the PDT compares the current and historic ranges. A literature review reveals that the species inhabits only $32 \%$ of its historic range in the Lower Colorado River Basin (Voeltz 2002), which is the enclosing watershed for the study area. Although $32 \%$ is above the minimal threshold considered necessary for viability, it is still in a range consistent with substantial long-term risk of extirpation and therefore the PDT assesses that the added habitat is important to long-term viability (consistent with Figure 14 in Step 1.3).

Table 33. EGS metrics for aquatic non-use services for FWOP and alternatives (end of 50-year analysis period).

\begin{tabular}{|l|c|c|c|c|c|c|}
\hline Metric & FWOP & A & B & C & D & E \\
\hline $\begin{array}{l}\text { Quality-adjusted area of high } \\
\text { functioning desert perennial river } \\
\text { ecosystems }\end{array}$ & 5 acres & 5 acres & 20 acres & 20 acres & 40 acres & 40 acres \\
\hline $\begin{array}{l}\text { Percentage of total high functioning } \\
\text { perennial river ecosystems in Arizona } \\
(3,366 \text { miles) that will occur within } \\
\text { the project area }\end{array}$ & $0.02 \%$ & $0.02 \%$ & $0.10 \%$ & $0.10 \%$ & $0.20 \%$ & $0.20 \%$ \\
\hline $\begin{array}{l}\text { Percentage of total restorable desert } \\
\text { perennial river ecosystems that will } \\
\text { occur within the project area }\end{array}$ & $0.07 \%$ & $0.07 \%$ & $0.29 \%$ & $0.29 \%$ & $0.58 \%$ & $0.58 \%$ \\
\hline $\begin{array}{l}\text { Contribution to the viability of } \\
\text { Roundtail Chub - percentage } \\
\text { contribution to total historic habitat } \\
\text { within the Lower Colorado River Basin }\end{array}$ & $0.09 \%$ & $0.09 \%$ & $0.36 \%$ & $0.36 \%$ & $0.73 \%$ & $0.73 \%$ \\
\hline
\end{tabular}

\section{Natural hazard mitigation: Property flood risk mitigation}

Using the geospatial results of the ecological outcome analysis and the town's tax assessment data, the PDT uses GIS tools to estimate the decrease in number of properties at risk of flooding and the associated average annual damage costs avoided for the 50-year analysis period. The estimates in Table 34 represent the median of the potential range of impacts that were generated as part of the uncertainty analysis. ${ }^{1}$ The PDT uses the number of properties affected as the non-monetary EGS metric and monetary values of property damage avoided (minus the costs of cropland leases forfeit due to increased risk of flooding) to directly represent social benefits. This value is the only monetized benefit used in plan evaluation and comparison.

1 Uncertainty analysis techniques will vary by the type of EGS, but in all cases, a range of values is generated to represent different assumptions about input variables and/or system dynamics.

\begin{tabular}{l|l|l|l|l|}
\hline Step $1>$ Step $2>$ Step $3>$ Step $4>$ Step 6 \\
\hline
\end{tabular}




\section{Case Study Example Box. Step 4.2 - Plan evaluation by measuring EGS changes (cont.)}

Table 34. EGS and benefit metrics for property flood risk mitigation (average annual values).

\begin{tabular}{|l|c|c|c|c|c|c|}
\hline Metric & FWOP & A & B & C & D & E \\
\hline $\begin{array}{l}\text { Number of private } \\
\text { properties (businesses } \\
\text { and residences) in } \\
\text { affected area }\end{array}$ & 0 & 0 & 0 & 20 & 81 & 81 \\
\hline $\begin{array}{l}\text { Private property } \\
\text { damage avoided } \\
(2014 \$)\end{array}$ & 0 & 0 & 0 & $\$ 5.4 \mathrm{M}$ & $\$ 25.5 \mathrm{M}$ & $\$ 25.5 \mathrm{M}$ \\
\hline $\begin{array}{l}\text { Public property } \\
\text { damage avoided } \\
(2014 \$)\end{array}$ & 0 & 0 & 0 & 0 & $\$ 12.0 \mathrm{M}$ & $\$ 12.0 \mathrm{M}$ \\
\hline $\begin{array}{l}\text { Municipal cleanup } \\
\text { costs avoided (2014\$) }\end{array}$ & 0 & 0 & 0 & $\$ 37,000$ & $\$ 148,000$ & $\$ 148,000$ \\
\hline
\end{tabular}

\section{Recreation}

General recreation. To identify the number of residents who would be likely to use the site for general recreation (including walking, hiking, running, dog-walking, and other activities), the PDT uses the results of a recent city survey. The survey reveals that the trails would only receive substantial use by recreators if the surrounding forest has sufficient tree canopy cover to shade the trail and if trails with shade were at least 4 miles long.

The PDT matches survey results of canopy closure to HGM metrics of native tree cover to estimate that an $\mathrm{FCl}$ score of 0.4 or greater would provide the minimum desirable tree cover for the trail. The PDT estimates all acres along the 5-mile trail with a score of 0.4 or greater and multiplies that acreage by its associated $\mathrm{FCl}$ score (Table 29) to assess total trail length meeting user preferences (Table 35). For the alternatives that meet the two criteria (C, D, and E), they estimate the number of recreators and annual recreation days for general recreation (Table 36) based the survey results.

Birdwatching. The PDT consults with birders in the area and concludes that a site with a minimum of 100 medium- to high-quality acres is consistent with providing the desired level of bird diversity for birdwatching. The PDT multiplies the number of strata variable index scores by the relevant acres (Table 31) to identify which alternatives provide the required quality-adjusted acres and assigns yes or no to represent whether this criterion has been achieved (Table 35).

Birdwatching participation was quickly estimated in Step 1.3 to fill out the Impact Evaluation table. At this point, the PDT aims to refine that calculation using site-specific data. To estimate birdwatching participation for the alternatives that provide sufficient bird diversity, the PDT looks for birding participation data for parks in the city. Finding none, they estimate the number of user days by developing a replicable GIS analysis method that is based on three types of data for the region: residential population distribution, average driving distance by recreator type (specific to this geographic region), and average state-wide participation rate in birdwatching away from home, as described in (Wainger et al. 2015). ${ }^{1}$

1 If the population living near a site does not reflect average state demographics (e.g., higher poverty than state average), it will be more accurate to estimate participation by individual demographic groups (e.g., Mazzotta et al. 2015).

Step $1>$ Step $2>$ Step $3>$ Step $4>$ Step $5>$ Step 6


Case Study Example Box. Step 4.2 - Plan evaluation by measuring EGS changes (cont.)

Table 35. Do the plan alternatives meet EGS user preferences?

\begin{tabular}{|l|c|c|c|c|c|c|}
\hline EGS & FWOP & A & B & C & D & E \\
\hline General recreation & No & No & No & Yes & Yes & Yes \\
\hline Birdwatching & No & No & No & Yes & Yes & Yes \\
\hline
\end{tabular}

Table 36. EGS metrics of general recreation for the FWOP and alternatives (average annual).

\begin{tabular}{|l|c|c|c|c|c|c|}
\hline Metric & FWOP & A & B & C & D & E \\
\hline $\begin{array}{l}\text { Number of general } \\
\text { recreation users }\end{array}$ & 0 & 0 & 0 & 33,000 & 33,000 & 33,000 \\
\hline $\begin{array}{l}\text { Annual general } \\
\text { recreation user } \\
\text { days* }\end{array}$ & 0 & 0 & 0 & $3.4 \mathrm{M}$ & $3.4 \mathrm{M}$ & $3.4 \mathrm{M}$ \\
\hline $\begin{array}{l}\text { Number of } \\
\text { birdwatchers }\end{array}$ & 0 & 0 & 0 & 19,000 & 19,000 & 19,000 \\
\hline $\begin{array}{l}\text { Annual } \\
\text { birdwatching days* }\end{array}$ & 0 & 0 & 0 & $1.7 \mathrm{M}$ & $1.7 \mathrm{M}$ & $1.7 \mathrm{M}$ \\
\hline
\end{tabular}

* General recreation and birdwatching days are defined as the number of days in a year that recreators partake in the activity for any amount of time.

Aggregate benefits assessment

After evaluating the individual benefit metrics for each service, the analytic team decides which metrics are appropriate to combine. Methods for aggregation were discussed in Step 2.2 for non-monetary benefit metrics. For monetized values, teams must decide whether values are sufficiently distinct before combining to avoid double-counting benefits. 


\section{Case Study Example Box. Step 4.2.1 - Aggregate benefits assessment (cont.)}

To comprehensively assess benefits due to the project over the entire 50-year analysis period, the PDT follows USACE guidance to construct a timeline of baseline conditions (FWOP) and changes generated by each alternative. For an EGS analysis, the timeline of conditions will need to reflect biophysical recovery or degradation (relative to reference condition) and any substantial changes to beneficiaries (e.g., reflecting changes in demand as a function of system quality or population growth). For the case study example, the timelines are used to calculate average annual conditions, project conditions at the end of the project, and total benefits over the 50-year period, which are all used to compare alternatives to the FWOP.

The annual average benefit calculations over the 50-year period include projected population and business growth in the ecosystem service areas. The PDT estimates population projections by projecting the current population growth rate into the future. New residential and business growth within the floodplain is projected to be minor, given that new zoning will restrict new permits but not prevent use of existing permits. The PDT asks the Springfield planning and zoning office to provide an estimate of expected growth within the delineated floodplain.

The PDT constructs the timeline of conditions for the alternatives by generating conceptual restoration recovery functions. In most cases, the EGS metrics are expected to increase linearly and rapidly in the period immediately following the completion of restoration measures and then level off. For simplicity, the PDT uses a hockey stick function to reflect these two different rates of recovery through time (Figure 16). For each EGS metric, the PDT picks three parameters: (1) the current condition of the EGS metric; (2) the year at which 80\% of the maximum EGS outcomes are expected to be achieved (e.g., year 30 in Figure 16); and (3) the maximum percentage of benefits expected at the site. Two lines connect these three points to create the hockey stick function.

Figure 16. Timeline of restoration recovery for 50-year analysis period.

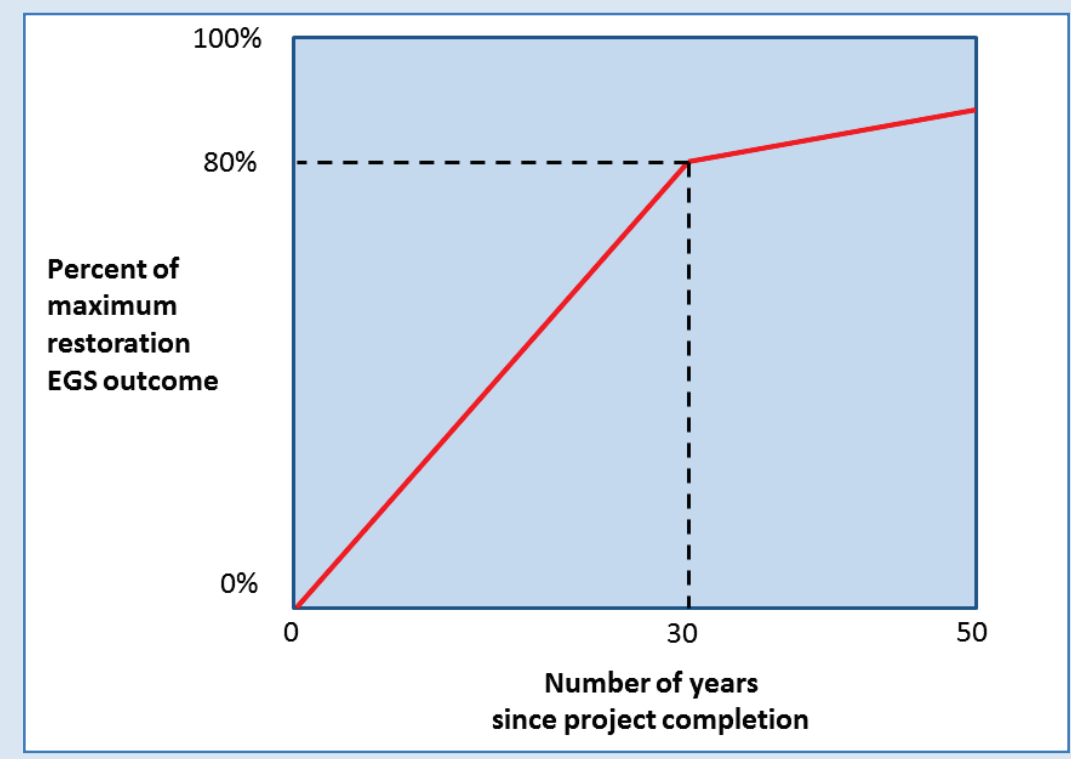

Through the timeline analysis, the PDT estimates changes in benefits due to the project, using key EGS metrics for use and non-use service (Table 37 and Table 38). For the flood damage avoided metrics, which are measured in 2014 dollars, a discount rate of $3.375 \%$ is used to assess the present value ${ }^{1}$ of damages avoided. Non-monetary metrics are not discounted, to be consistent with the most recent guidance (USACE 2000, App E). PDTs should consult current guidance to ensure current methods are applied.

1 Present value is the value of a future stream of costs and benefits that are converted to current dollars (e.g., 2014 dollars) to better compare the equivalence of alternative investments when the stream of services is delivered over a long time period. The discount rate for use by the USACE is specified in law and is provided in an economic guidance memo (CECW-P 2014).

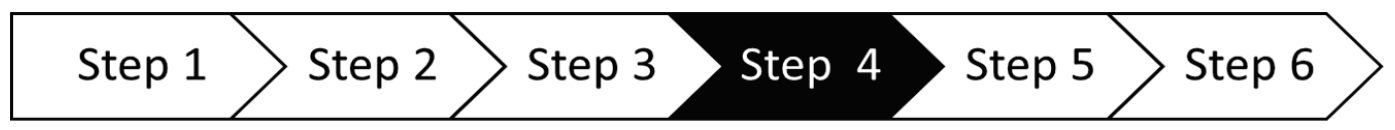




\section{Case Study Example Box. Step 4.2.1 - Aggregate benefits assessment (cont.)}

The final metrics shown in the tables cannot be summed because benefits overlap across metrics. For example, some of the value of protecting an ecosystem lies in its production of habitat benefits for scarce species.

Table 37. Summary of benefits due to project for use services by project alternative.

\begin{tabular}{|c|c|c|c|c|c|c|}
\hline $\begin{array}{l}\text { EGS Metric/Social } \\
\text { Benefit metric }\end{array}$ & Value & A & B & $\mathrm{C}$ & D & $E$ \\
\hline \multirow{2}{*}{$\begin{array}{l}\text { Private properties } \\
\text { protected from } \\
\text { flooding }\end{array}$} & $\begin{array}{l}\text { Average } \\
\text { annual }\end{array}$ & 0 & 0 & 13 & 52 & 52 \\
\hline & $\begin{array}{c}\text { Year } 50 \\
\text { annual }\end{array}$ & 0 & 0 & 20 & 81 & 81 \\
\hline \multirow{3}{*}{$\begin{array}{l}\text { Private property } \\
\text { damage avoided } \\
(2014 \$)^{\star}\end{array}$} & $\begin{array}{l}\text { Average } \\
\text { annual }\end{array}$ & $\$ 0$ & $\$ 0$ & $\$ 797,800$ & $\$ 3.8 \mathrm{M}$ & $\$ 3.8 \mathrm{M}$ \\
\hline & $\begin{array}{l}\text { Year } 50 \\
\text { annual }\end{array}$ & $\$ 0$ & $\$ 0$ & $\$ 183,300$ & $\$ 866,700$ & $\$ 866,700$ \\
\hline & Total & $\$ 0$ & $\$ 0$ & $\$ 39.9 \mathrm{M}$ & $\$ 188.4 \mathrm{M}$ & $\$ 188.4 \mathrm{M}$ \\
\hline \multirow{3}{*}{$\begin{array}{l}\text { Public property } \\
\text { damage avoided } \\
(2014 \$)^{\star}\end{array}$} & $\begin{array}{l}\text { Average } \\
\text { annual }\end{array}$ & $\$ 0$ & $\$ 0$ & $\$ 0$ & $\$ 1.8 \mathrm{M}$ & $\$ 1.8 \mathrm{M}$ \\
\hline & $\begin{array}{l}\text { Year } 50 \\
\text { annual }\end{array}$ & $\$ 0$ & $\$ 0$ & $\$ 0$ & $\$ 407,400$ & $\$ 407,400$ \\
\hline & Total & $\$ 0$ & $\$ 0$ & $\$ 0$ & $\$ 88.7 \mathrm{M}$ & $\$ 88.7 \mathrm{M}$ \\
\hline \multirow{3}{*}{$\begin{array}{l}\text { Municipal cleanup } \\
\text { costs avoided } \\
(2014 \$)^{*}\end{array}$} & $\begin{array}{l}\text { Average } \\
\text { annual }\end{array}$ & $\$ 0$ & $\$ 0$ & $\$ 5,500$ & $\$ 21,900$ & $\$ 21,900$ \\
\hline & $\begin{array}{l}\text { Year } 50 \\
\text { annual }\end{array}$ & $\$ 0$ & $\$ 0$ & $\$ 1,300$ & $\$ 5,000$ & $\$ 5,000$ \\
\hline & Total & $\$ 0$ & $\$ 0$ & $\$ 273,000$ & $\$ 1.1 \mathrm{M}$ & $\$ 1.1 \mathrm{M}$ \\
\hline \multirow{3}{*}{$\begin{array}{l}\text { General recreation } \\
\text { days }\end{array}$} & $\begin{array}{l}\text { Average } \\
\text { annual }\end{array}$ & 0 & 0 & $2.2 \mathrm{M}$ & $2.2 \mathrm{M}$ & $2.2 \mathrm{M}$ \\
\hline & $\begin{array}{l}\text { Year } 50 \\
\text { annual }\end{array}$ & 0 & 0 & $3.4 \mathrm{M}$ & $3.4 \mathrm{M}$ & $3.4 \mathrm{M}$ \\
\hline & Total & 0 & 0 & $109.8 \mathrm{M}$ & $109.8 \mathrm{M}$ & $109.8 \mathrm{M}$ \\
\hline \multirow{3}{*}{ Birdwatching days } & $\begin{array}{c}\text { Average } \\
\text { annual }\end{array}$ & 0 & 0 & $1.1 \mathrm{M}$ & $1.1 \mathrm{M}$ & $1.1 \mathrm{M}$ \\
\hline & $\begin{array}{l}\text { Year } 50 \\
\text { annual }\end{array}$ & 0 & 0 & $1.7 \mathrm{M}$ & $1.7 \mathrm{M}$ & $1.7 \mathrm{M}$ \\
\hline & Total & 0 & 0 & $55.9 \mathrm{M}$ & $55.9 \mathrm{M}$ & $55.9 \mathrm{M}$ \\
\hline
\end{tabular}




\section{Case Study Example Box. Step 4.2.1 - Aggregate benefits assessment (cont.)}

Table 38. Summary of benefits due to project for non-use services (average annual and Year 50 total).

\begin{tabular}{|c|c|c|c|c|c|c|}
\hline EGS Metric & Value & A & B & C & D & $E$ \\
\hline \multirow{2}{*}{$\begin{array}{l}\text { Quality-screened acres of } \\
\text { cottonwood-willow forest }\end{array}$} & $\begin{array}{l}\text { Average } \\
\text { annual }\end{array}$ & 0 & 18 & 28 & 28 & 28 \\
\hline & Year 50 Total & 0 & 28.7 & 43.2 & 43.2 & 43.2 \\
\hline \multirow{2}{*}{$\begin{array}{l}\text { Percentage of total cottonwood- } \\
\text { willow forest ecosystem that } \\
\text { will occur within the project } \\
\text { area }\end{array}$} & $\begin{array}{l}\text { Average } \\
\text { annual }\end{array}$ & $0 \%$ & $0.01 \%$ & $0.03 \%$ & $0.03 \%$ & $0.03 \%$ \\
\hline & Year 50 Total & $0 \%$ & $0.02 \%$ & $0.04 \%$ & $0.04 \%$ & $0.13 \%$ \\
\hline \multirow{2}{*}{$\begin{array}{l}\text { Percentage of restorable } \\
\text { cottonwood-willow forest } \\
\text { ecosystem that will occur within } \\
\text { the project area }\end{array}$} & $\begin{array}{l}\text { Average } \\
\text { annual }\end{array}$ & $0 \%$ & $0.08 \%$ & $0.13 \%$ & $0.13 \%$ & $0.13 \%$ \\
\hline & Year 50 Total & $0 \%$ & $0.13 \%$ & $0.20 \%$ & $0.20 \%$ & $0.20 \%$ \\
\hline \multirow{2}{*}{$\begin{array}{l}\text { Percentage achieved of USFWS } \\
\text { goal for Southwestern Willow } \\
\text { Flycatcher territories }\end{array}$} & $\begin{array}{l}\text { Average } \\
\text { annual }\end{array}$ & $0 \%$ & $0 \%$ & $0.48 \%$ & $0.60 \%$ & $0.60 \%$ \\
\hline & Year 50 Total & $0 \%$ & $0 \%$ & $0.75 \%$ & $0.94 \%$ & $0.94 \%$ \\
\hline \multirow{2}{*}{$\begin{array}{l}\text { Quality-adjusted acres of high } \\
\text { functioning desert perennial } \\
\text { rivers }\end{array}$} & $\begin{array}{l}\text { Average } \\
\text { annual }\end{array}$ & 0 & 10 & 10 & 22 & 22 \\
\hline & Year 50 Total & 0 & 15 & 15 & 35 & 35 \\
\hline \multirow{2}{*}{$\begin{array}{l}\text { Percentage of total high } \\
\text { functioning perennial rivers in } \\
\text { Arizona that will occur within } \\
\text { the project area }\end{array}$} & $\begin{array}{l}\text { Average } \\
\text { annual }\end{array}$ & $0 \%$ & $0.05 \%$ & $0.05 \%$ & $0.12 \%$ & $0.12 \%$ \\
\hline & Year 50 Total & $0 \%$ & $0.08 \%$ & $0.08 \%$ & $0.18 \%$ & $0.18 \%$ \\
\hline \multirow{2}{*}{$\begin{array}{l}\text { Percentage of restorable desert } \\
\text { perennial rivers that will occur } \\
\text { within the project area }\end{array}$} & $\begin{array}{l}\text { Average } \\
\text { annual }\end{array}$ & $0 \%$ & $0.14 \%$ & $0.14 \%$ & $0.33 \%$ & $0.33 \%$ \\
\hline & Year 50 Total & $0 \%$ & $0.22 \%$ & $0.22 \%$ & $0.51 \%$ & $0.51 \%$ \\
\hline \multirow{2}{*}{$\begin{array}{l}\text { Contribution to the population } \\
\text { viability of Roundtail Chub - } \\
\text { total habitat within the Lower } \\
\text { Colorado River Basin }\end{array}$} & $\begin{array}{l}\text { Average } \\
\text { annual }\end{array}$ & $0 \%$ & $0.17 \%$ & $0.17 \%$ & $0.41 \%$ & $0.41 \%$ \\
\hline & Year 50 Total & $0 \%$ & $0.27 \%$ & $0.27 \%$ & $0.64 \%$ & $0.64 \%$ \\
\hline
\end{tabular}

* Monetary values are discounted at a rate of 3.375\%; non-monetary metrics are not discounted.

\section{Risk-informed decision-making}

Several types of risks can affect a project's effect on an EGS and the ability of a site to maintain a stream of benefits into the future. The USACE risk register identifies three types of risk: study risk (analytical error, study delays, study cost increase, poor planning decision); implementation risk (schedule and cost of implementation, redesign); and outcome risk (hazard risk and project performance risk) (USACE 2014). All of these risks apply to EGS analysis, but EGS outcomes will be particularly sensitive to outcome risk. Conditions and future changes at the watershed or landscape scale (such as future land development, water withdrawals or sea level rise) will influence the ability of a given site to function appropriately in the future. Non-use EGS related to supporting species, in 


\begin{abstract}
particular, can be dependent on having complementary landscape features needed to attract and support wildlife. Since these complementary landscape conditions are often outside the project footprint, they may be largely beyond the control of the PDT. However, the PDT can consider such risks during planning through sensitivity analyses and other approaches and can evaluate options to manage risk (e.g., methods described in Salafsky et al. 2008).
\end{abstract}

\title{
Case Study Example Box. Step 4.2.2 - Risk-informed decision-making
}

In this project, the PDT identifies major risks stemming from changes in land use adjacent to the riparian project, invasive species spread, water withdrawals, and extreme weather events early in the project development (especially drought). The PDT also identifies a management risk that the planned flow modifications at the dam might not be implemented, given that dam flow schedules must be approved by many partners. The PDT manages these risks in several ways. During design, the PDT uses a sufficiently wide riparian area to buffer any incompatible land uses. They add irrigation channels that will consistently provide water to the riparian areas and thus mitigate against both drought and the inability to achieve the ideal environmental flows via dam management. As a result, the alternatives with irrigation channels $(C, D$, and $E)$ are expected to be more robust to these risks than other alternatives.

To manage the risks that depend on local governance (land use management, water withdrawals, and invasive species control), the PDT meets with local government officials and NGO representatives and prepares a report that details the conditions that would be most supportive of the project over the long run. The partners commit to promoting these conditions through zoning, permitting decisions, and invasive species management. If the PDT were not able to manage risk in this manner, they would revisit the benefits/damage estimation metrics and adjust the future values, in proportion to the future performance risk. For additional information and resources concerning risk, the reader is directed to the USACE Risk Analysis Gateway (http://www.corpsriskanalysisgateway.us/index.cfm). 


\section{Step 5 - Compare Plans}

The goal of Step 5 of the planning process is to compare the different plan alternatives with one another in terms of how well they meet project goals and their relative costs (USACE 2000). Since the inclusion of EGS does not require substantial alterations to standard USACE procedures for this step, this section only covers the elements that do change. More details on comparing plan alternatives can be found in Planning Guidance Notebook (USACE 2000).

As discussed in the Introduction of this report, changes in EGS per plan can be described, quantified, or monetized, as appropriate. Decision analysis approaches to compare plans in terms of EGS include quantitative communication, MCDA or related approaches, and benefit aggregation and tradeoff analysis (Figure 5). Planners would follow USACE guidance for reporting

Section Highlights

- EGS may alter plan comparison because they introduce a wide range of benefit measures (in different measurement units) that require that either key effects be selected or that multiple effects be summarized or aggregated to effectively support decisions.

- For multi-use projects or projects with significant tradeoffs among EGS and other types of goods and services, all benefit and harms would need to be compared at this stage. This report aims to incorporate EGS into decision support but does not supplant prior guidance for incorporating all relevant effects.

- The case study summarizes an MCDA process and outputs as one approach to handle the large number of metrics produced and demonstrates that the MCDA results can generate an aggregate benefit metric for use in CEA/ICA.

EGS impacts and comparing them to other types of benefits and harms, as part of plan comparison (USACE 2000; White House Council on Environmental Quality 2013).

However, an EGS analysis may provide distinct challenges due to the difficulty of using multiple metrics to compare benefits and tradeoffs, either among EGS or among EGS and other types of goods and services. If metrics are kept separate, results will be transparent and allow decisionmakers to consider each metric's relevance to the decision-making process. However, it may be difficult for users to consider many divergent outcomes simultaneously. Combining metrics into an overall index score is an approach that reduces complexity but it can also obscure important details and create sources of bias. Therefore, teams may need discretion in deciding which approach works best for their situation.

MCDA is often recommended as an approach that promotes equal consideration of benefits measured with monetary and non-monetary metrics. For projects that effect a mix of non-use and use EGS (e.g., some 


\section{mixed-use projects), tools that consider preferences of all stakeholders may be the only way to weigh tradeoffs among outcomes measured with mixed units. Future guidance will need to be developed to establish acceptable methods for combining mixed unit indicators.}

\section{Case Study Example Box. Step 5 - Comparing plan alternatives (cont.)}

Because the PDT has used a wide variety of ecological outcome and EGS metrics to assess the potential benefits of alternatives, they compare the pros and cons of presenting (1) the individual metrics, (2) a statistically developed aggregate index, or (3) an MCDA index weighted either in terms of mission priorities or overall public welfare (further described in USACE, Institute for Water Resources, and CDM, Inc. 2010).

In this case study, the EGS are almost all complementary because actions to increase one benefit increase all EGS. The one exception was the small loss of cropland value due to local flooding. (This loss was much smaller than the flood risk mitigation benefits to Springfield and thus is captured as a small reduction to the aggregate value of flood risk damage avoided.) As a result of the complementarity of most effects, the PDT decides that a statistically aggregate index or MCDA would both be acceptable for comparing alternatives, since it would not obscure tradeoffs among EGS.

The PDT eventually chooses to conduct an MCDA so that the results will clearly represent benefits in terms of meeting planning objectives. ${ }^{1}$ This approach differs from using MCDA to represent social benefits because it will include input from the PDT only and not the general public. ${ }^{2}$ The PDT coordinates with the vertical team and decides how to apply the MCDA including who will participate and whether an outside MCDA specialist will be used to guide and facilitate the process. ${ }^{3}$

The MCDA group first constructs their objectives hierarchy to represent goals and to nest the relevant ecological outcome and EGS metrics under those goals. Only those EGS outcomes that are within the project authorities and mission areas are used in the hierarchy. During the creation of the objective hierarchy, participants may wish to consider changes in non-EGS goods and services, such as land available for commercial development that may be affected by the restoration activities to reveal the full suite of tradeoffs.

The hierarchy created by the MCDA group uses a single overarching goal of maximize ecological restoration benefits. This goal is broken down into general EGS categories and then the more specific EGS that were included in the planning objectives. For example, the second level of the hierarchy would include restore ecosystem sustainability and provide recreational opportunities. At the next level down in the hierarchy, these goals would be represented by more specific EGS sub-goals. For example, general recreation and birdwatching would nest under the goal of provide recreational opportunities.

${ }^{1} \mathrm{~A}$ full description of MCDA is beyond the scope of this document. It will likely be necessary to engage an experienced MDCA practitioner to conduct such an assessment. While this section provides a very simple example, a variety of sophisticated MCDA techniques have been designed to elicit participant preferences and to assign weights to different criteria in ways that promote consistency and rigor (Mendoza and Martins 2006).

2 To represent social benefits with MCDA, the PDT would need to form a panel representing all interested parties and include all goals, not just the EGS within project authorities and mission areas. This approach could require a Federal Advisory Committee Act (FACA) review.

3 When MCDA is conducted with members of the public (to generate measures of social benefits), the use of an unbiased and experienced facilitator is useful for ensuring that the objectives hierarchy fairly accounts for all views.

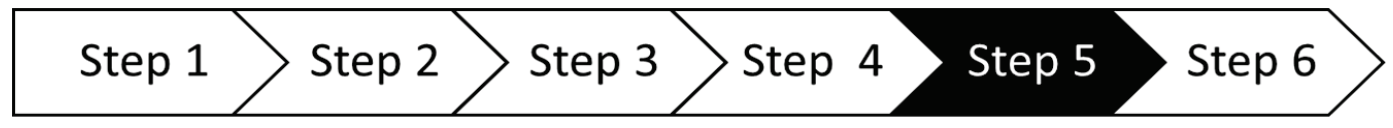




\section{Case Study Example Box. Step 5 - Comparing plan alternatives (cont.)}

At the bottom of the hierarchy are a sub-set of the EGS metrics created in planning Step 4 (Table 39). Metrics are normalized to range from 0 to 1 for easier comparison (Table 39). Next, the participants develop weights (Table 39) that will be used to score each alternative in terms of its ability to meet the project goals. The participants assign weights to goals at every level of the hierarchy by allocating a total of 100 points to represent the relative importance of each goal at that level to the overarching goal. Next, metrics are given weights to represent their relative importance for measuring the EGS benefits. Following MCDA methods, various approaches are used to elicit weights from the group to ensure that they represent goals that are consistent with the authorities and constraints of the project (USACE, Institute for Water Resources and CDM, Inc. 2010; Mendoza and Martins 2006).

The objectives hierarchy with weightings is thus a formula for aggregating the metrics at the bottom of the hierarchy to compare relative benefits of alternatives by giving each alternative a score. The aggregate scores represent the ability of each alternative to support the overarching goal (Table 40).

Table 39. Variables and weights used to calculate MCDA aggregate scores.

\begin{tabular}{|c|c|c|c|}
\hline EGS & Metric & Normalizing variable & $\begin{array}{c}\text { Weight } \\
\text { (out of } \\
100 \text { ) }\end{array}$ \\
\hline $\begin{array}{l}\text { Riparian } \\
\text { ecosystem } \\
\text { sustainability }\end{array}$ & $\begin{array}{l}\text { Quality-screened acres of } \\
\text { cottonwood-willow forest } \\
\text { that contain adequate soil } \\
\text { moisture for foundation tree } \\
\text { recruitment }\end{array}$ & $\begin{array}{l}\text { Maximum acreage that the project } \\
\text { could restore (excluding FWOP } \\
\text { acres) that meets both the soil } \\
\text { moisture and plant composition } \\
\text { criteria ( } 60 \text { acres) }\end{array}$ & 20 \\
\hline $\begin{array}{l}\text { Aquatic } \\
\text { ecosystem } \\
\text { sustainability }\end{array}$ & $\begin{array}{l}\text { Quality-adjusted acres of } \\
\text { intact desert perennial } \\
\text { rivers }\end{array}$ & $\begin{array}{l}\text { The maximum acreage that the } \\
\text { project could restore (excluding } \\
\text { FWOP acres); ( } 60 \text { acres) }\end{array}$ & 30 \\
\hline $\begin{array}{l}\text { Roundtail Chub } \\
\text { viability }\end{array}$ & Habitat acres & $\begin{array}{l}\text { Maximum habitat acreage that the } \\
\text { project could restore (excluding } \\
\text { FWOP acres); ( } 55.6 \text { acres) }\end{array}$ & 15 \\
\hline $\begin{array}{l}\text { Southwestern } \\
\text { Willow } \\
\text { Flycatcher } \\
\text { viability }\end{array}$ & $\begin{array}{l}\text { Contribution to population } \\
\text { viability of Southwestern } \\
\text { Willow Flycatcher in terms } \\
\text { of number of territories }\end{array}$ & $\begin{array}{l}\text { Number of breeding territories } \\
\text { (651) still needed to reach USFWS } \\
\text { goal of } 1,950 \text { territories }\end{array}$ & 15 \\
\hline $\begin{array}{l}\text { Property flood } \\
\text { risk mitigation }\end{array}$ & $\begin{array}{l}\text { Reduction in acres } \\
\text { impacted by flooding }\end{array}$ & $\begin{array}{l}\text { Maximum downstream acreage } \\
\text { that could be impacted by the } \\
\text { project ( } 20 \text { acres) }\end{array}$ & 10 \\
\hline $\begin{array}{l}\text { General } \\
\text { recreation }\end{array}$ & $\begin{array}{l}\text { Number of general } \\
\text { recreation days }\end{array}$ & $\begin{array}{l}\text { Maximum number of general } \\
\text { recreation days that the project } \\
\text { could produce. ( } 3.4 \text { million days) }\end{array}$ & 5 \\
\hline $\begin{array}{l}\text { Recreational } \\
\text { birding }\end{array}$ & $\begin{array}{l}\text { Number of birdwatching } \\
\text { days. }\end{array}$ & $\begin{array}{l}\text { Maximum number of birdwatching } \\
\text { days that the project could produce } \\
\text { (1.7 million days) }\end{array}$ & 5 \\
\hline
\end{tabular}

\section{Step 1}




\section{Case Study Example Box. Step 5 - Comparing plan alternatives (cont.)}

Table 40. Summary of MCDA results for case study.

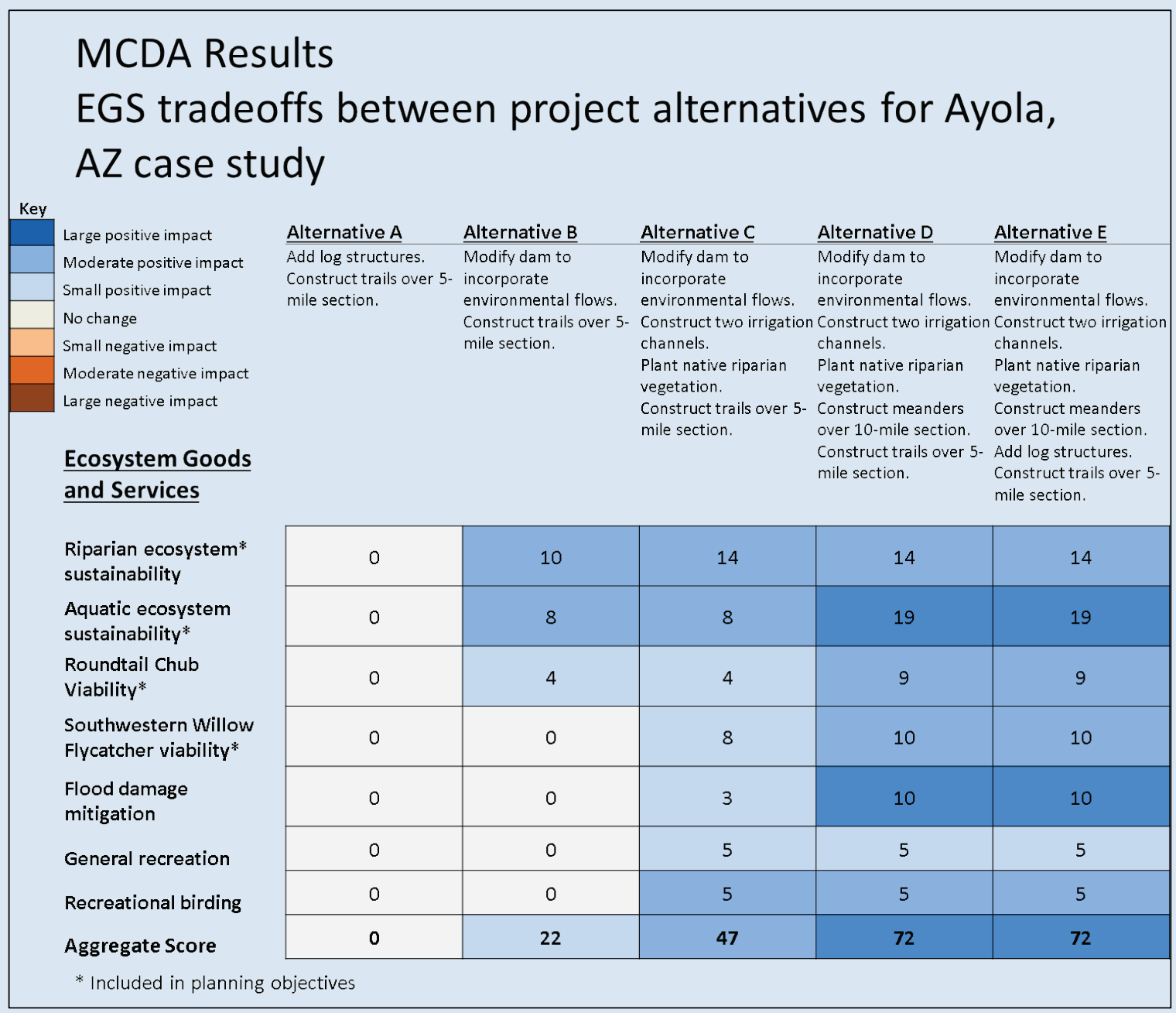

\section{Cost Effectiveness Analysis (CEA) and Incremental Cost Analysis (ICA)}

A joint CEA and ICA (Robinson et al. 1995) is performed to compare the alternative plans using the MCDA results to represent effectiveness. Benefits are measured using the MCDA aggregate scores and individual habitat metrics to evaluate the consistency of results across individual vs. aggregate metrics. Analyses show that option D is Cost Effective and a Best Buy. Option E is inefficient because it has the same benefits as D, according to the MCDA analysis, but is slightly more expensive. This result is driven by the fact that adding logs to stream (the practice added to option E) could not be demonstrated with available evidence or models to be effective at increasing the in-stream habitat benefits. 


\section{Step 6 - Select Plan and Summarize Target and Incidental EGS Benefits and Harms}

In Step 6, the PDT selects one of the plan alternatives to recommend or chooses to take no action, based on the comparison of the plan alternatives in Step 5 (USACE 2000). The PDT then summarizes the different EGS benefits and harms that the plan will provide to effectively communicate the outcomes of the project. As in Step 5, the EGS framework requires few changes to existing planning methods, so the details of the step are not discussed in this report. They can be found in the Section Highlights

- This section is brief to reflect that EGS analysis does not fundamentally alter the selection of the tentatively selected plan (TSP), which is based on plan costeffectiveness and incremental cost analysis (CEA/ICA).

- Once the TSP is selected, a wide range of EGS (representing target and incidental benefits) might be quantified and monetized to estimate the TSP benefits.

Planning Guidance Notebook (USACE 2000).

\section{Case Study Example Box. Step 6 - Plan selection (cont.)}

The PDT reviews the results of the MCDA analysis (Table 40) and CEA/ICA of the alternatives. The PDT chooses Alternative D as the TSP because it has the highest cost-effectiveness. Since the partners are only interested in a plan that can be fully cost-shared by the USACE, they do not consider alternatives that might maximize benefits that fall outside the project authorities and mission areas. As a final step, to fully characterize the benefits of Alternative D, the PDT analyzes all EGS that are expected to be substantially affected (medium and high impact in Table 14), including some that were not originally included in the plan comparison. Further, they seek to monetize as many of the benefits as is credibly feasible for communicating with a broad audience.

\section{Valuing EGS benefits for the tentatively selected plan in the case study}

The PDT receives permission from the vertical team to explore the possibility of monetizing benefits for the TSP for two EGS - Ecosystem Sustainability and Recreation using PDT resources. In addition, outside partners agree to monetize aesthetic benefits to homeowners and carbon sequestration. For the in-house analysis, the team follows all relevant USACE guidance to conduct the monetization and report the present value of benefits over the 50 -year time horizon.

\section{Benefits from non-use services of ecosystems and species (in-house analysis)}

The PDT did not initially seek to monetize non-use services because monetization of these services using contingent valuation is prohibited by USACE guidance. However, they learn that some academic economists have applied cutting-edge contingent choice methods to estimate the social value of EGS changes in a similar desert riparian ecosystem. The team thinks that this valuation information might be useful for communicating the benefits of the TSP to outside decision-makers.

An economist reviews the economic study and notes that although the ecosystem being evaluated is similar, the project extent and species being protected are quite different. The proposed policy being evaluated will protect almost half of the remaining extent of a unique ecosystem that serves as critical habitat for two endangered charismatic bird species. In comparison, the case study ecosystem is substantially more abundant, and the project will support a much smaller portion of the total habitat of an endangered bird (Southwestern Willow Flycatcher). As a result, the economist determines that the academic study results cannot be transferred to the case study without overestimating potential benefits. The economist conducts a literature review and finds that no appropriate economic studies are available. The PDT decides that it is not possible to monetize the non-use services of the project using benefit transfer.

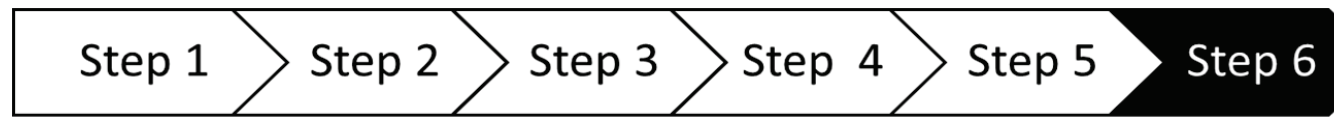




\section{Case Study Example Box. Step 6 - Plan selection (cont.) \\ Benefits from property flood risk mitigation (in-house analysis)}

Property damage costs avoided were already estimated in Step 4 following USACE guidance (Scodari 2009). The present value of these costs for the selected alternative is presented in Table 41.

\section{Benefits from general recreation and birdwatching (in-house analysis)}

The PDT initially chose benefit transfer as an appropriate technique for monetizing recreational EGS (Figure 12, Step 1). In this case, multiple studies have been conducted on the social benefits that can be attributed to a change in quality or quantity of outdoor recreational activities. Thus, this EGS is one of the easiest to monetize using benefit transfer (Rosenberger and Loomis 2001).

The PDT chooses to conduct a unit value ${ }^{1}$ transfer for the two recreational EGS because the database developers were unable to fit a significant statistical model to use in functional transfer (Loomis and Richardson 2008). To create a unit value to use in estimating the benefits of wildlife viewing at the case study site, the PDT selects values for general recreation and wildlife viewing using a database of economic valuation studies, the Recreational Use Values database, and associated documentation that were created for conducting benefit transfer (Loomis et al. 2007; Loomis and Richardson 2008; Rosenberger 2013). To use the database, the team selects studies with similar geographic, ecological, and socio-demographic characteristics. The team then multiplies the average user day value across the selected studies and multiplies by the user days estimated in the ecosystem service analysis for the two recreation EGS to generate a total monetary value. ${ }^{2}$

\section{Aesthetic benefits to property - Hedonic analysis (partner analysis)}

After reviewing the case study, the external partners conclude that the 25 homes that are estimated to have improved views (based on a GIS viewshed analysis) are an insufficient number to warrant conducting a hedonic property analysis.

\section{Valuing carbon sequestration (partner analysis)}

Carbon sequestration is not a primary EGS of the case study, but it is a common service to value. The valuation of carbon is fairly straightforward because existing models and valuation approaches have been developed.

The partners conducting the valuation first need to show that the restored site will sequester more carbon than the FWOP. A review of the the literature reveals that there is no standard model for comparing net carbon sequestration (defined as a net reduction in release of $\mathrm{CO}_{2}$ and $\mathrm{CO}_{2}$ equivalent gases to the atmosphere) in desert riparian zones. However, a methodology for estimating net emissions from different types of land covers was adapted to local ecosystem and climatic conditions, using available literature, to evaluate the change in annual net carbon sequestration (Intergovernmental Panel on Climate Change [IPCC] 2006).

\footnotetext{
1 Unit value transfer is the transfer of an average or other single value between sites. In contrast, a functional transfer uses an equation to adjust values between sites based on socio-demographic, site, and study characteristics(Loomis and Richardson 2008).

2 Currently, the USACE recommends a unit day value approach to conduct benefit transfer, as described in the NED benefit evaluation procedures (USACE 2000, App. E, Section VII). Other approved methods for primary studies to value recreation are travel cost (TC) and CV method. This example of an alternative method is for illustration only.
}

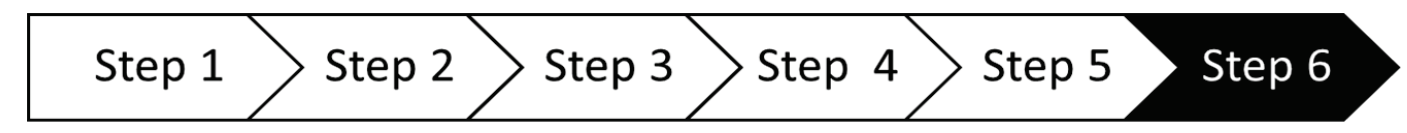




\section{Case Study Example Box. Step 6 - Plan selection (cont.)}

The external analysis team uses the available estimates of the social value of carbon sequestration (Interagency Working Group on Social Cost of Carbon 2010, 2013) to conduct a benefit transfer. ${ }^{1}$ These reports evaluate a wide variety of beneficial outcomes that could result from carbon sequestration, such as prevention of property damage and disease. The carbon analysis is more straightforward than most benefit transfer exercises because the beneficiaries have already been estimated as part of the estimate of social value per ton of $\mathrm{CO}_{2}$ sequestered.

Table 41. Benefits assessments of the tentatively selected plan (Alternative D).

\begin{tabular}{|c|c|c|}
\hline EGS & Quantitative Measure & $\begin{array}{l}\text { Monetary Value (Present } \\
\text { value of 50-year period; } \\
2014 \$ \text { ) }\end{array}$ \\
\hline $\begin{array}{l}\text { Ecosystem Sustainability - Non-use } \\
\text { services from restoring a portion of } \\
\text { threatened riparian forest to meet } \\
\text { quality threshold }\end{array}$ & $\begin{array}{l}43.2 \text { acres added of restored riparian } \\
\text { ecosystem of high conservation priority. } \\
0.03 \% \text { increase in area of total } \\
\text { ecosystem. } \\
0.2 \% \text { of restorable ecosystem restored } \\
\text { in project area. } \\
11 \text { (MCDA benefit units) }\end{array}$ & $\mathrm{n} / \mathrm{a}$ \\
\hline $\begin{array}{l}\text { Ecosystem Sustainability - Non-use } \\
\text { services from restoring a portion of } \\
\text { threatened desert perennial river } \\
\text { ecosystem to meet quality threshold }\end{array}$ & $\begin{array}{l}35 \text { acres added of restored aquatic } \\
\text { system of high conservation priority. } \\
0.18 \% \text { increase in area of total } \\
\text { ecosystem. } \\
0.51 \% \text { of restorable ecosystem restored. } \\
19 \text { (MCDA benefit units) }\end{array}$ & $\mathrm{n} / \mathrm{a}$ \\
\hline $\begin{array}{l}\text { Ecosystem Sustainability - Non-use } \\
\text { services from improving viability of the } \\
\text { declining Roundtail Chub }\end{array}$ & $\begin{array}{l}0.64 \% \text { increase in Roundtail Chub } \\
\text { habitat area in terms of its historic } \\
\text { extent } \\
9 \text { (MCDA benefit units) }\end{array}$ & $\mathrm{n} / \mathrm{a}$ \\
\hline $\begin{array}{l}\text { Ecosystem Sustainability - Non-use } \\
\text { services from improving viability of the } \\
\text { endangered Southwestern Willow } \\
\text { Flycatcher }\end{array}$ & $\begin{array}{l}\text { 0.94\% increase ( } 18 \text { territories added) } \\
\text { toward USFWS goal for minimum } \\
\text { number of flycatcher territories } \\
7 \text { (MCDA benefit units) }\end{array}$ & $\mathrm{n} / \mathrm{a}$ \\
\hline EGS & Quantitative Measure & $\begin{array}{l}\text { Monetary value (present } \\
\text { value of } 50 \text {-year period; } \\
2014 \$ \text { ) }\end{array}$ \\
\hline $\begin{array}{l}\text { Natural Hazard Mitigation - Property } \\
\text { flood risk mitigation }\end{array}$ & $\begin{array}{l}81 \text { residences and business protected } \\
\text { from flooding } \\
15 \text { (MCDA benefit units) }\end{array}$ & $\begin{array}{l}\text { Private property damage } \\
\text { avoided: } \$ 188.4 \mathrm{M} \\
\text { Public property damage } \\
\text { avoided: } \$ 88.7 \mathrm{M} \\
\text { Municipal cleanup } \\
\text { avoided: } \$ 1.1 \mathrm{M}\end{array}$ \\
\hline
\end{tabular}

1 Note the social value of carbon is not the same as the market value and is a preferred indicator of social benefits because it represents the value of damages that might be avoided and what people might be willing to pay to avoid harms associated with climate change. Market value is relevant to those trying to generate a private income stream but is less effective as a metric of social value since it reflects market failures and market disequilibria due to such factors as uncertainty of future government policies.

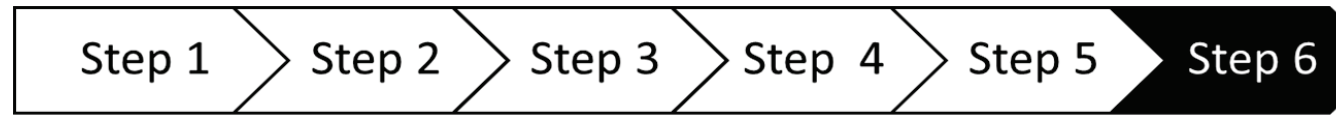




\section{Case Study Example Box. Step 6 - Plan selection (cont.)}

\begin{tabular}{|l|l|l|}
\hline EGS & Quantitative Measure & $\begin{array}{l}\text { Monetary Value (Present } \\
\text { value of 50-year period; } \\
\text { 2014\$) }\end{array}$ \\
\hline Recreation - General recreation & $\begin{array}{l}3.4 \text { million user days/year provided } \\
\text { (once the native tree canopy has } \\
\text { reached the ideal level for general } \\
\text { recreators) or } 109.8 \text { million user days } \\
\text { over the 50-year planning horizon } \\
5 \text { (MCDA benefit units) }\end{array}$ & $\begin{array}{l}\$ 91.4 \mathrm{M} \\
\text { Recreation consumer } \\
\text { surplus }\end{array}$ \\
\hline Recreation - Birdwatching & $\begin{array}{l}1.7 \text { million user days/year provided } \\
\text { (when bird diversity has reached its } \\
\text { maximum potential) or } 55.9 \text { million user } \\
\text { days over the 50-year planning horizon } \\
10 \text { (MCDA benefit units) }\end{array}$ & $\begin{array}{l}\text { \$75.7 M- } \\
\text { Recreation consumer } \\
\text { surplus }\end{array}$ \\
\hline Carbon Sequestration & 230,000 additional tCO2 sequestered & $\begin{array}{l}\$ 1.3-\$ 8.6 \mathrm{M} \text { damages } \\
\text { avoided } \\
\text { (range represents } \\
\text { uncertainty) }\end{array}$ \\
\hline Total & $\begin{array}{l}\text { 76 (MCDA benefit units; does not } \\
\text { include all services listed) }\end{array}$ & \$446.6 - $\$ 453.9 \mathrm{M}$ \\
\hline
\end{tabular}




\section{Conclusions and Summary of Recommendations for Ecosystem Goods and Services (EGS) Analysis}

The EGS framework offers potential advantages for formulating projects to address multiple goals and for improving the communication of social benefits or damages produced. Further, it introduces many concepts drawn from economics that help to frame project outcomes in terms of social benefits or harms, even when values are not monetized. The methods are proposed as the foundation for more complete guidance that could enhance ongoing development of effective and consistent social benefit metrics used to compare alternatives and demonstrate project or program cost-effectiveness.

The EGS conceptual models, which form the core of the approach, are intended to help project delivery teams consider the breadth of EGS that can be produced simultaneously (without diminishing primary goals), with a set of management measures, at a specific site. The response functions and ecosystem service analyses that are used throughout the framework require analysts to clearly demonstrate the relationships between management measures and beneficial outcomes. The proposed tables provide a structure for documenting evidence that management measures create beneficial outcomes.

A key difference between EGS analysis and much of the existing metrics used to capture biophysical changes is that benefits are assessed from the perspective of beneficiary needs or desires. Metrics include characteristics that determine value including tests of whether ecological quality is sufficient to provide an EGS, whether supporting infrastructure is available to realize use of an EGS, and whether the change ameliorates or exacerbates scarcity of that EGS. For example, the concept of nonlinearities (including thresholds) in the delivery of ecosystem goods and services with restoration effort was used to convey the idea that unless sufficient quality is achieved, a benefit may not be derived from an ecological improvement. 
The primary recommendations for using EGS in U.S. Army Corps of Engineers planning follow:

- Leverage existing planning components to reduce the effort of EGS analysis (scoping workshops, National Environmental Policy Act documents, etc.).

- Use an appropriate level of analysis effort, given project resources.

- Use EGS conceptual models to clarify how non-monetary metrics are used to assess project impacts.

- Do not use EGS that are outside of the project authorities to justify the recommended plan.

- Use recent scientific evidence to link management measures to meaningful ecological outcomes.

- Carefully select and design ecological outcome metrics to present a compelling representation of benefits and harms by considering concerns of potential beneficiaries.

- Consider whether thresholds in system responses make some management measures more likely to deliver benefits or cause damage.

- Evaluate potential scarcity of services (demand in excess of supply) as the means to demonstrate relative importance of an EGS change, when EGS impacts are not being monetized.

- Use robust monetization approaches for estimating benefits and harms of the selected plan, when appropriate. 


\section{References}

Andersen, T., J. Carstensen, E. Hernández-García, and C. M. Duarte. 2009. "Ecological Thresholds and Regime Shifts: Approaches to Identification.” Trends in Ecology and Evolution 24: 49-57.

Arizona Game and Fish Department. 2006. Arizona Statewide Conservation Agreement for Roundtail Chub (Gila robusta), Headwater Chub (Gila nigra), Flannelmouth Sucker (Catostomus latipinnis), Little Colorado River Sucker (Catostomus spp.), Bluehead Sucker (Catostomus discobolus), and Zuni Bluehead Sucker (Catostomus discobolus yarrowi). Wildlife Management Division Nongame Branch Native Fish Program.

Banks-Leite, C., R. Pardini, L. R. Tambosi, W. D. Pearse, A. A. Bueno, R. T. Bruscagin, T. H. Condez, M. Dixo, A. T. Igari, A. C. Martensen, and J. P. Metzger. 2014. "Using Ecological Thresholds to Evaluate the Costs and Benefits of Set-Asides in a Biodiversity Hotspot." Science 345: 1041-1045.

Barrio M., and M. L. Loureiro. 2010. "A Meta-Analysis of Contingent Valuation Forest Studies.” Ecological Economics 69: 1023-1030.

Bateman, I. J., D. Abson, B. Andrews, A. Crowe, A. Darnell, S. Dugdale, C. Fezzi, J. Foden, R. Haines-Young, M. Hulme, P. Munday, U. Pascual, J. Paterson, G. Perino, A. Sen, G. Siriwardena, and M. Termansen. 2011. Valuing Changes in Ecosystem Services: Scenario Analyses. Chapter 26. UK National Ecosystem Assessment: Technical Report. Cambridge: UNEP-WCMC.

Bockstael, N. E., A. M. Freeman, R. J. Kopp, P. R. Portney, and V. K. Smith. 2000. "On Measuring Economic Values for Nature." Environmental Science and Technology 34: 1384-1389.

Bonar, S. A., N. Mercado-Silva, and D. Rogowski. 2010. Habitat Use by the Fishes of a Southwestern Desert Stream: Cherry Creek, Arizona. Fisheries Research Report 02-10. Tucson, AZ: USGS Arizona Cooperative Fish and Wildlife Research Unit.

Boyd, J., and S. Banzhaf. 2007. "What Are Ecosystem Services? The Need for Standardized Environmental Accounting Units.” Ecological Economics 63: 616626.

Boyd, J., and L. A. Wainger. 2002. "Landscape Indicators of Ecosystem Service Benefits." American Journal of Agricultural Economics 84: 1371-1378.

Bromley, D. W., editor. 1995. The Handbook of Environmental Economics. Oxford: Blackwell Publishers.

Brook, B. W., J. J. O’Grady, A. P. Chapman, M. A. Burgman, H. R. Akçakaya, and R. Frankham. 2000. "Predictive Accuracy of Population Viability Analysis in Conservation Biology.” Nature 404: 385-387. 
Brown, D. E., C. H. Lowe, and C. P. Pase. 1979. "A Digitized Classification System for the Biotic Communities of North America, with Community (Series) and Association Examples for the Southwest." Journal of the Arizona-Nevada Academy of Science 14: 1-16.

Brown, G. M., and J. F. Shogren. 1998. "Economics of the Endangered Species Act." Journal of Economic Perspectives 12: 3-20.

Bushnell, W., and K. Knight. 2011. Regional Economic Development (RED) Procedures Handbook. 2011-NaN-1. Alexandria, VA: U.S. Army Corps of Engineers, Institute for Water Resources.

Carson, R. T. 2012. "Contingent Valuation: A Practical Alternative When Prices Aren't Available." The Journal of Economic Perspectives 26: 27-42.

Directorate of Civil Works Planning and Policy Division (CECW-P). 2014. Economic Guidance Memorandum: Federal Interest Rates for Corps of Engineers Projects for Fiscal Year 2015. Washington, DC: U.S. Army Corps of Engineers. https://planning.erdc.dren.mil/toolbox/library/EGMs/EGM15-01.pdf.

Champ, P. A., K. J. Boyle, and T. C. Brown. 2003. A Primer on Nonmarket Valuation: The Economics of Non-Market Goods and Resources. New York: Springer.

Chan, K. M. A., A. D. Guerry, P. Balvanera, S. Klain, T. Satterfield, X. Basurto, A. Bostrom, R. Chuenpagdee, R. Gould, B. S. Halpern, N. Hannahs, J. Levine, B. Norton, M. Ruckelshaus, R. Russell, J. Tam, and U. Woodside. 2012. "Where are Cultural and Social in Ecosystem Services? A Framework for Constructive Engagement." BioScience 62: 744-756.

Dale, V. H., and S. C. Beyeler. 2001. "Challenges in the Development and Use of Ecological Indicators.” Ecological Indicators 1: 3-10.

Desert Fish Habitat Partnership Workgroup. 2008. Framework for Strategic Conservation of Desert Fish. Desert Fish Habitat Partnership. https://www.nature.nps.gov/water/Fisheries_Partnership/Documents/dfhp_final_LOWRES.pdf.

Desvousges, W., K. Mathews, and K. Train. 2012. "Adequate Responsiveness to Scope in Contingent Valuation.” Ecological Economics 84: 121-128.

Durst, S. L., M. K. Sogge, S. D. Stump, H. A. Walker, B. E. Kus, and S. J. Sferra. 2008. Southwestern Willow Flycatcher Breeding Site and Territory Summary-2007, 31. Open-File Report 2008-1303. Reston, VA: U.S. Geological Survey.

Feld, C. K., S. Birk, D. C. Bradley, D. Hering, J. Kail, A. Marzin, A. Melcher, D. Nemitz, M. L. Pedersen, and F. Pletterbauer. 2011. "From Natural to Degraded Rivers and Back Again: A Test of Restoration Ecology Theory and Practice." Advances in Ecological Research 44: 119-209.

Ferraro, P. J. 2004. “Targeting Conservation Investments in Heterogeneous Landscapes: A Distance-Function Approach and Application to Watershed Management." American Journal of Agricultural Economics 86: 905-918. 
Finch, D. M., S. I. Rothstein, J. C. Boren, W. L. Graf, J. L. Holechek, B. E. Kus, R. M. Marshall, M. M. Pohl, S. J. Sferra, M. K. Sogge, J. C. Stromberg, B. A. Valentine, M. J. Whitfield, and S. O. Williams. 2002. Final Recovery Plan of the Southwestern Willow Flycatcher (Empidonax traillii extimus), 529. Albuquerque, NM: U.S. Fish and Wildlife Service, Region 2. http://www.treesearch.fs.fed.us/pubs/35557.

Freeman, A. M. 2003. The Measurement of Environmental and Resource Values: Theory and Methods. Washington, DC: RFF Press.

Freeman, A. M., J. A. Herriges, and C. L. Kling. 2014. The Measurement of Environmental and Resource Values: Theory and Methods. New York: Rff Press.

Goodwin, P., and G. Wright. 2014. Decision Analysis for Management Judgment, $5^{\text {th }}$ Edition. Hoboken, NJ: Wiley.

Hanley, N., J. F. Shogren, and B. White. 2001. Introduction to Environmental Economics. Oxford, UK: Oxford University Press.

Hatten, J. R., E. H. Paxton, and M. K. Sogge. 2010. "Modeling the Dynamic Habitat and Breeding Population of Southwestern Willow Flycatcher." Ecological Modelling 221(13-14): 1674-1686.

Hausman, J. 2012. "Contingent Valuation: From Dubious to Hopeless." The Journal of Economic Perspectives 26: 43-56.

Hernández-Morcillo, M., T. Plieninger, and C. Bieling. 2013. "An Empirical Review of Cultural Ecosystem Service Indicators.” Ecological Indicators 29: 434-444.

Hobbs, R. J., E. Higgs, and J. A. Harris. 2009. "Novel Ecosystems: Implications for Conservation and Restoration." Trends in Ecology and Evolution 24: 599-605.

Holland, D. S., J. N. Sanchirico, R. J. Johnston, and D. Joglekar. 2010. Economic Analysis for Ecosystem-Based Management: Applications to Marine and Coastal Environments. Washington, DC: Rff Press.

Interagency Working Group on Social Cost of Carbon. 2010. Social Cost of Carbon for Regulatory Impact Analyses under Executive Order 12866. Appendix 15A. U.S. Government. https://pdfs.semanticscholar.org/e4f4/b6ea8aa1cbaf4196e5453b31a6203b88241c.pdf?_ga $=2.186050537 .1162786653 .1518473512-29756023.1518473512$.

Interagency Working Group on Social Cost of Carbon. 2013. Technical Update of the Social Cost of Carbon for Regulatory Impact Analysis - Under Executive Order 12866. Technical Support Document. http://www.ourenergypolicy.org/wpcontent/uploads/2013/06/social_cost_of_carbon_for_ria_ 2013 update.pdf.

Intergovernmental Panel on Climate Change (IPCC). 2006. 2006 IPCC Guidelines for National Greenhouse Gas Inventories. Agriculture, Forestry and Other Land Use. Appendix 3, Ch 4, Emissions from Flooded Land: Basis for Future Methodological Development. http://www.ipcc-nggip.iges.or.jp/public/2006gl/vol4.html. 
Johnston, R. J., and M. Russell. 2011. "An Operational Structure for Clarity in Ecosystem Service Values.” Ecological Economics 70: 2243-2249.

Johnston, R. J., and L. A. Wainger. 2015. "Benefit Transfer for Ecosystem Service Valuation: An Introduction to Theory and Methods." In Benefit Transfer of Environmental and Resource Values, edited by R. Johnston, J. Rolfe, R. Rosenberger, and R. Brouwer. Berlin: Springer. https://link.springer.com/chapter/10.1007/978-94-017-9930-0_12.

Kiker, G. A., T. S. Bridges, A. Varghese, T. P. Seager, and I. Linkov. 2005. “Application of Multicriteria Decision Analysis in Environmental Decision Making." Integrated Environmental Assessment and Management 1: 95-108.

Latta, M. J., C. J. Beardmore, and T. E. Corman. 1999. Arizona Partners in Flight Bird Conservation Plan. Technical 142. Phoenix, AZ: Nongame and Endangered Wildlife Program, Arizona Game and Fish Department.

Loomis, J. 2005. Economic Values without Prices: The Importance of Nonmarket Values and Valuation for Informing Public Policy Debates. http://www.choicesmagazine.org/2005-3/nonmarket/2005-3-01.htm.

Loomis, J., T. Kroeger, L. Richardson, and F. Casey. 2007. The Benefit Transfer and Use Estimating Model Toolkit. Fort Collins, CO: Colorado State University, Dept. of Agric. and Resource Economics. http://dare.colostate.edu/tools/benefittransfer.aspx.

Loomis, J., and L. Richardson. 2008. Technical Documentation of Benefit Transfer and Visitor Use Estimating Models of Wildlife Recreation, Species and Habitats. Fort Collins, CO: Colorado State University, Dept. of Agric. and Resource Economics. http://dare.agsci.colostate.edu/outreach/tools/\#BT.

Loomis, J. B., and R. Richardson. 2000. Economic Values of Protecting Roadless Areas in the United States. Prepared for The Wilderness Society and Heritage Forests Campaign. Fort Collins, CO: Colorado State University, Dept. of Agric. and Resource Economics. https://www.sierraforestlegacy.org/Resources/Conservation/FireForestEcology/ForestEconomic s/Economics-Loomis00.pdf.

Maguire, L., D. Urban, C. Ihlo, L. Olander, P. Ringold, and E. Schieffer. 2014. "Social Impact Analysis: Non-Monetary Methods (Multi-Criteria Evaluation).” Federal Resource Management and Ecosystem Services Guidebook. Duke University: National Ecosystem Services Partnership. https://nespguidebook.com.

Mazzotta, M. J., L. A. Wainger, S. D. Sifleet, J. T. Petty, and B. Rashleigh. 2015. "Benefit Transfer with Limited Data: An Application to Recreational Fishing Losses from Surface Mining." Ecological Economics 119C: 384-398.

Mendoza, G. A., and H. Martins. 2006. "Multi-Criteria Decision Analysis in Natural Resource Management: A Critical Review of Methods and New Modelling Paradigms." Forest Ecology and Management 230: 1-22.

Millenium Ecosystem Assessment. 2005. Ecosystems and Human Well-Being: Synthesis, 155. Washington, DC: Island Press. http://www.millenniumassessment.org/documents/document.356.aspx.pdf. 
Murray, E. O., J. Cushing, L. Wainger, and D. J. Tazik. 2013. Incorporating Ecosystem Goods and Services in Environmental Planning: Definitions, Classification and Operational Approaches. ERDC TN-EMRRP-ER-18. Vicksburg, MS: U.S. Army Engineer Research and Development Center.

National Ecosystem Services Partnership. 2014. The Federal Resource Management and Ecosystem Services Guidebook. Durham, NC: Duke University, National Ecosystem Services Partnership.

National Research Council (NRC). 1999. Perspectives on Biodiversity: Valuing Its Role in an Everchanging World, 129. Washington, DC: National Academies Press.

NRC. 2005. Valuing Ecosystem Services: Toward Better Environmental DecisionMaking. Washington, DC: National Academies Press. http://www.nap.edu/catalog.php?record_id=11139.

National Survey on Recreation and the Environment (NSRE). 2000. National Survey on Recreation and the Environment (NSRE): 200O-2002. Fifth report. The Interagency National Survey Consortium, Coordinated by the USDA Forest Service, Recreation, Wilderness, and Demographics Trends Research Group, Athens, GA and the Human Dimensions Research Laboratory, University of Tennessee, Knoxville, TN.

National Wildlife Federation. 2018. Fremont Cottonwood. Accessed February 7. http://www.nwf.org/Wildlife/Wildlife-Library/Plants/Fremont-Cottonwood.aspx.

Nicholson, E., D. A. Keith, and D. S. Wilcove. 2009. "Assessing the Threat Status of Ecological Communities." Conservation Biology 23: 259-274.

Noss, R. F. 1990. "Indicators for Monitoring Biodiversity: A Hierarchical Approach.” Conservation Biology 4: 355-364.

Noss, R. F., E. T. LaRoe, and J. M. Scott. 1995. Endangered Ecosystems of the United States: A Preliminary Assessment of Loss and Degradation. Washington, DC: U.S. Department of the Interior, National Biological Service.

OMB (Office of Management and Budget), CEQ, OSTP. 2015. Memorandum for Executive Departments and Agencies: Incorporating Ecosystem Services into Federal Decision Making. https://nepis.epa.gov/Exe/ZyPDF.cgi/P100PDZ.PDF?Dockey=P100PDZ.PDF.

Ogden, J. C., S. M. Davis, K. J. Jacobs, T. Barnes, and H. E. Fling. 2005. "The Use of Conceptual Ecological Models to Guide Ecosystem Restoration in South Florida." Wetlands 25: 795-809.

Palmer, M. A., E. S. Bernhard, J. D. Allan, P. S. Lake, G. Alexander, S. Brooks, J. Carr, S. Clayton, C. N. Dahm, J. F. Shah, D. L. Galat, S. G. Loss, P. Goodwin, D. D. Hart, B. Hassett, R. Jenkinson, G. M. Kondolf, R. Lave, J. L. Meyer, T. K. O’Donnell, L. Pagano, and E. Sudduth. 2005. "Standards for Ecologically Successful River Restoration.” Journal of Applied Ecology 42: 208-217. 
Palmer, M. A., L. Wainger, L. Craig, C. Febria, J. Hosen, and K. Politano. 2011. Promoting Successful Restoration through Effective Monitoring in the Chesapeake Bay Watershed. Solomons, MD: Chesapeake Biological Laboratory, University of Maryland Center for Environmental Science.

Palmquist, R. B. 2005. "Property Value Models." Handbook of Environmental Economics 2: $763-819$.

Paxton, E. H., M. K. Sogge, S. L. Durst, T. C. Theimer, and J. R. Hatten. 2007. The Ecology of the Southwestern Willow Flycatcher in Central Arizona - A 10-Year Synthesis Report, 143. U.S. Geological Survey Open-File Report 2007-1381. Reston, VA: U.S. Geological Survey. http://pubs.usgs.gov/of/2007/1381/.

Peters, B. G. 2011. Institutional Theory in Political Science: The New Institutionalism. London, UK: Bloomsbury Publishing.

Peters-Stanley, M., G. Gonzalez, and D. Yin. 2013. Covering New Ground: State of the Forest Carbon Markets 2013. Washington, DC: Forest Trends' Ecosystem Marketplace and Bloomberg New Energy Finance.

Phillips, S. J., M. Dudík, and R. E. Schapire. 2004. "A Maximum Entropy Approach to Species Distribution Modeling," 83. In Proceedings of the Twenty-First International Conference on Machine Learning. ACM, New York, NY, USA. http://doi.acm.org/10.1145/1015330.1015412.

Ready, R., and S. Navrud. 2005. "Benefit Transfer - The Quick, the Dirty, and the Ugly?” Choices: The Magazine of Food, Farm, and Resource Issues 20: 195-199.

Reed, D., L. Martin, and J. Cushing. 2013. Using Information on Ecosystem Goods and Services in Corps Planning: An Examination of Authorities, Policies, Guidelines, and Practices. 2013-NaN-7. Alexandria, VA: U.S. Army Corps of Engineers, Institute for Water Resources.

Reed, M. S. 2008. "Stakeholder Participation for Environmental Management: A Literature Review.” Biological Conservation 141: 2417-2431.

Richardson, L., and J. Loomis. 2009. "The Total Economic Value of Threatened, Endangered, and Rare Species: An Updated Meta-Analysis.” Ecological Economics 68: 1535-1548.

Robinson, R., W. Hansen, K. Orth, and S. Franco. 1995. Evaluation of Environmental Investments Procedures Manual - Interim: Cost Effectiveness and Incremental Cost Analyses, 118. IWR-95-R-1. Fort Belvoir, VA: U.S. Army Corps of Engineers, Institute for Water Resources. http://www.dtic.mil/docs/citations/ADA304128.

Rodríguez, J. P., K. M. Rodríguez -Clark, J. E. M. Baillie, N. Ash, J. Benson, T. Boucher, C. Bown, N. D. Burgess, B. Collen, M. Jennings, D. A. Keith, E. Nicholson, C. Revenga, B. Reyers, M. Rouget, T. Smith, M. Spalding, A. Taber, M. Walpole, I. Zager, and T. Zamin. 2011. "Establishing IUCN Red List Criteria for Threatened Ecosystems." Conservation Biology 25: 21-29.

Rosenberger, R S. 2013. Recreation Use Values Database. Corvallis, OR: Oregon State University. http://recvaluation.forestry.oregonstate.edu/. 
Rosenberger, R. S., and J. B. Loomis. 2001. Benefit Transfer of Outdoor Recreation Use Values: A Technical Document Supporting the Forest Service Strategic Plan (rev. 2000), 59. Gen. Tech. Rep. RMRS-GTR-72. Fort Collins, CO: U.S. Department of Agriculture, Forest Service, Rocky Mountain Research Station.

Rosenberger, R. S., and T. D. Stanley. 2006. "Measurement, Generalization, and Publication: Sources of Error in Benefit Transfers and Their Management." Ecological Economics 60: 372-378.

Roy, S. B., L. Chen, E. Girvetz, E. P. Maurer, W. B. Mills, and T. M. Grieb. 2010. Evaluating Sustainability of Projected Water Demands under Future Climate Change Scenarios. Prepared for Natural Resources Defense Council. Lafayette, CA: Tetra Tech Inc.

Salafsky, N., D. W. Salzer, A. J. Stattersfield, C. Hilton-Taylor, R. A. Neugarten, S. H. M. Butchart, B. Collen, N. A. Cox, L. L. Master, S. J. M. O’Connor, and D. Wilkie. 2008. "A Standard Lexicon for Biodiversity Conservation: Unified Classifications of Threats and Actions." Conservation Biology 22: 897-911.

Scodari, P. 2009. National Economic Development Procedures Manual: Overview Manual. IWR Report 09-R-2. Washington, DC: U.S. Army Corps of Engineers, Institute for Water Resources.

Sogge, M. K., D. Ahlers, and S. Sferra. 2010. A Natural History Summary and Survey Protocol for the Southwestern Willow Flycatcher: U.S. Geological Survey Techniques and Methods, 38, 2A-10. Reston, VA: U.S. Geological Survey.

Stevens, T. H. 2005. "Can Stated Preference Valuations Help Improve Environmental Decision Making?” Choices: The Magazine of Food, Farm and Resource Issues 20: 189-193.

Stromberg, J. C. 1993. "Frémont Cottonwood-Goodding Willow Riparian Forests: A Review of Their Ecology, Threats, and Recovery Potential." Journal of the Arizona-Nevada Academy of Science 27: 97-110.

Tazik, D. J., J. Cushing, E. O. Murray, and L. Wainger. 2013. Incorporating Ecosystem Goods and Services in Environmental Planning - A Literature Review of Definitions, Classification, and Operational Approaches. ERDC/EL TR-13-17. Vicksburg, MS: U.S. Army Engineer Research and Development Center.

Tear, T. H., P. Kareiva, P. L. Angermeier, P. Comer, B. Czech, R. Kautz, L. Landon, D. Mehlman, K. Murphy, M. Ruckelshaus, J. M. Scott, and G. Wilhere. 2005. "How Much Is Enough? The Recurrent Problem of Setting Measurable Objectives in Conservation." BioScience 55: 835-849.

The Nature Conservancy. 2018. Hassayampa River Preserve. http://www.nature.org/ourinitiatives/regions/northamerica/unitedstates/arizona/placesweprot ect/hassayampa-river-preserve.xml.

The Nature Conservancy's Center for Science and Public Policy. 2010. Arizona Statewide Freshwater Assessment GIS Data Package. http://azconservation.org/downloads/arizona_statewide_freshwater_assessment_gis_data_pa ckage. 
The Nature Conservancy's Center for Science and Public Policy. 2018. Arizona's Rivers and Water. http://azconservation.org/projects/water.

TNC Conservation Portfolio. 2011. http://maps.tnc.org/files/metadata/Portfolio.xml.

Traill, L. W., C. J. A. Bradshaw, and B. W. Brook. 2007. "Minimum Viable Population Size: A Meta-Analysis of 30 Years of Published Estimates." Biological Conservation 139: 159-166.

Traill, L. W., B. W. Brook, R. R. Frankham, and C. J. A. Bradshaw. 2010. "Pragmatic Population Viability Targets in a Rapidly Changing World.” Biological Conservation 143: 28-34.

Tran, L. T., C. G. Knight, R. V. O’Neill, and E. R. Smith. 2004. “Integrated Environmental Assessment of the Mid-Atlantic Region with Analytical Network Process." Environmental Monitoring and Assessment 94: 263-277.

Troy, A., and M. A. Wilson. 2006. "Mapping Ecosystem Services: Practical Challenges and Opportunities in Linking GIS and Value Transfer." Ecological Economics 60: 435-449.

Turner, R. K., S. G. Georgiou, and B. Fisher. 2008. Valuing Ecosystem Services: The Case of Multi-Functional Wetlands. London: Earthscan.

U.S. Army Corps of Engineers (USACE). 2000. Planning Guidance Notebook. ER 1105-2100. Washington, DC: U.S. Army Corps of Engineers.

USACE. 2013. Planning Community Toolbox: Planning SMART Guide. http://planning.usace.army.mil/toolbox/smart.cfm.

USACE. 2014. Tips, Tools, and Techniques: Using a Risk Register in Feasibility Studies. http://planning.usace.army.mil/toolbox/smart.cfm? Section=8\&Part=4.

USACE, Institute for Water Resources, CDM, Inc. 2010. IWR Planning Suite MCDA Module User's Guide. Carbondale, IL: U.S. Army Corps of Engineers Institute for Water Resources.

U.S. Environmental Protection Agency (U.S. EPA). 2014. Percent Potentially Restorable Wetlands - Enviroatlas.

http://enviroatlas.epa.gov/enviroatlas/DataFactSheets/pdf/ESN/PercentPotentiallyRestorable Wetlands.pdf.

U.S. EPA, Science Advisory Board (SAB). 2009. Valuing the Protection of Ecological Systems and Services: A Report of the EPA Science Advisory Board. Science Advisory Board (SAB) Committee on Valuing the Protection of Ecological Systems and Services (CVPESS). EPA-SAB-09-012. http://yosemite.epa.gov/sab/sabproduct.nsf/WebBOARD/ValProtEcolSys\%26Serv?0penDocum ent.

U.S. Geological Survey (USGS). 2011. National Gap Analysis Program (GAP) | Land Cover Data Portal. http://gapanalysis.usgs.gov/gaplandcover/. 
Voeltz, J. B. 2002. Roundtail Chub (Gila Robusta) Status Survey of the Lower Colorado River Basin. Nongame and Endangered Wildlife Program Technical Report 186. Phoenix, AZ: Arizona Game and Fish Department.

Wainger, L. A. 2014. "Integrating Ecological and Social Measures: Benefit-Relevant Indicators." In The Federal Resource Management and Ecosystem Services Guidebook, edited by L. Olander et al. National Ecosystem Services Partnership, Nicholas School of the Environment, Duke University. https://nespguidebook.com/assessment-framework/benefit-relevant-indicators/.

Wainger, L. A., and J. W. Boyd. 2009. "Valuing Ecosystem Services." In Ecosystem-Based Management for the Oceans, edited by K. McLeod and H. Leslie, 92-111. Washington, DC: Island Press.

Wainger, L. A., D. M. King, R. N. Mack, E. W. Price, and T. Maslin. 2010. "Can the Concept of Ecosystem Services Be Practically Applied to Improve Natural Resource Management Decisions?” Ecological Economics 69: 978-987.

Wainger, L., and M. Mazzotta. 2011. "Realizing the Potential of Ecosystem Services: A Framework for Relating Ecological Changes to Economic Benefits." Environmental Management 48: 710-733.

Wainger, L., S. Sifleet, D. Shafer, and S. Bourne. 2015. "Ecosystem Service Benefits of USACE Ecological Restoration Projects in the Coastal Northeast: Hurricane Sandy Case Study." In Use of Natural and Nature-Based Features in Coastal Systems, edited by T. Bridges et al., Ch. 7, in collaboration with USACE IWR and UMCES. ERDC SR-15-1. Vicksburg, MS: U.S. Army Engineer Research and Development Center. http://www.nad.usace.army.mil/Portals/40/docs/NACCS/NNBF\%20FINAL.pdf.

Wallenius, J., J. S. Dyer, P. C. Fishburn, R. E. Steuer, S. Zionts, and K. Deb. 2008. "Multiple Criteria Decision Making, Multiattribute Utility Theory: Recent Accomplishments and What Lies Ahead.” Management Science 54: 1336-1349.

Walsh, R. G., J. B. Loomis, and R. A. Gillman. 1984. "Valuing Option, Existence, and Bequest Demands for Wilderness.” Land Economics 60: 14-29.

Weber, M. A., and S. Stewart. 2009. "Public Values for River Restoration Options on the Middle Rio Grande.” Restoration Ecology 17: 762-771.

White House Council on Environmental Quality. 2013. Principles and Requirements for Federal Investments in Water Resources. http://www.whitehouse.gov/sites/default/files/final_principles_and_requirements_march_201 3.pdf.

Wilson, M. A., and J. P. Hoehn. 2006. "Valuing Environmental Goods and Services Using Benefit Transfer: The State-of-the-Art and Science." Ecological Economics 60: 335-342. 


\section{Appendix A: Tables for Identifying and Rating EGS}

Excel versions of Tables A.1 to A.5 are available upon request from author. 
Table A-1. Blank impact evaluation table.

\section{Directions}

1. List specific goods and services that will be impacted.

2. Biophysical Changes: Rate the impact this project is likely to have on the biophysica

processes driving this EGS, the duration of the impact (Table 9), and whether it will be

substantial (Table 10)

3. Affected Beneficiaries: Rate the impact this project is likely to have on the beneficiarie

of this EGS, the duration of the impact (Table 9), and whether it will be substantial (Table 10).

4. Does this EGS have low-cost or readily available substitutes?

5. Assign a aggregate rating using Figure 11 in the report.

\begin{tabular}{|c|c|c|c|c|c|c|c|c|c|}
\hline \multirow[t]{2}{*}{$\begin{array}{l}\text { Ecosystem Goods } \\
\text { and Services (EGS) }{ }^{1}\end{array}$} & \multicolumn{3}{|c|}{ Biophysical Impacts ${ }^{2}$} & \multicolumn{3}{|c|}{ Beneficiary Impacts $^{3}$} & \multirow{2}{*}{$\begin{array}{c}\text { Substitutes } \\
\text { Available }^{4} \\
\text { (yes, no) }\end{array}$} & \multirow{2}{*}{$\begin{array}{c}\text { Aggregate } \\
\text { Impact Rating } \\
\text { (no/negligible, } \\
\text { low, med, high) }\end{array}$} & \multirow[t]{2}{*}{ Notes } \\
\hline & Magnitude & Duration & $\begin{array}{l}\text { Is the impact } \\
\text { substantial? }\end{array}$ & Magnitude & Duration & $\begin{array}{l}\text { Is the impact } \\
\text { substantial? }\end{array}$ & & & \\
\hline & & & & & & & & & \\
\hline & & & & & & & & & \\
\hline & & & & & & & & & \\
\hline & & & & & & & & & \\
\hline & & & & & & & & & \\
\hline & & & & & & & & & \\
\hline & & & & & & & & & \\
\hline & & & & & & & & & \\
\hline & & & & & & & & & \\
\hline & & & & & & & & & \\
\hline & & & & & & & & & \\
\hline
\end{tabular}

\section{Magnitude Key}

+++/- - - High Positive/Negative Change

++ - - Medium Change

+ +- Low Change

- No / Negligible Change

ii Insufficient Information

n/a Not applicable

Duration Key

*** Long-term * Temporary 
Table A-2. Blank decision criteria table.

\section{Directions}

1. Transfer EGS and associated aggregate impact rating from the Impact Evaluation Table.

2. Rate your overall confidence (Table 11) of the aggregate impact rating identified in the Impact Evaluation Table.

3. Is this EGS within project authorities?

4. Are there other important considerations regarding the EGS? (e.g., is it within a Corps mission area (Table 12), is it a NEPA concerns, etc.)?

5. Combine aggregate impact rating with confidence rating (Table 13) and filter EGS by project authorities and other considerations, as appropriate, to select EGS for further analysis.

\begin{tabular}{|c|c|c|c|c|c|c|}
\hline $\begin{array}{l}\text { Ecosystem Goods } \\
\text { and Services (EGS) }\end{array}$ & $\begin{array}{c}\text { Aggregate Impact } \\
\text { Rating }^{1} \\
\text { (no/negligible, low, } \\
\text { med, high) }\end{array}$ & $\begin{array}{c}\text { Confidence } \\
\text { Rating }^{2} \\
\text { (low, med, high) }\end{array}$ & $\begin{array}{c}\text { Within the } \\
\text { project } \\
\text { authorities? } \\
\text { (yes, no) }\end{array}$ & $\begin{array}{c}\text { Other } \\
\begin{array}{c}\text { considerations? } \\
\text { (yes, no) }\end{array}\end{array}$ & $\begin{array}{l}\text { Include in } \\
\text { further } \\
\text { analysis? } \\
\text { (yes, no) }\end{array}$ & Notes \\
\hline & & & & & & \\
\hline & & & & & & \\
\hline & & & & & & \\
\hline & & & & & & \\
\hline & & & & & & \\
\hline & & & & & & \\
\hline & & & & & & \\
\hline & & & & & & \\
\hline & & & & & & \\
\hline & & & & & & \\
\hline & & & & & & \\
\hline & & & & & & \\
\hline
\end{tabular}


Table A-3. Blank rating documentation table.

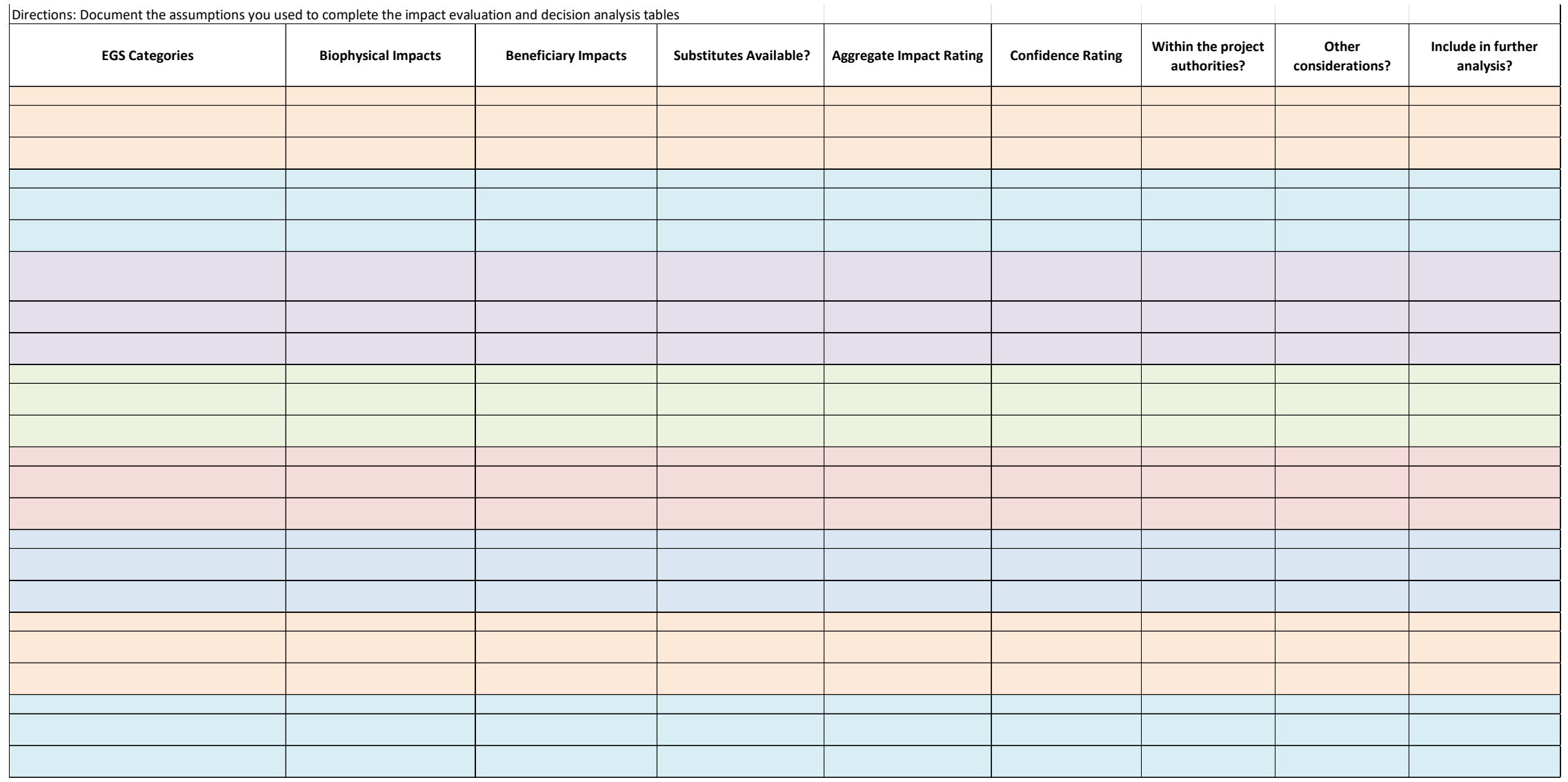

Table A-4. Rating documentation for case study example Tables 15 and 16.

\begin{tabular}{|c|c|c|c|c|c|c|c|c|}
\hline $\begin{array}{l}\text { EGS } \\
\text { Categories }\end{array}$ & Biophysical Impacts & Beneficiary Impacts & $\begin{array}{l}\text { Substitutes } \\
\text { Available? }\end{array}$ & $\begin{array}{l}\text { Aggregate } \\
\text { Impact Rating }\end{array}$ & $\begin{array}{l}\text { Confidence } \\
\text { Rating }\end{array}$ & $\begin{array}{c}\text { Within the } \\
\text { Project } \\
\text { Authorities? }\end{array}$ & $\begin{array}{c}\text { Other } \\
\text { Considerations? }\end{array}$ & $\begin{array}{l}\text { Include in } \\
\text { Further Analysis? }\end{array}$ \\
\hline \multicolumn{9}{|c|}{ Ecosystem Sustainability } \\
\hline
\end{tabular}




\begin{tabular}{|c|c|c|c|c|c|c|c|c|}
\hline $\begin{array}{l}\text { EGS } \\
\text { Categories }\end{array}$ & Biophysical Impacts & Beneficiary Impacts & $\begin{array}{l}\text { Substitutes } \\
\text { Available? }\end{array}$ & $\begin{array}{l}\text { Aggregate } \\
\text { Impact Rating }\end{array}$ & $\begin{array}{l}\text { Confidence } \\
\text { Rating }\end{array}$ & $\begin{array}{c}\text { Within the } \\
\text { Project } \\
\text { Authorities? }\end{array}$ & $\begin{array}{c}\text { Other } \\
\text { Considerations? }\end{array}$ & $\begin{array}{l}\text { Include in } \\
\text { Further Analysis? }\end{array}$ \\
\hline $\begin{array}{l}\text { Non-use } \\
\text { services from } \\
\text { restoring a } \\
\text { portion of a } \\
\text { threatened } \\
\text { riparian } \\
\text { forest to } \\
\text { meet quality } \\
\text { threshold }\end{array}$ & $\begin{array}{l}\text { The project is expected to } \\
\text { significantly increase } \\
\text { recruitment of foundation } \\
\text { tree species by meeting the } \\
\text { required soil moisture } \\
\text { threshold. Meeting this soil } \\
\text { moisture threshold will also } \\
\text { lead to more characteristic } \\
\text { plant communities of } \\
\text { cottonwood-willow riparian } \\
\text { forests. Overall, the team } \\
\text { assesses that there will be } \\
\text { a high positive (+++) } \\
\text { magnitude of impact. } \\
\text { These results will be over } \\
\text { the long-run (***); } \\
\text { therefore, the impact will } \\
\text { be substantial. }\end{array}$ & $\begin{array}{l}\text { The team decides there will } \\
\text { be a low positive impact }(+) \\
\text { because the project is } \\
\text { expected to lead to a small } \\
\text { increase in the cottonwood- } \\
\text { willow forest's extent in } \\
\text { North America. Restoration } \\
\text { of this riparian ecosystem } \\
\text { has been identified as a } \\
\text { conservation priority in } \\
\text { scientific papers and by } \\
\text { NGOs. This impact is long- } \\
\text { term }(* * *), \text { so it is } \\
\text { substantial. }\end{array}$ & $\begin{array}{l}\text { No } \\
\text { Based on the } \\
\text { team's } \\
\text { experience and } \\
\text { a preliminary } \\
\text { GIS analysis } \\
\text { they found few } \\
\text { examples of } \\
\text { intact or } \\
\text { potentially } \\
\text { restorable } \\
\text { cottonwood- } \\
\text { willow riparian } \\
\text { forests that } \\
\text { exist in this } \\
\text { region. }\end{array}$ & $\begin{array}{l}\text { High } \\
\text { Since both } \\
\text { the } \\
\text { biophysical } \\
\text { and } \\
\text { beneficiary } \\
\text { impacts are } \\
\text { substantial } \\
\text { and there are } \\
\text { no available } \\
\text { substitutes, } \\
\text { the } \\
\text { cumulative } \\
\text { impact is } \\
\text { high. }\end{array}$ & $\begin{array}{l}\text { Medium } \\
\text { There is some } \\
\text { uncertainty } \\
\text { about the } \\
\text { ability to } \\
\text { restore the } \\
\text { native } \\
\text { ecosystem } \\
\text { given the } \\
\text { potential } \\
\text { threat of plant } \\
\text { invasion, } \\
\text { projected } \\
\text { human use, } \\
\text { and changes } \\
\text { to the system } \\
\text { due to climate } \\
\text { change. }\end{array}$ & Yes & - & $\begin{array}{l}\text { Yes The team } \\
\text { decides to } \\
\text { include this EGS } \\
\text { in the planning } \\
\text { objectives, } \\
\text { because the } \\
\text { aggregate } \\
\text { impact is } \\
\text { expected to be } \\
\text { high, there is } \\
\text { medium } \\
\text { uncertainty, and } \\
\text { ecosystem } \\
\text { biodiversity is } \\
\text { within project } \\
\text { authorities and } \\
\text { mission areas. }\end{array}$ \\
\hline
\end{tabular}




\begin{tabular}{|c|c|c|c|c|c|c|c|c|}
\hline $\begin{array}{l}\text { EGS } \\
\text { Categories }\end{array}$ & Biophysical Impacts & Beneficiary Impacts & $\begin{array}{l}\text { Substitutes } \\
\text { Available? }\end{array}$ & $\begin{array}{l}\text { Aggregate } \\
\text { Impact Rating }\end{array}$ & $\begin{array}{l}\text { Confidence } \\
\text { Rating }\end{array}$ & $\begin{array}{c}\text { Within the } \\
\text { Project } \\
\text { Authorities? }\end{array}$ & $\begin{array}{c}\text { Other } \\
\text { Considerations? }\end{array}$ & $\begin{array}{l}\text { Include in } \\
\text { Further Analysis? }\end{array}$ \\
\hline $\begin{array}{l}\text { Non-use } \\
\text { services from } \\
\text { restoring a } \\
\text { portion of a } \\
\text { threatened } \\
\text { desert } \\
\text { perennial } \\
\text { river } \\
\text { ecosystem to } \\
\text { meet quality } \\
\text { threshold }\end{array}$ & $\begin{array}{l}\text { Habitat of Roundtail Chub } \\
\text { was chosen as the } \\
\text { ecological indicator for } \\
\text { perennial river systems } \\
\text { because the ideal habitat } \\
\text { for these fish constitutes } \\
\text { healthy river systems. } \\
\text { Habitat quality for the fish } \\
\text { is expected to improve in } \\
\text { the stretch of river within } \\
\text { the study area because of } \\
\text { better water flow } \\
\text { conditions. The team } \\
\text { comes to the conclusion } \\
\text { that this will be a medium } \\
\text { positive (++) impact. Since } \\
\text { it is long-term (***), the } \\
\text { team judges this to be a } \\
\text { substantial impact. }\end{array}$ & $\begin{array}{l}\text { The project will increase } \\
\text { the amount of desert } \\
\text { perennial river ecosystem } \\
\text { that runs through Ayola. } \\
\text { Desert perennial river } \\
\text { ecosystems represent a } \\
\text { group of aquatic } \\
\text { ecosystems that are } \\
\text { considered collectively as } \\
\text { a conservation priority by a } \\
\text { number of regional and } \\
\text { national groups including } \\
\text { The Nature Conservancy. } \\
\text { The additional quality- } \\
\text { adjusted area of the river } \\
\text { system will only contribute } \\
\text { a small amount to the total } \\
\text { extent of desert rivers (+). } \\
\text { This impact will be long- } \\
\text { term ( } * * \text { ), however, so } \\
\text { the team decides that the } \\
\text { impact will be substantial. }\end{array}$ & $\begin{array}{l}\text { No } \\
\text { There are few } \\
\text { examples of } \\
\text { intact or } \\
\text { potentially } \\
\text { restorable rivers } \\
\text { that exist in this } \\
\text { region. }\end{array}$ & $\begin{array}{l} \\
\text { High } \\
\text { The team } \\
\text { assessed that } \\
\text { both the } \\
\text { biophysical } \\
\text { and } \\
\text { beneficiary } \\
\text { impacts } \\
\text { would be } \\
\text { substantial, } \\
\text { and there } \\
\text { would be no } \\
\text { substitute. }\end{array}$ & $\begin{array}{l}\text { Medium } \\
\text { There is some } \\
\text { uncertainty } \\
\text { about the } \\
\text { ability to } \\
\text { restore the } \\
\text { section of the } \\
\text { river given the } \\
\text { potential } \\
\text { threat of plant } \\
\text { invasion, } \\
\text { projected } \\
\text { human use, } \\
\text { and changes } \\
\text { to the system } \\
\text { due to } \\
\text { climate } \\
\text { change. }\end{array}$ & Yes & - & $\begin{array}{l}\text { Yes Because the } \\
\text { cumulative } \\
\text { impact is } \\
\text { expected to be } \\
\text { high, there is } \\
\text { medium } \\
\text { uncertainty, and } \\
\text { ecosystem } \\
\text { biodiversity is } \\
\text { within the } \\
\text { project } \\
\text { authorities and } \\
\text { mission areas, } \\
\text { the team } \\
\text { decides to } \\
\text { include it as a } \\
\text { planning } \\
\text { objective. }\end{array}$ \\
\hline
\end{tabular}

$$
\text { N }
$$




\begin{tabular}{|c|c|c|c|c|c|c|c|c|}
\hline $\begin{array}{l}\text { EGS } \\
\text { Categories }\end{array}$ & Biophysical Impacts & Beneficiary Impacts & $\begin{array}{l}\text { Substitutes } \\
\text { Available? }\end{array}$ & $\begin{array}{l}\text { Aggregate } \\
\text { Impact Rating }\end{array}$ & $\begin{array}{l}\text { Confidence } \\
\text { Rating }\end{array}$ & $\begin{array}{c}\text { Within the } \\
\text { Project } \\
\text { Authorities? }\end{array}$ & $\begin{array}{c}\text { Other } \\
\text { Considerations? }\end{array}$ & $\begin{array}{l}\text { Include in } \\
\text { Further Analysis? }\end{array}$ \\
\hline $\begin{array}{l}\text { Non-use } \\
\text { services from } \\
\text { improving } \\
\text { viability of } \\
\text { the declining } \\
\text { species } \\
\text { Roundtail } \\
\text { Chub }\end{array}$ & $\begin{array}{l}\text { Habitat quality for the } \\
\text { Roundtail Chub is } \\
\text { expected to improve in the } \\
\text { stretch of river within the } \\
\text { study area because of } \\
\text { better water flow } \\
\text { conditions. Therefore, the } \\
\text { team estimates that there } \\
\text { will be a medium positive } \\
(++) \text { change. Since it will } \\
\text { be a long-term change } \\
(* * *) \text {, the team judges } \\
\text { this to be a substantial } \\
\text { impact. }\end{array}$ & $\begin{array}{l}\text { Given the relatively small } \\
\text { area in which habitat } \\
\text { quality will improve, the } \\
\text { project will only lead to a } \\
\text { slight increase in the } \\
\text { probability of long-term } \\
\text { population persistence. } \\
\text { However, since the range } \\
\text { of the subpopulation in the } \\
\text { Lower Colorado River } \\
\text { Basin is only } 32 \% \text { of its } \\
\text { historic range, the increase } \\
\text { in quality habitat falls in } \\
\text { the maximum marginal } \\
\text { benefits zone for social } \\
\text { value, (text Figure } 14) \text {. } \\
\text { Given this, the team } \\
\text { assesses that there will be } \\
\text { a small positive impact (+) } \\
\text { over the long-term ( } * * \text { ). } \\
\text { They come to the } \\
\text { conclusion that the impact } \\
\text { will be substantial. }\end{array}$ & $\begin{array}{l}\text { No } \\
\text { There are few } \\
\text { examples of } \\
\text { intact or } \\
\text { potentially } \\
\text { restorable } \\
\text { habitat for the } \\
\text { fishes in this } \\
\text { region. }\end{array}$ & $\begin{array}{l}\text { High } \\
\text { Because both } \\
\text { the } \\
\text { biophysical } \\
\text { and } \\
\text { beneficiary } \\
\text { impacts are } \\
\text { deemed } \\
\text { substantial } \\
\text { and there are } \\
\text { no available } \\
\text { substitutes, } \\
\text { the } \\
\text { cumulative } \\
\text { impact is } \\
\text { high. }\end{array}$ & $\begin{array}{l}\text { Medium } \\
\text { There is some } \\
\text { uncertainty } \\
\text { about the } \\
\text { ability to } \\
\text { restore } \\
\text { necessary } \\
\text { habitat given } \\
\text { the potential } \\
\text { threat of plant } \\
\text { invasion, } \\
\text { projected } \\
\text { human use, } \\
\text { and changes } \\
\text { to the system } \\
\text { due to } \\
\text { climate } \\
\text { change. }\end{array}$ & Yes & - & $\begin{array}{l}\text { Yes Because the } \\
\text { cumulative } \\
\text { impact is } \\
\text { expected to be } \\
\text { high, there is } \\
\text { medium } \\
\text { uncertainty, and } \\
\text { species viability } \\
\text { is in the project } \\
\text { authorities and } \\
\text { missions, the } \\
\text { team includes it } \\
\text { in the planning } \\
\text { objectives. }\end{array}$ \\
\hline
\end{tabular}




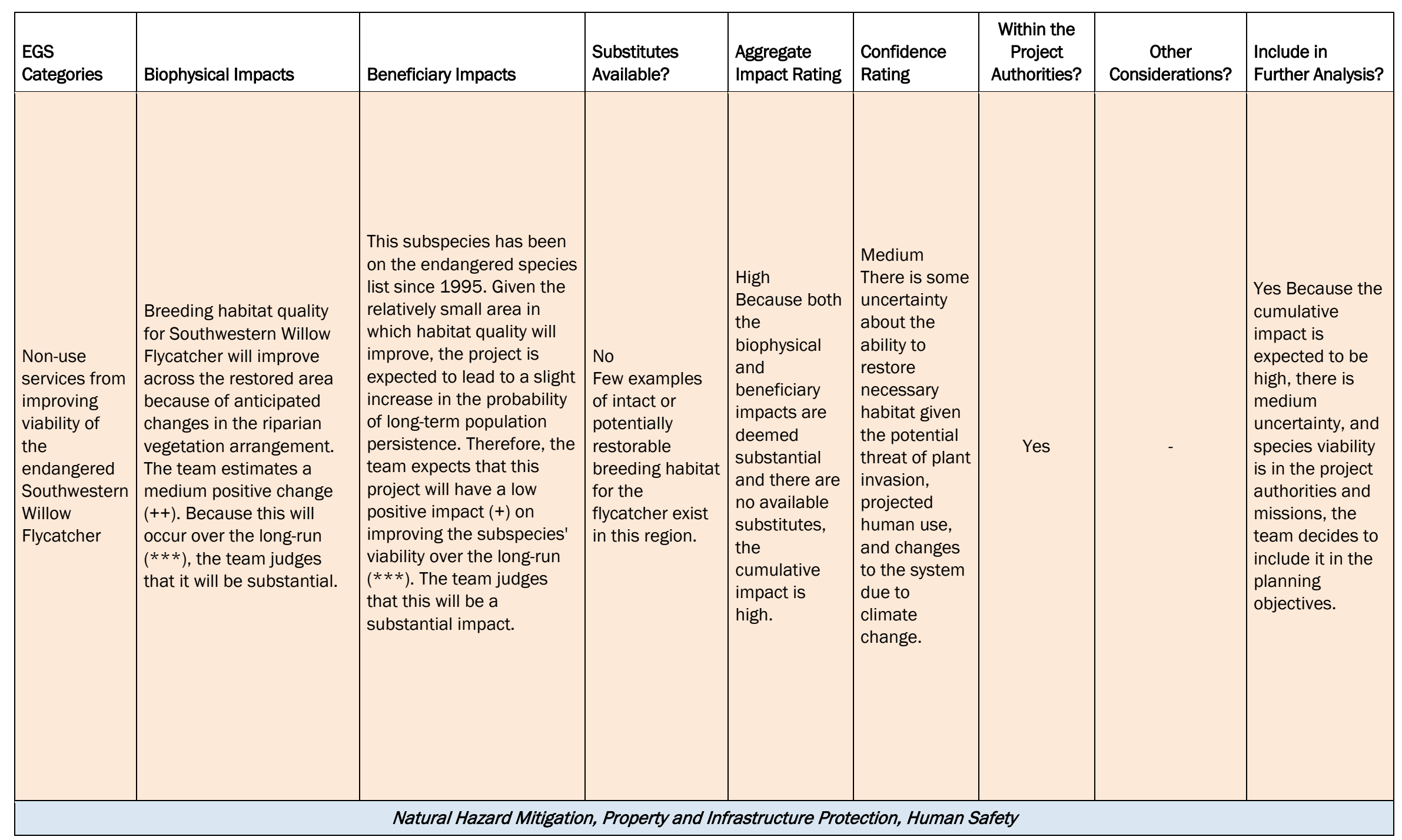




\begin{tabular}{|c|c|c|c|c|c|c|c|c|}
\hline $\begin{array}{l}\text { EGS } \\
\text { Categories }\end{array}$ & Biophysical Impacts & Beneficiary Impacts & $\begin{array}{l}\text { Substitutes } \\
\text { Available? }\end{array}$ & $\begin{array}{l}\text { Aggregate } \\
\text { Impact Rating }\end{array}$ & $\begin{array}{l}\text { Confidence } \\
\text { Rating }\end{array}$ & $\begin{array}{c}\text { Within the } \\
\text { Project } \\
\text { Authorities? }\end{array}$ & $\begin{array}{c}\text { Other } \\
\text { Considerations? }\end{array}$ & $\begin{array}{l}\text { Include in } \\
\text { Further Analysis? }\end{array}$ \\
\hline $\begin{array}{l}\text { Property } \\
\text { flood risk } \\
\text { mitigation }\end{array}$ & $\begin{array}{l}\text { Flow modifications of the } \\
\text { dam will lead to a small } \\
\text { increase in flood intensity } \\
\text { and frequency in the river's } \\
\text { floodplain in the immediate } \\
\text { vicinity of the project. This } \\
\text { negative impact, however, } \\
\text { will be mitigated by the } \\
\text { purchase of conservation } \\
\text { easements of affected } \\
\text { riparian areas. Increased } \\
\text { water retention of riparian } \\
\text { areas due to the project is } \\
\text { expected to decrease the } \\
\text { area of the } 10 \text {-year } \\
\text { floodplain downstream, in } \\
\text { the town of Springfield. } \\
\text { This decrease is judged to } \\
\text { be a small positive impact } \\
(+) \text { over the long-term } \\
(* * *) \text { The team decides } \\
\text { that the overall impacts will } \\
\text { be substantial. }\end{array}$ & $\begin{array}{l}\text { The decrease in flood } \\
\text { intensity and frequency will } \\
\text { have a medium positive } \\
\text { impact ( }++ \text { ) on several } \\
\text { Springfield residences, } \\
\text { businesses, and municipal } \\
\text { properties that previously } \\
\text { were in the floodplain. This } \\
\text { impact will be over the } \\
\text { long-term }(* * *) \text {. Therefore, } \\
\text { there will be a substantial } \\
\text { beneficiary impact. }\end{array}$ & $\begin{array}{l}\text { No } \\
\text { There are no } \\
\text { other } \\
\text { downstream } \\
\text { flood control } \\
\text { mechanisms in } \\
\text { place or that are } \\
\text { cost-effective to } \\
\text { implement. }\end{array}$ & $\begin{array}{l}\text { High } \\
\text { Overall } \\
\text { cumulative } \\
\text { impact of } \\
\text { flooding is } \\
\text { projected to } \\
\text { be high given } \\
\text { the } \\
\text { substantial } \\
\text { biophysical } \\
\text { and } \\
\text { beneficiary } \\
\text { impacts and } \\
\text { the fact that } \\
\text { there are no } \\
\text { substitutes. }\end{array}$ & $\begin{array}{l}\text { Medium } \\
\text { Given the } \\
\text { uncertainties } \\
\text { of successfully } \\
\text { restoring the } \\
\text { riparian and } \\
\text { aquatic } \\
\text { ecosystems } \\
\text { and potential } \\
\text { changes to } \\
\text { the system } \\
\text { due to climate } \\
\text { change, the } \\
\text { team } \\
\text { assesses that } \\
\text { the } \\
\text { confidence } \\
\text { level of the } \\
\text { aggregate } \\
\text { impact is } \\
\text { medium. }\end{array}$ & No & $\begin{array}{l}\text { Yes } \\
\text { Within the flood } \\
\text { risk management } \\
\text { primary mission } \\
\text { area of the } \\
\text { USACE. }\end{array}$ & $\begin{array}{l} \\
\text { Yes } \\
\text { Given the high } \\
\text { projected } \\
\text { cumulative } \\
\text { impact, medium } \\
\text { confidence in } \\
\text { these } \\
\text { projections, and } \\
\text { the fact that } \\
\text { flood risk } \\
\text { management is } \\
\text { a primary } \\
\text { mission area of } \\
\text { the USACE, the } \\
\text { team decides to } \\
\text { include it for } \\
\text { further analysis. }\end{array}$ \\
\hline
\end{tabular}




\begin{tabular}{|c|c|c|c|c|c|c|c|c|}
\hline $\begin{array}{l}\text { EGS } \\
\text { Categories }\end{array}$ & Biophysical Impacts & Beneficiary Impacts & $\begin{array}{l}\text { Substitutes } \\
\text { Available? }\end{array}$ & $\begin{array}{l}\text { Aggregate } \\
\text { Impact Rating }\end{array}$ & $\begin{array}{l}\text { Confidence } \\
\text { Rating }\end{array}$ & $\begin{array}{l}\text { Within the } \\
\text { Project } \\
\text { Authorities? }\end{array}$ & $\begin{array}{c}\text { Other } \\
\text { Considerations? }\end{array}$ & $\begin{array}{l}\text { Include in } \\
\text { Further Analysis? }\end{array}$ \\
\hline $\begin{array}{l}\text { General } \\
\text { Recreation }\end{array}$ & $\begin{array}{l}\text { Restoration is projected to } \\
\text { increase the native tree } \\
\text { cover in the project area. } \\
\text { This ecological metric has } \\
\text { been linked to the benefits } \\
\text { that people receive from } \\
\text { trail-based recreation in } \\
\text { forested areas (walking, } \\
\text { running, etc.). The team } \\
\text { judges that there will be a } \\
\text { medium positive }(++) \\
\text { impact over the long-term } \\
(* * *) \text {. This is a substantial } \\
\text { impact. }\end{array}$ & $\begin{array}{l}\text { In a public survey } \\
\text { performed by the city, } \\
\text { about one-third of city } \\
\text { residents stated they } \\
\text { would use the trails in the } \\
\text { restored riparian area to } \\
\text { go walking, running, } \\
\text { picnicking, etc. The team } \\
\text { translates this to a } \\
\text { medium positive (++) } \\
\text { impact. This impact is } \\
\text { expected to be for the } \\
\text { long-term (***) and } \\
\text { therefore substantial. }\end{array}$ & $\begin{array}{l}\text { Yes } \\
\text { There are other } \\
\text { places to go } \\
\text { walking and } \\
\text { running in the } \\
\text { city. However, } \\
\text { none of them } \\
\text { offer the } \\
\text { pleasant natural } \\
\text { environment by } \\
\text { the river with } \\
\text { substantial } \\
\text { native tree } \\
\text { cover that the } \\
\text { project area will } \\
\text { offer. The } \\
\text { closest location } \\
\text { that offers a } \\
\text { similar } \\
\text { environment for } \\
\text { trail-based } \\
\text { recreation is } 10 \\
\text { miles away. }\end{array}$ & $\begin{array}{l}\text { Medium } \\
\text { The } \\
\text { biophysical } \\
\text { and } \\
\text { beneficiary } \\
\text { impacts are } \\
\text { substantial } \\
\text { even though } \\
\text { there are } \\
\text { other less } \\
\text { desirable } \\
\text { substitute } \\
\text { locations } \\
\text { inside the city } \\
\text { and outside } \\
\text { of city limits. }\end{array}$ & $\begin{array}{l}\text { Medium } \\
\text { There is some } \\
\text { uncertainty } \\
\text { about the } \\
\text { ability to } \\
\text { restore the } \\
\text { tree cover } \\
\text { given the } \\
\text { potential } \\
\text { threat of plant } \\
\text { invasion, } \\
\text { projected } \\
\text { human use, } \\
\text { and changes } \\
\text { to the system } \\
\text { due to } \\
\text { climate } \\
\text { change. }\end{array}$ & No & $\begin{array}{l}\text { Yes } \\
\text { Within the } \\
\text { recreation } \\
\text { secondary } \\
\text { mission area of } \\
\text { the USACE. }\end{array}$ & $\begin{array}{l}\text { Yes Given the } \\
\text { medium } \\
\text { projected } \\
\text { cumulative } \\
\text { impact, medium } \\
\text { confidence in } \\
\text { these } \\
\text { projections, and } \\
\text { the fact that } \\
\text { recreation is a } \\
\text { secondary } \\
\text { mission area of } \\
\text { the USACE, the } \\
\text { team decides to } \\
\text { include it for } \\
\text { further analysis. }\end{array}$ \\
\hline
\end{tabular}




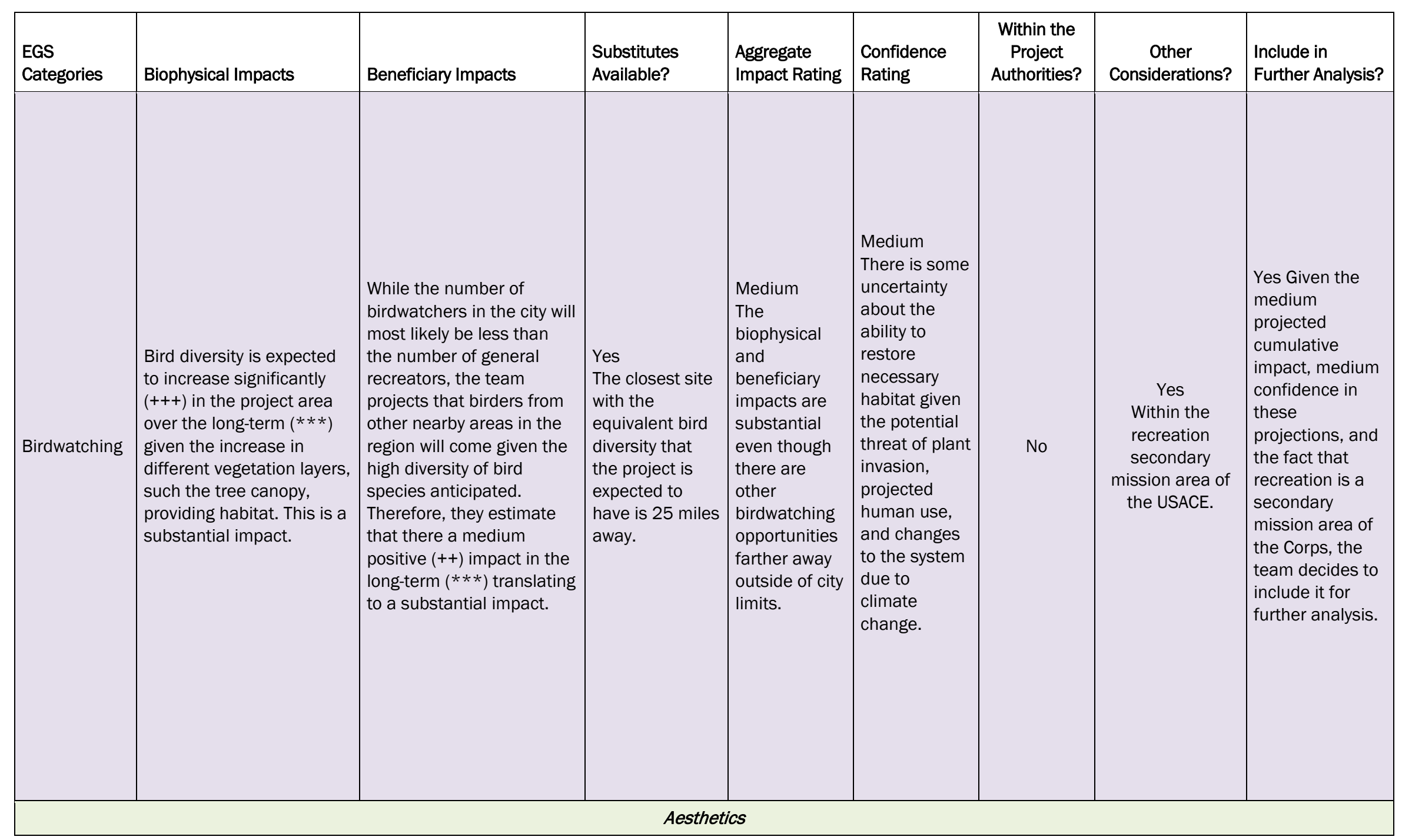




\begin{tabular}{|c|c|c|c|c|c|c|c|c|}
\hline $\begin{array}{l}\text { EGS } \\
\text { Categories }\end{array}$ & Biophysical Impacts & Beneficiary Impacts & $\begin{array}{l}\text { Substitutes } \\
\text { Available? }\end{array}$ & $\begin{array}{l}\text { Aggregate } \\
\text { Impact Rating }\end{array}$ & $\begin{array}{l}\text { Confidence } \\
\text { Rating }\end{array}$ & $\begin{array}{l}\text { Within the } \\
\text { Project } \\
\text { Authorities? }\end{array}$ & $\begin{array}{c}\text { Other } \\
\text { Considerations? }\end{array}$ & $\begin{array}{l}\text { Include in } \\
\text { Further Analysis? }\end{array}$ \\
\hline $\begin{array}{l}\text { Visual } \\
\text { enjoyment by } \\
\text { riparian } \\
\text { neighbors }\end{array}$ & $\begin{array}{l}\text { Restoration is expected to } \\
\text { increase cover of native } \\
\text { tree species and } \\
\text { vegetation density, key } \\
\text { inputs in how people value } \\
\text { the aesthetics of the area } \\
\text { (Weber and Stewart } \\
2009) \text {. The team } \\
\text { translates these changes } \\
\text { to a medium positive }(++) \\
\text { impact over the long-term } \\
(* * *) \text {. Overall, the team } \\
\text { judges that the impact will } \\
\text { be substantial. }\end{array}$ & $\begin{array}{l}\text { Only about } 25 \text { homes } \\
\text { situated directly uphill of } \\
\text { the site of the project will } \\
\text { be affected. Therefore, } \\
\text { there will be a low positive } \\
(+) \text { impact. Despite the } \\
\text { long-term impact ( } * *) \text {, } \\
\text { the team judges that } \\
\text { overall impact is not } \\
\text { substantial due to the } \\
\text { small number of } \\
\text { residences. }\end{array}$ & $\begin{array}{l}\text { No } \\
\text { No other } \\
\text { opportunities } \\
\text { for improving } \\
\text { the aesthetic } \\
\text { benefits from } \\
\text { the river are } \\
\text { available within } \\
\text { city limits. }\end{array}$ & $\begin{array}{l}\text { Low } \\
\text { Even though } \\
\text { the biophysical } \\
\text { impacts are } \\
\text { substantial } \\
\text { and there are } \\
\text { no substitutes, } \\
\text { the beneficiary } \\
\text { impacts are } \\
\text { not } \\
\text { substantial. }\end{array}$ & $\begin{array}{l}\text { Medium } \\
\text { There are } \\
\text { some } \\
\text { uncertainties } \\
\text { given } \\
\text { potential } \\
\text { changes to } \\
\text { the system } \\
\text { due to } \\
\text { climate } \\
\text { change and } \\
\text { the possible } \\
\text { limitations of } \\
\text { successful } \\
\text { restoration } \\
\text { due to plant } \\
\text { invasion and } \\
\text { human use. }\end{array}$ & No & No & $\begin{array}{l}\text { No Because of } \\
\text { the fact that } \\
\text { there will be a } \\
\text { low cumulative } \\
\text { impact with } \\
\text { medium } \\
\text { uncertainty and } \\
\text { the fact that the } \\
\text { service is not in } \\
\text { the project } \\
\text { authorities and } \\
\text { mission areas, } \\
\text { the team will not } \\
\text { pursue an EGS } \\
\text { analysis. }\end{array}$ \\
\hline
\end{tabular}


Table A-5. EGS classification by major categories and sub-categories.

\begin{tabular}{|c|c|c|c|c|c|c|c|c|c|c|c|}
\hline \begin{tabular}{|l} 
Ecosystem \\
Sustainability
\end{tabular} & $\begin{array}{l}\text { Water Supply \& } \\
\text { Regulation }\end{array}$ & \begin{tabular}{|l|} 
Natural Hazard \\
Mitigation, \\
Property \& \\
Infrastructure \\
Protection, \\
Human Safety \\
\end{tabular} & Navigation & Recreation & \begin{tabular}{|l|} 
lultural, Spiritual \\
\& Educational \\
Support
\end{tabular} & Aesthetics & Food Provisioning & \begin{tabular}{|l} 
Raw Goods and \\
Materials \\
Provisioning
\end{tabular} & \begin{tabular}{|l} 
Water Purification \\
\& Waste \\
Treatment \\
\end{tabular} & $\begin{array}{l}\text { Climate } \\
\text { Regulation, } \\
\text { Carbon } \\
\text { Sequestration } \\
\end{array}$ & $\begin{array}{l}\text { Human Health } \\
\text { (other than water } \\
\text { quality) }\end{array}$ \\
\hline Species diversity & \begin{tabular}{|l} 
Surface water \\
quantity for \\
drinking and \\
household use
\end{tabular} & \begin{tabular}{|l|} 
Protection of \\
property or \\
infrastructure \\
from extreme \\
weather events \\
(flooding, wind, \\
fire, storm surges, \\
landslides)
\end{tabular} & $\begin{array}{l}\begin{array}{l}\text { Provision of water } \\
\text { of sufficient depth } \\
\text { to transport } \\
\text { people and goods. }\end{array} \\
\end{array}$ & Wildlife viewing & $\begin{array}{l}\begin{array}{l}\text { Support of cultural } \\
\text { knowledge } \\
\text { systems and } \\
\text { 'sense of place' }\end{array} \\
\end{array}$ & \begin{tabular}{|l|}
$\begin{array}{l}\text { Aesthetic } \\
\text { enjoyment (visual, } \\
\text { oral or olfactory) } \\
\text { from public spaces }\end{array}$ \\
\end{tabular} & $\begin{array}{l}\begin{array}{l}\text { Subsistence fishing } \\
\text { (tribal or other) }\end{array} \\
\end{array}$ & $\begin{array}{l}\text { Commercial timber, } \\
\text { wood pulp, and } \\
\text { paper production }\end{array}$ & $\begin{array}{l}\text { Drinking water } \\
\text { quality }\end{array}$ & \begin{tabular}{|l|} 
Carbon \\
sequestration \\
rates to promote \\
global benefits
\end{tabular} & \begin{tabular}{|l} 
Regulation of \\
species that are \\
disease vectors \\
(e.g.g., mosquitoes)
\end{tabular} \\
\hline \begin{tabular}{|l} 
Genetic diversity \\
or evolutionary \\
information
\end{tabular} & \begin{tabular}{|l} 
Groundwater \\
quantity for \\
drinking and \\
household use
\end{tabular} & \begin{tabular}{|l|} 
Prevention of \\
human injuries or \\
deaths from \\
extreme weather \\
events
\end{tabular} & \begin{tabular}{|l} 
Reduction of \\
sediment exports \\
from ecosystems \\
adjacent to \\
streams used for \\
navigation
\end{tabular} & $\begin{array}{l}\text { Recreational } \\
\text { fishing }\end{array}$ & Historic heritage & $\begin{array}{l}\text { Enhancement of } \\
\text { private property }\end{array}$ & \begin{tabular}{|l} 
Aquaculture \\
opportunities
\end{tabular} & \begin{tabular}{|l|} 
Fuelwood for local \\
gatherers
\end{tabular} & $\begin{array}{l}\text { Agricultural water } \\
\text { quality }\end{array}$ & Enter your own... & $\begin{array}{l}\text { Health benefits } \\
\text { derived from } \\
\text { interacting with } \\
\text { the natural } \\
\text { environment }\end{array}$ \\
\hline $\begin{array}{l}\text { Ecosystem or } \\
\text { community } \\
\text { diversity }\end{array}$ & $\begin{array}{l}\text { Water supply for } \\
\text { irrigated } \\
\text { agriculture }\end{array}$ & \begin{tabular}{|l|} 
Protection from \\
erosion or mass \\
wasting (i.e., river \\
banks, coastline)
\end{tabular} & Enter your own... & Boating & Indigenous uses & \begin{tabular}{|l} 
Artistic and \\
creative \\
inspiration
\end{tabular} & $\begin{array}{l}\text { Subsistence } \\
\text { hunting }\end{array}$ & $\begin{array}{l}\text { Fibers \& resins for } \\
\text { local collection and } \\
\text { use (e.g., reeds, } \\
\text { hemp, rubber, } \\
\text { twine, rope) }\end{array}$ & $\begin{array}{l}\text { Industrial water } \\
\text { quality }\end{array}$ & & $\begin{array}{l}\text { Protection from } \\
\text { harmful air } \\
\text { temperatures }\end{array}$ \\
\hline $\begin{array}{l}\text { Landscape } \\
\text { processes (e.g., } \\
\text { appropriate } \\
\text { disturbance } \\
\text { regimes, patch } \\
\text { heterogeneity, } \\
\text { connectivity) }\end{array}$ & $\begin{array}{l}\text { Water supply for } \\
\text { industrial use }\end{array}$ & Enter your own... & & Swimming & \begin{tabular}{|l|} 
Spiritual or \\
religious uses
\end{tabular} & Enter your own... & \begin{tabular}{|l|} 
Edible plant \\
products for \\
commercial or \\
household \\
consumption \\
(e.g., maple syrup, \\
mushrooms, \\
fruits, nuts, wild \\
grains)
\end{tabular} & \begin{tabular}{|l} 
Sand and gravel \\
resources
\end{tabular} & 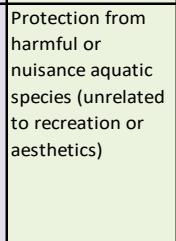 & & $\begin{array}{l}\begin{array}{l}\text { Protection from } \\
\text { harmful air quality }\end{array} \\
\end{array}$ \\
\hline \multirow[t]{3}{*}{ Enter your own... } & $\begin{array}{l}\text { Water supply for } \\
\text { generating } \\
\text { hydroelectric } \\
\text { power }\end{array}$ & & & \begin{tabular}{|l|} 
Trail-based \\
recreation \\
(walking, hiking, \\
jogging, dog \\
walking)
\end{tabular} & $\begin{array}{l}\text { Scientific research } \\
\text { opportunities }\end{array}$ & & \begin{tabular}{|l|} 
lommercial crop \\
production (e.g., \\
through \\
pollination or pest \\
regulation \\
functions) \\
\end{tabular} & $\begin{array}{l}\text { Genetic resources } \\
\text { for agricultural and } \\
\text { medicinal uses }\end{array}$ & $\begin{array}{l}\text { Water quality for } \\
\text { aquatic habitat } \\
\text { (i.e., to comply } \\
\text { with water quality } \\
\text { regulations) }\end{array}$ & & $\begin{array}{l}\begin{array}{l}\text { Protection from } \\
\text { harmful levels of } \\
\text { artificial light and } \\
\text { noise }\end{array} \\
\end{array}$ \\
\hline & Enter your own... & & & Enter your own... & \begin{tabular}{|l|} 
Educational \\
opportunities
\end{tabular} & & Enter your own... & \begin{tabular}{|l|} 
Biochemical \\
resources for \\
agricultural and \\
medicinal uses
\end{tabular} & Enter your own... & & Enter your own... \\
\hline & & & & & Enter your own... & & & $\begin{array}{l}\text { Ornamental plants } \\
\text { for commerical and } \\
\text { non-commercial } \\
\text { uses }\end{array}$ & & & \\
\hline
\end{tabular}




\section{Appendix B: Conceptual Ecological Model}

Figure B.1. Conceptual ecological model for the case study area.

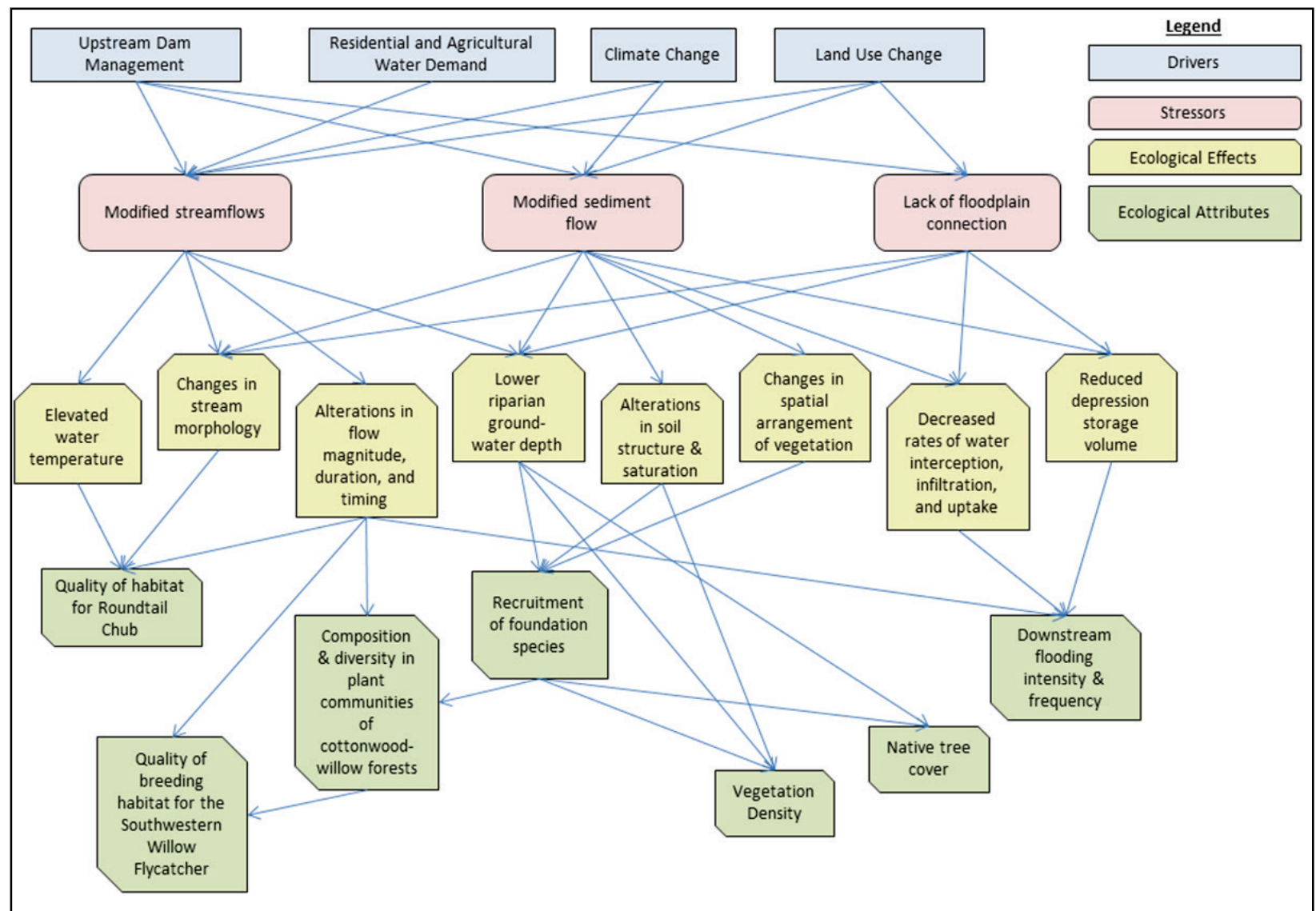




\section{Appendix C: Resources for Evaluating Species or Ecosystem Scarcity and National Significance}


Table C.1. Resources for evaluating species or ecosystem scarcity and national significance ${ }^{1}$.

\begin{tabular}{|c|c|c|c|c|c|c|c|c|}
\hline $\begin{array}{l}\text { Resources } \\
\text { (green highlight = available as interactive spatial webtool) }\end{array}$ & Scarcity & Representativeness & $\begin{array}{l}\text { Status and } \\
\text { Trends }\end{array}$ & Connectivity & $\begin{array}{l}\text { Critical } \\
\text { Habitat }\end{array}$ & Biodiversity & Threats & $\begin{array}{c}\text { Priority } \\
\text { Ranking? }\end{array}$ \\
\hline $\begin{array}{l}\text { Freshwater Ecoregions of North America: } \\
\text { A Conservation Assessment } \\
\text { WWF and TNC: } \text { http://www.feow.org/index.php }\end{array}$ & * & * & & & & * & * & * \\
\hline $\begin{array}{l}\text { Critical Watersheds for Freshwater Species } \\
\text { TNC and NatureServe: } \\
\text { http://www.natureserve.org/library/riversoflife.pdf }\end{array}$ & * & & * & & * & * & & * \\
\hline $\begin{array}{l}\text { Essential Fish Habitat Mapper v3.0 } \\
\text { NOAA: } \\
\text { http://www.habitat.noaa.gov/protection/efh/habitatmapper. } \\
\text { html }\end{array}$ & & & & & * & & & * \\
\hline $\begin{array}{l}\text { Evaluating Sustainability of Project Water Demands under } \\
\text { Future Climate Change Scenarios } \\
\text { Tetra Tech Inc. and NRDC: } \\
\text { http://rd.tetratech.com/climatechange/projects/doc/Tetra } \\
\text { Tech_Climate_Report_2010_lowres.pdf }\end{array}$ & * & & * & & & & & * \\
\hline $\begin{array}{l}\text { Vulnerability of U.S. Water Supply to Shortage: A Technical } \\
\text { Document Supporting the Forest Service } 2010 \text { RPA } \\
\text { Assessment (2013) } \\
\text { USDA Forest Service: } \\
\text { http://www.fs.fed.us/rmrs/news/releases/content/?id=13- } \\
\underline{02-21}\end{array}$ & * & & * & & & & * & * \\
\hline $\begin{array}{l}\text { Biodiversity Priority Index } \\
\text { http://biodiversitymapping.org }\end{array}$ & * & & & & * & * & & * \\
\hline $\begin{array}{l}\text { Landscope America } \\
\text { Natureserve and National Geographic: } \\
\text { http://www.landscope.org/ }\end{array}$ & * & & * & * & * & * & * & $\begin{array}{c}\text { *(user- } \\
\text { designed) }\end{array}$ \\
\hline
\end{tabular}

1 Compendium of tools and databases that offer rankings or other metrics to quantify and describe conservation and restoration priorities. Updated table and further description will be available at http://waingerlab.cbl.umces.edu/. Columns represent USACE significance criteria (in italics) and common conservation metrics, and a star indicates that a criteria/metric is addressed by the tool and is available from the source. 


\begin{tabular}{|c|c|c|c|c|c|c|c|c|}
\hline $\begin{array}{l}\text { Resources } \\
\text { (green highlight = available as interactive spatial webtool) }\end{array}$ & Scarcity & Representativeness & $\begin{array}{l}\text { Status and } \\
\text { Trends }\end{array}$ & Connectivity & $\begin{array}{l}\text { Critical } \\
\text { Habitat }\end{array}$ & Biodiversity & Threats & $\begin{array}{c}\text { Priority } \\
\text { Ranking?1 }\end{array}$ \\
\hline $\begin{array}{l}\text { Enviroatlas } \\
\text { EPA: } \\
\text { http://enviroatlas.epa.gov/enviroatlas/atlas.html }\end{array}$ & * & & & & & * & & $\begin{array}{c}{ }^{*} \text { (user- } \\
\text { designed) }\end{array}$ \\
\hline $\begin{array}{l}\text { State Wildlife Action Plans } \\
\text { (individual State Wildlife Management Agencies) } \\
\text { http://www.teaming.com/state-wildlife-action-plans-swaps }\end{array}$ & * & & * & & * & & * & * \\
\hline $\begin{array}{l}\text { NatureServe Explorer } \\
\text { NatureServe: http://www.natureserve.org/explorer/ }\end{array}$ & * & & * & & & & * & * \\
\hline $\begin{array}{l}\text { Terrestrial Ecoregional Assessments for the US } \\
\text { TNC: } \mathrm{http}: / / \text { uspriorityareas.tnc.org/ }\end{array}$ & * & * & * & & & * & * & * \\
\hline $\begin{array}{l}\text { IUCN Red List of the Continental Ecosystems of the Americas } \\
\text { (not yet released) } \\
\text { http://www.iucnredlistofecosystems.org/about-us/ongoing- } \\
\text { initiatives/alaska-patagonia/ }\end{array}$ & * & & * & & & & * & * \\
\hline $\begin{array}{l}\text { US Gap Analysis } \\
\text { USGS: } \\
\text { http://gapanalysis.usgs.gov// }\end{array}$ & * & & & & * & * & & \\
\hline $\begin{array}{l}\text { Linkage Mapper } \\
\text { TNC: } \\
\text { https://code.google.com/p/linkage-mapper/ }\end{array}$ & & & & * & & & & \\
\hline $\begin{array}{l}\text { Guidos Toolbox } \\
\text { Joint Research Centre: } \\
\text { http://forest.jrc.ec.europa.eu/download/software/guidos/ }\end{array}$ & & & & * & & & & \\
\hline
\end{tabular}

1 This column notes whether the information source ranks conservation priorities. This could include rankings of areas based on their species richness, number of rare animals, sustainability of local water supplies, etc. Datasets identified as having "user-designed" priority ranking refer to those that provide the user with different options for ranking conservation priorities. 


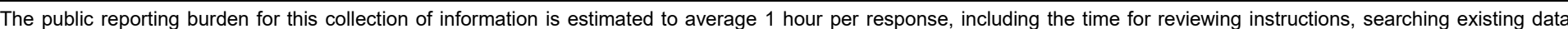

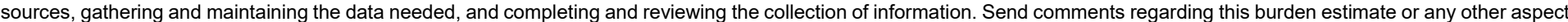

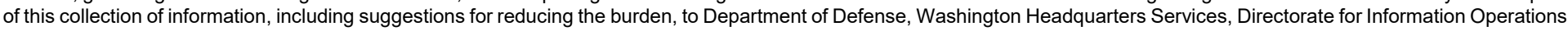

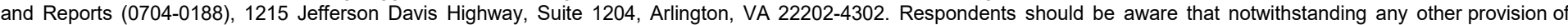
law, no person shall be subject to any penalty for failing to comply with a collection of information if it does not display a currently valid OMB control number. PLEASE DO NOT RETURN YOUR FORM TO THE ABOVE ADDRESS.
1. REPORT DATE
August 2020
2. REPORT TYPE
Final Report
3. DATES COVERED (From - To)

4. TITLE AND SUBTITLE

A Proposed Ecosystem Services Analysis Framework for the U.S. Army Corps of Engineers 5a. CONTRACT NUMBER

5b. GRANT NUMBER

5c. PROGRAM ELEMENT NUMBER

5d. PROJECT NUMBER

5e. TASK NUMBER

5f. WORK UNIT NUMBER

8. PERFORMING ORGANIZATION REPORT NUMBER

ERDC/EL SR-20-2

10. SPONSOR/MONITOR'S ACRONYM(S) EMRRP

11. SPONSOR/MONITOR'S REPORT NUMBER(S)

\section{Halls Ferry Road}

U.S. Army Engineer Research and Development Center

Vicksburg, MS 39180-6199

12. DISTRIBUTION/AVAILABILITY STATEMENT

Approved for public release; distribution is unlimited.

13. SUPPLEMENTARY NOTES

Funding Account Code U436285, AMSCO Code 031342

14. ABSTRACT

Ecosystem goods and services (EGS) have been promoted as a way to effectively examine tradeoffs and improve communication of project-related environmental outcomes in terms of human well-being. This document proposes a framework to inform the development of any future guidance to U.S. Army Corps of Engineers (USACE) District planners for projecting changes in EGS from proposed civil works activities. The framework offers an analytical and communications approach for incorporating EGS in USACE decision-support processes. The core of the framework is a conceptual model that establishes a series of causal relationships that link management actions to EGS benefits/damages, applying economic concepts in both monetary and non-monetary benefit relevant indicators.

The six-step planning process is used to demonstrate how the EGS framework might be integrated into existing analytic approaches and modified to fit different levels of resource availability and decision contexts. A hypothetical case study is used to demonstrate analytic techniques. The framework is compatible with goals to create a single decision-support document covering National Environmental Policy Act requirements and planning objectives when comparing project alternatives. The example is intended to generally illustrate the use of EGS in any type of program planning or project evaluation.

15. SUBJECT TERMS

Ecology, Ecosystem services, Environmental impact analysis, Environmental management-Multiple criteria decision making

16. SECURITY CLASSIFICATION OF:

\begin{tabular}{|l|c|l|}
\hline a. REPORT & b. ABSTRACT & c. THIS PAGE \\
Unclassified & Unclassified & Unclassified \\
\hline
\end{tabular}

17. LIMITATION OF ABSTRACT

SAR
18. NUMBER OF PAGES

149 19a. NAME OF RESPONSIBLE PERSON Elizabeth O. Murray

19b. TELEPHONE NUMBER (Include area code) 925-212-1359 
7. PERFORMING ORGANIZATION NAME(S) AND ADDRESS(ES) (continued)

University of Maryland Center for Environmental Science

146 Williams St

Solomons, MD 20688

U.S. Army Engineer Research and Development Center 3909 Halls Ferry Road

Vicksburg, MS 39180-6199

U.S. Army Engineer Institute for Water Resources

7701 Telegraph Road

Alexandria, Virginia 22315 